\title{
Edge curling effect on interface delamination of concrete overlays for bridge decks
}

Tao Hong

West Virginia University

Follow this and additional works at: https://researchrepository.wvu.edu/etd

\section{Recommended Citation}

Hong, Tao, "Edge curling effect on interface delamination of concrete overlays for bridge decks" (2006). Graduate Theses, Dissertations, and Problem Reports. 1771.

https://researchrepository.wvu.edu/etd/1771

This Thesis is protected by copyright and/or related rights. It has been brought to you by the The Research Repository @ WVU with permission from the rights-holder(s). You are free to use this Thesis in any way that is permitted by the copyright and related rights legislation that applies to your use. For other uses you must obtain permission from the rights-holder(s) directly, unless additional rights are indicated by a Creative Commons license in the record and/ or on the work itself. This Thesis has been accepted for inclusion in WVU Graduate Theses, Dissertations, and Problem Reports collection by an authorized administrator of The Research Repository @ WVU. For more information, please contact researchrepository@mail.wvu.edu. 


\title{
Edge Curling Effect on Interface Delamination of Concrete Overlays for Bridge Decks
}

\author{
by \\ Tao Hong \\ Thesis submitted to the \\ College of Engineering and Mineral Resources \\ at West Virginia University \\ in partial fulfillment of the requirements \\ for the degree of \\ Master of Science \\ in \\ Civil Engineering
}

Julio F. Davalos, Ph.D., Chair

Indrajit Ray, Ph.D., Co-Chair

Xingbo Liu, Ph.D.

Department of Civil and Environmental Engineering

Morgantown, West Virginia

2006

Keywords: Concrete Overlay, Interface, Shrinkage, Curling Effect, Early Age, Cracking, Delamination, Ultrasonic Pulse Velocity. 


\section{ABSTRACT \\ Edge Curling Effect on Interface Delamination of Concrete Overlays \\ for Bridge Decks}

Tao Hong

Advisors: Dr. Julio F. Davalos and Dr. Indrajit Ray

Deterioration of reinforced concrete bridge decks caused by various environmental conditions and traffic loads is a problem of significant concern. A protective thin overlay of about 2 -inches is typically placed over newly constructed concrete bridge decks. Concrete overlay mixtures offer high resistance to traffic loads and environmental attacks, and often serve as leveling finished surfaces. A critical problem however has been the debonding and delamination propagation of the interface between overlay and substrate concrete, as observed in several bridges in West Virginia. Several studies indicated that during early-age of overlay curing, the debonding usually starts at corners or edges of the slab by curling stresses due to differential shrinkage between newly cast overlays and mature substrate. With time the crack front progressively grows within the interface leading to delamination of the overlay, and further distress cracking and deterioration.

As a part of a large-scale study on bridge deck overlays for the WVDOH, the current investigation focuses on early age curling and delamination behavior of four types of overlays for three substrate surface conditions at two ambient temperatures. A number of bi-layer prismatic specimens were produced and conditioned and tested in an environmentally controlled chamber. A circular interface delamination notch was introduced at the specimen's corner. The corner and edge crack-openings due to possible delamination propagations were continuously monitored using, respectively, a clip-on gage and three displacement transducers (LVDT) connected to a data acquisition system. An ultrasonic pulse velocity method was used to predict the interface crack front propagation. The waveform was recorded with a digital oscilloscope, and through Fast Fourier Transform the amplitude-time history was converted into power spectrum for analysis. The temperature-time gradient across the overlay was measured with thermocouples to evaluate its role on edge curling and delamination.

Results showed that the initial corner crack propagated along the interface edges and within the interface surface. The readings were consistent within and among the specimens. Higher temperature resulted in more delamination and the substrate surface with saturated condition and applied bonding slurry performed best, while the dry surface condition was the worst. Among overlays, the silica fume modified concrete cracked and debonded more than the latex modified concrete. However the use of shrinkage reducing admixtures significantly reduced the curling and delamination. The results of the ultrasonic pulse velocity test to map the crackfront propagation were consistent with the displacement-time data obtained with the transducers. The spectral analysis showed that the highly irregular overlay-substrate delaminated interface surface generated additional frequency components lower than the natural frequency of the transmitting transducer. The time-temperature profile did not appear to affect the curling and debonding as the temperature gradient was nearly stable within 24 hours and before delamination growth was detected. 


\section{ACKNOWLEDGEMENTS}

This thesis would not have been possible without the support of many people. First, I would like to thank Dr. Julio F. Davalos, a great teacher and advisor, for providing valuable guidance, support and resource to accomplish this research. My sincere gratitude goes to Dr. Indrajit Ray, my co-advisor, for his enormous support, insightful guidance in the whole research project. His wise advice and suggestion has significantly helped the finishing of my thesis work. Also, I would like to sincerely thank Dr. Xingbo Liu for serving as my committee member and provided me with valuable technical suggestions.

My thanks go to Doug Cutlip, David Turner, Justin Robinson, and William Comstock for their valuable help with the laboratory work. I want to thank my colleagues, Zhenhua Sun, Zhiguo Gong, Yi Chen, Dayong Fan, and Aniruddha Chatterjee for their help and great suggestions.

I gratefully acknowledge the financial support provided by West Virginia Department of Transportation- Division of Highways and WVU Research Corp. Incentive Grant Program. I also acknowledge Arrow Concrete Company, Martin Marietta Aggregates, BASF, Ahern and Associates Inc., Dow Chemicals, and Columbian Fiber Inc. for their generous supplies of materials.

I would like to dedicate this thesis to my family for their love, support and encouragement. 


\section{TABLE OF CONTENTS}

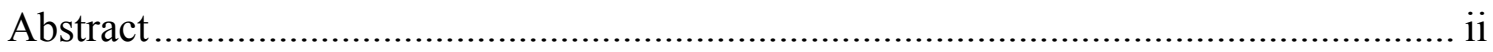

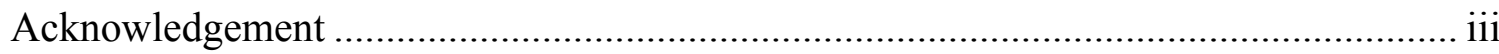

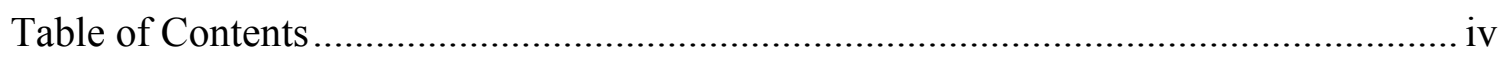

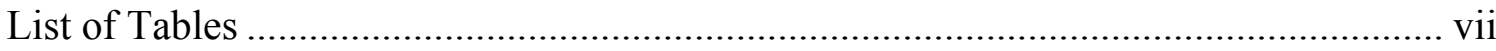

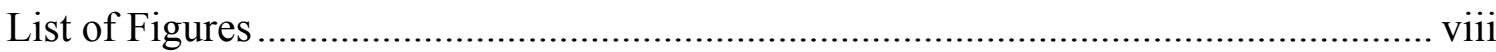

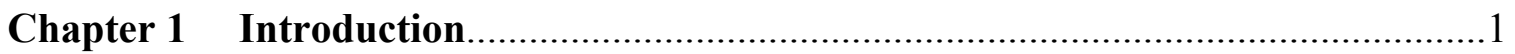

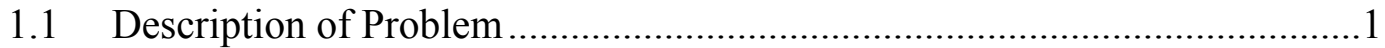

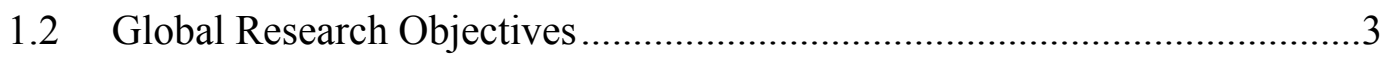

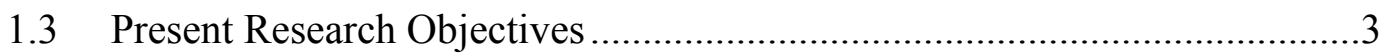

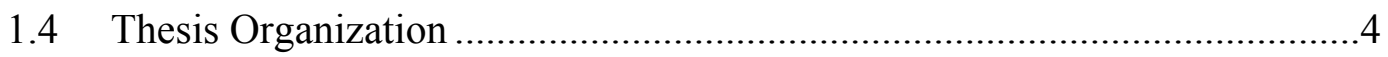

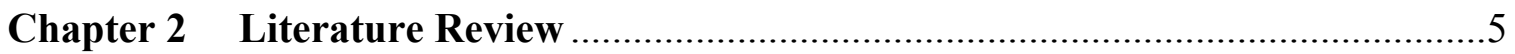

2.1 Volume Changes of Concrete ………………................................................5

2.1.1 Early Age Volume Changes.......................................................5

2.1.1.1 Latex Modified Concrete (LMC)..................................5

2.1.1.2 Autogenous Shrinkage...............................................

2.1.2 Drying Shrinkage of Hardened Concrete ……….........................

2.1.3 Differential Shrinkage ..........................................................

2.1.4 Concrete Volume Change due to Temperature ..........................11

2.2 Surface Preparation of the Concrete Substrate ...........................................12

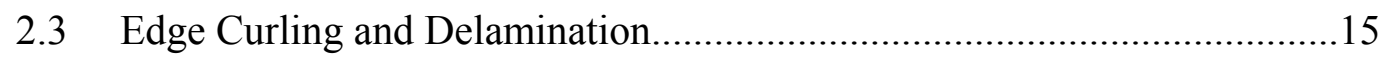

2.4 Ultrasonic Pulse Velocity Technique....................................................25

2.5 Research Significance .........................................................................29

Chapter 3 Materials and Fabrication of Specimens ……………………..............30

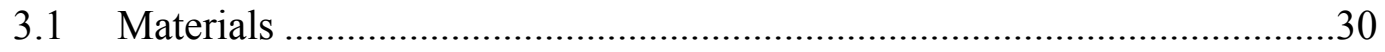

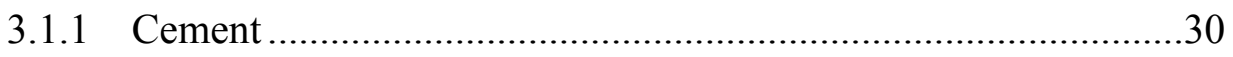

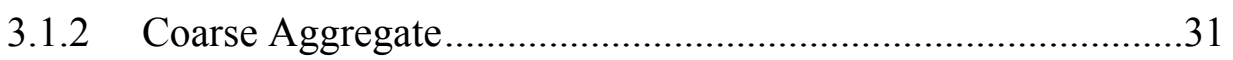

3.1.3 Fine Aggregate ……………………….................................... 


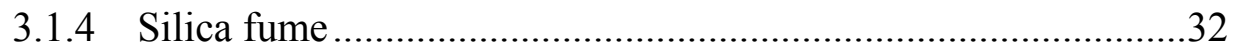

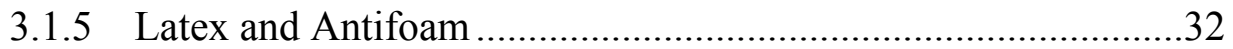

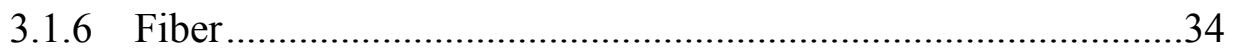

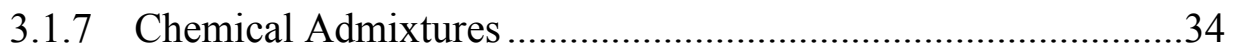

3.1.7.1 Shrinkage-reducing admixture..................................34

3.1.7.2 High-range water reducing admixture ......................34

3.1.7.3 Water-reducing and retarding admixture.................34

3.1.7.4 Air-entraining admixture ..........................................34

3.2 Mixture Proportions for Substrate and Specialized Overlays .......................35

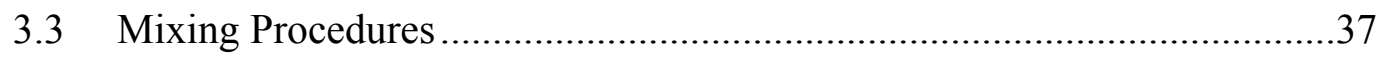

3.3.1 Normal Concrete for substrate (NC) .........................................37

3.3.2 Concretes for Overlay ................................................................

3.3.2.1 Silica Fume Modified Concrete (SFMC) ……….....37

3.3.2.2 Latex Modified Concrete (LMC) .............................38

3.3.2.3 Fiber Reinforced Concrete (FRC) ............................38

3.3.2.4 Silica Fume Modified Concrete with Shrinkagereducing Admixture (SFMC + SRA) ......................38

3.4 Fabrication of Specimens ........................................................................

3.4.1 Preparation of Substrate .............................................................

3.4.2 Preparation of Specimens for Curling Effect Tests .....................41

3.4.3 Preparation of Specimens for Temperature Measurement...........45

3.4.4 Preparation of Specimens for Direct Tensile Test .......................46

Chapter 4 Testing of Bilayer Prismatic Specimens ………………..........................50

4.1 Overlay Curling Effect and Delamination Tests.........................................50

4.1.1 Testing Procedure ……………………………..................50

4.1.2 Configuration of LVDTs and Clip-on Gauges ……..................52

4.1.3 Data Acquisition .....................................................................54

4.2 Overlay Temperature Measurement …………………..........................54

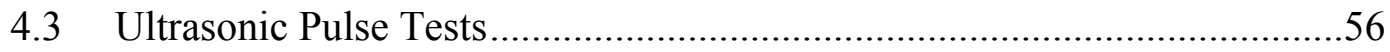

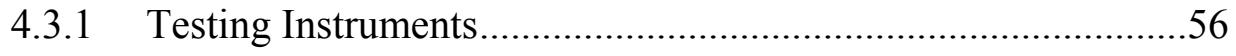


4.3.2 Testing Procedure …………………………….......................58

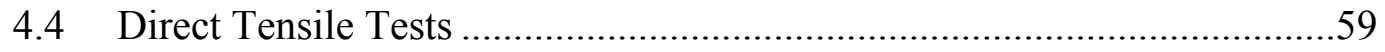

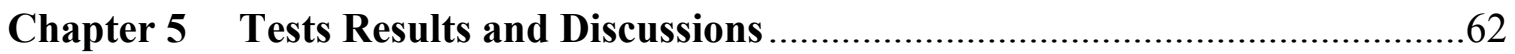

5.1 Edge Curling Effect Tests .........................................................................62

5.1.1 Relative Displacement at the Interface .....................................62

5.1.2 Comparison of Substrate Surface Conditions ...............................65

5.1.3 Comparison Between Two Temperatures ……………………...69

5.1.4 Comparison Among Different Overlay Mixes .............................71

5.2 Ultrasonic Pulse Test ............................................................................

5.2.1 Ultrasonic pulse transmitting time measurement .......................77

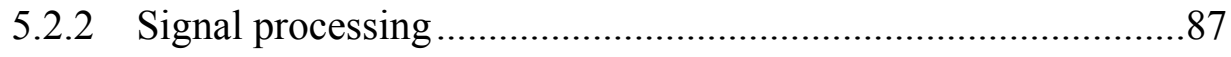

5.2.2.1 Spectral Analysis (Matlab Help Documentation)...87

5.2.2.2 Results Discussion................................................... 89

5.3 Overlay Temperature Measurement …………………………................99

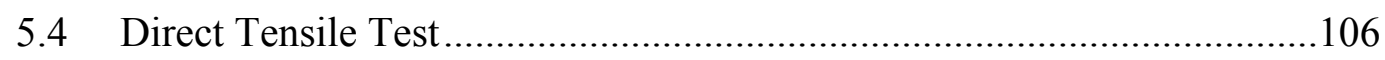

Chapter 6 Conclusions and Recommendations....................................................109

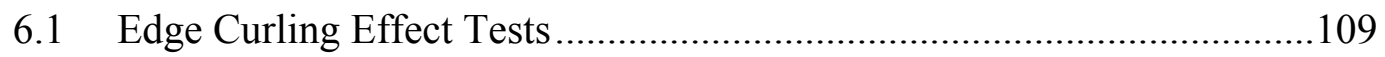

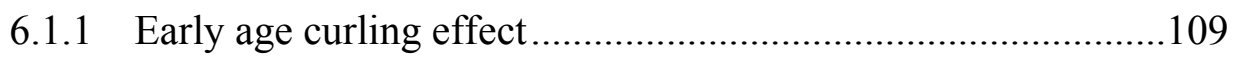

6.1.2 Ultrasonic Pulse Test ............................................................111

6.1.3 Overlay Temperature Measurement ..........................................112

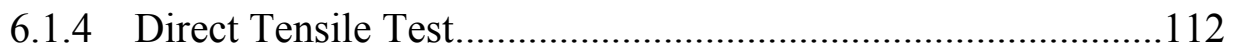

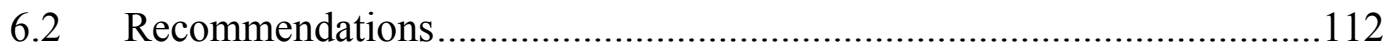

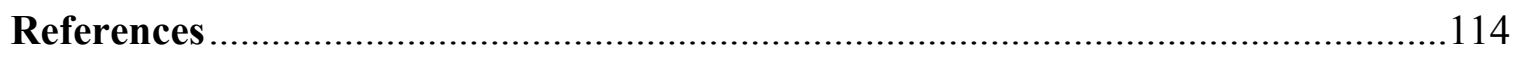

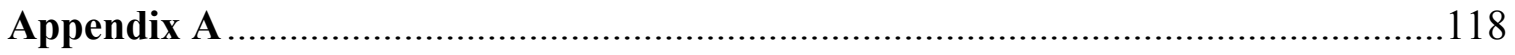

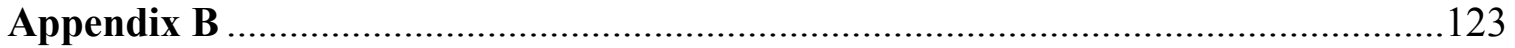

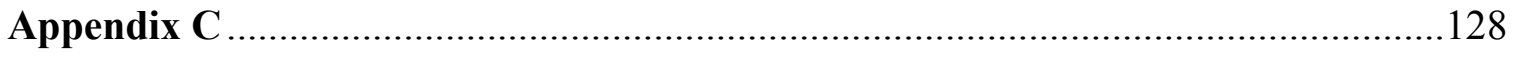




\section{LIST OF TABLES}

Table 3.1 Physical properties of Type I portland cement used.........................................30

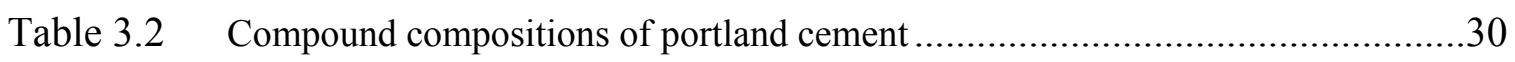

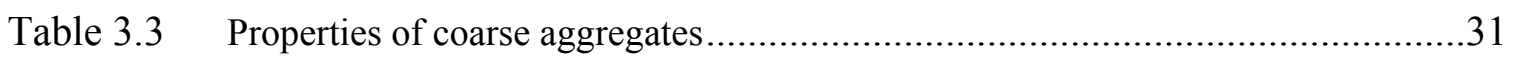

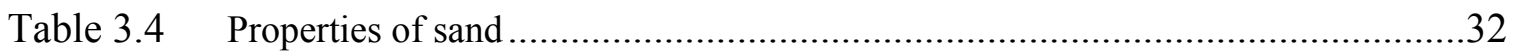

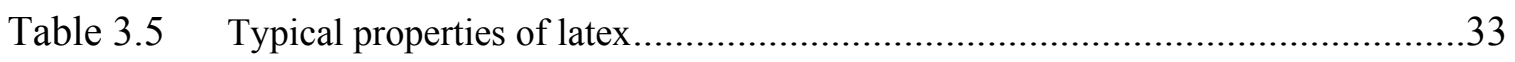

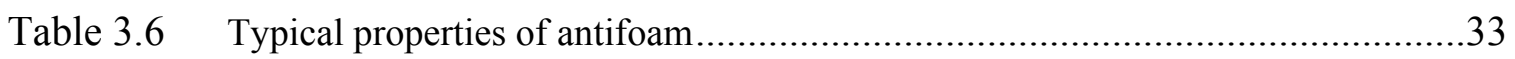

Table 3.7 Mixture proportions of overlays and substrate (for cubic meter of concrete) ........36

Table 5.1 Comparison of Substrate Surface Conditions at $23^{\circ} \mathrm{C}\left(73^{\circ} \mathrm{F}\right)$..........................68

Table 5.2 Comparison of Different Temperatures ........................................................ 70

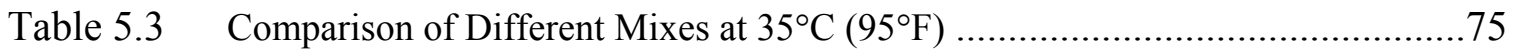

Table 5.4 Pulse transmitting time at points 1-A and 8-D for SFMC-dry @ $23^{\circ} \mathrm{C} \# 1$............91

Table 5.5 Summary of Temperatures in the Overlay Concrete .....................................106 


\section{LIST OF FIGURES}

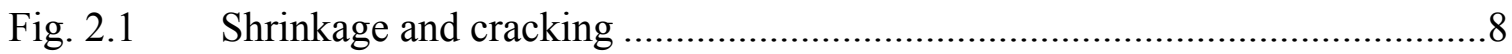

Fig. 2.2 Progress of Shrinkage with time as a function of distance from drying surface

Fig. 2.3 Curling at a saw-cut joint.....................................................................10

Fig. 2.4 Slab edge curling resulting in a 20\% loss of sub-base contact......................11

Fig. 2.5 Curling of a plain concrete wall panel due to temperature varying uniformly

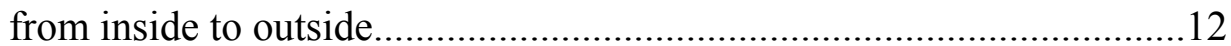

Fig.2.6 Concrete surface preparation methods .......................................................14

Fig. 2.7 Overlay curling due to temperature and shrinkage difference .......................16

Fig. 2.8 One-way Slab Action as Failure Is Approached ……………………….......18

Fig. 2.9 Grid layout for multi-reference impact test .................................................21

Fig. 2.10 Bonded Concrete Overlay Cracking and Debonding Mechanism due to

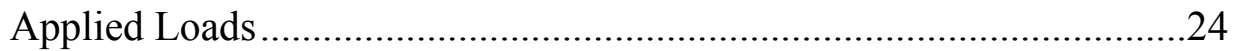

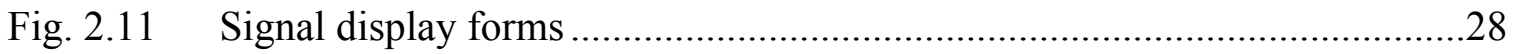

Fig. 3.1 Substrate specimen after casing ................................................................ 40

Fig. 3.2 Typical substrate specimen after surface preparation according to ICRI \#2

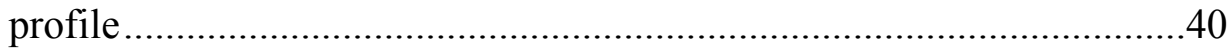

Fig. 3.3 Dimensions of Prismatic Specimen for Curling Effect Tests........................41

Fig. 3.4 Substrate beam installed in GFRP molds .....................................................42

Fig. 3.5 Substrate beam with bonding slurry applied .................................................43

Fig. 3.6 Specimen ready to install LVDTs and Clip-on gauge...................................44

Fig. 3.7 Specimen ready to cast overlay concrete for temperature measurement.......45

Fig. 3.8 Substrate specimens after casting t..............................................................46

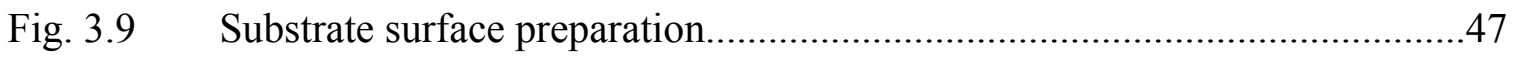

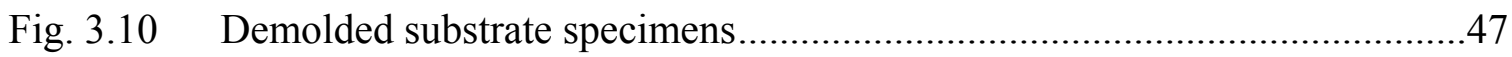

Fig. 3.11 Substrate specimens reinstalled back to molds...............................................48

Fig. 3.12 Specimen after casting of overlay concrete ................................................48

Fig. 3.13 Bi-Layer specimen with notches ................................................................49

Fig. 4.1 Curling effect and delamination testing scheme.........................................52 
Fig. 4.2 Layout of Monitoring Points for Overlay Displacement Measurement for

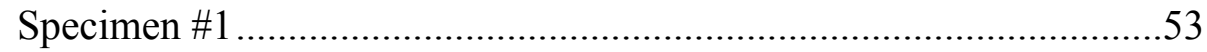

Fig. 4.3 Specimen \#1 installed with LVDTs and clip-on Gauge .............................53

Fig. 4.4 Specimen \#2 Installed with LVDTs and Clip-on Gauge..............................54

Fig. $4.5 \quad$ Layout of thermocouple configuration ...................................................55

Fig. 4.6 Specimen under testing for temperature measurement..............................55

Fig. 4.7(a) Schematic set-up of ultrasonic pulse testing ............................................56

Fig. 4.7(b) Ultrasonic pulse testing instruments ......................................................56

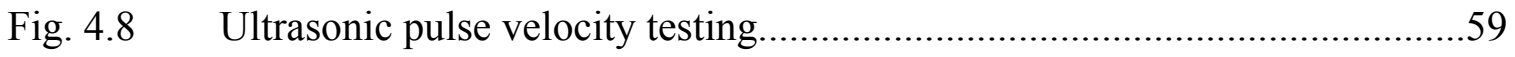

Fig. 4. 9 Gridlines on the Grinded Overlay Surface .............................................59

Fig. $4.10 \quad$ Schematic Direct Tensile Test Set-up .....................................................60

Fig. 4.11 Specimen Ready for Direct Tensile Test................................................61

Fig. 5.1 Typical crack due to debonding at the interface .......................................64

Fig. 5.2 Relative Displacement in SFMC-Dry-without Slurry @ $23^{\circ} \mathrm{C} \# 2$.................64

Fig. 5.3 Relative Displacement in SFMC-Saturated-without Slurry @ $23^{\circ} \mathrm{C} \# 1$.......65

Fig. 5.4 Relative Displacement in SFMC-Saturated-with Slurry @ $23^{\circ} \mathrm{C} \# 2$............66

Fig. 5.5 Relative Displacement in SFMC-Saturated-with Slurry @35 $35^{\circ} \mathrm{C} \# 1$...........69

Fig. 5.6 Relative Displacement in LMC-Saturated-with Slurry @ $35^{\circ} \mathrm{C} \# 1$.............71

Fig. 5.7 Relative Displacement in SFMC+SRA-Saturated-with Slurry @ $35^{\circ} \mathrm{C} \# 1 . .72$

Fig. 5.8 Relative Displacement in FRC-Saturated-with Slurry @ $35^{\circ} \mathrm{C} \# 1$..............72

Fig. 5.9 Development of Free Shrinkage ........................................................... 76

Fig. 5.10 Map of pulse transmitting time for SFMC-Dry @ $23^{\circ} \mathrm{C} \# 1-\mathrm{a}$.........................78

Fig. 5.11 Map of pulse transmitting time for SFMC-Dry @ $23^{\circ} \mathrm{C} \# 1-\mathrm{b}$.......................78

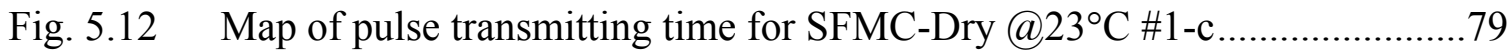

Fig. 5.13 Predicted crack front movement for SFMC-Dry @ $23^{\circ} \mathrm{C} \# 1$........................80

Fig. 5.14 Predicted crack front movement for SFMC-Dry @ $23^{\circ} \mathrm{C} \# 2$.......................81

Fig. 5.15 Predicted Crack front movement for SFMC-Saturated @ $23^{\circ} \mathrm{C} \# 1$..............82

Fig. 5.16 Predicted crack front movement for SFMC-Saturated-w/Slurry @23 ${ }^{\circ} \mathrm{C} \# 1.83$

Fig. 5.17 Predicted crack front movement for SFMC-Saturated-w/Slurry @35 $35^{\circ} \mathrm{C} 1.83$

Fig. 5.18 Predicted crack front movement for LMC-Saturated-w/Slurry @ $35^{\circ} \mathrm{C} \# 1 \ldots 86$ 
Fig. 5.19 Predicted crack font movement for SFMC+SRA-Saturated-w/Slurry @35 ${ }^{\circ} \mathrm{C}$

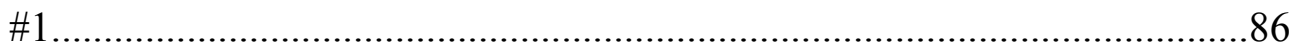

Fig. 5.20 Predicted crack front movement for FRC-Saturated-w/Slurry @35 $35^{\circ} \mathrm{C} \# 1$...87

Fig. 5.21 Virgin signal in time domain and frequency domain ................................90

Fig. 5.22 Locations for signal recording and processing .........................................91

Fig. 5.23 Comparison of waveforms of SFMC-dry @ $23^{\circ} \mathbf{C} \# 1$.................................92

Fig. 5.24 Comparison of power distribution spectral of SFMC-dry @ $23^{\circ} \mathrm{C} \# 1$..........93

Fig. 5.25 Waveforms of point 1-A in each overlay ...............................................97

Fig. 5.26 Waveforms of point 1-A in each overlay ...................................................98

Fig. 5.27 Waveforms of point 1-A in each overlay .................................................99

Fig. 5.28 Temperature Evolution in FRC Overlay ................................................ 100

Fig. 5.29 Temperature Gradient in FRC Overlay ...................................................101

Fig. 5.30 Temperature evolution in SFMC overlay over time..................................102

Fig. 5.31 Temperature gradient in SFMC overlay …...............................................102

Fig. 5.32 Temperature evolution in LMC overlay over time..................................103

Fig. 5.33 Temperature gradient in LMC overlay ...................................................103

Fig. 5.34 Temperature evolution in SFMC+SRA overlay over time.........................104

Fig. 5.35 Temperature gradient in SFMC+SRA overlay .......................................104

Fig. 5.36 Typical failure surfaces in direct tensile tests.........................................107

Fig. 5.37 Tensile Bond Strength of Overlays at Different Ages...............................108

Fig. 5.38 Development of Tensile Bond Strength of Overlays................................108 


\section{CHAPTER 1}

\section{INTRODUCTION}

\subsection{Description of Problem}

Deterioration of reinforced concrete decks caused by various environmental conditions and traffic loading is one of the most severe problems in highway bridges during service life. Concrete overlays can be a cost-effective alternative to deck replacement and an effective approach to protect bridge decks from deterioration. Thus, overlay systems have been widely used as deck protective layers in the United States. As shown by recent studies, concrete overlay systems placed compositely over decks were useful in extending the service life of bridge decks for both newly constructed and rehabilitated old bridges, thus reducing overall costs for bridge structures.

In the field, concrete undergoes volume changes due to constantly changing environmental conditions such as temperature and humidity. These volume changes introduce stresses in the concrete if it is restrained. For a bi-layer system such as overlay and bridge deck system, the underlying reinforced concrete substrate is much stiffer than the top layer of overlay and acts as a restrain to the overlay. More severely, the overlay concrete being relatively new undergoes more drying shrinkage and temperature changes compared to the substrate concrete. While the substrate concrete volume is relatively stable, the difference in volume change with the overlay causes stresses between the two concrete layers, thus causing transverse cracking in the new concrete overlay, and subsequent debonding at the interface of the bi-layer system. 
For many years, concrete overlay systems, cast-in-place over substrates, have been used by the West Virginia Department of Transportation, Division of Highways (WVDOH) to protect bridge decks from environmental exposures and provide a durable riding surface. Details of the overlay systems are defined by the WVDOH Standard Specifications for Roads and Bridges (Section 679, WVDOH, 2000). Normally, a 50mm ( 2 in) overlay, which acts as a protective layer to the bridge deck, is applied on top of a reinforced concrete substrate deck section. Under any circumstance, the thickness of overlay shall not be less than $31 \mathrm{~mm}\left(1 \frac{1 / 4}{\mathrm{in}}\right)$ according to WVDOH.

In order to fulfill the design purpose and achieve optimal performance, a concrete overlay must act compositely with the substrate bridge deck during its service life. Despite the debate regarding the best types of overlays to use there is consensus that a good bond between the concrete overlay and the existing bridge deck is critical to the performance of the bi-layer system. The most important factor affecting the bonding quality is the surface preparation of the bridge deck (Sprinkel 1997). Suprenant (1988) also mentioned that the surface preparation, overlay materials and curing are three major factors, which could affect the concrete-to-concrete bond. This was also observed in the previous research done at WVU (Sun 2004). Other factors, such as the temperature of concrete, curing conditions and the maturity of concrete can also affect the deck characteristics and eventually affect the overall performance of the bi-layer system.

This research, as a part of a comprehensive program on concrete overlays supported by WVDOH, investigates the early-age edge curling effect and delamination of cast-in-place concrete overlays under different ambient temperatures. At early ages, the newly cast concrete overlays experience severe changes in temperature and shrinkage due 
to continuous hydration and volume changes. During curing, certain gradients in drying shrinkage and temperature are induced through the thickness of the overlay, which make the overlay tend to curl up or down at the edges and joints. As a result, the induced stresses at the interface tend to tear up the overlay from the underlying reinforced bridge deck. The debonding between the overlay and the bridge deck is initiated at the edges. Then, due to external traffic loading and temperature and humidity changes, this debonding can further propagate into the interface and cause delamination of the overlay.

\subsection{Global Research Objectives}

The goals of the overall project are: (1) to review existing information and investigate current practices of concrete overlay construction prevalent in WV and in other states; (2) to conduct a focused study on materials characterization; (3) to develop and study delamination of overlay-substrate bi-layer systems; and (4) to develop preliminary specifications for the WVDOH for concrete overlay applications.

\subsection{Present Research Objectives}

The objectives of the present research are:

1. To investigate the edge curling effect on interface delamination for several overlays at early age, by considering several parameters related to interface conditions and exposure to temperature and humidity changes;

2. To investigate the delamination profiles of overlay-deck bi-layer systems at early age using both displacement sensors and ultrasonic pulse velocity technique; 
3. To characterize the delamination at the interface between overlay and substrate by using waveforms recorded by oscilloscope;

4. To measure the temperature gradient over the thickness for different overlays at early age.

\subsection{Thesis Organization}

The present introductory Chapter 1 provides the overview on background, and global and present research objectives. Chapter 2 includes a detailed literature reviews regarding the early age curling and delamination of overlay and ultrasonic pulse velocity technique used in damage assessment in concrete. Chapter 3 describes the materials used in the laboratory and the fabrication of test specimens. Chapter 4 presents experimental tests procedures. Chapter 5 discusses detailed tests results. Finally, Chapter 6 draws conclusions from this research and makes recommendations for future study. 


\section{CHAPTER 2}

\section{LITERATURE REVIEW}

\subsection{Volume Changes of Concrete}

Volume change is defined merely as an increase or decrease in volume. Most commonly, the subject of concrete volume changes deals with linear expansion and contraction due to temperature and moisture cycles. Chemical effects such as carbonation shrinkage, sulfate attack, and disruptive expansion of alkali-aggregate reactions also cause volume changes. The following sections briefly discuss early age volume changes, drying shrinkage, differential shrinkage, and volume changes due to temperature.

\subsubsection{Early Age Volume Changes}

Kosmatka et al. (2002) explained that when water moves out of a porous body, which is not fully rigid, contraction takes place. The volume of concrete begins to change shortly after it is cast. Early-age volume change, within 24 hours, can influence not only the overall volume (such as drying shrinkage) but also crack formation in hardened concrete, especially for low water to cement ratio concrete.

\subsubsection{Plastic Shrinkage}

Plastic shrinkage refers to volume change occurring while the concrete is still fresh, before hardening. It is due to the loss of water by evaporation from the surface of fresh concrete or by suction of underlying dry concrete or soil. It is usually observed in the form of plastic shrinkage cracks occurring before or during finishing. The cracks 
often resemble tears on the surface. Plastic shrinkage results from a combination of chemical and autogenous shrinkage and rapid evaporation of moisture from the surface that exceeds bleeding rate. The greater the cement content of the mix and the lower the water to cement ratio are, the greater plastic shrinkage will be. Plastic shrinkage cracking can be controlled by minimizing surface evaporation through the use of fogging, wind breaks, shading, plastic sheet covers, wet burlap, spray-on finishing aids (evaporation retarders), and plastic fibers.

\subsubsection{Autogenous Shrinkage}

Autogenous shrinkage is the macroscopic volume reduction (visible dimensional change) of cement paste, mortar, or concrete caused by cement hydration. It is the consequence of the withdrawal of water from the capillary pores by the hydration of the unhydrated cement, a process also known as self-desiccation. During the process, there is no moisture movement to or from the cement paste. In practice it occurs in the interior of a concrete mass. The macroscopic volume reduction of autogenous shrinkage is much less than the absolute volume reduction of chemical shrinkage because of the rigidity of the hardened paste structure. Chemical shrinkage is the driving force behind autogenous shrinkage. When external water is available, autogenous shrinkage cannot occur. When external water is not available, cement hydration consumes pore water resulting in self desiccation of the paste and a uniform reduction of volume (Copeland and Bragg 1955). Autogenous shrinkage increases with a decrease in water to cement ratio and with an increase in the amount of cement paste. Normal concrete has negligible autogenous shrinkage; however, autogenous shrinkage is most prominent in concrete with water to cement ratio under 0.42 (Holt 2001). High strength and low water to cement ratio $(0.30)$ 
concrete can experience autogenous shrinkage as high as 200 to 400 micrometer/meter $(\mu \mathrm{m} / \mathrm{m})$. Autogenous shrinkage can be half that of drying shrinkage for concretes with a water to cement ratio of 0.30 . Recent use of high performance, low water to cement ratio concrete in bridges and other structures has resulted in renewed interest in autogenous shrinkage to control crack development. Concretes susceptible to large amounts of autogenous shrinkage should be cured with external water for at least 7 days to help control crack development. Fogging should be provided as soon as the concrete is cast. The hydration of supplementary materials also contributes to autogenous shrinkage, although at different levels than portland cement. In addition to adjusting paste content and water to cement ratios, autogenous shrinkage can be reduced by using shrinkage reducing admixtures or internal curing techniques. (Kosmatka et al. 2002)

\subsubsection{Drying Shrinkage of Hardened Concrete}

Withdrawal of water from concrete stored in unsaturated air causes drying shrinkage. A part of this movement is irreversible and should be distinguished from the reversible moisture movement caused by alternating storage under wet and dry conditions. Since the moisture migration occurs over a long-term period, drying shrinkage is directly related to long-term deflection, loss of prestressing, and cracking. Since the currently used method (ACI-209) may not give accurate estimation, drying shrinkage of concrete is an uncertain property.

As drying takes place, concrete shrinks. Where there is no restraint, movement occurs freely and no stresses or cracks develop (Figure 2.1 top). If the tensile stress that results from restrained drying shrinkage exceeds the tensile strength of the concrete, cracks can develop (Figure 2.1 bottom). 


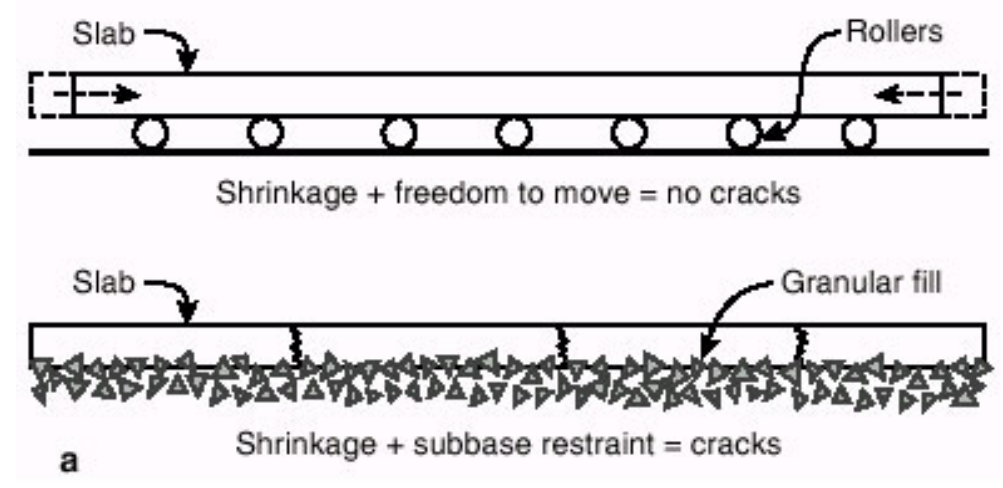

Fig. 2.1 Shrinkage and cracking (Kosmatka et al. 2002)

\subsubsection{Differential Shrinkage}

It is mentioned above that shrinkage takes place due to loss of moisture in concrete. Kosmatka et al. (2002) pointed out that moisture loss occurs mainly at the surface, leading to a moisture gradient through the depth of the concrete specimen, which is thus subjected to differential shrinkage. The potential shrinkage is compensated by strains due to internal stresses, tensile near the surface and compressive in the core. When drying takes place in an unsymmetrical manner, warping (curling) can result.

The progression of shrinkage extends gradually from the drying surface into the interior of the concrete, but does so at a very slow rate. Hermite in 1978 established a relation between shrinkage progression with time and distance from the drying surface, as shown in Fig 2.2. 


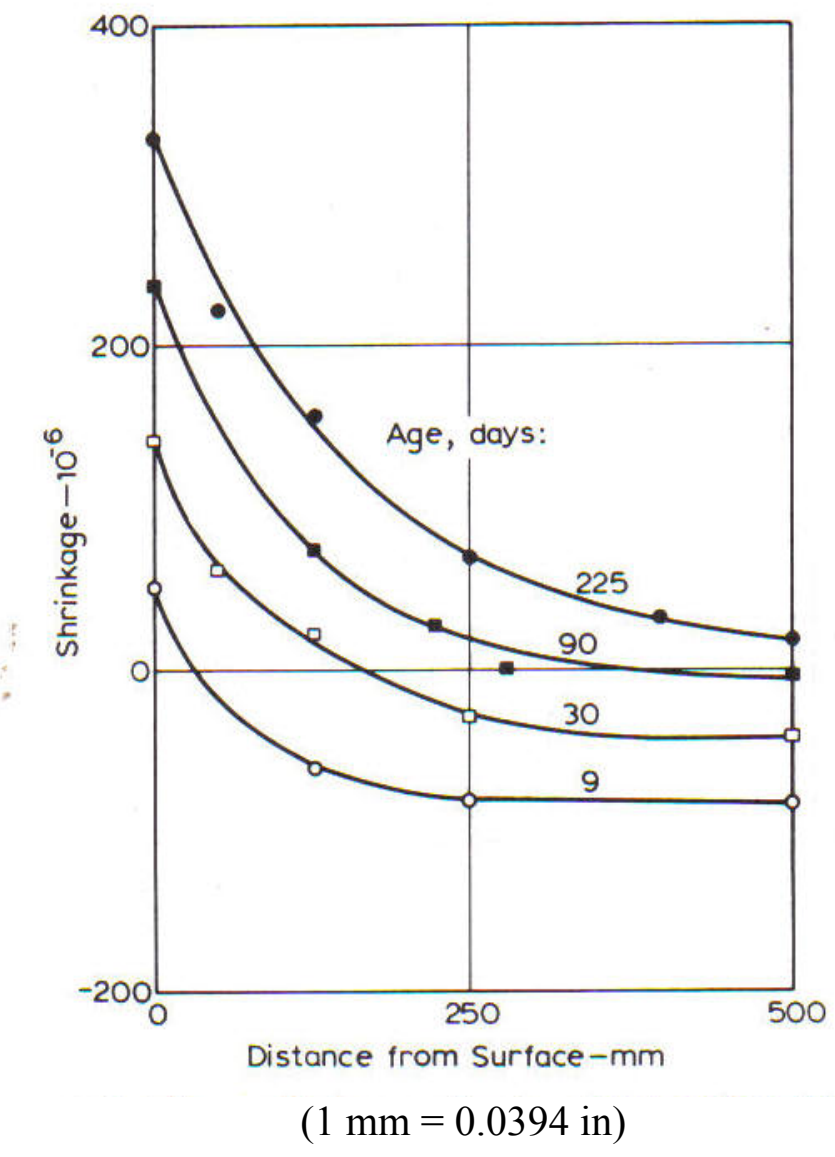

Fig. 2.2 Progression of shrinkage with time as a function of distance from the drying surface (Hermite, 1978)

In Fig. 2.2, it is noticed that the differential shrinkage develops from the surface to a depth of around $250 \mathrm{~mm}(10 \mathrm{in})$ at the early age of 9 days. For normal application, the thickness of overlays used on bridge decks is between $50 \mathrm{~mm}$ ( 2 in) to $100 \mathrm{~mm}$ (4 in), which means that a differential shrinkage will very likely be induced in overlay concrete at early age.

Suprenant et al. (1999) reported the curling phenomenon in bonded overlays used in pavements. They found that curling is most noticeable at construction joints, but it can 
also occur at cracks and saw-cut joints (Figure 2.3). At slab corners, the upward curl can be as much as $25 \mathrm{~mm}(1 \mathrm{in})$.
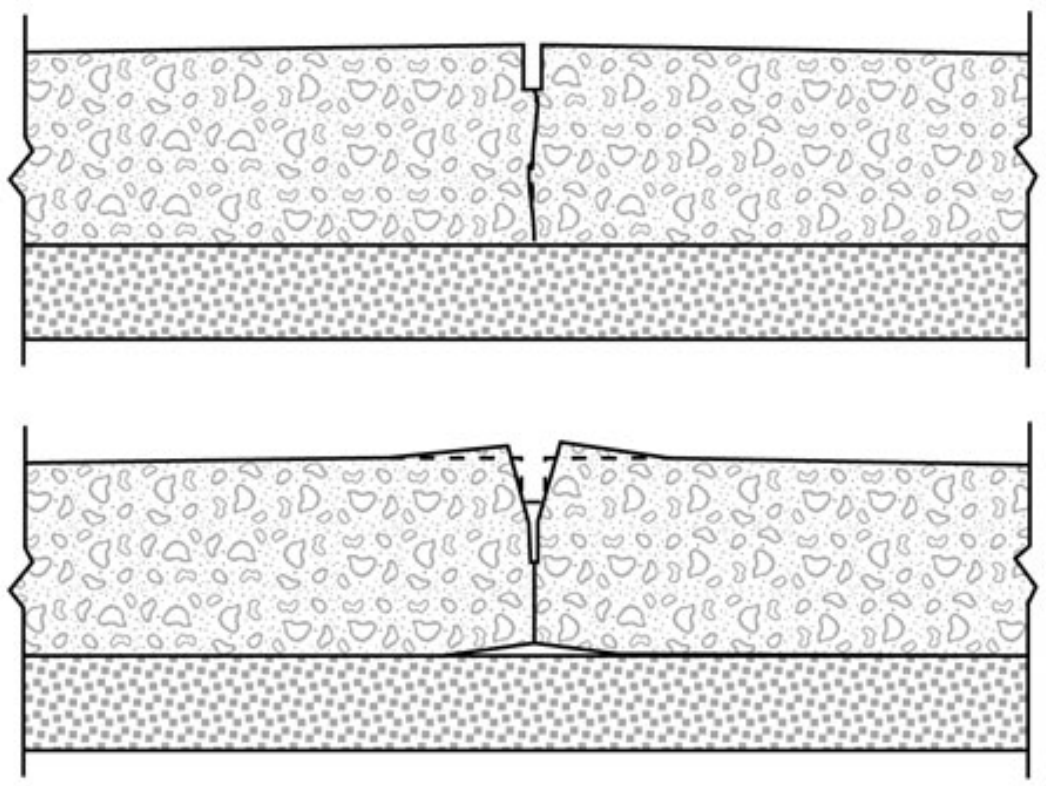

Figure 2.3 Curling at a saw-cut joint (Suprenant et al. 1999)

Mailvaganam et al. (2000) reported that at construction joints that have no provision for load transfer, curling generally results in a loss of subbase contact over about $20 \%$ of the slab length between joints (Figure 2.4), twice the amount lost at saw-cut or doweled joints. They explained that the basic cause of curling is differential shrinkage that occurs in a slab as the exposed top surface shrinks and the core does not. This shrinkage is usually due to drying, but can also be caused by carbonation of the surface concrete, or, in low water-cement ratio high-strength concrete mixes by the internal desiccation (autogenous shrinkage) that occurs as the cement paste hydrates. Concrete, like many construction materials, is not dimensionally stable when subjected to changes in moisture content. As new slabs dry from the surface down, the moisture gradient through the slab leads to differential shrinkage. 


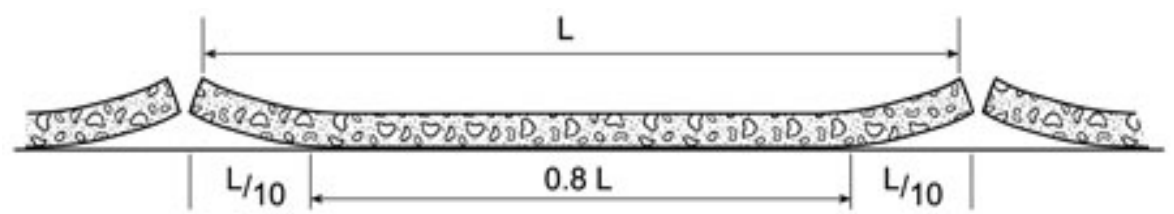

Figure 2.4 Slab edge curling resulting in a $20 \%$ loss of sub-base contact

(Mailvaganam et al. 2000)

\subsubsection{Concrete Volume Change due to Temperature}

Kosmatka et al. (2002) explained that concrete expands slightly as temperature rises and contracts as temperature falls. Also it can expand slightly as free water in the concrete freezes. Temperature changes in concrete may be caused by environmental conditions or by cement hydration. An average value for the coefficient of thermal expansion of concrete is about $10 \times 10^{-6} /{ }^{\circ} \mathrm{C}\left(5.5 \times 10^{-6} /{ }^{\circ} \mathrm{F}\right)$. This amounts to a length change of $5 \mathrm{~mm}(1 / 5 \mathrm{in})$ for $10 \mathrm{~m}(33 \mathrm{ft})$ of concrete. Thermal expansion and contraction of concrete varies with factors such as aggregate type, cement content, water to cement ratio, temperature range, concrete age, and relative humidity.

Temperature changes that result in shortening can crack concrete members that are highly restrained by boundary conditions. Consider a long restrained concrete member cast without joints that, after moist curing, is exposed to a drop in temperature. As the temperature drops, the concrete tends to shorten, but cannot because it is restrained longitudinally. The resulting tensile stresses cause the concrete to crack.

Precast wall panels and slabs and bridge decks are susceptible to bending and curling caused by temperature gradients that develop when concrete is cool on one side and warm on the other. An example showing the deformation of a precast wall panel due to temperature gradient is shown in Fig. 2.5. 


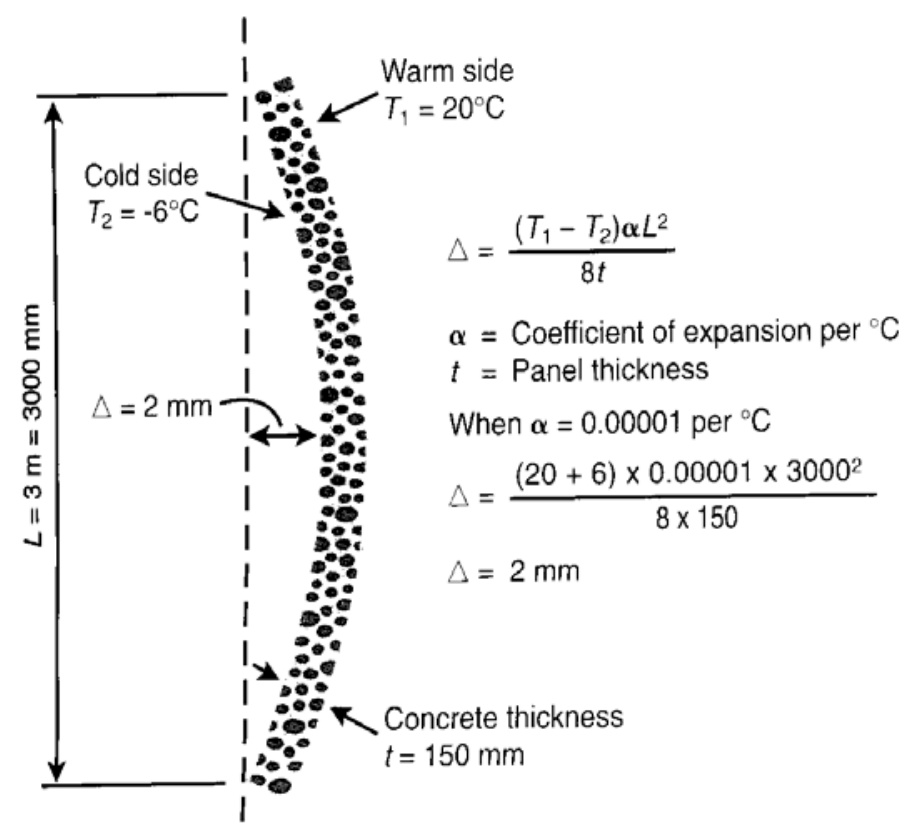

Fig. 2.5 Curling of a plain concrete wall panel due to temperature varying uniformly from inside to outside (Kosmatka et al. 2002)

\subsection{Surface Preparation of the Concrete Substrate}

Surface preparation is a critical factor in the performance of coatings and repair materials applied to concrete. The surface preparation of concrete substrate in readiness for the application of overlaying concrete includes all the steps taken after the removal of the deteriorated concrete. Proper preparation provides a dry, even and level surface free of dirt, dust, oil and grease. Removal of surface contaminants on a rough surface allows overlaying concrete to have direct contact with the substrate, increasing the contact surface areas and providing increased anchorage of overlay.

The optimal condition of the concrete surface, however, depends on the type of repair being undertaken and the condition of the substrate. Also, it is not always possible to determine which material must be removed, because the zones of damaged or 
deteriorated concrete are sometimes not well defined. Thus, the best approach is to remove material until aggregate particles are being broken rather than simply being pried loose from the matrix.

Mailvaganam et al. (1998) recommended that before applying cement-based repair materials, the substrate should be saturated to prevent the rapid loss of water from the repair material (into the substrate) and subsequent shrinkage and cracking. However, for resin-based materials the concrete surface must be dry for maximum adhesion to be achieved. Whenever deteriorated concrete is removed using impact tools, the surface of the remaining concrete may be damaged. If this latter damaged layer is not removed, the repair material will debond from the substrate. The remaining concrete should therefore undergo further preparation using wet sandblasting or high-pressure water jetting to remove this damaged surface material. Surfaces to receive the bonded concrete overlay must be inspected after the surface is prepared to insure that the substrate is sound and structurally durable. Areas found to be unsound or non-durable must be removed and replaced. Dust or other deleterious substances not removed after the initial surface preparation must be vacuumed, leaving the surface dust free and clean.

The Sherwin-Williams Company published "Guideline Instructions for Concrete Surface Preparation" in 2005. It is recommended that prior to overlaying the substrate, the substrate surface must be decontaminated. Decontamination of the concrete surface requires the removal of oils, grease, wax, fatty acids and other contaminants, and may be accomplished by the use of detergent scrubbing with a heavy duty cleaner/degreaser, low pressure water cleaning (less than 5,000 psi), or chemical cleaning. The success of these methods is dependent upon the depth of penetration of the contaminant; which is 
completely dependent upon the contaminant's viscosity, the concrete's permeability and the duration of exposure. A simple method to ensure sound concrete is to test the $\mathrm{pH}$. The chemistry of concrete is alkaline in nature. Normal concrete should be in the range of 11 to 13. Most of the contaminants mentioned are neutral to acidic in nature. After preparations the substrate should be tested at multiple locations using distilled water and $\mathrm{pH}$ evaluation strips. If the $\mathrm{pH}$ is 10 or lower additional preparation will be required to ensure a good bond.

The surface profile is the measure of the average distance from the peaks of the surface to the valleys as seen through a cross sectional view of the surface of the concrete. This dimension is defined pictorially and through physical samples in the ICRI (International Concrete Repair Institute) Technical Guideline No 03732, and is expressed as a Concrete Surface Profile number (CSP 1 through 9). Fig. 2.6 shows the corresponding preparation methods.

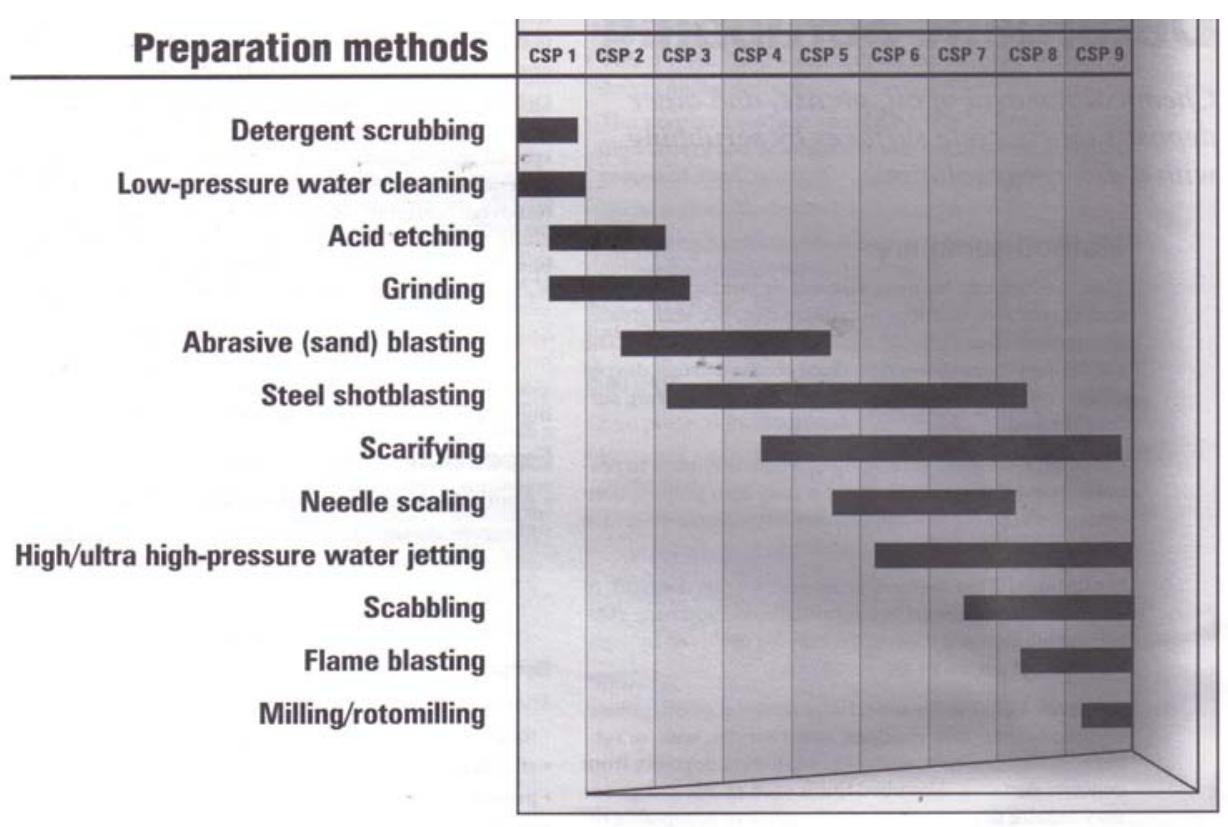

Fig. 2.6 Concrete surface preparation methods (ICRI technical guideline No. 03732) 


\subsection{Edge Curling and Delamination}

Concrete undergoes volume changes due to shrinkage under environmental conditions such as temperature and humidity. Volume changes of concrete causes cracking if the concrete is restrained. In the case of bonded overlays, the underlying reinforced concrete bridge deck acts as a restraint. While the new overlay concrete is affected by drying shrinkage and temperature changes, the old substrate concrete volume is relatively stable. The difference in volume change of the two layers causes cracking at the surface of new concrete and debonding at the interface between overlay and substrate. The curling behavior of overlay due to temperature and shrinkage difference is schematically shown in Figure 2.7. 

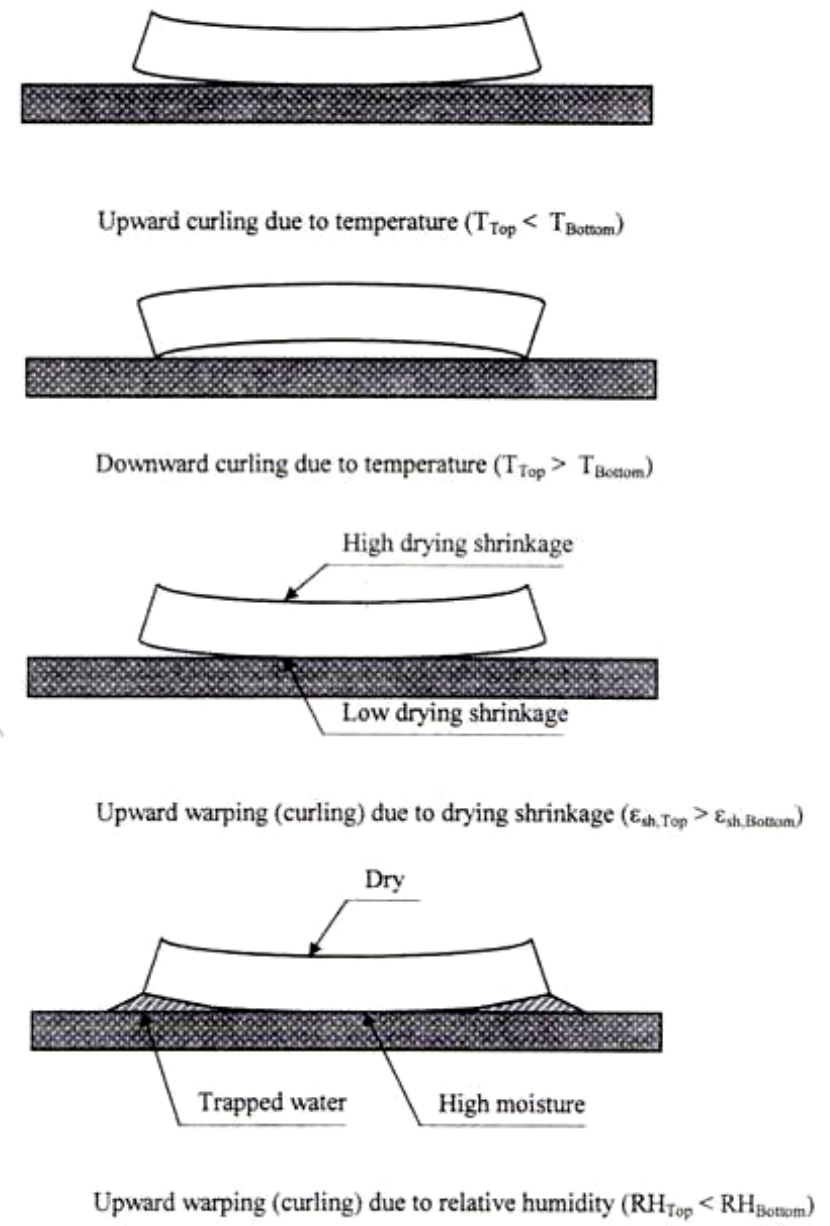

Figure 2.7 Overlay curling due to temperature and shrinkage difference

(Shin, 2000)

Usually bridges are built in open areas. Thus, concrete overlays often experience severe changes in temperature and drying shrinkage at early age. Due to drying shrinkage and temperature gradients through the thickness, an overlay tends to curl up or down at the edges and joints. This curling behavior may lead to the debonding at the interface between overlay and underlying reinforced concrete deck. Furthermore, debonding will 
finally result in the failure of overlay-deck system due to externally applied wheel loads and subsequent temperature changes.

Lau et al. (1994) analyzed the interface shear stress due to wheel loading of a pavement overlay system by using the nodal force output from a finite-element analysis. Maximum shear stress occurred at the perimeter of the loaded area under the action of normal wheel load and thermal warping. In the case of horizontal braking force, maximum shear stress was found to occur at the center of the loaded area. The calculated shear stresses ( $\leq 0.178 \mathrm{MPa}$, braking load; $\leq 0.064 \mathrm{MPa}$, vertical wheel and temperature load) were less than $1 / 20$ of the expected bond strength. It was concluded that wheel loading alone would not be critical in properly bonded pavement-overlay system. The fact that interface distress still occurred in the field indicated that other factors such as environmental effects and stress concentrations at initially small defects were significant in influencing the performance of interfacial bonds of pavement overlays.

In modeling stresses and strains in composite concrete beams subjected to differential shrinkage, Silfwerbrand (1997) found strain concentrations at the ends of experimentally overlaid beams of $6 \mathrm{~m}$ and $8 \mathrm{~m}$ in length. He concluded that differential shrinkage caused stresses in repaired concrete structures. The maximum normal and shear stresses occurred at the beam ends, which was consistent with the fact that delamination in the overlay-base system usually was initiated at the edge of the composite structure.

During the investigation of non-composite reinforced concrete bridge decks subjected to fatigue due to moving loads, Perdickaris and Beim (1998) conducted tests on $1 / 3$ and $1 / 6.6$ scale physical models of a full-scale $216 \mathrm{~mm}(8.5 \mathrm{in})$ thick and $15.24 \mathrm{~m}$ (50 ft) long simply supported no-composite reinforced concrete deck. They found that under 
moving constant wheel-load, the initial two-way deck slab action changes to a one-way action (transverse direction) as fatigue damage due to a moving wheel-load accumulates (Fig. 2.8).

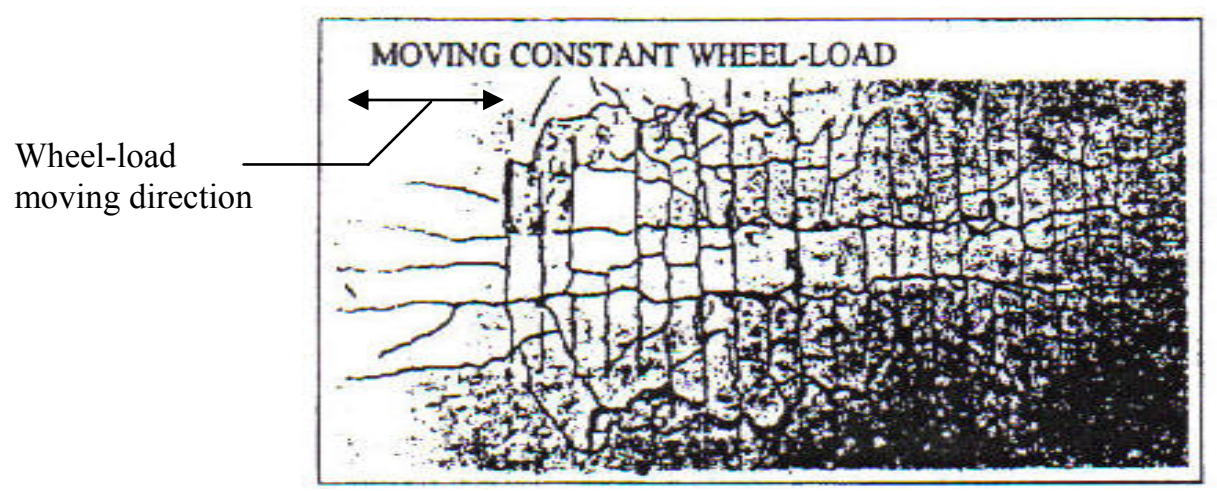

Fig. 2.8 One-way Slab Action as Failure Is Approached (Perdickaris and Beim, 1998)

Delatte (1998) drew the following conclusions by investigating the performance of bonded concrete overlays used in highway pavements:(1) The observed delaminations were often detected within 24 hours after overlay placement, and all of them were located next to a joint or crack. The delaminations did not appear to be progressive over three years of observations; (2) the bond strength near wide cracks was lower than that of other area, which was due to the larger differential movements between the bonded concrete overlays and the base slab; (3) the early age delamination of overlay was due mainly to inadequate paste adhesion caused by deficiencies in surface preparation, loss of available water to evaporation and absorption of dry base pavement and low initial water content.

By conducting finite element analysis, Delatte (1999) concluded that: (1) Debonding shear stresses are higher at a corner than at a free edge, based on comparisons of 2-D and 3-D results; (2) overlay tensile stresses and interface tensile stresses seem to 
be less affected; (3) stresses that occur at an interfacial crack with an overlay are higher than those at a free edge, due to the greater relative stiffness of the base.

Shin (2000) in his work found that debonding starts at the corner and propagates into the interior of the slab when using test-beam specimens of the dimension of $400 \mathrm{~mm}$ x $200 \mathrm{~mm}$ x $50 \mathrm{~mm}$ (Overlay)/75 mm (Substrate). The results agreed with his 3-D numerical analysis, which showed maximum tensile stress concentration at the corner of the interface. In the experiment, crack opening displacements (CODs) were measured by several transducers (LVDT) mounted at the interface and the debonding length was measured by a dye technique. It was concluded that the large debonding length and COD of HPC overlay was largely due to high shrinkage and low bond strength. Also, the difference in the elastic modulus between HPC overlay and portland cement substrate might have caused high stresses at the interface. It was observed that cracking on the overlay surface and debonding at the interface were interdependent. When surface cracking occurred, the stress at the interface decreased and debonding was reduced. Likewise, when the debonding propagated, the stress at the overlay surface decreased and surface cracking was reduced.

In a field test report, FHWA MCL Project \# 9904, published by FHWA in 2000, it was concluded that existing delaminations in the bridge deck prior to rehabilitation and damage from milling and partial depth concrete removal during rehabilitation contributed to the low tensile strengths in the top portions of the substrate material. A bridge deck is more susceptible to damage incurred as a result of deflections and impacts during dynamic loading from milling as well as normal service, than a fully supported approach 
slab. The pull-off tensile test can be a useful approach for estimating expected service life of bridge deck overlays, by measuring degradation of tensile strength with time.

Whiting et al. (2000) investigated the cracking tendency and drying shrinkage of silica fume modified concrete designed for bridge deck overlay applications. They found that silica fume affects the shrinkage at early ages. When the silica fume content is high, the required increase in water to cementitious materials ratio leads to significant increase in drying shrinkage. The improper curing is the primary reason for cracking of silica fume modified concrete. There is no statistically significant effect of silica fume on early age cracking in concrete. Curing silica fume modified concrete continuously for 7 days or more under moist condition substantially reduces the cracking tendency. Mixtures having high cement contents contain greater amounts of paste, which is the component of concrete that undergoes shrinkage and leads to cracking. It is recommended that silica fume of 6 to $8 \%$ by mass of cementitious material is preferred to control the cracking.

Ruiz (2001) concluded in their study that the temperature gradient in the overlay and Jointed Concrete Pavement (JCP) greatly influence the daily vertical movement at the edge. When the thermal gradient is at its peak value, the vertical movement reaches maximum. The axial temperature also influences the vertical movement, but to a lower magnitude than the temperature gradient. Drying shrinkage produces a vertical movement that tends to increase with time. From the interfacial restraint analysis performed, it was concluded that bonded overlay was subjected to a significant amount of drying shrinkages that caused delamination just after 20 hours. Beyond this initial time, the subsequent occurrence of delamination was observed from the LVDT analysis. The reinforcing steel in Continuous Reinforced Concrete Pavement (CRCP) restrains the 
underlying pavement from curling up and down and translating axially. This restraint increases the separation of the overlay from the CRCP.

Delatte et al. (2001) reported early age behavior must be considered as well as long-term behavior regarding the concrete overlay performance. Factors such as shrinkage and thermal contraction must be considered in designs, which in many cases will govern design. These factors are as important as strength. Performance of overlays also depends on surface preparation and curing. If these are neglected, even the bestdesigned materials may fail. Management of overlay temperatures at early ages is very important. It was found in this study that the time of casting affects the overlay performance very much. Morning casting on sunny days should be avoided and late afternoon casting is recommended.

Cole et al. (2002) investigated performance of overlays placed over sealed decks under static and fatigue loading. It was found that the failure modes were remarkably different depending on the direction of bending. When subjected to positive bending moment (overlay in compression), the overlay, acting as "fixed-free" beam, buckled outward and tensile stresses normal to the plane of the interface were produced. The failure mode was not classical bond failure and the overlay did not slide off. When subjected to negative bending moment (overlay in tension), the whole beam acted like a typical under-reinforced concrete beam. Flexural cracking reduces the level of the shear stress that can be developed. By conducting a prototype test on a 1/3-scale bridge deck specimen, the response of the specimen after several fatigue loading cycles up to $1,000,000$ was measured via modal test by using 27 -point multi-reference impact testing techniques (Fig. 2.9). It was found that the service-level fatigue loading did not 
deteriorate the available bond between the overlay and the deck, which had been sealed with high molecular weight methacrylate (HMWM), and prepared by broadcasting sand immediately after applying HMWM. This conclusion was also confirmed by intermediate static tests regarding the stiffness change of the specimen.

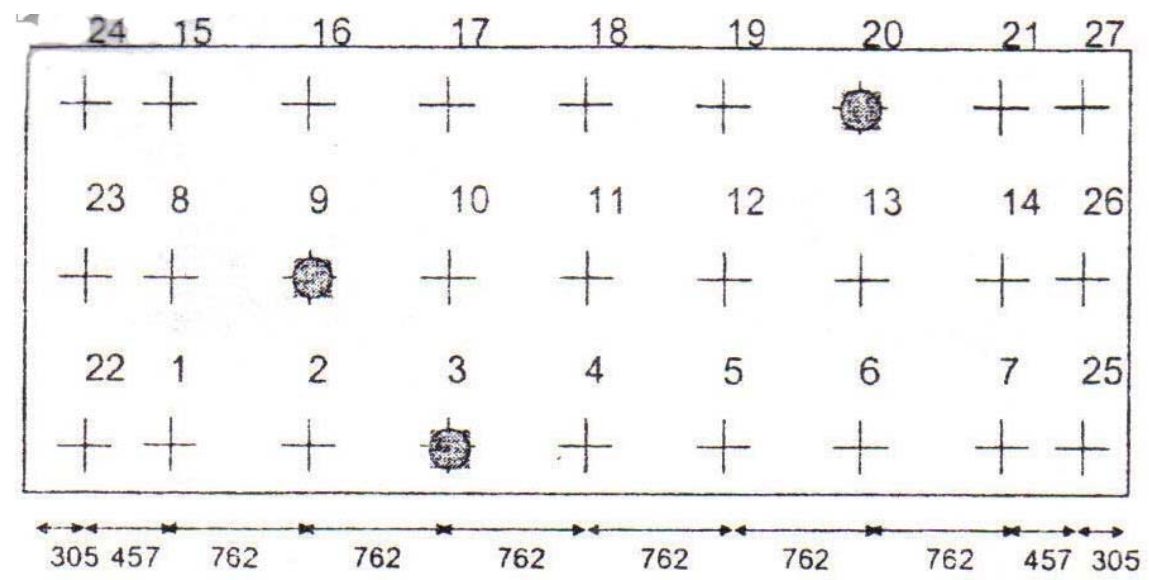

Accelerometer Locations All dimensions are in $\mathrm{mm}$.

Fig. 2.9 Grid layout for multi-reference impact test (Cole et al. 2002)

Zhang and Li (2002) conducted a study on the monotonic and fatigue performance in a FRC overlay system. They concluded that when Engineered Cementitious Composite (ECC) is used as overlay material, both load carrying capacity and deformability represented by deflection at peak load of the overlaid beams in flexure were significantly increased compared to those of plain concrete (PC) overlaid beams. The fatigue life of ECC overlaid beams in flexure was not influenced by the layer/base interfacial characteristics, such as smooth casting surface or sand-blasted rough surface. However, the deformation ability of the overlaid beams, such as deflection at midpoint of beam in both static and cyclic loading cases, was influenced by the interfacial property. The smooth casting surface leads to larger deformation at peak load under monotonic 
loading and at failure under fatigue loading than the corresponding values for beams with a rough casting surface.

Kim et al. (2003) observed the following: (1) Daily vertical movement at the edge of the overlay and the existing continuously reinforced concrete pavements was caused primarily by temperature gradient through the overlay; (2) the interfacial normal and shear stresses increase as the overlay's elastic modulus, thickness or coefficient of thermal expansion increased and as the slab length (crack spacing) increased; (3) the interfacial stresses at the corner of the slab can be calculated using a 3D finite element model. The corner stresses were larger than the edge stresses at mid-slab, as was expected since delamination initiated at the corner.

Granju et al. (2004) explained the debonding mechanism of the interface between an old concrete pavement and bonded concrete overlay. He concluded that: (1) debonding is initiated from a discontinuity of the overlay, a crack or the boundary of the overlay; (2) although the interface is stressed in mixed mode, in the case of a bond between cementbased materials, debonding is always initiated by tension perpendicular to the interface; (3) the reinforcement of the overlay by fibers, by providing some continuity through the cracks, delays debonding initiation and its propagation. Ordinary steel reinforcing bars or welded wire mesh bring some benefit as well. Fig. 2.10 shows Granju's illustration (2004) of the cracking and debonding mechanism of bonded concrete overlay. 


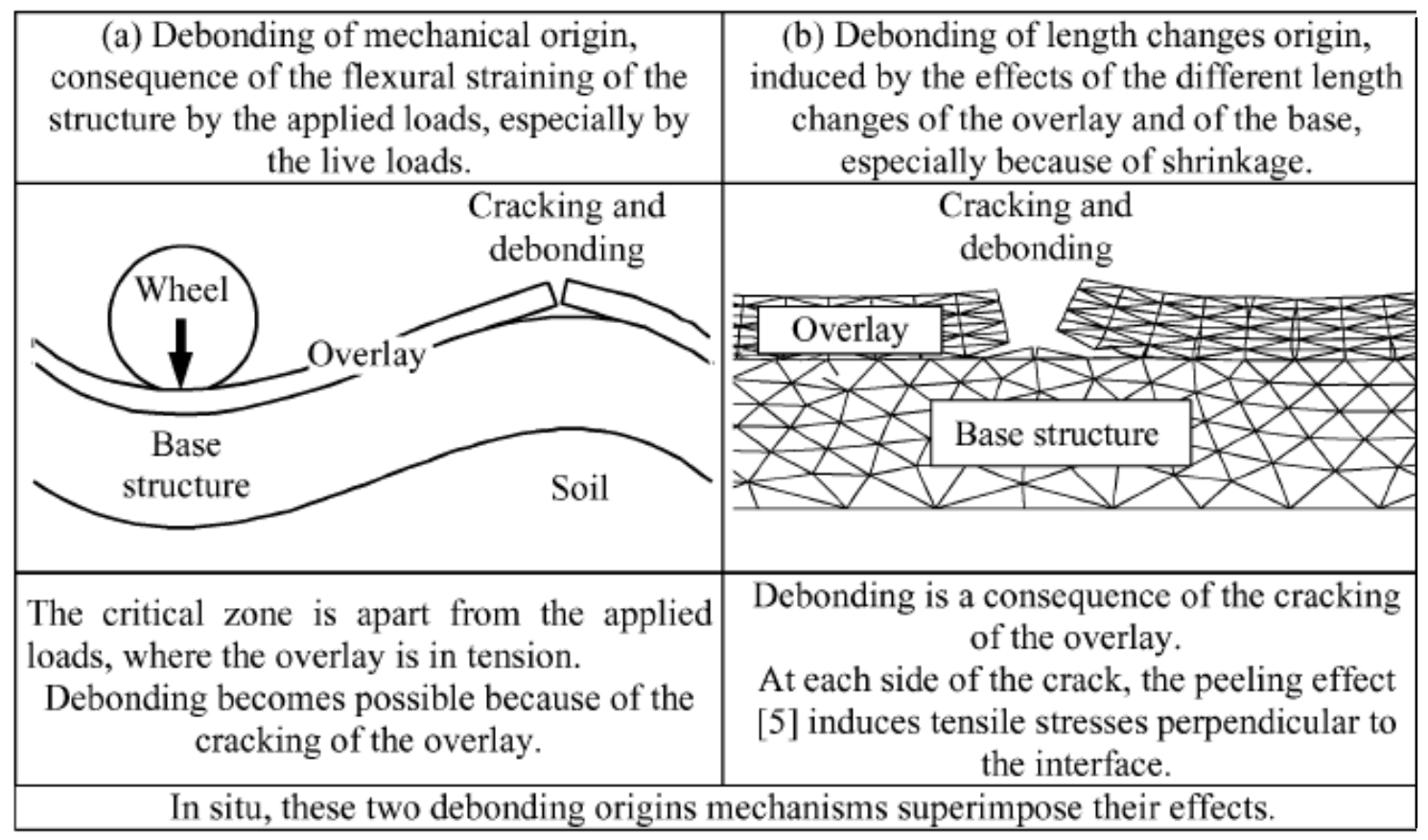

Fig. 2.10 Bonded Concrete Overlay Cracking and Debonding Mechanism due to Applied Loads (Granju, 2004)

From the literatures reviewed above the following can be concluded. The debonding at overlay-slab interface is initiated from a discontinuity of the overlay, a crack through the overlay or a discontinuity at the boundary of the overlay, due to shrinkage, temperature gradient or other, which propagates under repeated wheel loading. Also, when failure of a two-way deck slab under wheel loading is approached, the slab will change action to a one-way slab. Therefore, the investigation of the performance of deck slab can be focused in one geometrical direction. Moreover, the surface condition prior to the casting of overlay greatly influences the performance of overlay under normal service loading conditions and environmental changes. 


\subsection{Ultrasonic Pulse Velocity Technique}

Ultrasonic waves are mechanical waves that are generated by exciting a piezoelectric crystal with a high voltage pulse. The wave is then transmitted through the tested material, which is in contact with the transducer containing the crystal. When this wave impinges upon a receiving transducer it produces an output voltage. Three basic types of stress waves are created in a solid medium when an ultrasonic pulse is sent through a test object: longitudinal, shear, and surface waves (ACI 1989). There are three possible ways in which the transducers may be arranged: direct, semi-direct, and indirect transmission. In the direct method the transducers are placed on opposite faces of the tested element. In the semi-direct method the transducers are placed at a $90^{\circ}$ angle, whereas in the indirect method both transducers are placed on one face of the tested element. Since the transmission path length and direction are not well defined in the indirect method, the results are less satisfactory. Thus, the indirect method does not give any information on deeper concrete; it only collects information about or near the surface.

The velocity of these waves depends upon the elastic properties of the propagating media, and is a characteristic of the test material. In general the velocity is constant for a given material for any wavelength and any frequency. The relationship between the velocities for the different waves is that the longitudinal wave travels the fastest, followed by the transverse wave, and finally the surface wave, which is the slowest.

When a mechanical wave is transmitted through a material, the elements of the medium are deformed. The disturbance propagates and carries energy through the medium. The medium deformation depends upon its properties of deformability and 
inertia. Each element of the material reached by the wave has the same oscillation frequency, as in the case of a non-disperse material. When a mechanical wave hits an interface, according to the interface dimension, the wave can be reflected, transmitted or diffracted. The amount of transmitted energy depends upon the relationship between the impedance of the two materials.

The impedance is the product of the density of the material and the wave velocity in the material, and it may be thought of as the resistance of the material to the passage of the wave. Bodies in nature have natural frequencies, which define their modes of vibration. A mode of vibration is a way in which a system can vibrate. The frequencies at which it is possible to realize the vibrations depend on the properties of the system. The lowest frequency is associated with the first mode of vibration and is called the fundamental frequency. Experimentally, the natural frequency of a body can be known if a resonance is induced on the body. A resonance on a body is induced when a vibration that interacts with the body has at least a frequency of vibration equal to a natural frequency of vibration of the analyzed body.

The pulse transit time between the two transducers is governed by the fastest wave. The velocity of the ultrasonic wave in concrete depends on the physical properties of the material, such as elasticity and density. The pulse velocity in an elastic solid is given by:

$$
V_{p}=\sqrt{\frac{E(1-v)}{\rho(1+v)(1-2 v)}}
$$

where $V_{p}$ is the compressional pulse velocity, $E$ is the dynamic modulus of elasticity, $\rho$ is the density, and $v$ is Poisson's ratio. This equation can be used to determine the 
velocity of transmission of longitudinal pulses through a solid of any shape or size, provided the smallest lateral dimension perpendicular to the path of travel is not less than the wavelength of the pulse vibrations.

Jones and Facaoaru (1969) stated that the use of the ultrasonic pulse technique for locating flaws, voids or other defects in concrete is based on the negligible transmission of ultrasonic energy across a concrete-air interface. Any air-filled crack or void lying immediately between two transducers will obstruct the direct ultrasonic beam when its projected area is greater than the area of the transducers. When this happens the first pulse to arrive at the receiving transducer will be diffracted around the periphery of the defect and the transit time will be longer than in homogeneous concrete. Apart from the apparent decrease in pulse velocity, the amplitude of the received pulse is usually less than in homogeneous concretes and the decrease is most marked for transducers which produce a well-defined beam; i.e. those having a high resonant frequency and large crosssection.

Signal processing involves techniques that improve our understanding of information contained in received ultrasonic data. Normally, when a signal is measured with an oscilloscope, it is viewed in the time domain (vertical axis is amplitude or voltage and the horizontal axis is time). For many signals, this is the most logical and intuitive way to view them. Simple signal processing often involves the use of gates to isolate the signal of interest or frequency filters to smooth or reject unwanted frequencies.

When the frequency content of the signal is of interest, it makes sense to view the signal graph in the frequency domain The frequency domain display shows how much of the energy of the signal is present as a function of frequency. For a simple signal such as 
a sine wave, the frequency domain representation does not usually show us much additional information. However, with more complex signals, such as the response of a broad bandwidth transducer, the frequency domain gives a more useful view of the signal. Fig. 2.11 shows a typical sound data in both time domain (waveform) and frequency domain (power spectral).

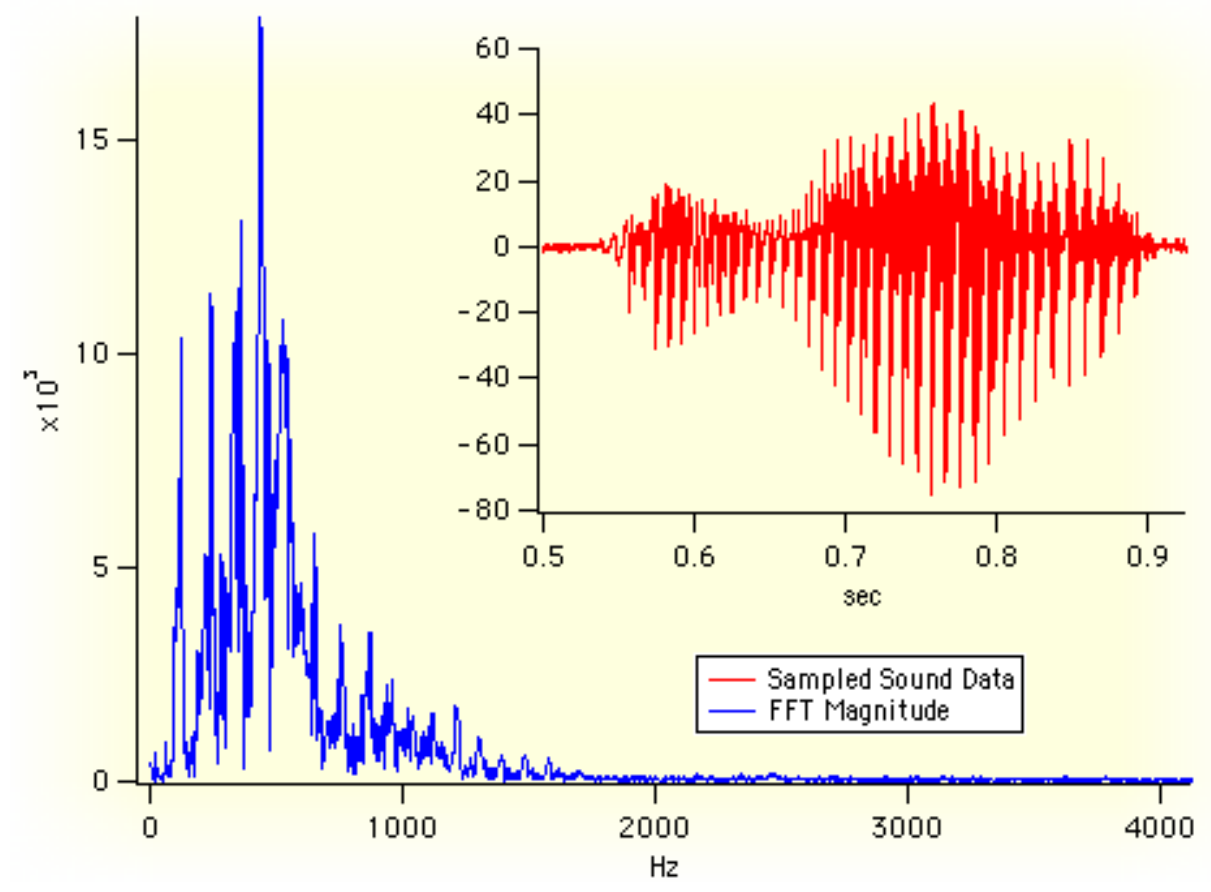

Fig. 2.11 Signal display forms (www.wavemetrics.com)

Fourier theory says that any complex periodic waveform can be decomposed into a set of sinusoids with different amplitudes, frequencies and phases. The process of doing this is called Fourier analysis, and the result is a set of amplitudes, phases, and frequencies for each of the sinusoids that make up the complex waveform. Adding these sinusoids together again will reproduce exactly the original waveform. A plot of the frequency or phase of a sinusoid against amplitude is called a spectrum. 


\subsection{Research Significance}

Early age differential shrinkage and temperature gradient initiate edge curling and cracking at the interface of overlay-substrate concrete bilayer systems. Continued differential shrinkage, temperature gradient, and fatigue and cyclic loading further induce delamination of interface between overlay and substrate. Surface condition and overlay types influence this edge curling and delamination. A study on the edge curling and delamination issues for different surface and overlay conditions is very useful, as this information can be used in the selection of particular overlay types and to prescribe appropriate surface conditions for minimizing or eliminating debonding and delamination within the interface. 


\section{CHAPTER 3}

\section{MATERIALS AND FABRAICATION OF SPECIMENS}

\subsection{Materials}

\subsubsection{Cement}

Commercially available Type I Portland cement was used in this study. The cement conformed to ASTM C150 (Standard Specification for Portland Cement). The basic physical properties and compound composition of cement are presented in Table 3.1 and 3.2 , respectively.

Table 3.1 Physical properties of Type I portland cement used

\begin{tabular}{|c|c|c|c|}
\hline \multirow{2}{*}{ Specific Gravity } & \multirow{2}{*}{ Fineness } & \multicolumn{2}{|c|}{ Setting time } \\
\cline { 3 - 4 } & & Initial (min) & Final (min) \\
\hline 3.15 & $320 \mathrm{~m}^{2} / \mathrm{Kg}$ & 90 & 260 \\
\hline
\end{tabular}

$1 \mathrm{~m}^{2} / \mathrm{Kg}=578.6 \mathrm{in}^{2} / \mathrm{lb}$

Table 3.2 Compound compositions of portland cement

\begin{tabular}{|c|c|}
\hline Compounds & Percentage by mass \\
\hline Tricalcium Silicate & 49 \\
\hline Dicalcium Silicate & 25 \\
\hline Tricalcium Aluminate & 12 \\
\hline Tetracalcium Aluminoferrite & 8 \\
\hline Calcium Sulfate & 2.2 \\
\hline Calcium Oxide & 0.8 \\
\hline Magnesium Oxide & 2.0 \\
\hline Others & 1.0 \\
\hline
\end{tabular}




\subsubsection{Coarse Aggregate}

According to the test results from previous research work collaborated with Zhenhua Sun at WVU in 2004 (Sun, 2004), concrete overlays using crushed limestone had higher bonding strength than those using crushed gravel. Thus, only crushed limestone conforming to ASTM C33 (Standard Specification for Concrete Aggregates) from WV source was used. Table 3.3 shows the properties of the crushed limestone used in the laboratory tests.

Table 3.3 Properties of coarse aggregates

\begin{tabular}{|c|c|c|}
\hline \multicolumn{2}{|c|}{ Items } & Crushed Limestone \\
\hline \multicolumn{2}{|c|}{ Source } & Cave In Rock Quarry \\
\hline \multicolumn{2}{|c|}{ SSD Bulk Specific Gravity } & 2.68 \\
\hline \multicolumn{2}{|c|}{ Absorption } & $1.17 \%$ \\
\hline \multirow{5}{*}{$\begin{array}{c}\text { Sieve } \\
\text { analysis } \\
\text { data }\end{array}$} & $12.7 \mathrm{~mm}$ & $100^{*}$ \\
\hline & $9.5 \mathrm{~mm}$ & $94^{*}$ \\
\hline & $6.4 \mathrm{~mm}$ & $29^{*}$ \\
\hline & $3.2 \mathrm{~mm}$ & $6^{*}$ \\
\hline & $1.6 \mathrm{~mm}$ & $1^{*}$ \\
\hline
\end{tabular}

\subsubsection{Fine Aggregate}

Only one type of fine aggregate was used in this study. It was obtained from Joe Lucas Dredge, which conformed to ASTM C33 (Standard Specification for Concrete Aggregates). Table 3.4 shows the properties of sand. 
Table 3.4 Properties of sand

\begin{tabular}{|l|l|}
\hline \multicolumn{2}{|l|}{ Source and Basic Properties } \\
\hline Facility source & Joe Lucas Dredge \\
\hline Type & Natural silica sand \\
\hline SSD bulk specific gravity & 2.61 \\
\hline Absorption & $1.5 \%$ \\
\hline Fineness Modulus & 2.96 \\
\hline \multicolumn{2}{|c|}{ Sieve Analysis } \\
\hline Sieve size & Percentage passing \\
\hline $9.5 \mathrm{~mm}$ & 100 \\
\hline $4.75 \mathrm{~mm}$ & 99 \\
\hline $3.2 \mathrm{~mm}$ & 84 \\
\hline $1.6 \mathrm{~mm}$ & 59 \\
\hline $0.8 \mathrm{~mm}$ & 38 \\
\hline $0.6 \mathrm{~mm}$ & - \\
\hline $0.5 \mathrm{~mm}$ & 18 \\
\hline $0.3 \mathrm{~mm}$ & 6 \\
\hline $0.1 \mathrm{~mm}$ & 1.6 \\
\hline
\end{tabular}

Note: $1 \mathrm{~mm}=0.0394 \mathrm{in}$

\subsubsection{Silica fume}

The silica fume used in the study conformed to ASTM C 1240 (Standard Specification for Silica Fume for Use in Hydraulic-Cement Concrete and Mortar). It was a commercially available compacted silica fume manufactured by BASF. The specific gravity of the silica fume was 2.2 .

\subsubsection{Latex and Antifoam}

Both latex and antifoam used in this study were commercial products manufactured by BASF and Dow Chemical Company, respectively. The latex was 
proprietary styrene/butadiene latex supplied as a white liquid with suspended solids.

Table 3.5 shows the properties of latex used in this study.

Table3.5 Typical properties of latex

\begin{tabular}{|l|l|}
\hline Properties & Values \\
\hline Specific Gravity & 1.04 \\
\hline Solids (\%) & $47.0-49.0$ \\
\hline $\mathrm{pH}$ & $9.0-11.0$ \\
\hline 200 Mesh Residue, per $900 \mathrm{ml}$ & $0.50 \mathrm{Max}$ \\
\hline Particle Size, red filter (Angstrom) & $1900-2200$ \\
\hline Surface Tension $(\mathrm{dyn} / \mathrm{cm})$ & $22-31$ \\
\hline Freeze Thaw Stability, after 2 cycles $(\mathrm{g})$ & $0.1 \mathrm{Max}$ \\
\hline Butadiene Content $(\%)$ & $30-40$ \\
\hline Weight per Gallon $\left(\mathrm{Kg} / \mathrm{m}^{3}\right)$ & 62.9 to 64.4 \\
\hline
\end{tabular}

Note: $1 \mathrm{Kg} / \mathrm{m}^{3}=0.134 \mathrm{lb} / \mathrm{gal}$

The DOW Corning Antifoam 2210 was also used in this study to control the excessive foaming due to latex. The properties of the product are presented in the Table 3.6.

Table 3.6 Typical properties of antifoam

\begin{tabular}{|l|c|}
\hline Items & Description \\
\hline Appearance & White \\
\hline Active Ingredient (\%) & 10 \\
\hline Specific Gravity, at $25^{\mathrm{O}} \mathrm{C}\left(77^{\mathrm{O}} \mathrm{F}\right)$ & 1 \\
\hline Consistency at $25^{\mathrm{O}} \mathrm{C}\left(77^{\mathrm{O}} \mathrm{F}\right)$ & Medium \\
\hline Viscosity, cps & 2,500 \\
\hline $\mathrm{pH}$ & 7.0 \\
\hline Emulsifier Type & Nonionic \\
\hline
\end{tabular}




\subsubsection{Fiber}

The fiber used in this study was steel polypropylene hybrid fiber produced by SI concrete system. It was a blend of ASTM A820 steel and 100\% virgin homopolymer graded multifilament. The fiber complied with national building codes ASTM C-1116 Type III and ASTM A820.

\subsubsection{Chemical Admixtures}

\subsubsection{Shrinkage-reducing admixture}

A commercial shrinkage-reducing admixture (SRA) was used in the study. It was supplied by BASF.

\subsubsection{High-range water reducing admixture}

The commercially available high-range water reducing admixture (HRWRA) used in this study was produced by BASF. It conformed to ASTM C 494 Type A and F requirements.

\subsubsection{Water-reducing and retarding admixture}

The water-reducing and retarding admixture (WRA) used in this study was produced by BASF. It conformed to ASTM C 494 requirements for Type A waterreducing, Type $\mathrm{B}$ retarding and Type $\mathrm{D}$ water-reducing and retarding admixtures

\subsubsection{Air-entraining admixture}

The air-entraining admixture (AEA) used in the mixes was supplied by BASF. It conformed to the requirements of ASTM C 260. 


\subsection{Mixture Proportions for Substrate and Specialized Overlays}

Based on the results of previous research work at WVU in 2004 (Sun, 2004), four mixtures of best performing and commonly used overlays and one mixture of normal concrete substrate were prepared for this study. All the overlays used crushed limestone. Overlay types were also selected according to the published information by various DOTs, literature and WV state requirements. The mixture proportions used in the study are provided in Table 3.7. 
Table 3.7 Mixture proportions of overlays and substrate (For each cubic meter of concrete)

Notes:

\begin{tabular}{|l|l|l|l|l|l|}
\hline \multirow{2}{*}{ Ingredient } & Substrate & \multicolumn{5}{|c|}{ Overlay } \\
\cline { 2 - 6 } & NC & SFMC & LMC & FRC & SFMC + SRA \\
\hline Cement (kg) & 337 & 377 & 415 & 410 & 377 \\
\hline Silica fume (kg) & & 33 & & & 33 \\
\hline Latex (kg) & & & 126 & & \\
\hline Antifoam (kg) & & & 1.182 & & \\
\hline Fiber (kg) & & & & 24.5 & \\
\hline Water (kg) & 168.5 & 164 & 145 & 164 & 164 \\
\hline $\begin{array}{l}\text { Coarse } \\
\text { Aggregate (kg) }\end{array}$ & 1043 & 574 & 592 & 679 & 716 \\
\hline Sand (kg) & 718 & 832 & 858 & 982 & 937 \\
\hline HRWRA (ml) & 1860 & 3180 & & 1670 & 2390 \\
\hline WRA (ml) & & & & 1250 & \\
\hline SRA (ml) & & & & & 8200 \\
\hline AEA (ml) & 300 & 680 & & 275 & 680 \\
\hline w/cm & 0.5 & 0.4 & 0.35 & 0.4 & 0.4 \\
\hline
\end{tabular}

- $1 \mathrm{Kg}=2.205 \mathrm{lb}$

$$
1 \mathrm{ml}=0.0338 \mathrm{oz} \quad 1 \mathrm{Kg} / \mathrm{m}^{3}=0.062 \mathrm{lb} / \mathrm{ft}^{3}
$$

- Shrinkage reducing Admixture (SRA) was used 2\% by weight of cementitious materials;

- In LMC overlay, solid latex used was $15 \%$ by weight of cement;

- $\quad N C=$ normal concrete, $S F M C=$ Silica fume modified concrete, $L M C=$ Latex modified concrete, FRC $=$ Fiber reinforced concrete, $S F M C+$ SRA $=$ Silica fume modified concrete with $2 \%$ SRA by weight of cement, $w / \mathrm{cm}=$ water to cementitious materials ratio. 


\subsection{Mixing Procedures}

The mixing was performed in the laboratory using the standard rotary drum mixer. The mixing procedures for different mixtures are listed below:

\subsubsection{Normal Concrete for substrate (NC)}

1. Added coarse aggregate and approximately $3 / 4^{\text {th }}$ of water to the mixer and rotated the mixer until uniformly mixed.

2. Sand premixed with the AEA was added to mixer and mixed thoroughly until small air bubbles was visible.

3. Cement and remaining water were added and mixed for 3 minutes.

4. Stopped the mixer for 3 minutes.

5. Remixed for 2 minutes.

6. Added the HRWRA and mixed until the desired slump was obtained.

\subsubsection{Concretes for Overlay}

\subsubsection{Silica Fume Modified Concrete (SFMC)}

1. Added coarse aggregate and approximately $3 / 4^{\text {th }}$ of water to the mixer and rotated the mixer until uniformly mixed.

2. Added silica fume and continued to rotate.

3. Sand premixed with the AEA was added to mixer and mixed thoroughly until small air bubbles are visible.

4. Cement and remaining water were added and mixed for 3 minutes.

5. Stopped the mixer for 3 minutes.

6. Remixed for 2 minutes.

7. Added the HRWRA and mixed until the desired slump was obtained. 


\subsubsection{Latex Modified Concrete (LMC)}

1. Added latex premixed with antifoam and coarse aggregate to the mixer and rotated the mixer until uniformly mixed.

2. Added sand to mixer and mixed uniformly for about 1.5 minutes.

3. Cement and remaining water were added and mixed for 3 minutes.

4. Stopped the mixer for 3 minutes.

5. Remixed for 2 minutes.

\subsubsection{Fiber Reinforced Concrete (FRC)}

1. Added coarse aggregate and approximately $3 / 4^{\text {th }}$ of water mixed with WRA to the mixer, and rotated the mixer until uniformly mixed.

2. Sand premixed with the AEA was added to mixer and mixed thoroughly until small air bubbles are visible.

3. Cement and remaining water were added and mixed for 3 minutes

4. Stopped the mixer for 3 minutes

5. Remixed for 2 minutes.

6. Added fiber and HRWRA and mixed until the desired slump was obtained.

\subsubsection{Silica Fume Modified Concrete with Shrinkage-reducing Admixture (SFMC + SRA)}

1. Added coarse aggregate and approximately $3 / 4^{\text {th }}$ of water to the mixer and rotated the mixer until aggregate was uniformly mixed.

2. Added silica fume and continued to rotate.

3. Sand premixed with AEA was added to mixer and mixed thoroughly until small air bubbles were visible. 
4. Cement and remaining water were added and mixed for 3 minutes.

5. Stopped the mixer for 3 minutes

6. Added SRA and remixed for 2 minutes.

7. Added the HRWRA and mixed until the desired slump was obtained.

\subsection{Fabrication of Specimens}

\subsubsection{Preparation of Substrate}

Beams of $450 \mathrm{~mm}$ (18 in) long x 200mm ( 8 in) wide x 100mm (4 in) thick made of normal concrete were used as substrate in this study. All the substrate beams were cast by using partitioned Glass Fiber Reinforced Plastic (GFRP) molds (Fig. 3.1). A concrete vibrator was used to simulate the field consolidation. The specimens were then immediately covered with wet burlap in the curing room with temperature $23 \pm 2^{\circ} \mathrm{C}(73 \pm 4$ $\left.{ }^{\circ} \mathrm{F}\right)$. After about 6 hours, while the concrete was about to set, the surface preparation was finished with a steel brush and high-pressure air. A surface profile of \#2 was selected by referring to International Concrete Repair Institute Technical Guidelines (ICRI 03732 Surface Preparation Guide \& Surface Profile Chips) (Fig. 3.2). Initially ICRI \#5 profile was also selected. But the subsequent edge curling and delamination studies did not show any relative displacements at the interface, which were measured by LVDTs and clip-on gauges at $50 \%$ humidity and $35^{\circ} \mathrm{C}\left(95^{\circ} \mathrm{F}\right)$. As a result, only the ICRI \#2 profile was used in this study. The substrates were demolded after 24 hours, and cured in water at a temperature of $23 \pm 2^{\circ} \mathrm{C}\left(73 \pm 4^{\circ} \mathrm{F}\right)$ for 28 days ( 4 weeks). After that the substrates were air cured in a curing chamber at $50 \%$ relative humidity and temperature $23 \pm 2^{\circ} \mathrm{C}\left(73 \pm 4{ }^{\circ} \mathrm{F}\right)$ for about 10 weeks. Upon casting overlay concrete, all the substrate specimens except for 
two, were 14 weeks old. Due to limited time, two substrate specimens were only 5 weeks old upon casting of overlay concrete.

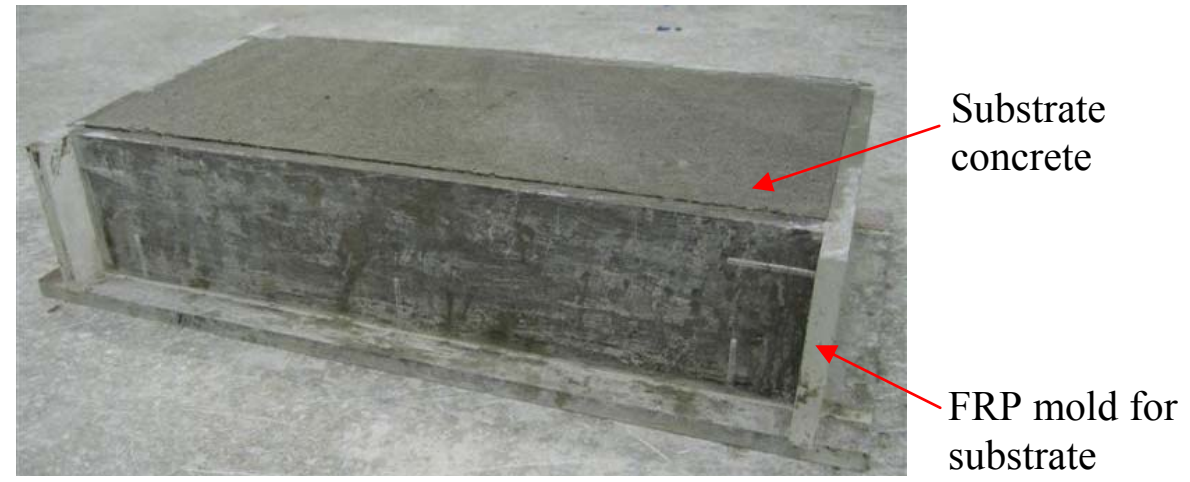

Fig. 3.1 Substrate specimen after casing

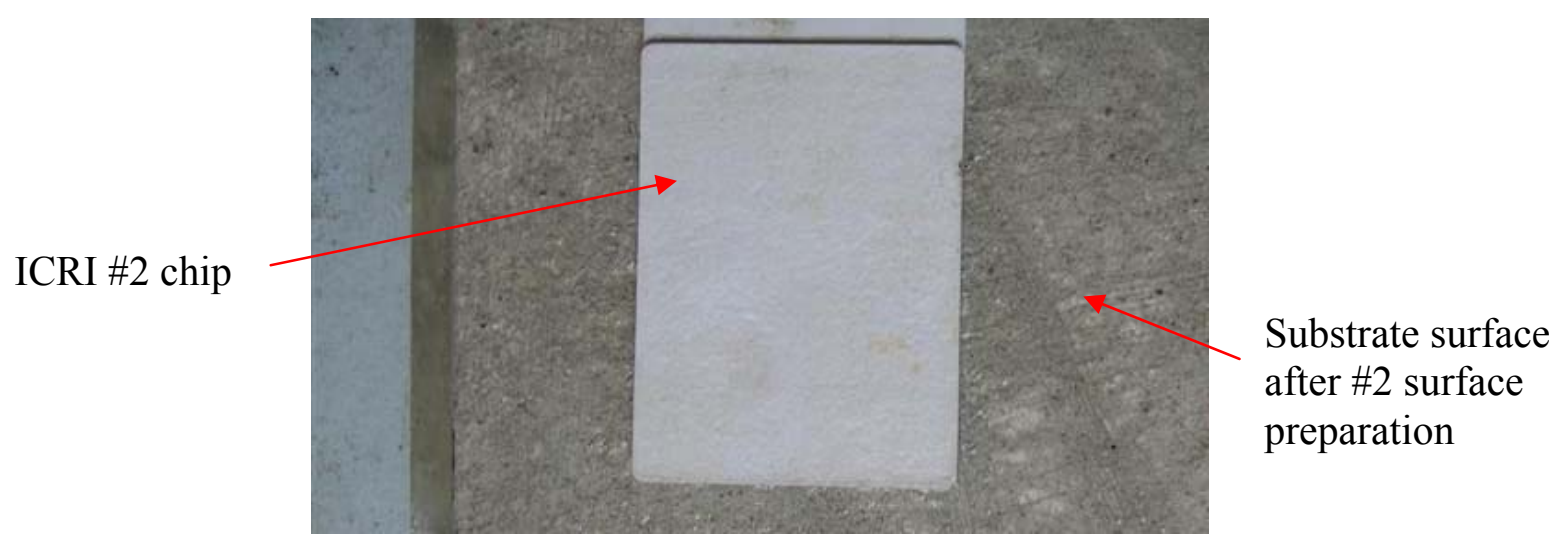

Fig 3.2 Typical substrate specimen after surface preparation according to ICRI \#2 profile 


\subsubsection{Preparation of Specimens for Curling Effect Tests}

Fig. 3.3 shows the dimensions of the prismatic specimen for curling effect tests and ultrasonic pulse velocity tests.

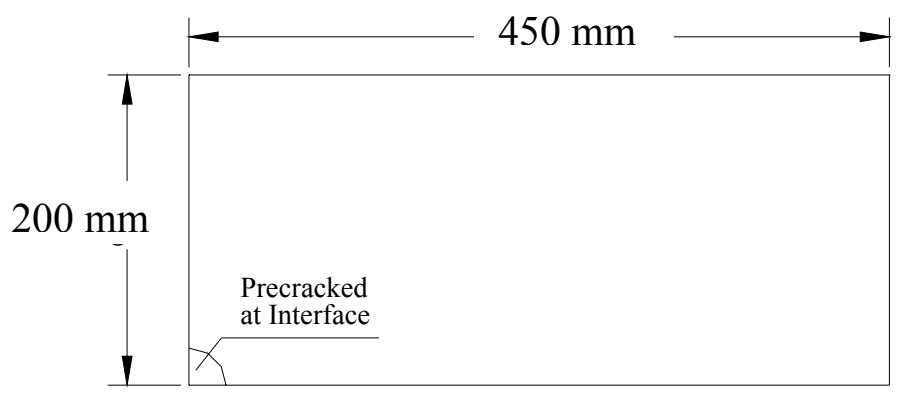

(a) Plan View

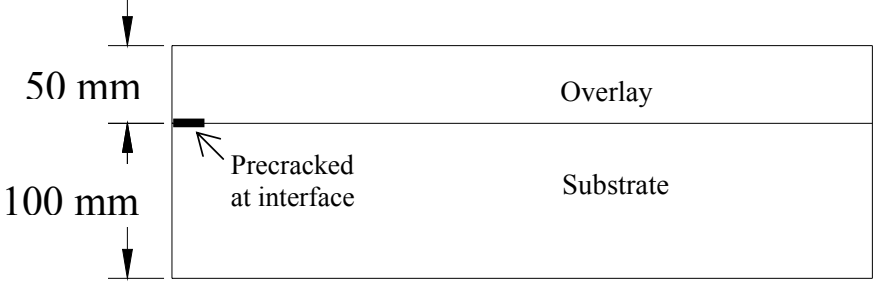

(b) Front View

Fig. 3.3 Dimensions of Prismatic Specimen for Curling Effect Tests

All the specimens that were used for early age edge curling effect test and ultrasonic velocity test were prepared by the following steps:

1. A cured substrate beam was installed in the partitioned GFRP mold that was designed to accommodate each of the substrate beams after volume changes due to shrinkage. The molds were 2 in higher than the substrate beams in order to be able to cast the overlay on top of substrate. The surfaces were cleaned using steel brush and highpressure air. A double-layer plastic sheet in 90-degree sector of $37.5 \mathrm{~mm}$ (1.5 in) radius 
was installed at one corner to serve as debonding area for future tests. This step is illustrated in Fig. 3.4.

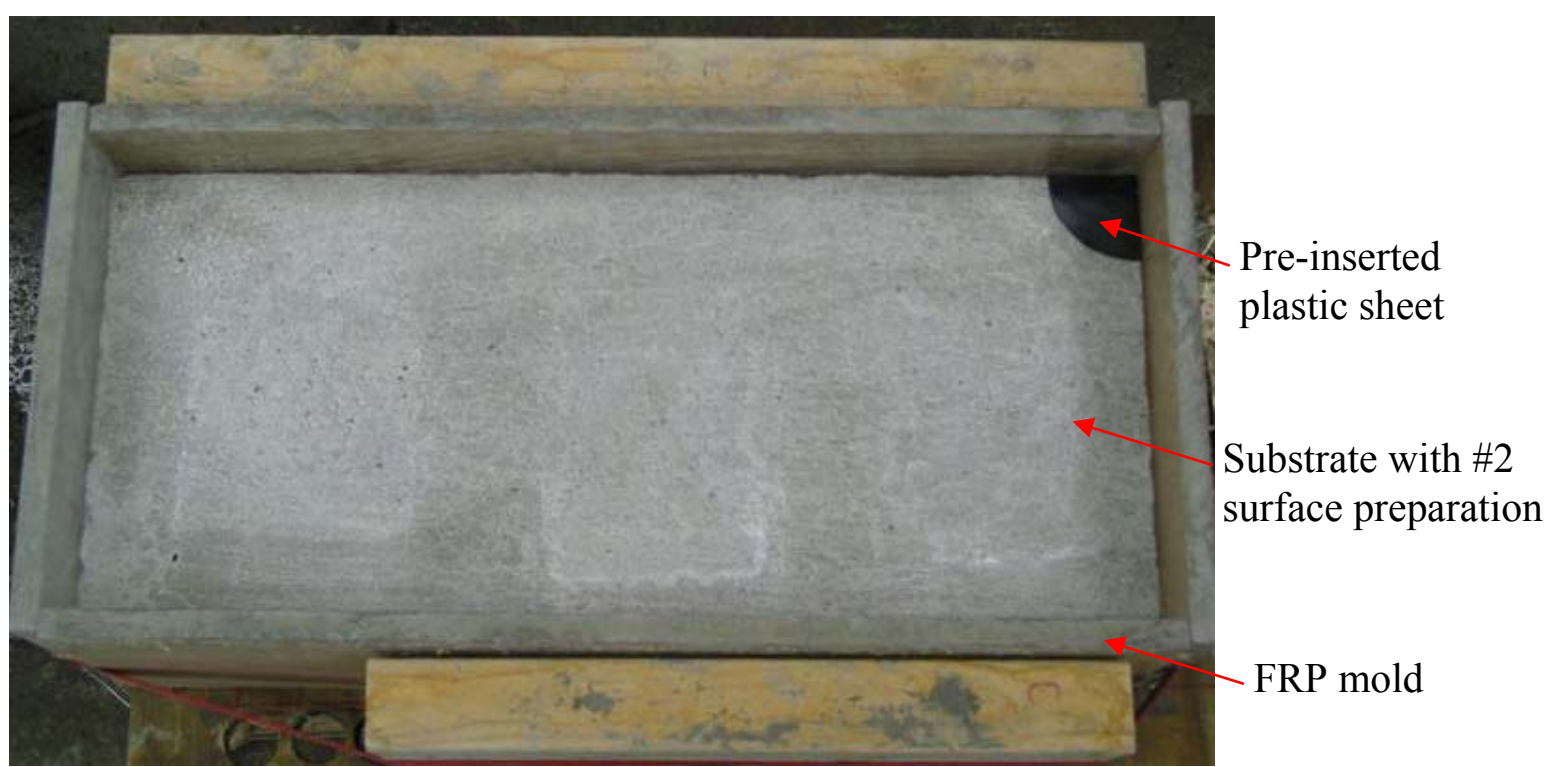

Fig. 3.4 Substrate beam installed in GFRP molds

2. Before casting overlay the surface of substrate beam was kept either dry or saturated or saturated with bonding slurry according to the test plan. When bonding slurry was used, it was placed on top of the saturated substrate surface by using steel brush as shown in Fig. 3.5. Bonding slurry was made of the same concrete used in overlay excluding the coarse aggregate. This was done according to WVDOH specification and to make the construction work easier for using the same material. 


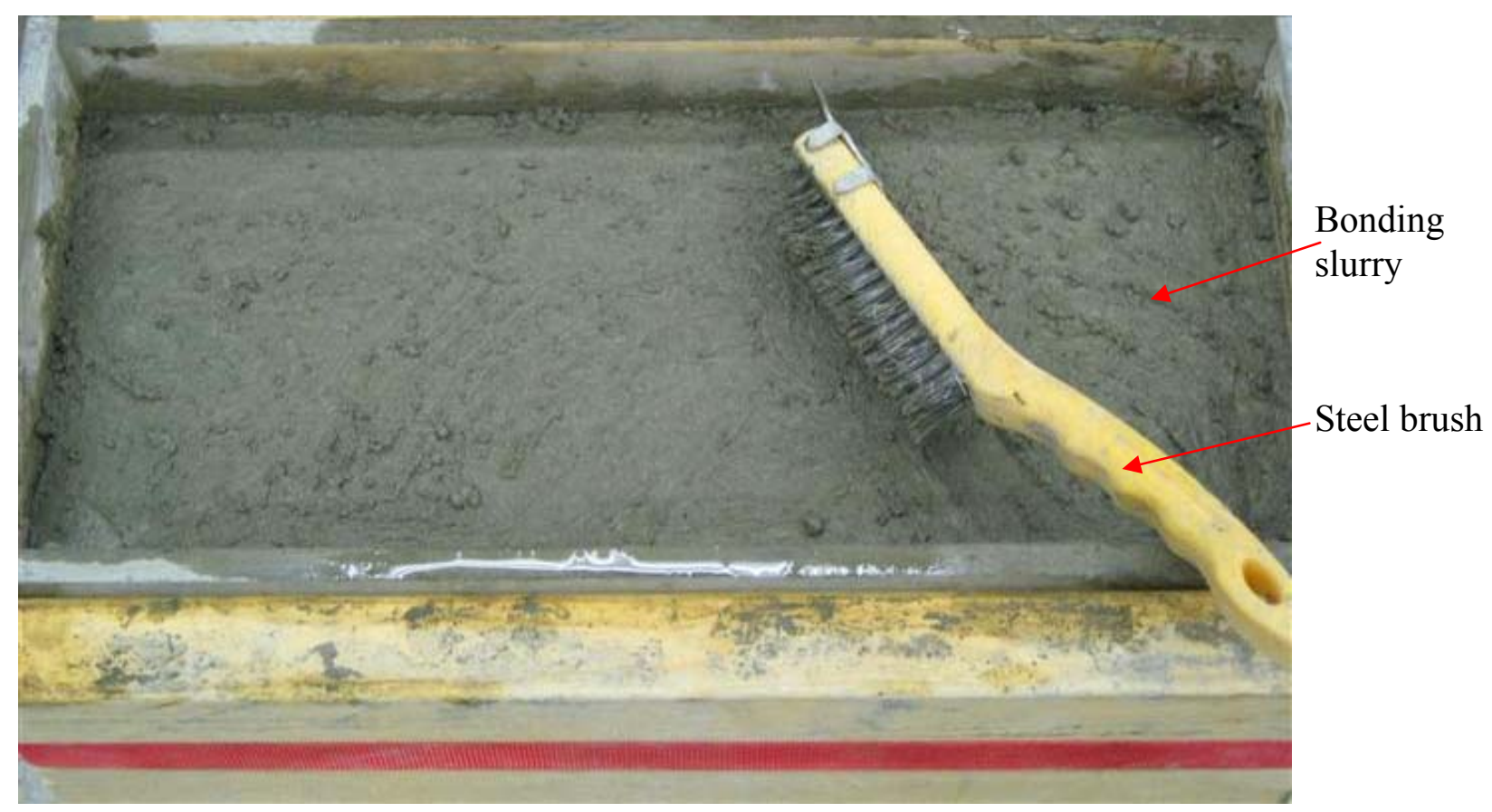

Fig. 3.5 Substrate beam with bonding slurry applied

3. During casting, the overlay concrete was consolidated by a concrete vibrator. The specimen was demolded after being cured for around 18 hours using wet burlap cover in the curing room at temperature $23 \pm 2^{\circ} \mathrm{C}\left(73 \pm 4{ }^{\circ} \mathrm{F}\right)$ to avoid any moisture loss. At this time aluminum holders for installing LVDTs and clip-on gauges were installed by using special epoxy compounds that could be attached to damp concrete surface. A layer of silicone was spread on the side surfaces of the specimen for sealing the side surfaces and leaving the top and bottom surfaces free. This way field condition of bridge deck overlay could be simulated, as in bridge deck the moisture could only evaporate from the top surface of overlay. At one end of the specimen a steel frame was installed to clamp the overlay and substrate together in order to prevent debonding at this end. This allowed the debonding to initiate at the pre-cracked location and propagate from there at free end. On both top and bottom surfaces grid lines with $25 \mathrm{~mm}$ (1 in) distance were drawn as 
coordinates for future ultrasonic velocity test. When the epoxy cured (in approximately 6 hours) to bond the aluminum holders, the LVDTs and clip-on gauges were installed for measuring overlay displacements. Fig. 3.6 shows the detailed configuration.

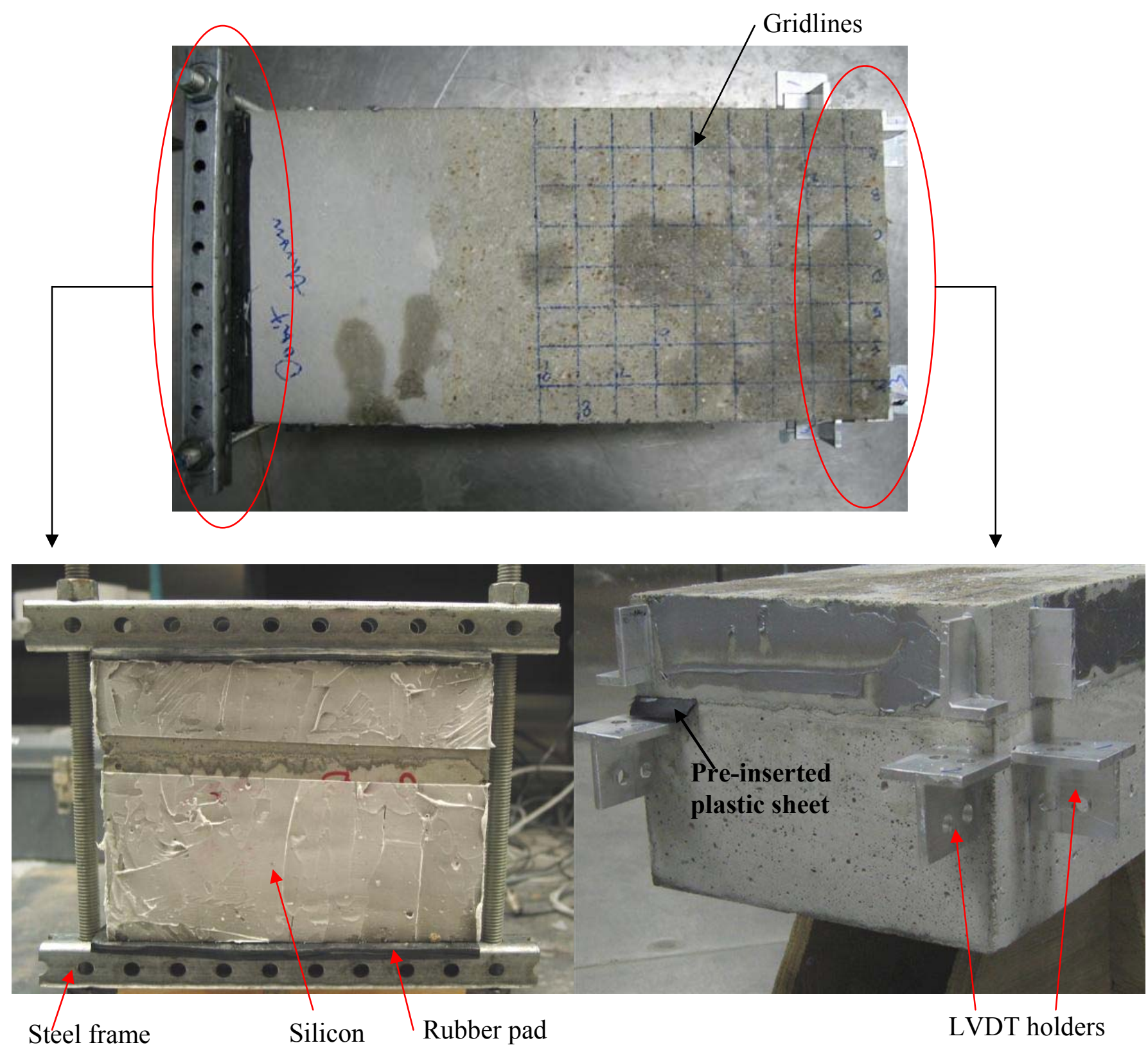

Fig. 3.6 Specimen ready to install LVDTs and Clip-on gauge 


\subsubsection{Preparation of Specimens for Temperature Measurement}

All the specimens that were used for temperature test were prepared by the following steps.

1. A cured substrate beam was installed in the partitioned GFRP mold that was designed to accommodate each of the substrate beams after volume changes due to shrinkage. The molds were 2 in higher than the substrate beams in order to cast the overlay on top of substrate. The surfaces were cleaned using steel brush and highpressure air. For each type of overlay, seven thermocouples (Omega 5TC-TT-K-36-36) were guided and fixed over the thickness of the overlay by using fishing lines as shown in Fig. 3.7.

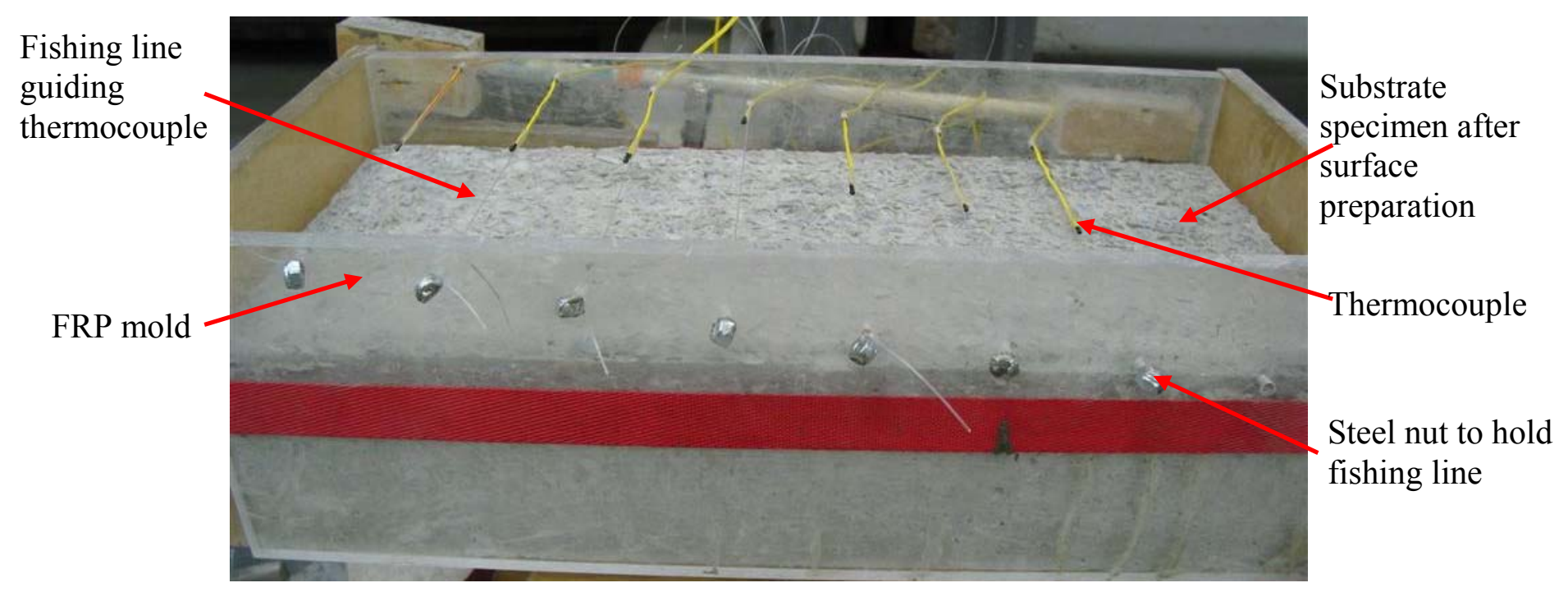

Fig 3.7 Specimen ready to cast overlay concrete for temperature measurement

2. Overlay concrete was consolidated using a concrete vibrator. When casting processes were finished, the specimens were covered with wet burlap and plastic sheet. The specimens were moved into the environmental chamber with temperature of $35^{\circ} \mathrm{C}$ $\left(95^{\circ} \mathrm{F}\right)$ and relative humidity of $50 \%$ for immediate measurement. The data was collected 
for 7 days by a data-logger (Omega OM-CP-OCTTEMP) that can monitor up to 8 channels simultaneously.

\subsubsection{Preparation of Specimens for Direct Tensile Test}

An innovative bi-layer butterfly type specimen that was used in previous research at WVU (Luo, 2000; and Sun, 2004) was selected to measure the tensile bond strength between the four overlays and the substrate. All these specimens were prepared in the following steps:

1. The substrates of thickness $38 \mathrm{~mm}$ (1.5 in) were cast in the 3 -specimen gang steel molds and compacted on a vibrating table. The specimens were then covered with wet burlap and stored in a curing room with a temperature of $23 \pm 2^{\circ} \mathrm{C}(73 \pm 4$ $\left.{ }^{\circ} \mathrm{F}\right)$. Fig. 3.8 shows substrate specimens after casting in a typical 3-specimen gang mold.

Substrate concrete before surface preparation

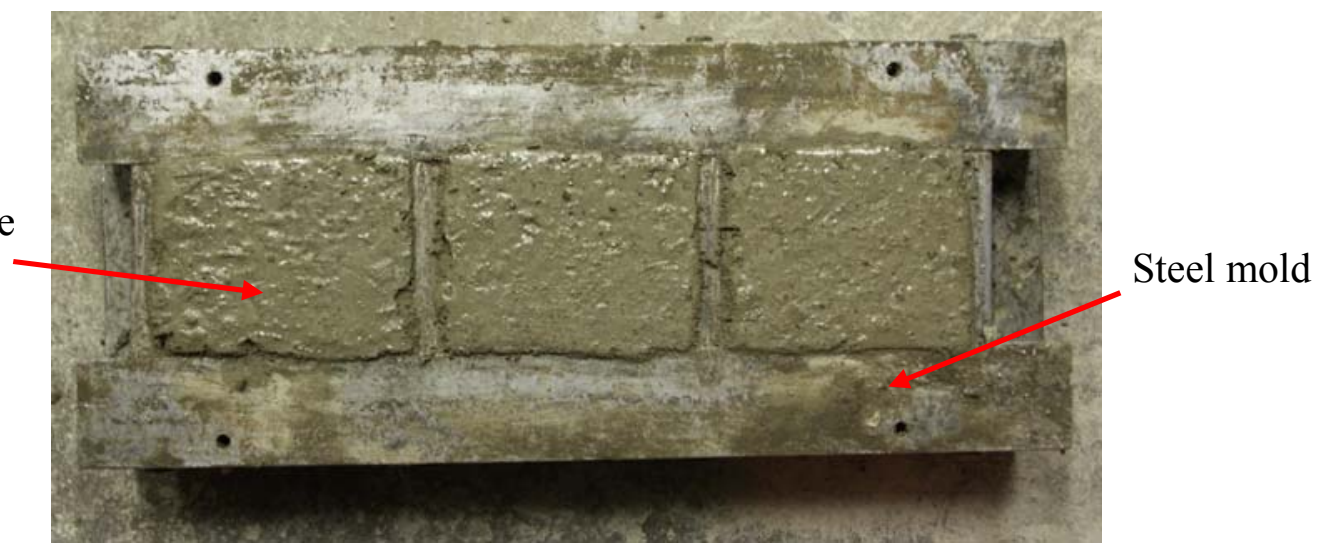

Fig. 3.8 Substrate specimens after casting

2. After curing for around 6 hours when concrete was about to set, the surface was roughened with a steel brush according to ICRI \#2 profile. For comparison, the corresponding ICRI profile CSP\#2 is displayed in Fig. 3.9. 


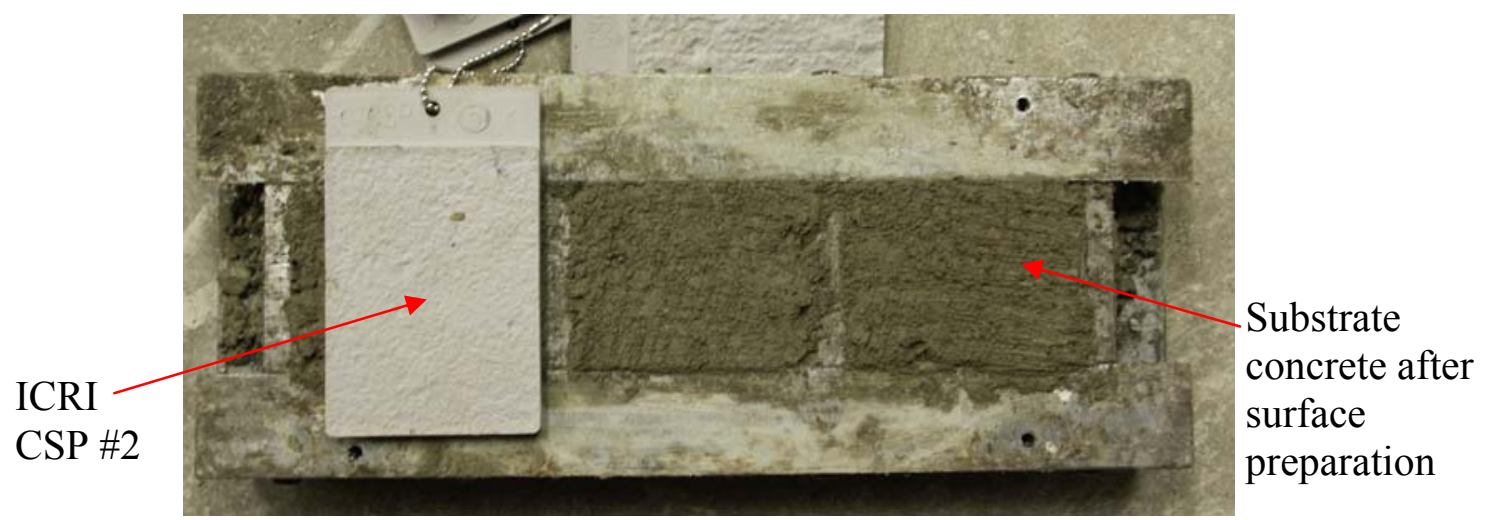

Fig. 3.9 Substrate surface preparation

3. The substrate specimens were demolded after 24 hours (Fig. 3.10), and cured in lime water at a temperature of $23 \pm 2^{\circ} \mathrm{C}\left(73 \pm 4^{\circ} \mathrm{F}\right)$ for 28 days.

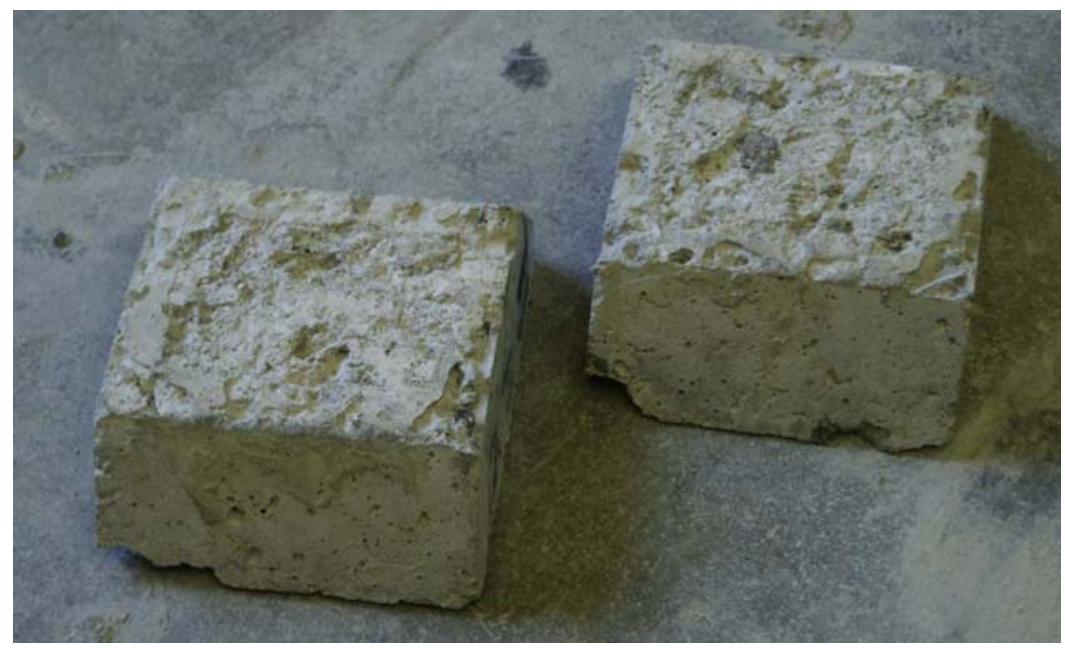

Fig. 3.10 Demolded substrate specimens

4. After 28 days curing, the substrate specimens were reinstalled into the molds. The surfaces were cleaned and moistened thoroughly before the second layers of molds were installed for casting of overlay (Fig. 3.11). 


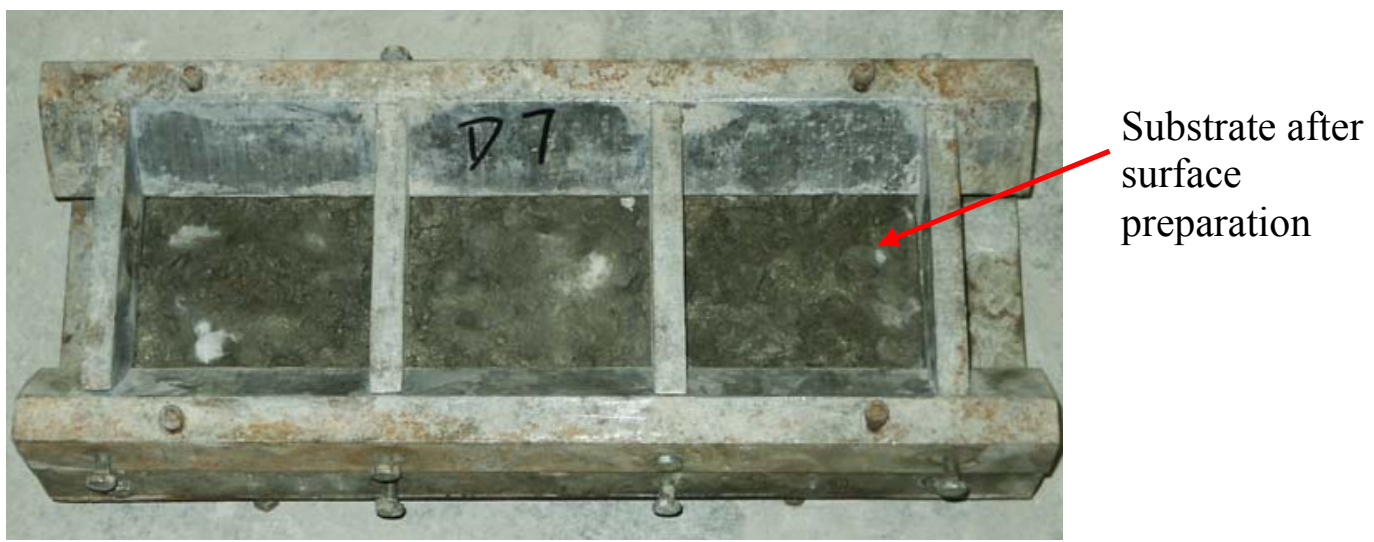

Fig. 3.11 Substrate specimens reinstalled back into molds

5. Bonding slurries made of the same type of overlay mixtures with coarse aggregate removed were applied thoroughly and scrubbed into the saturated surface according to the guidelines provided by the WVDOH. In case of FRC, fiber was excluded from the slurry.

6. The overlay of $38 \mathrm{~mm}$ (1.5 in) thick was cast over the substrate specimens. Fig. 3.12 shows the specimens right after casting of overlay concrete. When casting was finished, the specimens were covered with wet burlap and cured in a curing room with temperature of $23 \pm 2^{\circ} \mathrm{C}\left(73 \pm 4^{\circ} \mathrm{F}\right)$ for 24 hours.

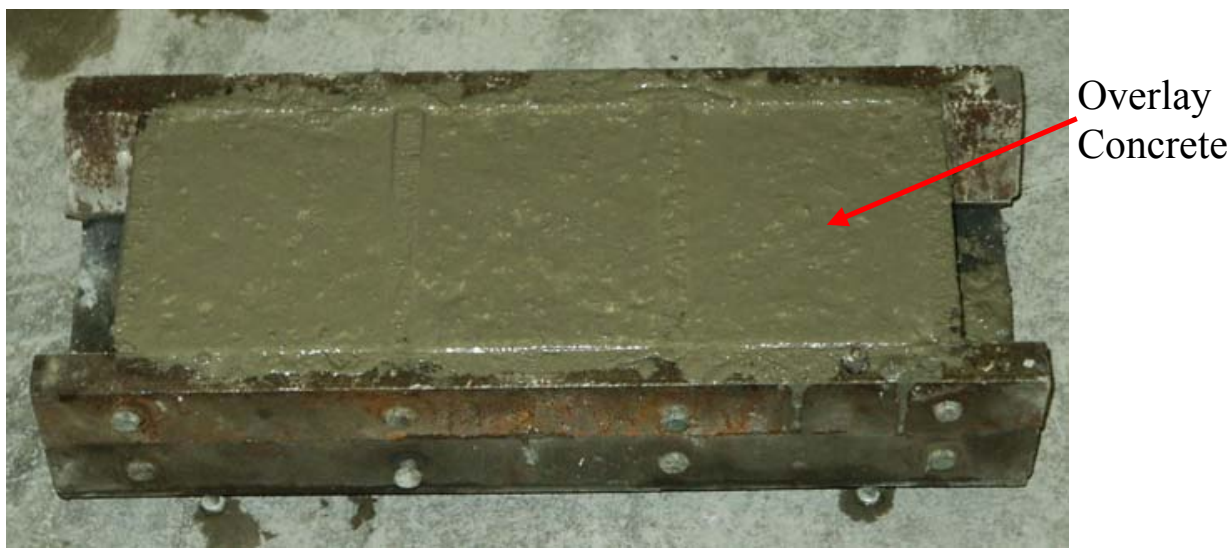

Fig. 3.12 Specimen after casting of overlay concrete 
7. After 24 hours of curing, the specimens were demolded carefully and cured in the air until the testing days (1, 3 and 7 days). The curing conditions of these specimens were the same as specimens for curling effect test.

8. Before testing, a $13 \mathrm{~mm}(1 / 2 \mathrm{in})$ deep notch around the interface periphery of each bi-layer specimen was cut by a $3 \mathrm{~mm}(1 / 8$ in) thick diamond saw. The notch helped to guide the crack through the interface. Fig. 3.13 shows the typical bilayer butterfly specimen with notches all around.

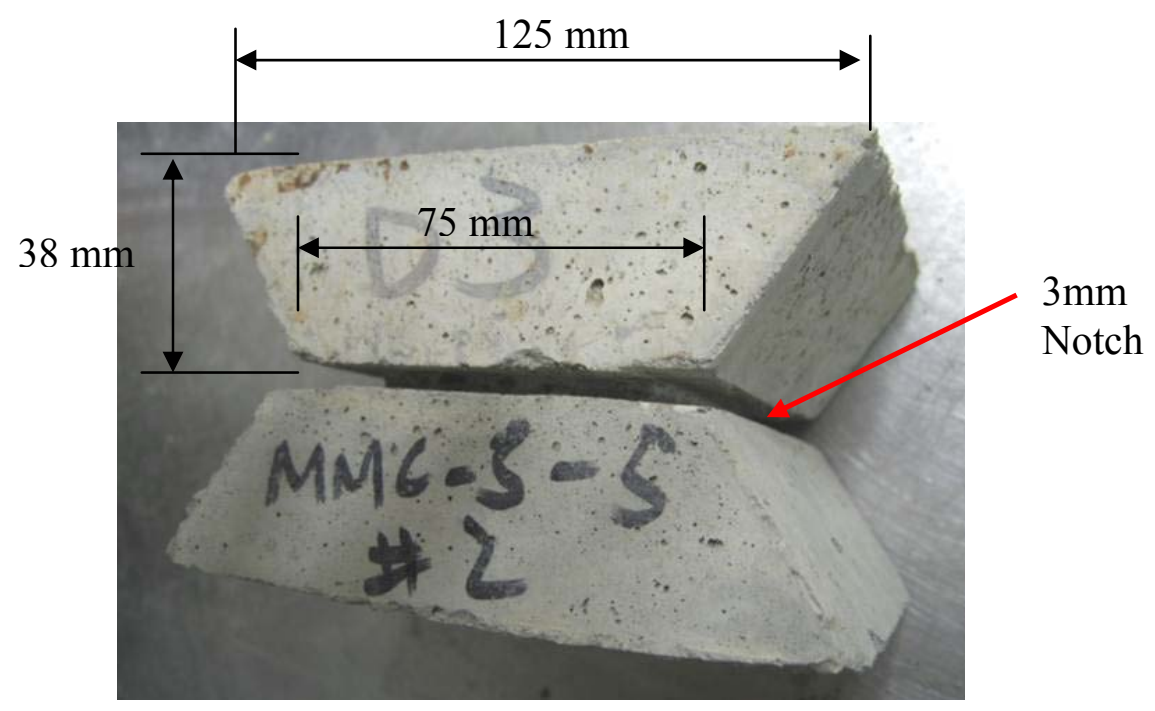

Fig. 3.13 Bi-Layer specimen with notches 


\section{CHAPTER 4}

\section{TESTING OF BILAYER PRISMATIC SPECIMENS}

\subsection{Overlay Curling Effect and Delamination Tests}

\subsubsection{Testing Procedure}

Three main factors were investigated in this test: overlay type, substrate surface condition, and ambient temperature.

Four types of overlay systems were tested in this study. They were SFMC (Silica Fume Modified Concrete), LMC (Latex Modified Concrete), SFMC+SRA (Silica Fume Modified Concrete with Shrinkage Reducing Admixture), and FRC (Fiber Reinforced Concrete).

Three substrate surface conditions were considered: dry surface, saturated surface, and saturated surface with bonding slurry. For dry surface, the substrate specimens were air dried at least 24 hours prior to casting the overlay; for saturated surface, water was constantly sprayed to the surface within two hours prior to casting the overlay without puddling; for saturated surface with bonding slurry, bonding slurry was applied onto the saturated surface prior to casting the overlay.

The substrate surface preparation profile for each of the specimens was \#2 with reference to International Concrete Repair Institute (ICRI) Technical Guidelines. According to ICRI, \#2 surface profile can be achieved by acid etching, grinding, or light abrasive blasting. In the preliminary tests it was found that more aggressive surface profiles, i.e. $\# 5$ or $\# 8$, would mask the effects of ambient temperature, surface condition, 
and overlay type, which made it impossible to investigate the edge curling and delamination in overlay-substrate system. Thus \#2 surface profile was selected in this study.

The tests were conducted in an environmental chamber with humidity at $50 \%$. It was assumed that overlay type, substrate surface condition, and ambient temperature were independent of each other, which has been shown to be reasonable by previous research conducted at WVU (Sun, 2004). The main purpose of these tests was to define the best surface condition and to investigate the performances of different overlays at early age under severe ambient temperature of $35^{\circ} \mathrm{C}\left(95^{\circ} \mathrm{F}\right)$. The overall test program was organized into two steps, as illustrated in Fig. 4.1. First the best surface condition was found out by using SFMC as overlay material at $23^{\circ} \mathrm{C}\left(73^{\circ} \mathrm{F}\right)$, then all the four overlay mixes were tested under $35^{\circ} \mathrm{C}\left(95^{\circ} \mathrm{F}\right)$ with the selected best surface condition. Higher temperature was selected to induce a more critical curling and delamination effect for the best surface condition. There were totally seven cases. For each case, two replicate specimens were tested to acquire relative displacements at the interface between the overlay and the substrate. At the same time, ultrasonic pulse velocity test was carried out on the same specimens to detect the progress of crack front or debonding area. 


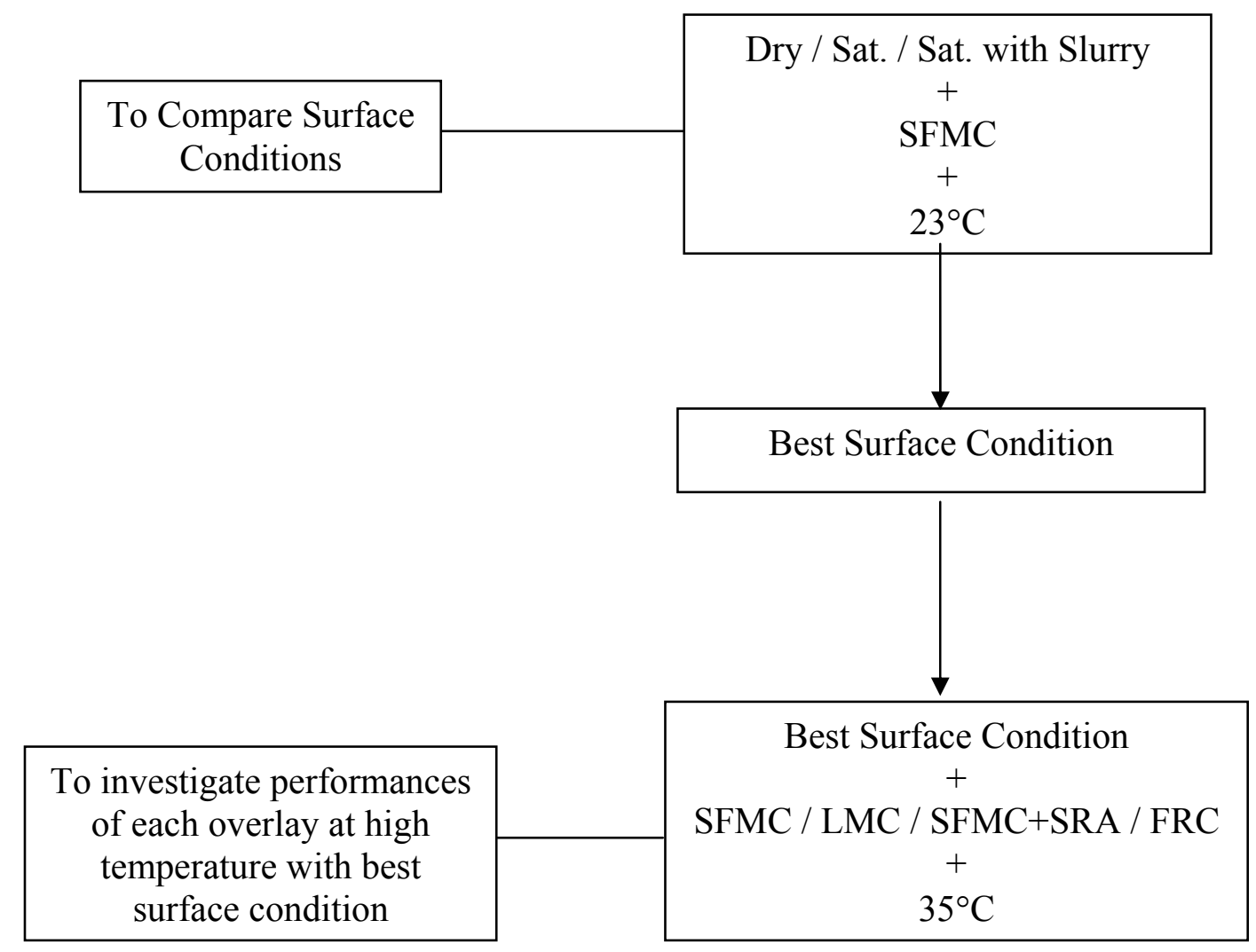

Fig. 4.1 Curling effect and delamination testing scheme

\subsubsection{Configuration of LVDTs and Clip-on Gauges}

A total of 5 LVDTs and 2 clip-on gauges were used in the relative displacement measurement for each testing case. In each case, two replicate specimens were tested. Thus, in each case one specimen was measured with 3 LVDTs and 1 clip-on gauge, the other one was measured with 2 LVDTs and 1 clip-on gauge. Figs. 4.2, 4.3, and 4.4 show the layout of monitoring points and instruments installed on the specimens. As shown in the figures, LVDTs and clip-on gauges were installed across the interface between overlay and substrate. In this way, the relative vertical displacements of overlay to substrate were measured. Therefore the relative displacements were the Crack Mouth Opening Displacements (CMODs) at different points along the interface edges. The more sensitive clip-on gauges were installed right at the tip of artificial crack along the longitudinal direction of the specimen in order to better capture the debonding of interface. 


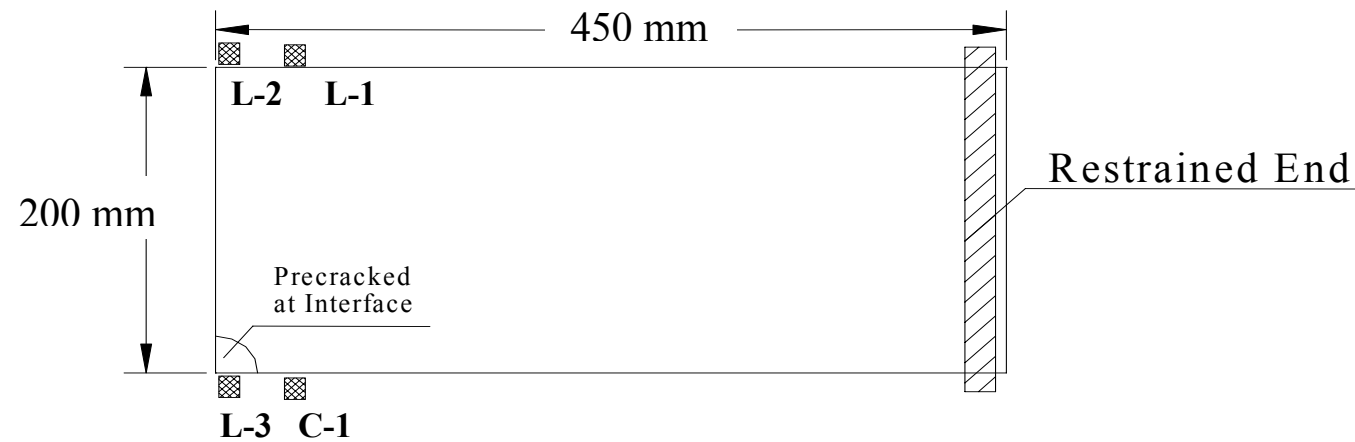

(a) Plan View

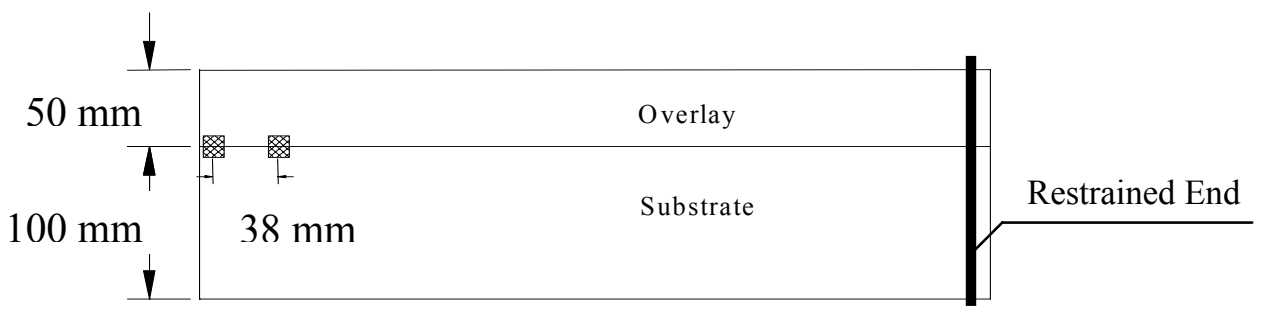

(b) Front View

- VDT: L-1, L-2, L-3; Clip-on Gauge: C-1

$1 \mathrm{~mm}=0.0394 \mathrm{in}$

Fig. 4.2 Layout of Monitoring Points for Overlay Displacement Measurement for Specimen $\# 1^{*}$

* Specimen \#2 is identical to \#1, but without L-1

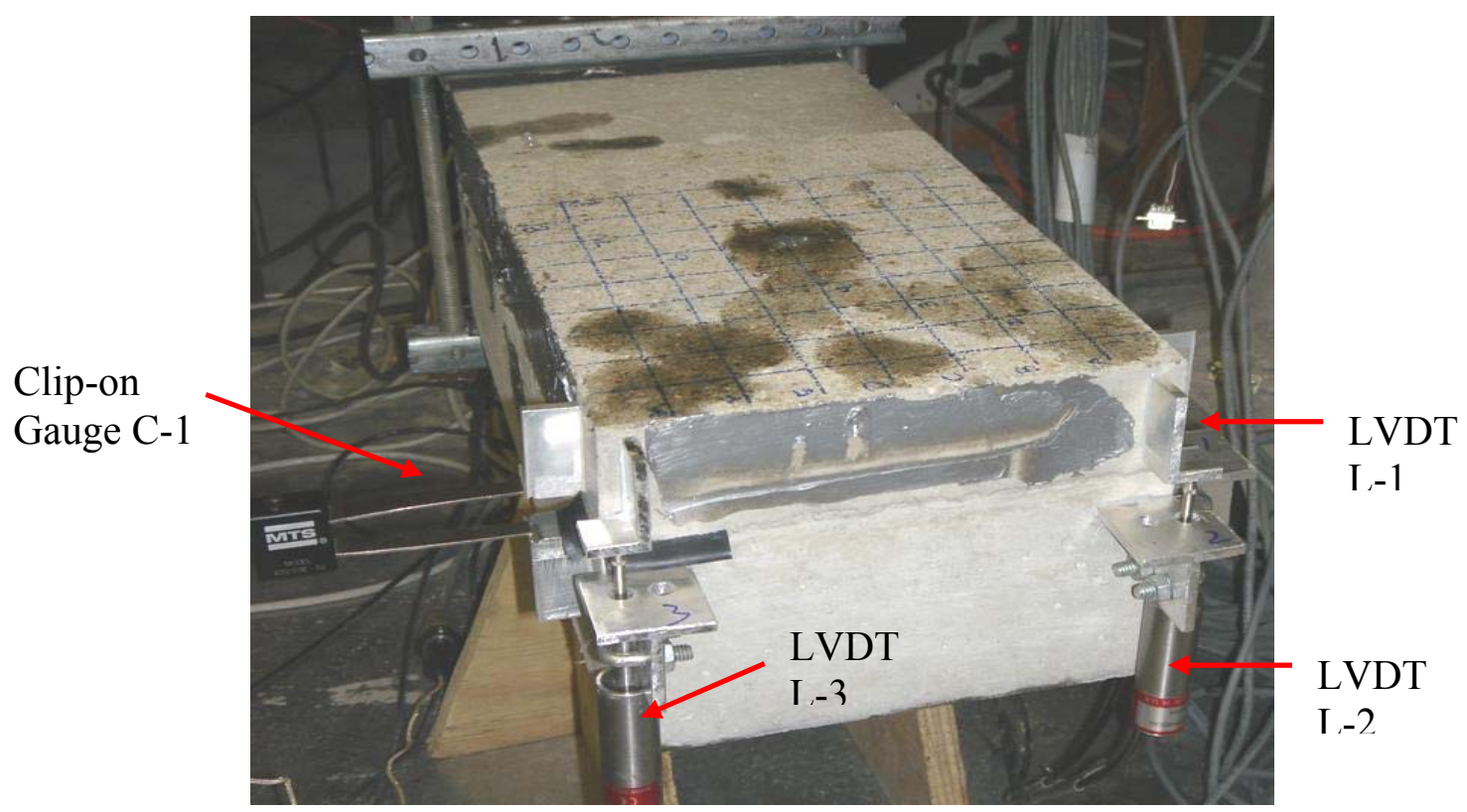

Fig. 4.3 Specimen \#1 installed with LVDTs and clip-on Gauge 


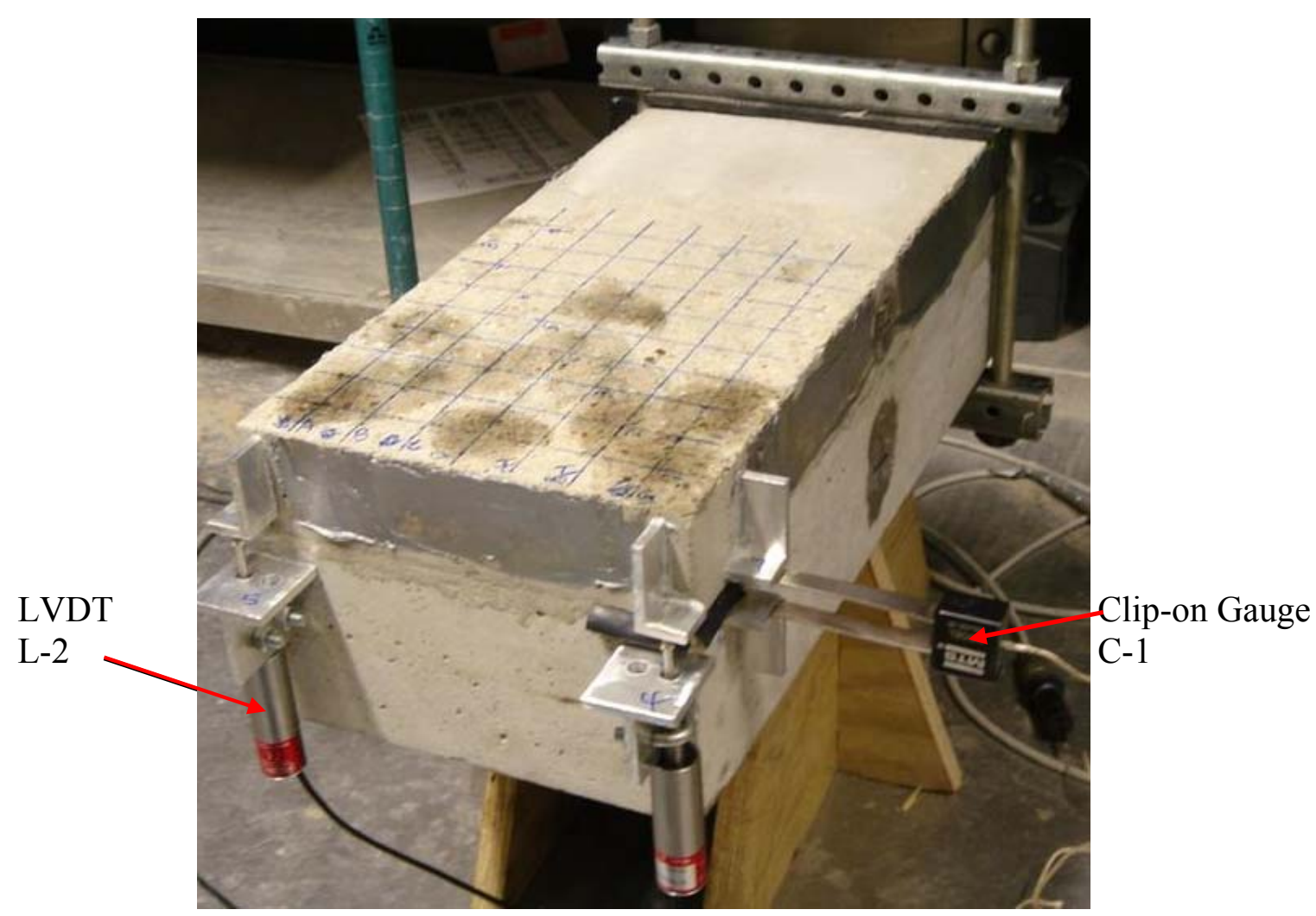

Fig. 4.4 Specimen \#2 Installed with LVDTs and Clip-on Gauge

\subsubsection{Data Acquisition}

All the LVDTs and clip-on gauges were connected to a data acquisition system, System 5000 Model 5100 Scanner from Vishay Intertechnology Company, which was managed by the data management software, StrainSmart installed in a desktop computer. The data was colleted every 15 minutes from 24 hours after overlay was cast till 7 days.

\subsection{Overlay Temperature Measurement}

As shown in Figure 4.5, temperature was measured at seven different locations over the thickness of overlay. The thermocouples were evenly distributed in both horizontal and vertical directions. Right after overlay concrete was cast and compacted, the specimen was covered with wet burlap and moved into the environmental chamber 
having temperature of $35^{\circ} \mathrm{C}\left(95^{\circ} \mathrm{F}\right)$ and humidity at $50 \%$. Wet burlap was removed after 24 hours. All the thermocouples were connected to the data logger, OM-CP-OCTTEMP from Omega Company, which was managed by the software installed in a desktop computer. Temperature data were collected every 60 seconds up to 7 days. Figure 4.6 shows the data logger and the instrumented specimen.

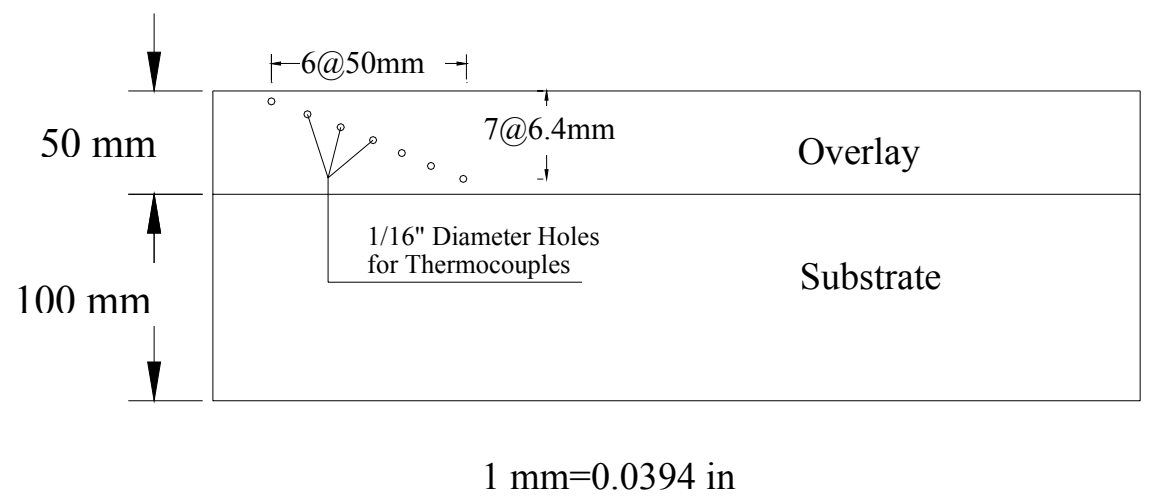

Fig. 4.5 Layout of thermocouple configuration

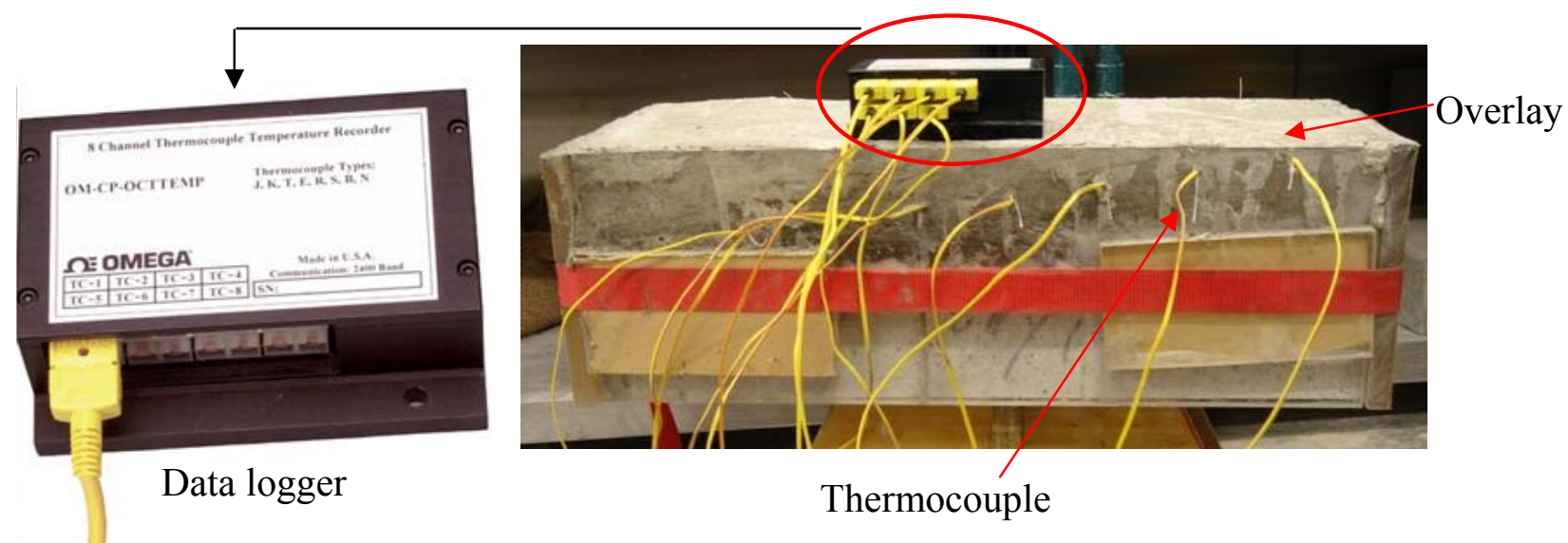

Fig. 4.6 Specimen under testing for temperature measurement 


\subsection{Ultrasonic Pulse Tests}

\subsubsection{Instruments for testing}

The ultrasonic pulse testing system used in this research consisted of a pulse velocity tester (V-Meter from James Instrument Inc.), two $150 \mathrm{kHz}$ transducers, and an oscilloscope. They are displayed in Figure 4.7.

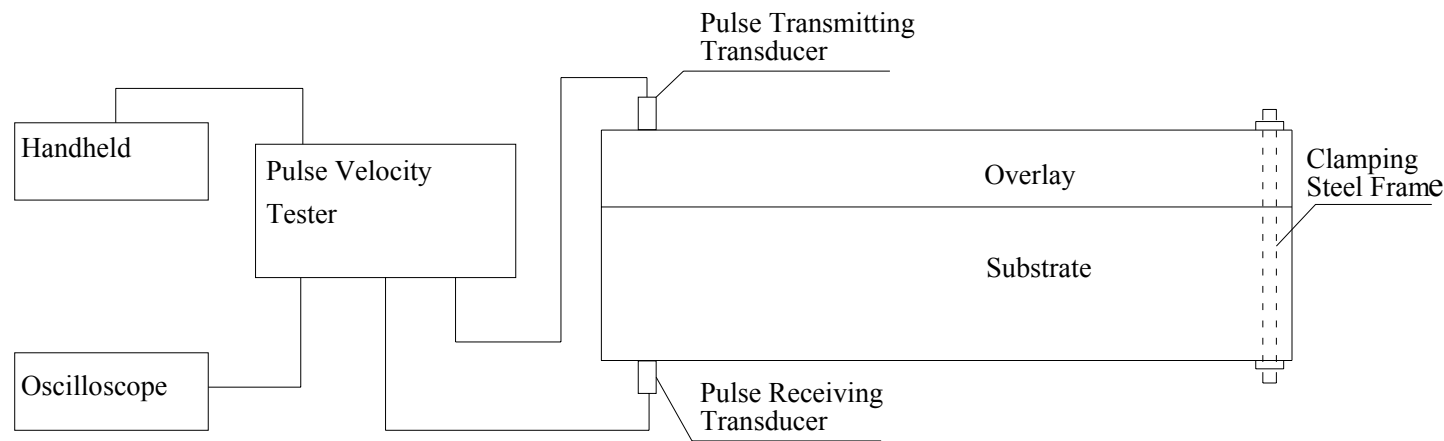

Fig. 4.7(a) Schematic set-up of ultrasonic pulse testing

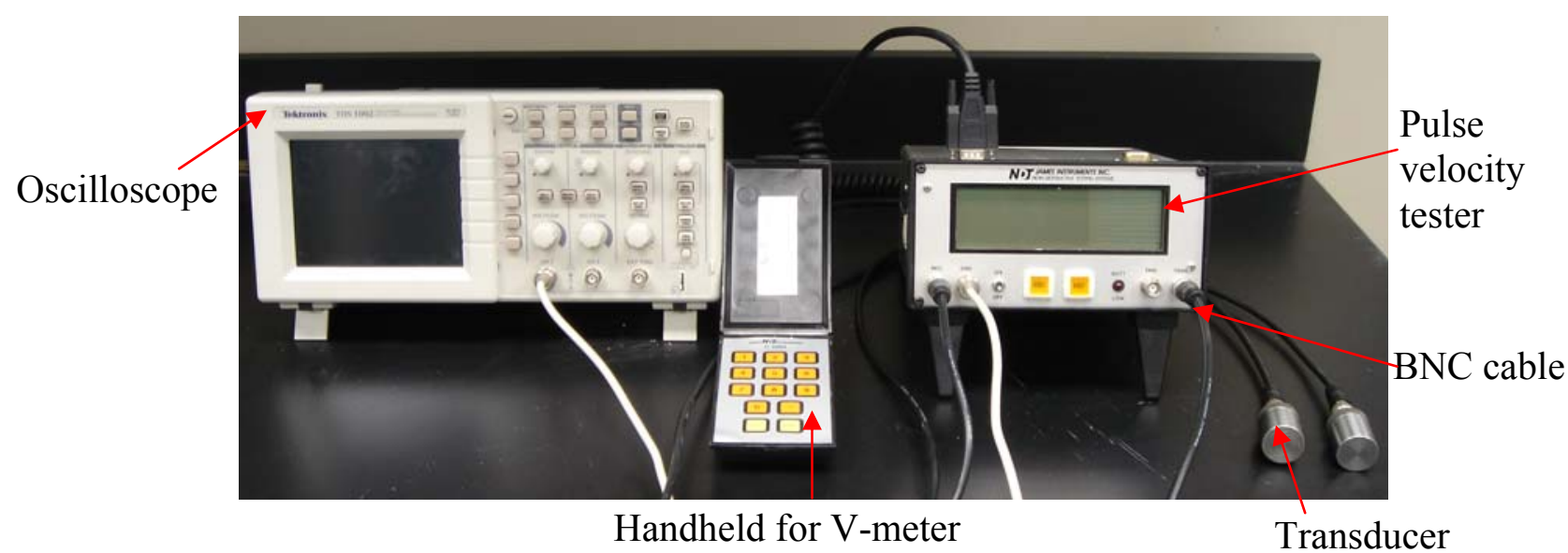

Fig. 4.7(b) Ultrasonic pulse testing instruments

The pulse velocity tester is a product from James Instrument Inc., the V-Meter MK II. It functions as a pulse generator, receiving amplifier and time measuring and 
displaying unit. An externally connected handheld unit was used to adjust parameters governing the V-Meter MK II. It is capable of giving a direct reading of the time of transmission of an ultrasonic pulse passing from a transmitting to a receiving transducer with resolution of 0.1 microseconds. Also the built in microcomputer is able to record the delay due to the different transducers and cables when first initialized, then subtracting the delay from the following measurement automatically. There is an output BNC connector for external oscilloscope on the front panel.

The transducers consist of lead zirconate titanate (PZT4) ceramic piezo electric elements mounted in stainless steel cases. The elements are very tightly held on to the inside face of the case to provide highly efficient acoustic transmission. To ensure a good contact between the transducers and the test specimen, a layer of coupling agent was applied between the transducer and the test specimen. The objective was to transmit the pulse better. The quantity of coupling agent used in each measurement was a small spoon of lubricating gel. It was important that the transducers were in complete contact with the test medium.

A digital storage oscilloscope, Tektronix TDS1002 $60 \mathrm{MHz} 2$ Channel Digital Real-Time Oscilloscope, was used to record the pulse waveform and attenuation. A sample rate up to $1 \mathrm{GS} / \mathrm{S}$, which is about 16 times the bandwidth, helps reduce the possibility of aliasing. This oscilloscope also features a function of Math FFT (Fast Fourier Transform), which converts the time-domain signal into frequency-domain spectrum. With this function, the pulse waveform and attenuation displayed on the oscilloscope were digitized and stored in both time-domain and frequency-domain in a compactflash card installed in a communication module. Those data can later be 
restored and analyzed by data processing software, i.e. MS Excel.

\subsubsection{Testing Procedure}

Before the specimens were tested, the overlay surface was grinded to ensure a good contact between the transducer and specimen. As illustrated in Figure 4.8, a steel block was placed on top of the receiving transducer to maintain a constant pressure. The transmitting transducer was pressed by hand to the bottom surface. As shown in the Fig. 4.9, gridlines of $25 \mathrm{~mm}$ ( $1 \mathrm{in}$ ) apart were drawn on both top and bottom surfaces of the prismatic bi-layer specimen to precisely indicate the location where the transducers were placed. The pulse transmitting time and pulse waveform in both time-domain and frequency-domain were recorded. Each measurement was recorded until the time reading on V-Meter II settled to minimum number, which indicated the least transmitting time. To avoid boundary effects the measuring points were taken at least $25 \mathrm{~mm}(1 \mathrm{in})$ away from all the edges. 


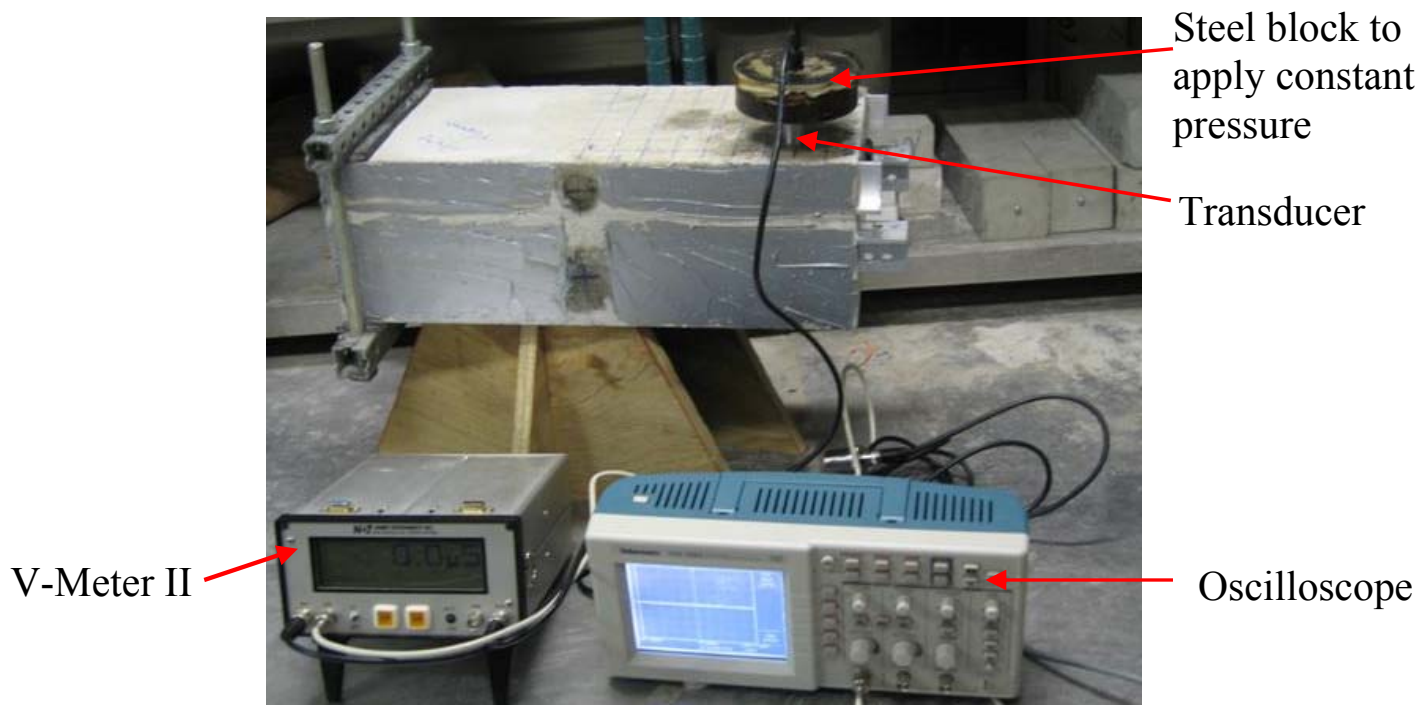

Fig. 4.8 Ultrasonic pulse velocity testing

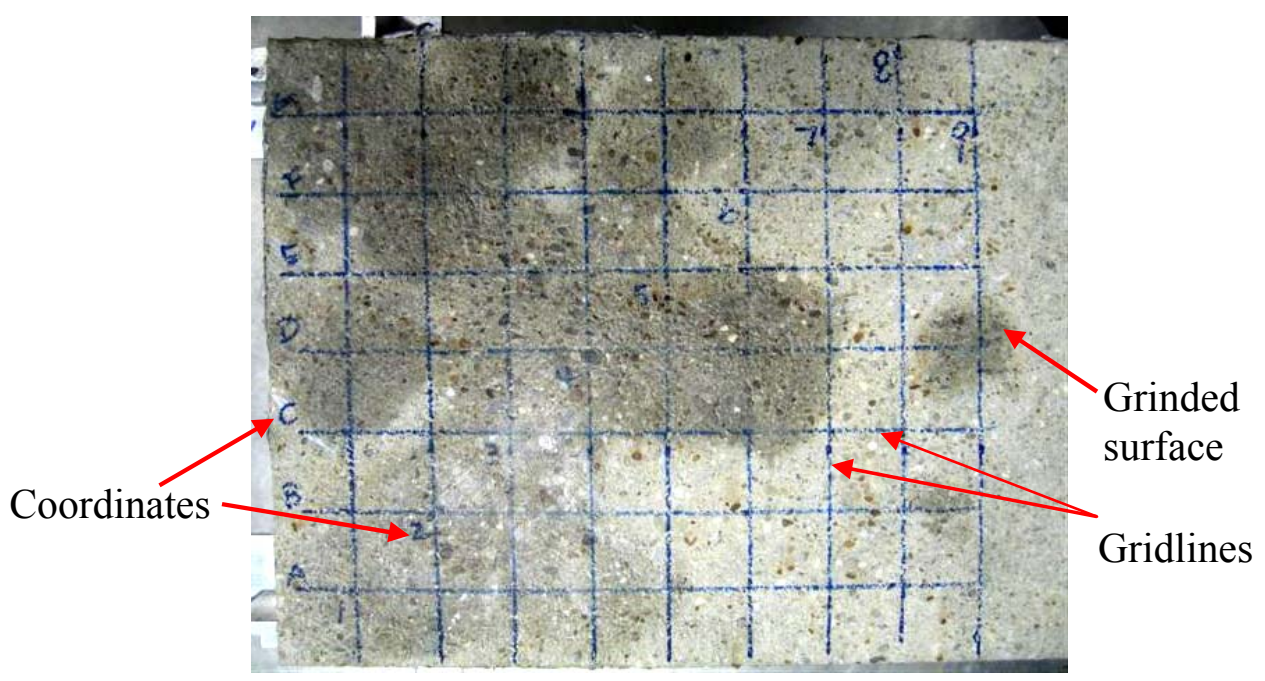

Fig. 4.9 Gridlines on the Grinded Overlay Surface

\subsection{Direct Tensile Tests}

In this study, the butterfly type bi-layer specimen was adopted. Figs. 4.10 and 4.11 show the set-up for direct tensile tests. Four rubber pads were inserted between the specimen and the loading tools in order to avoid local crushing. The specimens were 
tested at ages of 1,3 , and 7 days. For every age three replicate specimens were tested. The test was conducted in displacement-control mode, and the loading rate was $2.54 \mathrm{~mm} / \mathrm{min}(0.01 \mathrm{in} / \mathrm{min})$. After each specimen was broken, the actual failure surface was measured and recorded for calculation of tensile bond strength. The average tensile bond strength was calculated as dividing the maximum tensile load by the area of failure surface. Detailed discussion is presented in Chapter 5.

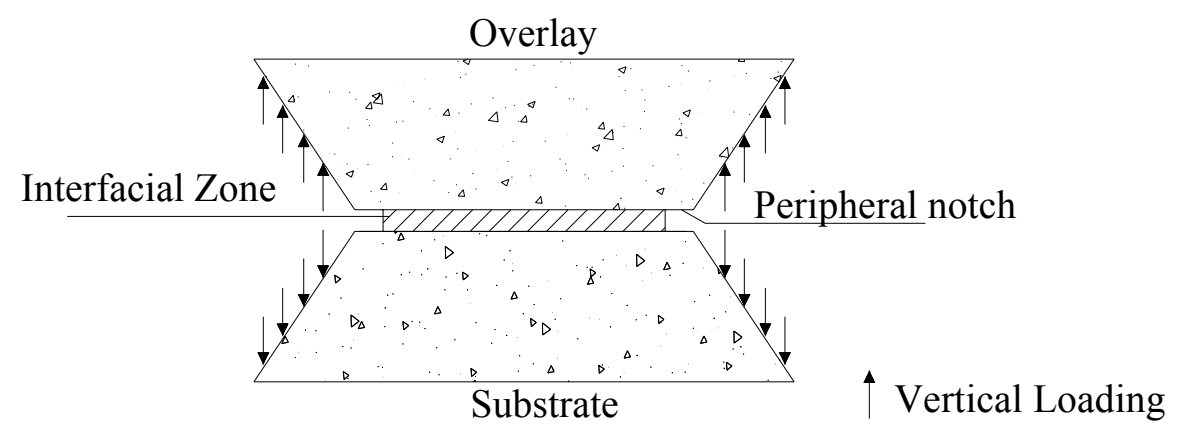

Fig. 4.10 Schematic Direct Tensile Test Set-up 


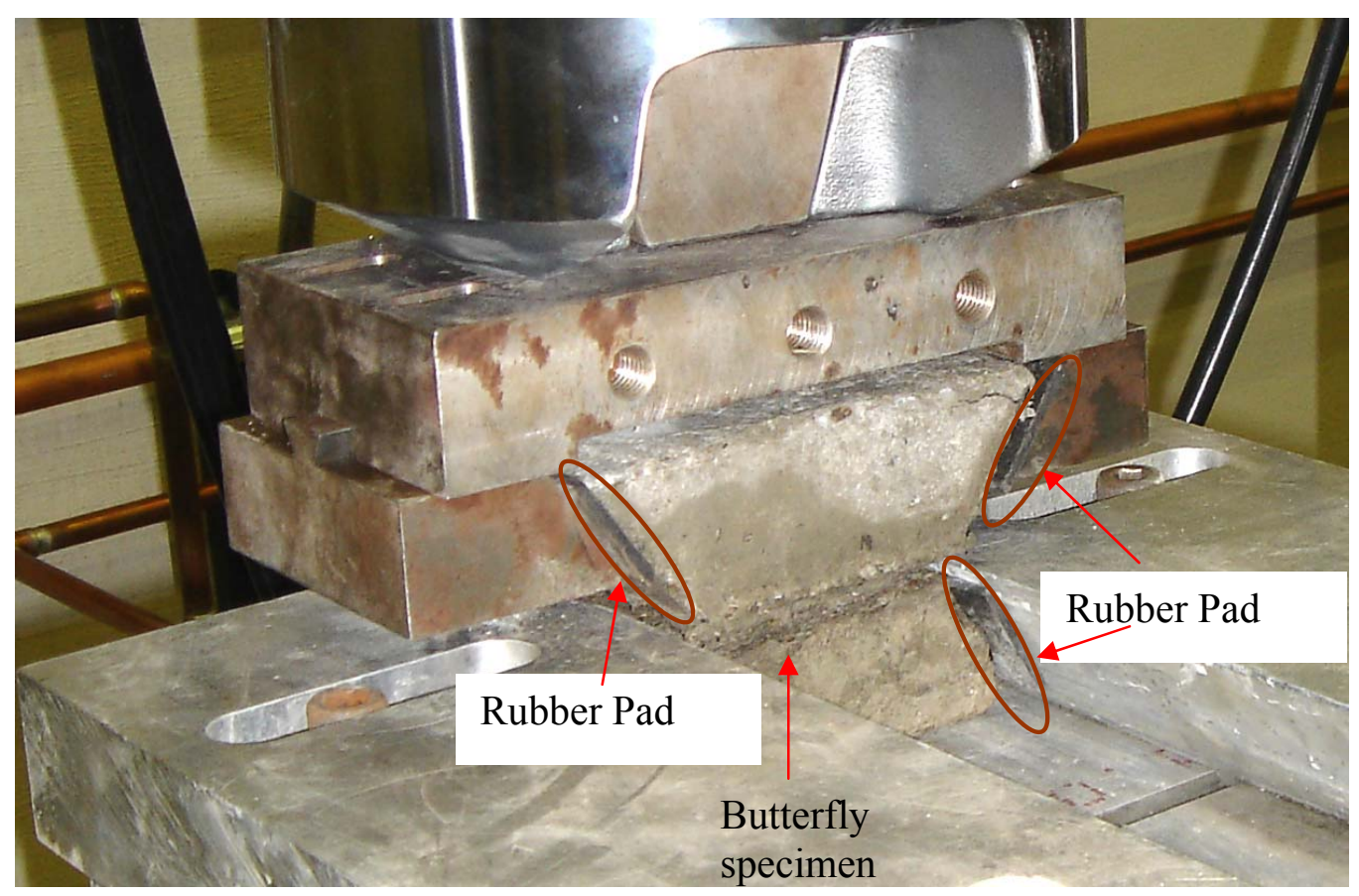

Fig. 4.11 Specimen Ready for Direct Tensile Test 


\section{CHAPTER 5}

\section{TESTS RESULTS AND DISCUSSIONS}

\subsection{Edge Curling Effect Tests}

According to the testing procedure described in Chapter 4, seven cases were investigated in this study. The detailed results are presented in Appendix A. In all the relative displacement versus time graphs, the time zero indicates the onset of the measurements. It means that the tests were started after the specimens were demolded and all the instruments were installed. At the onset of the readings, the overlay concrete reached 24 hours of maturity. No data could be recorded before 24 hours. However, until this period, no visible crack at the interface was found when observed through a microscope. Initially, the stresses at the interface were very low due to the low modulus of elasticity of overlay concrete in the first 24 hours.

\subsubsection{Relative Displacement at the Interface}

Fig. 5.1 illustrates the typical crack due to debonding at the interface. In this case it was observed that at the time of 7 days, the crack, which was easily visible, developed throughout the width of the interface at the free end and propagated along the side edges towards the clamped end as far as $200 \mathrm{~mm}$ (8 in) from the free end.

Fig. 5.2 shows a typical development of relative displacement at the interface of a bi-layer overlay-substrate specimen in which debonding and delamination occurred. In this case the overlay type was SFMC; the substrate surface condition was dry without bonding slurry; and the testing temperature was $23^{\circ} \mathrm{C}\left(73^{\circ} \mathrm{F}\right)$. LVDTs and clip-on gauge 
locations are illustrated in Fig. 4.2. There are several findings about the relative displacement versus time curve.

a. Relative displacement readings kept growing over time, which indicated continuous curling up of overlay. This was due to the developing shrinkage in the overlay concrete at early age. When upper overlay concrete shrunk, it was restrained by the underneath 4 months old relatively stable substrate. As a result, the overlay curled up.

b. There are several jumps $(30,60$, and 130 hours $)$ in the relative displacement versus time curves. This indicates the debonding process through the interface. Debonding occurred when the accumulated fracture energy exceeded the critical value. As a result, the relative displacement readings at the interface had sudden increases.

c. It is found that the step-wise debonding process took a couple hours to propagate. That means debonding occurred over a certain finite distance.

d. The debonding at different locations occurred at the same time, which indicates a continuous crack front in the specimen.

e. LVDTs at the corners (L-2 and L-3) had larger readings than clip-on gauge (C-1). The clip-on gauge was located at the tip of the artificial crack at the interface and was $38 \mathrm{~mm}$ (1.5 in) away from the free end. This indicates that the crack was initiated at the corner and propagated through the edges and within the specimen interface surface. 


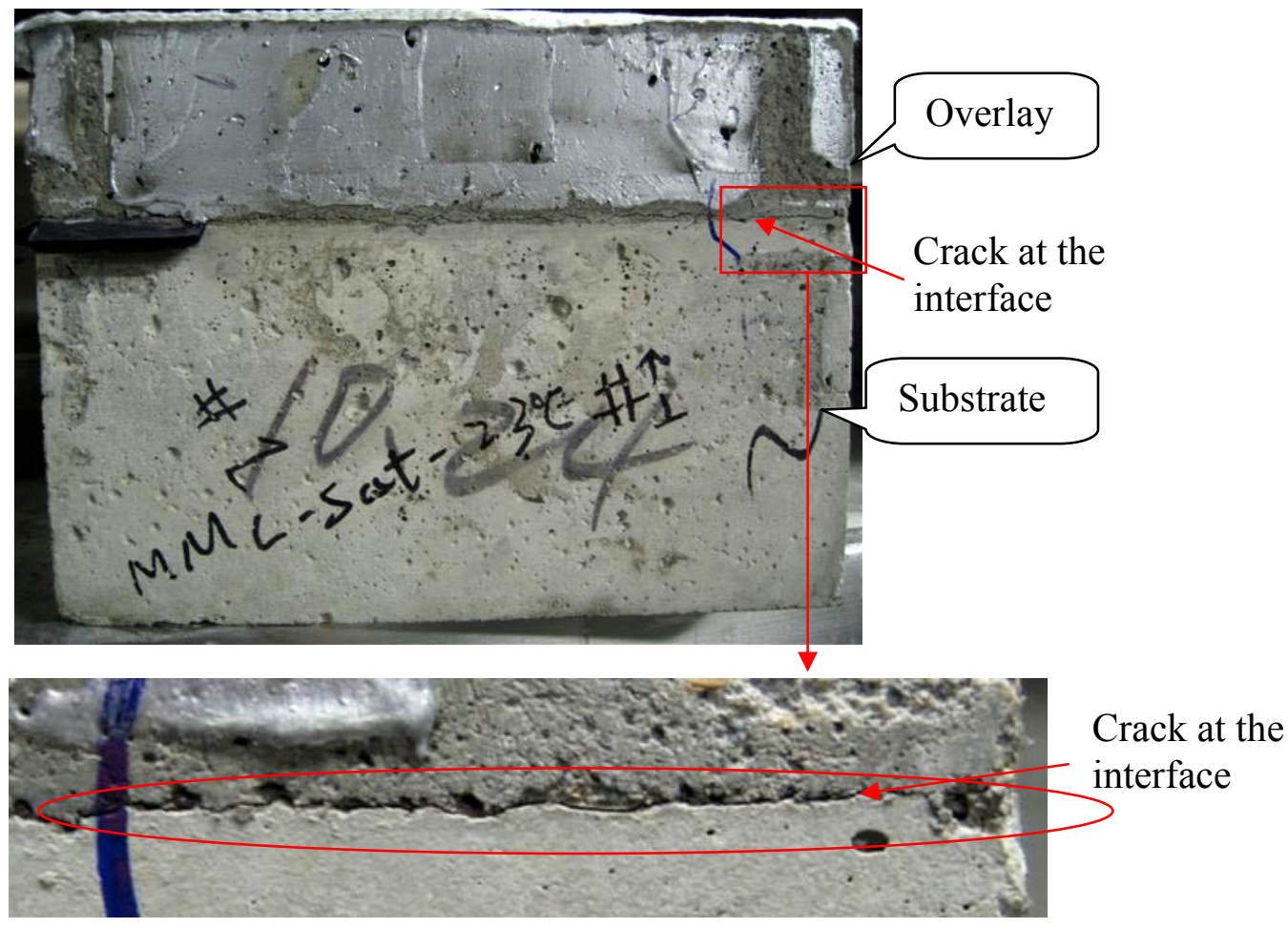

Fig. 5.1 Typical crack due to debonding at the interface

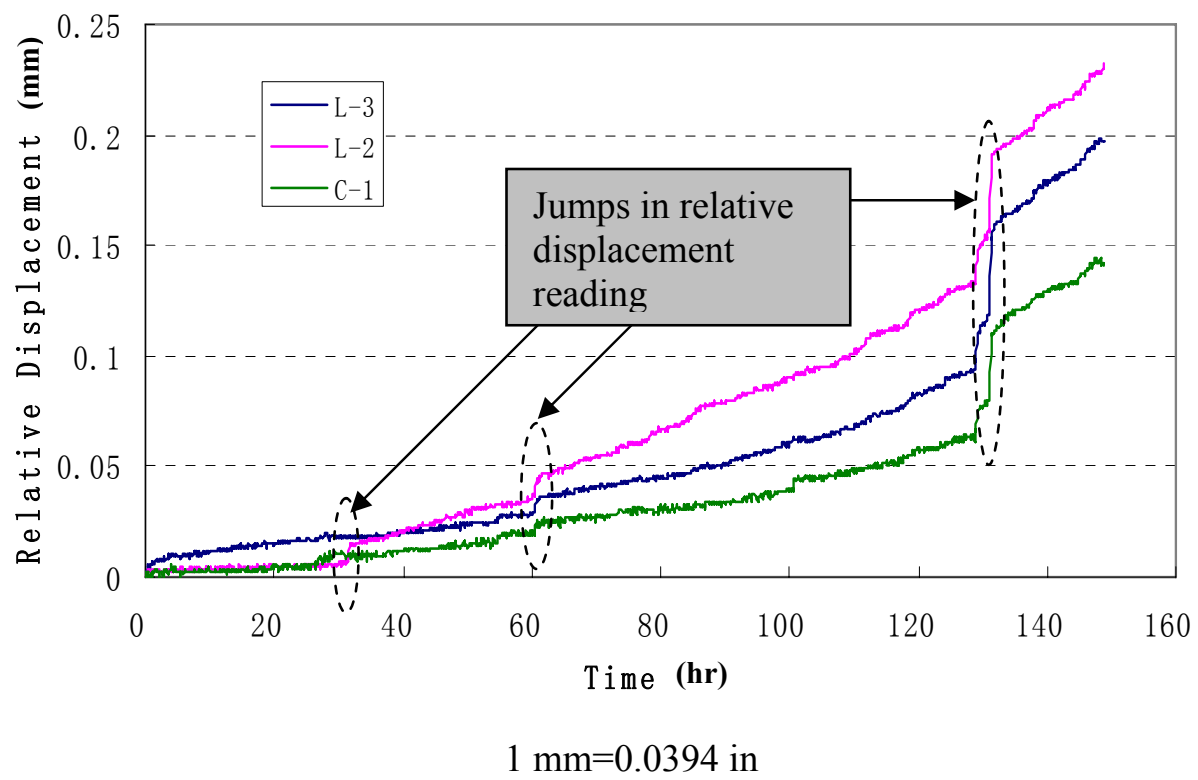

Fig. 5.2 Relative Displacement in SFMC-Dry-without Slurry @23ㄷ \#2 


\subsubsection{Comparison of Substrate Surface Conditions}

Three types of substrate surface conditions were investigated in this study. They were dry surface, saturated surface, and saturated surface with applied bonding slurry. At this stage all the overlays were made of SFMC. The temperature for testing was $23^{\circ} \mathrm{C}$ $\left(73^{\circ} \mathrm{F}\right)$. Figs. 5.3 and 5.4 show the typical relative displacement versus time curve for SFMC with saturated surface, and saturated surface with slurry, respectively. Table 5.1 shows the relative displacements at corners under each substrate surface condition at different ages.

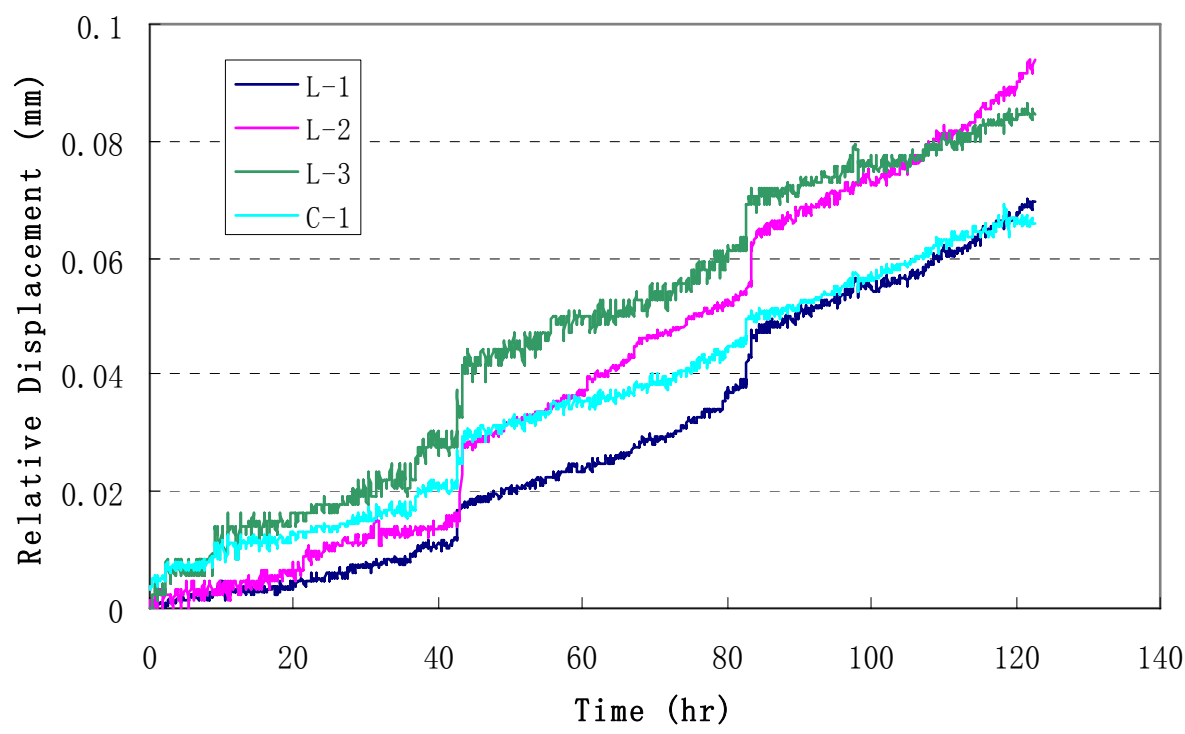

$1 \mathrm{~mm}=0.0394 \mathrm{in}$

Fig. 5.3 Relative Displacement in SFMC-Saturated-without Slurry @ $23^{\circ} \mathrm{C} \# 1$ 


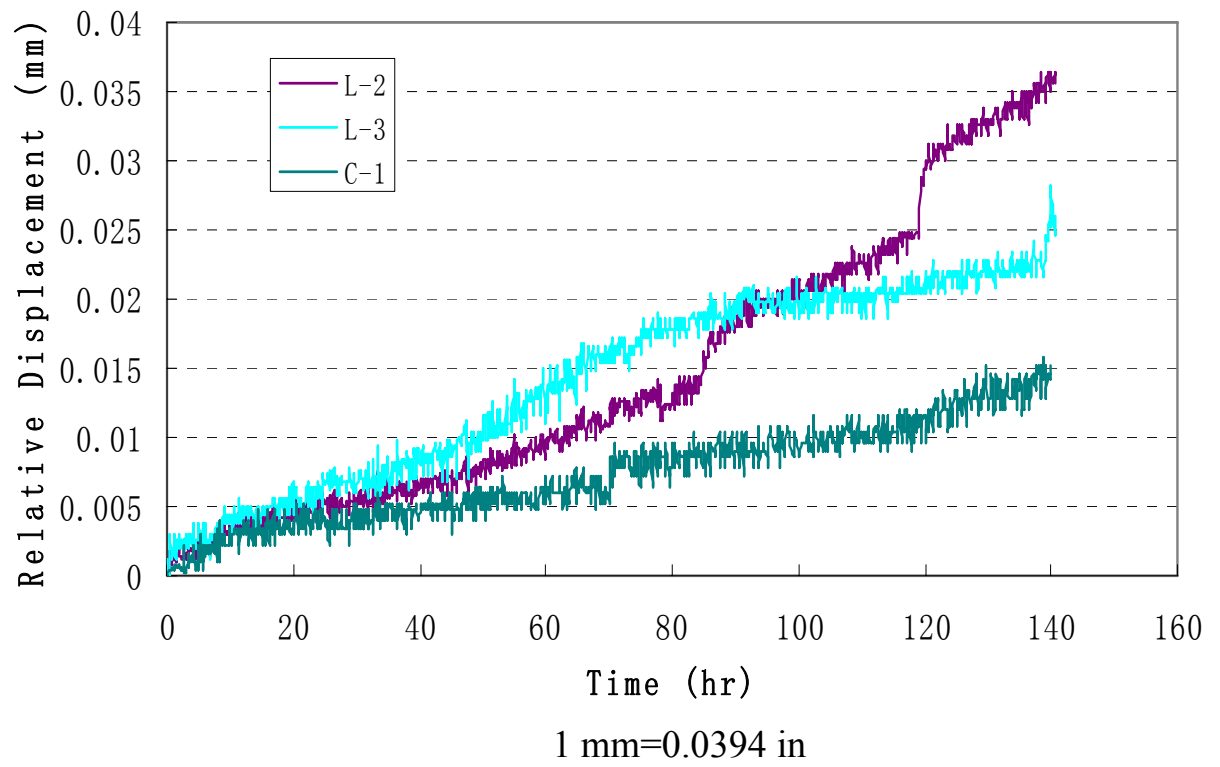

Fig. 5.4 Relative Displacement in SFMC-Saturated-with Slurry @ $23^{\circ} \mathrm{C} \# 2$

From the comparisons of Figs. 5.2, 5.3 and 5.4, it is noticed that the debonding (jumps in the relative displacement vs. time curves) occurred at different times. The SFMC-Dry-without Slurry had the earliest and largest jumps in the curves, followed by the SFMC-Saturated-without Slurry and SFMC-Saturated-with Slurry in sequence. This could be attributed to the differences of crack-tendency formation at the interface. While dry substrate without slurry tended to crack at the interface the most easily, both saturated and slurry-applied substrates decreased this tendency, which led to the smallest crack opening in SFMC-Saturated-with Slurry. Also it is noticed that the reading of clip-on gauge smoothed out when saturated substrate and bonding slurry were used. This indicates that the opening at the artificial crack tip was smoother, which means a less brittle failure.

From the listed results in Table 5.1, it is found that SFMC overlay with dry substrate surface had the largest relative displacements at the interface; followed by 
saturated substrate surface; and saturated substrate surface with slurry being the least. This could be because dry substrate surface absorbed moisture from overlay concrete, which increased the shrinkage in the overlay concrete. Also loss of moisture from overlay concrete to substrate might have decreased the degree of hydration of overlay concrete near the interface, thus leading to a weaker bonding zone between the overlay and substrate. The hand-brushed bonding slurry lowered the relative displacement readings as can be observed from the comparison. This can be attributed to the stronger bonding strength at the interface due to application of carefully applied slurry. The saturated substrate also improved the bond strength over the dry surface.

It can be concluded that saturated substrate surface with bonding slurry would be best among the three substrate surface condition methods. Considering this, the surface condition consisting of saturated substrate and bonding slurry was adopted in the subsequent tests. 
Table 5.1 Comparison of Substrate Surface Conditions at $23^{\circ} \mathrm{C}\left(7^{\circ} \mathrm{F}\right)$

\begin{tabular}{|c|c|c|c|c|c|c|c|c|c|c|c|c|}
\hline \multirow{3}{*}{$\begin{array}{c}\text { Overlay } \\
\text { Ages } \\
\text { (hrs) }\end{array}$} & \multicolumn{4}{|c|}{ Dry } & \multicolumn{4}{|c|}{ Saturated } & \multicolumn{4}{|c|}{ Saturated w/ Slurry } \\
\hline & \multicolumn{2}{|c|}{ Specimen \#1 } & \multicolumn{2}{|c|}{ Specimen \#2 } & \multicolumn{2}{|c|}{ Specimen \#1 } & \multicolumn{2}{|c|}{ Specimen \#2 } & \multicolumn{2}{|c|}{ Specimen \#1 } & \multicolumn{2}{|c|}{ Specimen \#2 } \\
\hline & L-2 & L-3 & L-2 & L-3 & L-2 & L-3 & L-2 & L-3 & L-2 & L-3 & L-2 & L-3 \\
\hline 48 & 0.034 & 0.033 & 0.005 & 0.017 & 0.010 & 0.018 & 0.027 & 0.023 & 0.002 & 0.003 & 0.004 & 0.005 \\
\hline 120 & 0.091 & 0.090 & 0.086 & 0.057 & 0.071 & 0.075 & 0.045 & 0.045 & 0.011 & 0.012 & 0.020 & 0.019 \\
\hline 168 & 0.129 & 0.116 & 0.230 & 0.199 & 0.094 & 0.085 & 0.049 & 0.052 & 0.015 & 0.018 & 0.036 & 0.028 \\
\hline
\end{tabular}

- LVDT readings are in $\mathrm{mm}$

- $1 \mathrm{~mm}=0.0394 \mathrm{in}$

- Overlay type: SFMC 


\subsubsection{Comparison between Two Temperatures}

In this study, other than $23^{\circ} \mathrm{C}\left(73^{\circ} \mathrm{F}\right)$, the performance of overlay-substrate system was also investigated at $35^{\circ} \mathrm{C}\left(95^{\circ} \mathrm{F}\right)$, which was considered as a harsh ambient temperature for overlay construction. This kind of ambient temperature may be encountered during summer time. Only one type of overlay was selected at this stage, which was silica fume modified concrete (SFMC). The substrate surface condition consisted of saturated with applied bonding slurry. Fig. 5.5 shows the development of relative interface displacement for the specimen tested at $35^{\circ} \mathrm{C}\left(95^{\circ} \mathrm{F}\right)$. Table 5.2 shows the relative displacements at corners for the two testing temperatures. It must be mentioned that specimen SFMC-Saturated-with Slurry \#2 exhibited a large discrepancy compared to the other specimens. Thus the data collected for this specimen is not used in this discussion.

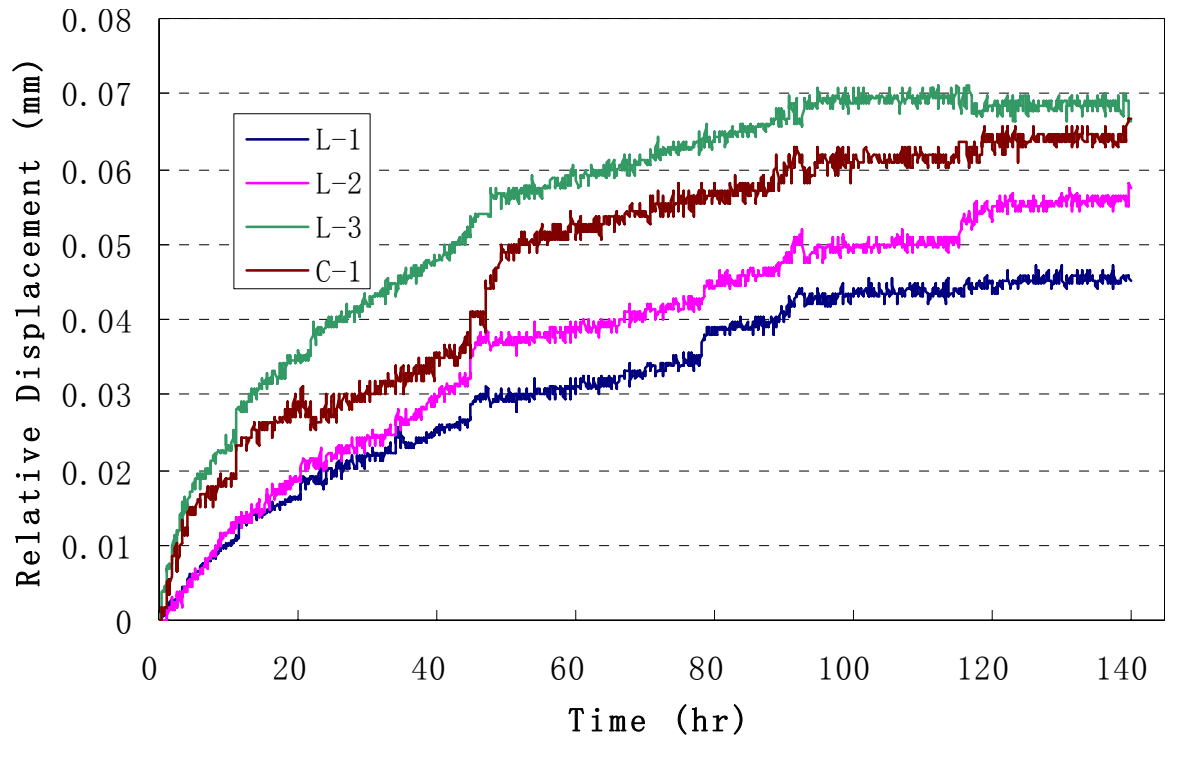

$1 \mathrm{~mm}=0.0394$ in

Fig. 5.5 Relative Displacement in SFMC-Saturated-with Slurry @35 $35^{\circ}$ \#1 
By comparing Fig. 5.4 (Saturated-with Slurry $@ 23^{\circ} \mathrm{C}$ ) and Fig. 5.5 (Saturatedwith Slurry $\left.@ 35^{\circ} \mathrm{C}\right)$, it is noticed that the displacement-time curves for $23^{\circ} \mathrm{C}\left(73^{\circ} \mathrm{F}\right)$ are slightly convex, while for $35^{\circ} \mathrm{C}\left(95^{\circ} \mathrm{F}\right)$ they are concave for all cases. This indicates that the CMOD for $35^{\circ} \mathrm{C}\left(95^{\circ} \mathrm{F}\right)$ started with larger values but slowed down with time compared to those at $23^{\circ} \mathrm{C}\left(73^{\circ} \mathrm{F}\right)$.

Table 5.2 Comparison of Different Temperatures

\begin{tabular}{|c|c|c|c|c|c|c|c|c|}
\hline \multirow{3}{*}{$\begin{array}{c}\text { Overlay } \\
\text { Ages } \\
\text { (hrs) }\end{array}$} & \multicolumn{4}{|c|}{$23^{\circ} \mathrm{C}\left(73^{\circ} \mathrm{F}\right)$} & \multicolumn{4}{|c|}{$35^{\circ} \mathrm{C}\left(95^{\circ} \mathrm{F}\right)$} \\
\hline & \multicolumn{2}{|c|}{ Specimen \#1 } & \multicolumn{2}{|c|}{ Specimen \#2 } & \multicolumn{2}{|c|}{ Specimen \#1 } & \multicolumn{2}{|c|}{ Specimen \#2 } \\
\hline & L-2 & L-3 & L-2 & L-3 & L-2 & L-3 & L-2 & L-3 \\
\hline 48 & 0.002 & 0.003 & 0.004 & 0.005 & 0.021 & 0.039 & \multirow{3}{*}{\multicolumn{2}{|c|}{$\mathrm{N} / \mathrm{A}$}} \\
\hline 120 & 0.011 & 0.012 & 0.020 & 0.019 & 0.049 & 0.069 & & \\
\hline 168 & 0.015 & 0.018 & 0.036 & 0.028 & 0.058 & 0.083 & & \\
\hline
\end{tabular}

- LVDT readings are in $\mathrm{mm}$

- $1 \mathrm{~mm}=0.0394 \mathrm{in}$

- Overlay: SFMC

- Surface Condition: Saturated with slurry

From Table 5.2 it is noticed that the specimen tested at $35^{\circ} \mathrm{C}\left(95^{\circ} \mathrm{F}\right)$ had exhibited larger relative displacements. This indicates that the higher temperature caused more severe debonding and delamination at the interface. At 48 hours the displacements at $35^{\circ} \mathrm{C}\left(95^{\circ} \mathrm{F}\right)$ were greater than those at $23^{\circ} \mathrm{C}\left(73^{\circ} \mathrm{F}\right)$ by an order of magnitude; however with time the difference reduced to about twice as large. The high temperature proved to 
be a very adverse factor for bonded concrete overlay at the early age. High temperature increased the moisture loss and accelerated the hydration process in the overlay concrete, which resulted in a high shrinkage at early age. A high shrinkage in overlay led to high debonding potential and more severe delmination, which was reflected by the increase in relative displacements at the interface.

\subsubsection{Comparison Among Different Overlay Mixes}

In order to better capture the differences among the performances of four overlay types investigated in this study, a higher temperature of $35^{\circ} \mathrm{C}\left(95^{\circ} \mathrm{F}\right)$ was selected. Figs. 5.6, 5.7, and 5.8 show the typical relative displacement-time curves for LMC, $\mathrm{SFMC}+\mathrm{SRA}$, and $\mathrm{FRC}$ at the temperature of $35^{\circ} \mathrm{C}\left(95^{\circ} \mathrm{F}\right)$. The measured relative displacements at corners for each mix are listed in Table 5.3.

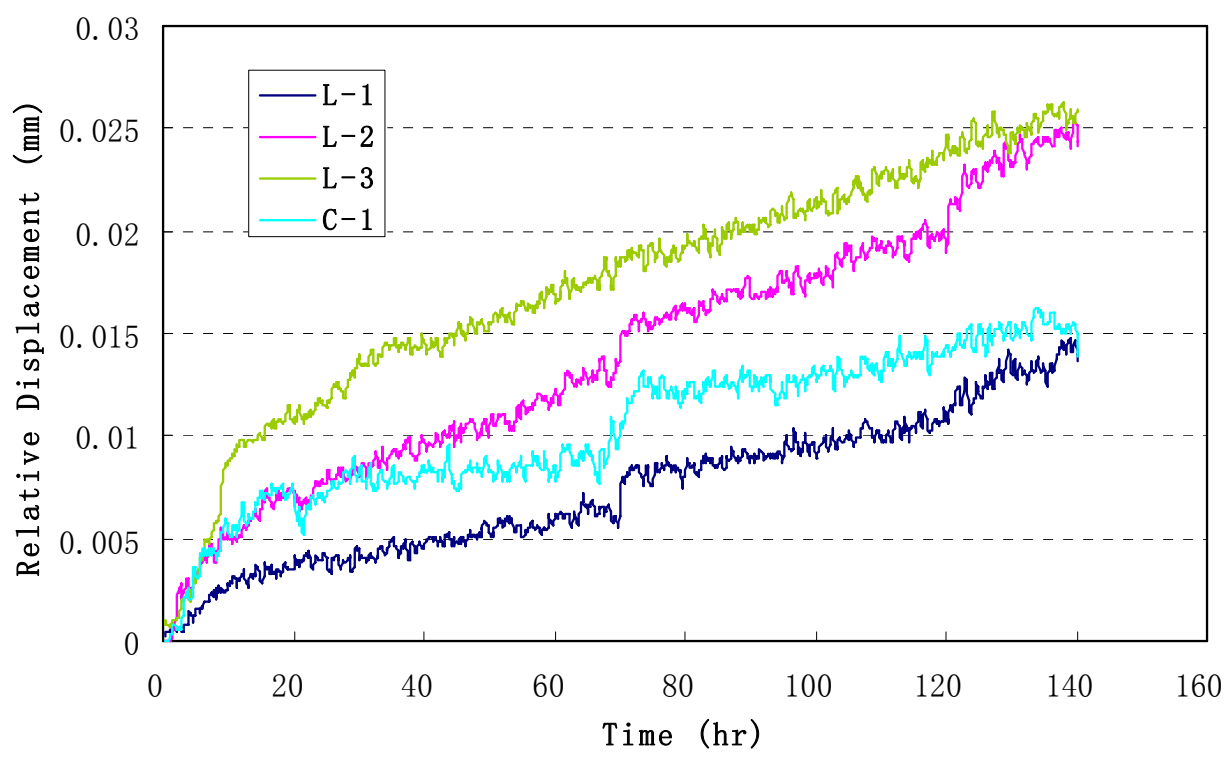

Fig. 5.6 Relative Displacement in LMC-Saturated-with Slurry @ $35^{\circ} \mathrm{C}$ \#1 


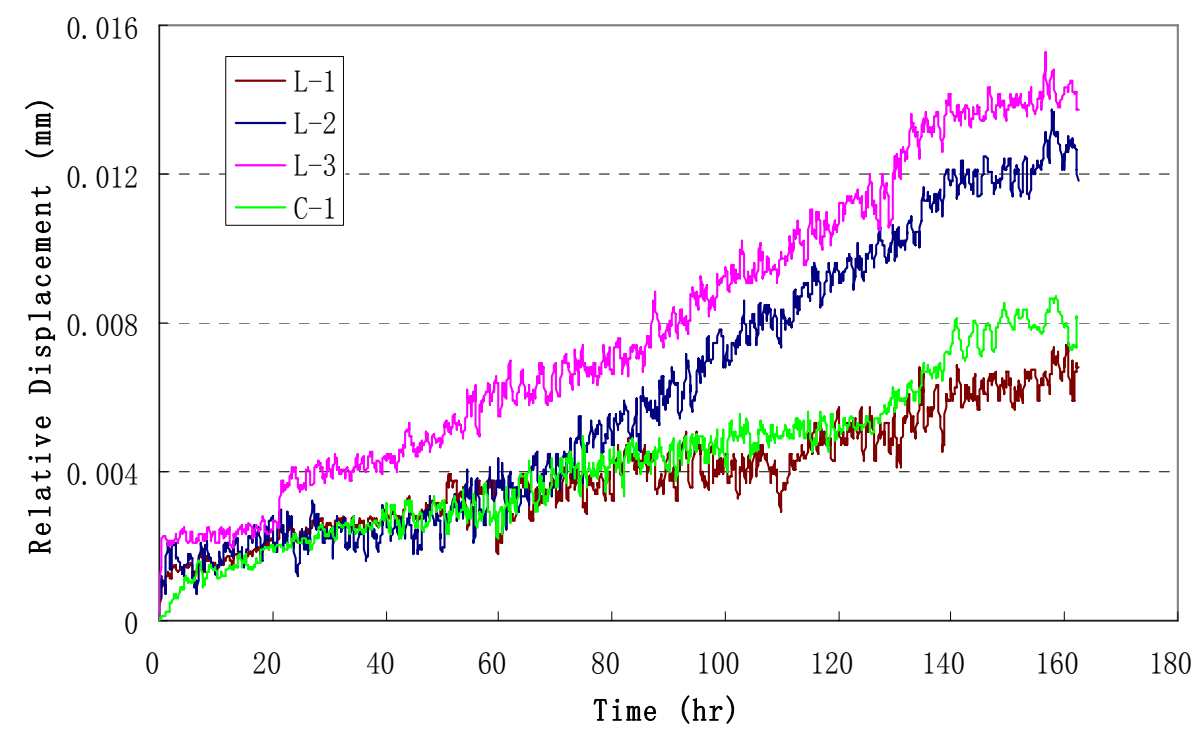

Fig. 5.7 Relative Displacement in SFMC+SRA-Saturated-with Slurry @ $35^{\circ} \mathrm{C} \# 1$

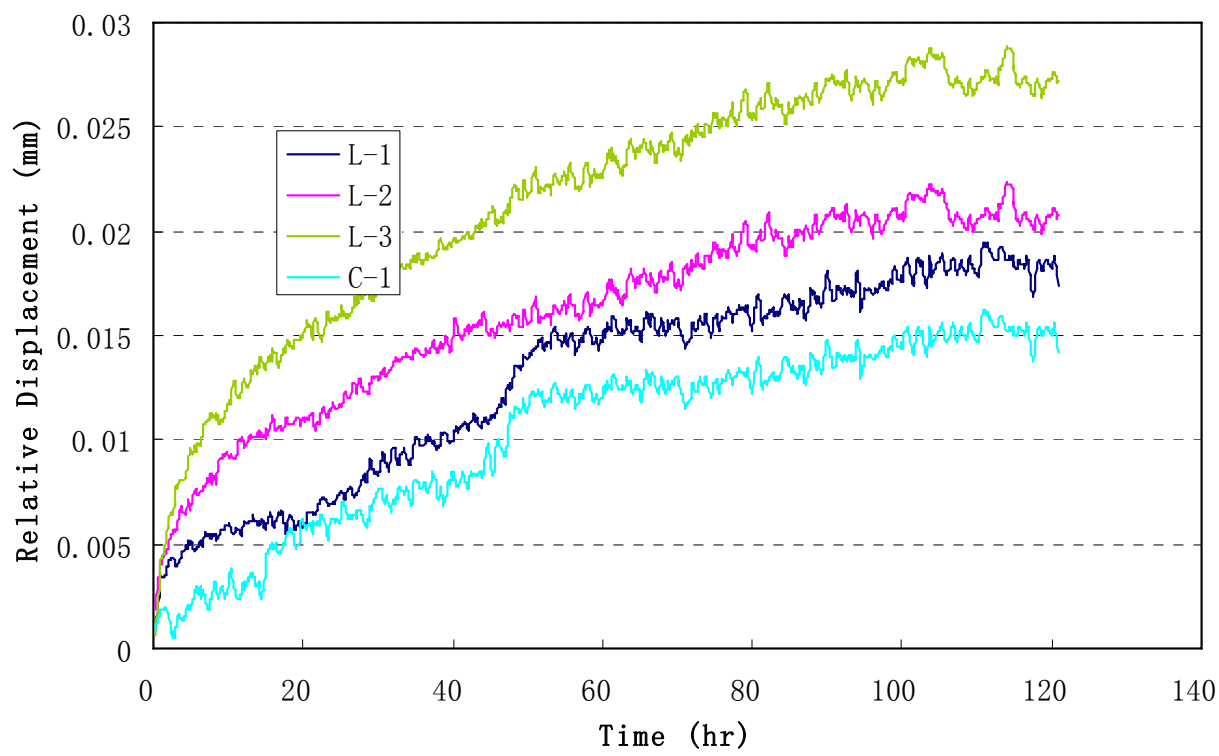

Fig. 5.8 Relative Displacement in FRC-Saturated-with Slurry @ $35^{\circ} \mathrm{C}$ \#1

From the comparison among Fig. 5.5 (SFMC), Fig. 5.6 (LMC), Fig. 5.7 (SFMC+SRA), and Fig. 5.8 (FRC), it is noticed that the readings from LVDT L-1 and clip-on gauge (C-1) are consistently close to each other and lower than those from LVDT 
L-2 and L-3. This indicates the test results are reliable and consistent. Also it can be seen that there are more jumps in the curves for SFMC than the others, which indicates a different behavior for SFMC, characterized by a more brittle interface fracture.

From Table 5.3, it is noticed that SFMC overlay had the largest readings. LMC, SFMC+SRA and FRC overlays had similar readings and the values were relatively small compared to those of SFMC. In order to better understand the results presented in Table 5.3, it is necessary to refer to the free shrinkage of each mix used in this study. Figure 5.9 gives the free shrinkage development of each mix. These data were collected from previous research at WVU in 2004 (Sun 2004). At early age Normal Concrete (NC), SFMC and FRC have fairly close free shrinkage, and LMC and SFMC+SRA have smaller free shrinkage. Though the information in this figure is not adequate to predict the differential shrinkage in the overlay concrete under restrained condition, it can reasonably explain the results in Table 5.3.

Upon casting overlay concrete, the NC substrates that were used with SFMC, LMC and SFMC+SRA overlays have been cured and air-dried for 16 weeks or 112 days, and the substrates for FRC have been cured and air dried for only 5 weeks or 35 days. There is an equation predicting the development of shrinkage with time according to ACI 209R-92:

$$
S_{t}=\frac{t}{35+t} S_{u l t}
$$

Where $S_{t}=$ shrinkage after $t$ days since the end of 7-day moist curing

$S_{u l t}=$ ultimate shrinkage, and $\boldsymbol{t}=$ time in days since the end of moist curing 
Thus during testing, the NC substrates were relatively stable compared to SFMC, LMC and SFMC+SRA overlays, and somewhat unstable compared to FRC overlay. This would explain the discrepancy between the SFMC and FRC overlays. Although both mixes have similar free shrinkage development at early age, due to the difference between the substrate shrinkages, SFMC had larger relative displacements than FRC. For LMC and SFMC+SRA, the small relative displacements were mainly due to low shrinkage of these overlays. The lower water to cement ratio of 0.35 and the presence of latex polymer contributed to the low shrinkage of LMC. The shrinkage reducing admixture (SRA) had very effectively decreased the free shrinkage in SFMC. Thus it is evident that relative volume change between overlay and substrate was the primary reason influencing the relative displacements at the interface. 
Table 5.3 Comparison of Different Mixes at $35^{\circ} \mathrm{C}\left(95^{\circ} \mathrm{F}\right)$

\begin{tabular}{|c|c|c|c|c|c|c|c|c|c|c|c|c|c|c|c|c|}
\hline \multirow{3}{*}{$\begin{array}{c}\text { Overlay } \\
\text { Ages } \\
\text { (hrs) }\end{array}$} & \multicolumn{4}{|c|}{ SFMC } & \multicolumn{4}{|c|}{ LMC } & \multicolumn{4}{|c|}{ SFMC+SRA } & \multicolumn{4}{|c|}{ FRC } \\
\hline & \multicolumn{2}{|c|}{ Specimen \#1 } & \multicolumn{2}{|c|}{ Specimen \#2 } & \multicolumn{2}{|c|}{ Specimen \#1 } & \multicolumn{2}{|c|}{ Specimen \#2 } & \multicolumn{2}{|c|}{ Specimen \#1 } & \multicolumn{2}{|c|}{ Specimen \#2 } & \multicolumn{2}{|c|}{ Specimen \#1 } & \multicolumn{2}{|c|}{ Specimen \#2 } \\
\hline & L-2 & L-3 & L-2 & L-3 & L-2 & L-3 & L-2 & L-3 & L-2 & L-3 & L-2 & L-3 & L-2 & L-3 & L-2 & L-3 \\
\hline 48 & 0.021 & 0.039 & \multirow{3}{*}{\multicolumn{2}{|c|}{ N/A }} & 0.007 & 0.011 & 0.004 & 0.009 & 0.004 & 0.003 & 0.003 & 0.008 & 0.012 & 0.016 & 0.010 & 0.014 \\
\hline 120 & 0.049 & 0.069 & & & 0.018 & 0.022 & 0.009 & 0.018 & 0.010 & 0.006 & 0.019 & 0.019 & 0.021 & 0.027 & 0.021 & 0.025 \\
\hline 168 & 0.058 & 0.083 & & & 0.024 & 0.026 & 0.021 & 0.024 & 0.014 & 0.006 & 0.026 & 0.023 & 0.022 & 0.028 & 0.024 & 0.027 \\
\hline
\end{tabular}

- LVDT readings are in $\mathrm{mm}$

- $1 \mathrm{~mm}=0.0394 \mathrm{in}$

- Surface Condition: Saturated with slurry

- * Age of substrate concrete was only 5 weeks 


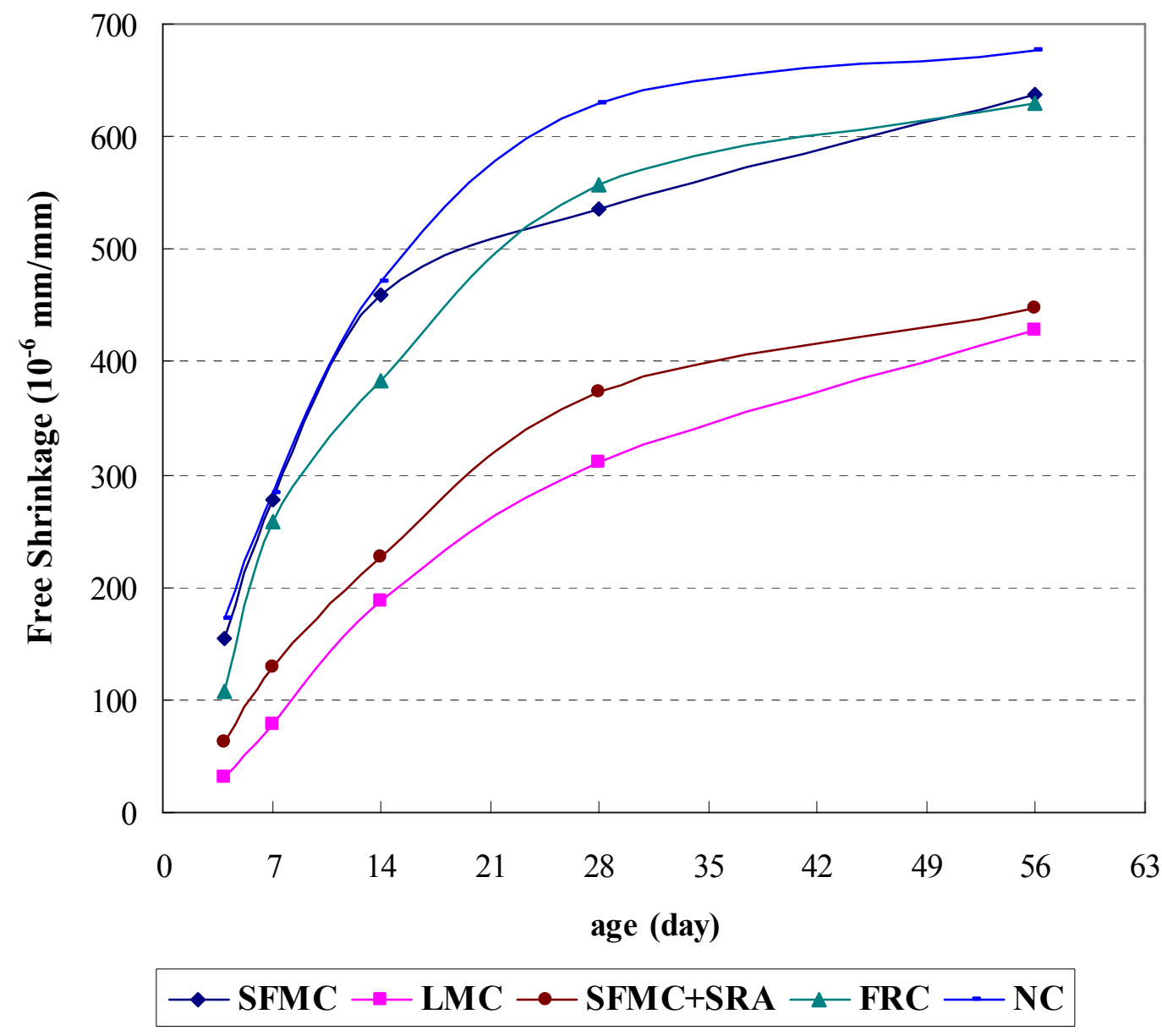

Fig. 5.9 Development of Free Shrinkage ${ }^{*}$

* Data for free shrinkage was obtained from previous research (Sun, 2004). 


\subsection{Ultrasonic Pulse Test}

\subsubsection{Ultrasonic pulse transmitting time measurement}

Ultrasonic pulse transmitting time was measured for each grid point within 150 $\mathrm{mm}(6 \mathrm{in})$ from the free end of the specimen. Signals at the point 8-D (Fig. 5.14) located at the middle of the specimen were always recorded as reference information for no crack zone. In the cases of SFMC-dry @ $23^{\circ} \mathrm{C}\left(73^{\circ} \mathrm{F}\right) \# 2$ and SFMC-saturated-w/ slurry (a) $35^{\circ} \mathrm{C}\left(95^{\circ} \mathrm{F}\right) \# 2$, the measurements were taken up to $225 \mathrm{~mm}$ (9 in) from the free end, and $10-\mathrm{D}$ was the reference point.

Since in this study bi-layer concrete with different properties was used, the thickness of each specimen was fairly constant. Therefore instead of pulse velocity, pulse transmitting time was measured over time at different locations to monitor the crack or delamination at the interface. Typical maps of pulse transmitting time at different ages are displayed in Figs. 5.10 - 5.12. In this case the specimen was SFMC-dry @ $23^{\circ} \mathrm{C}\left(73^{\circ} \mathrm{F}\right)$ \#1. 


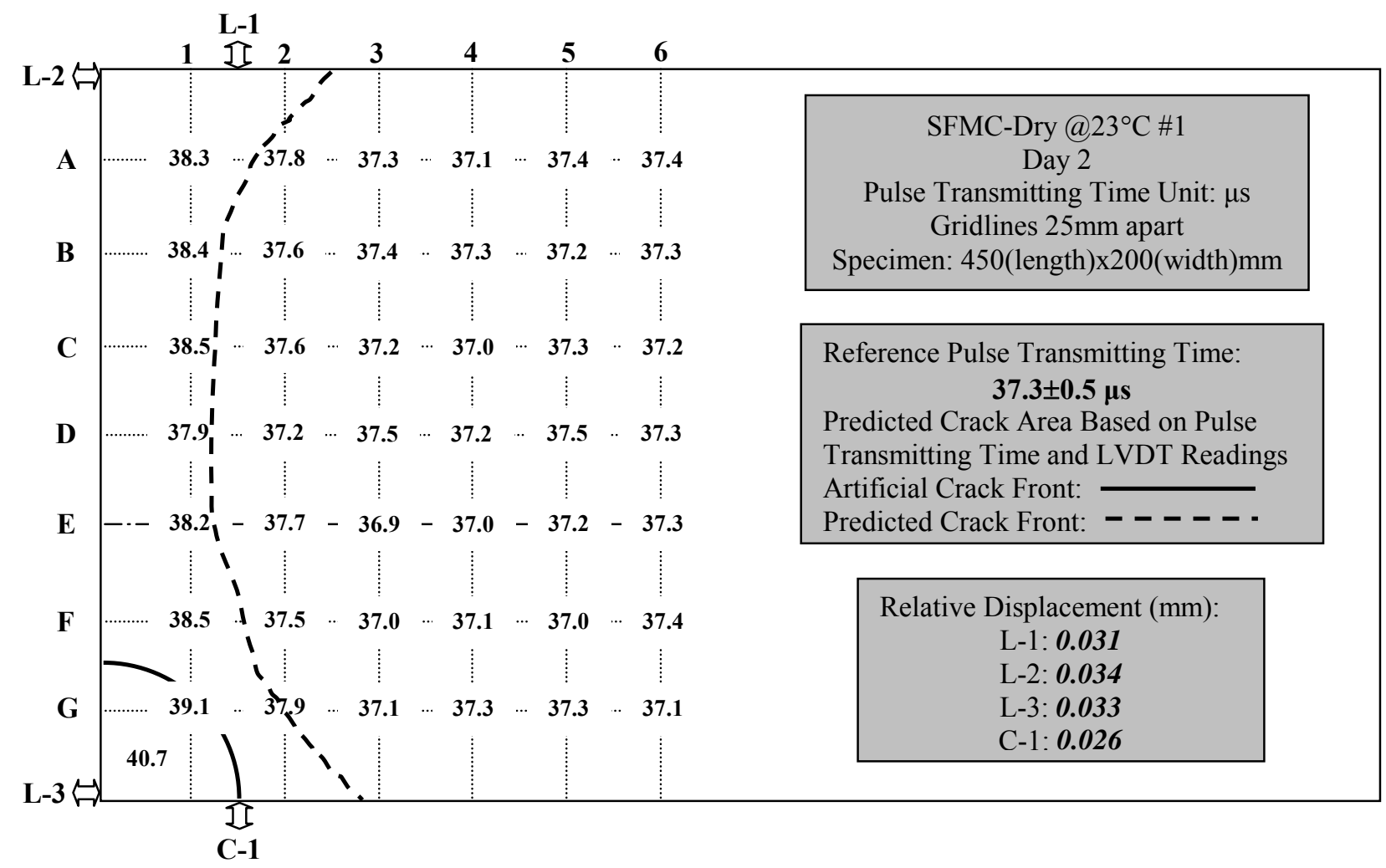

Fig. 5.10 Map of pulse transmitting time for SFMC-Dry @ $23{ }^{\circ} \mathrm{C} \# 1$-a

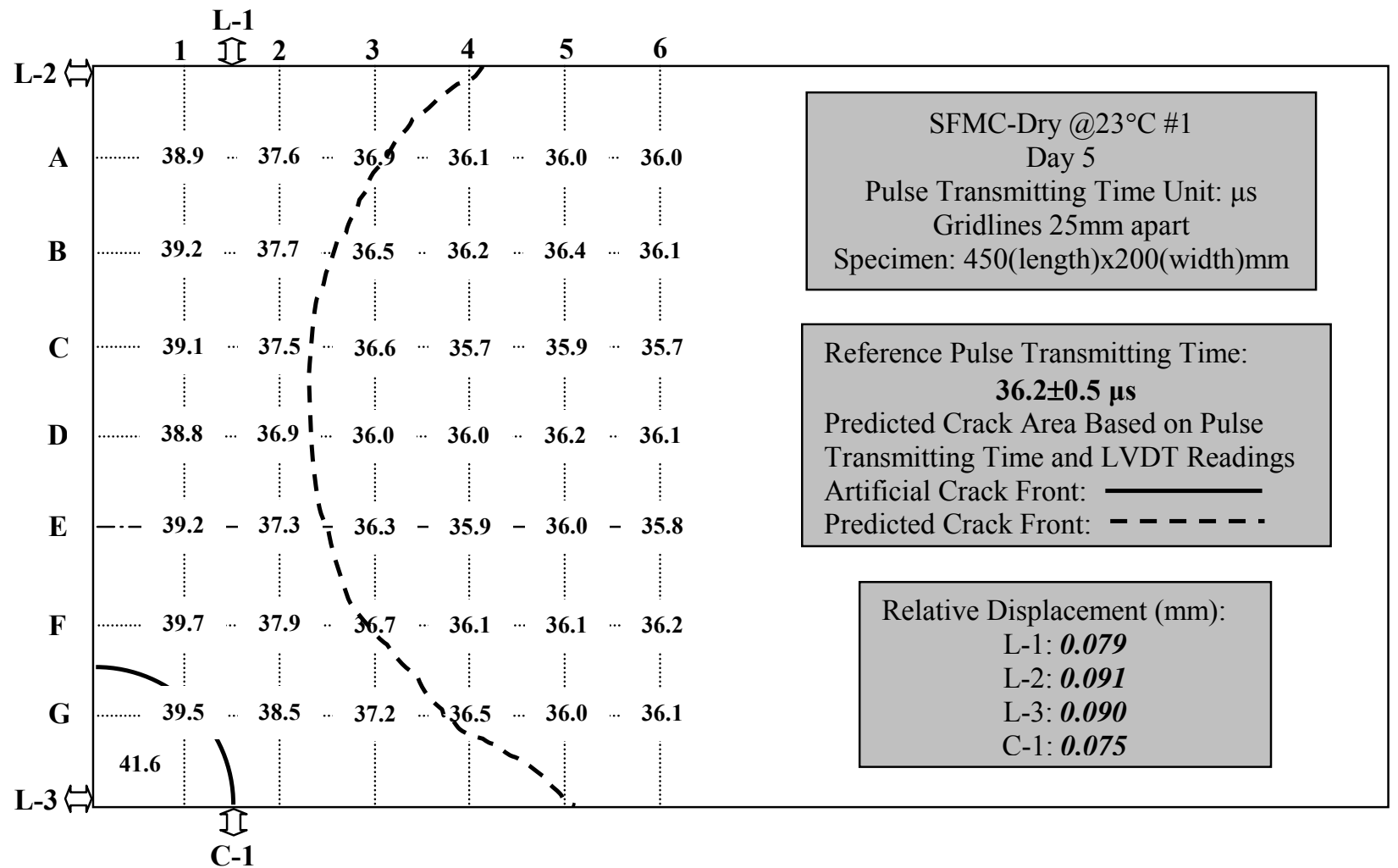

Fig. 5.11 Map of pulse transmitting time for SFMC-Dry @ $23^{\circ} \mathrm{C} \# 1-b$ 


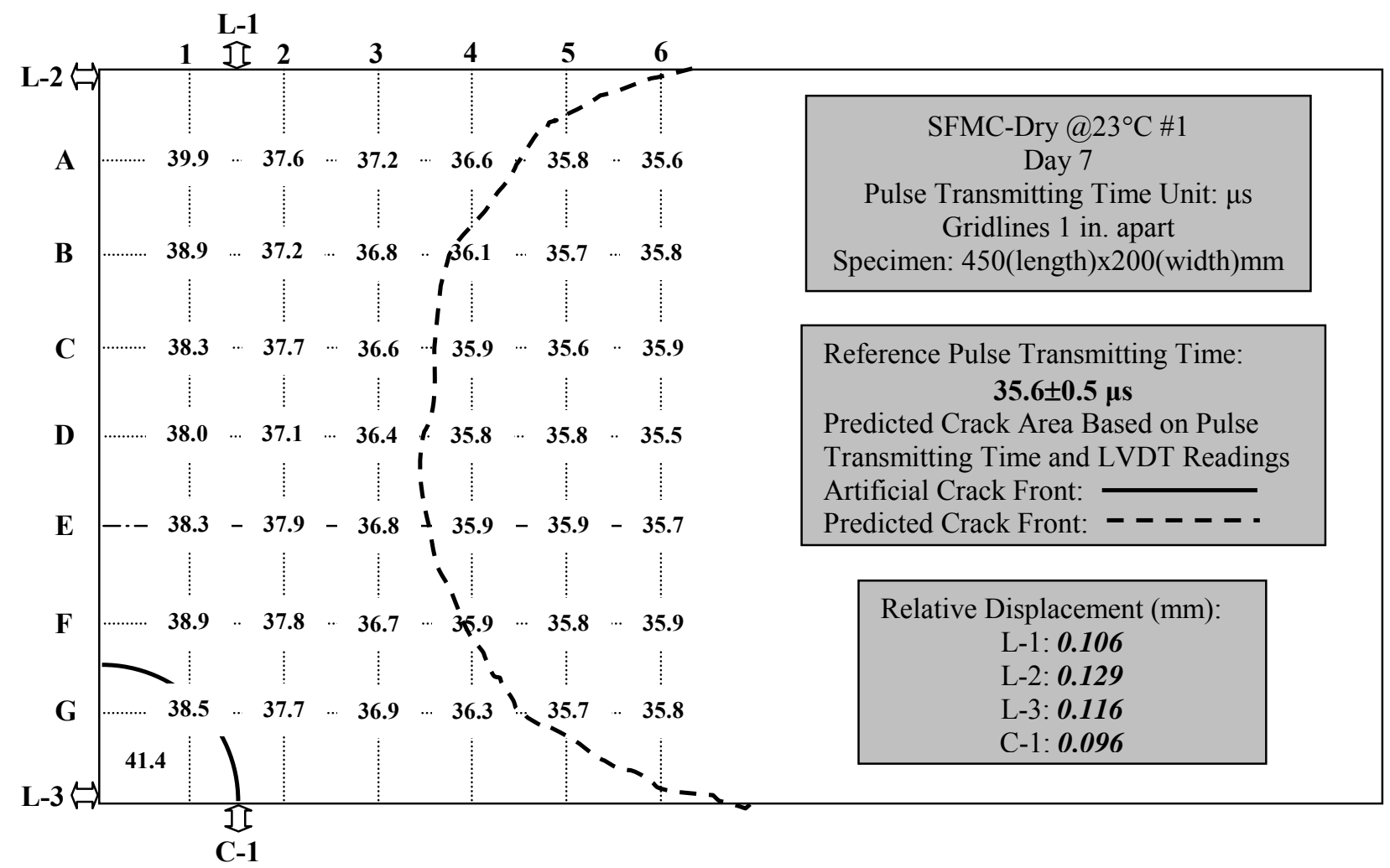

Fig. 5.12 Map of pulse transmitting time for SFMC-Dry @ $23^{\circ} \mathrm{C} \# 1-\mathrm{c}$

In each map, a reference pulse transmitting time was chosen to represent the intact interface. Considering the variation of the V-Meter and the variation of thickness in each specimen, a tolerance of $0.5 \mu \mathrm{s}$ was selected. Thus any grid point with a reading falling within the reference pulse transmitting time $\pm 0.5 \mu$ s would be considered as an intact point. Any number beyond that will be considered as location of cracking or delamination. In Fig. 5.10 the reference pulse transmitting time was $37.3 \pm 0.5 \mu$ s. From equation $2-1$, pulse velocity is proportional to the square root of dynamic modulus of elasticity. With the development of maturity in the overlay concrete, the overall dynamic modulus of elasticity of the specimen was increasing with time. This means the ultrasonic pulse velocity in the specimen would increase with time, or proportionately, the ultrasonic 
pulse transmitting time would decrease with time. This trend was noticed in all the readings. The reference pulse transmitting decreased gradually with time in each tested specimen.

By comparing the pulse transmitting time at each grid point with the reference reading, the crack front due to delamination at the interface was predicted and drawn in the map. Since overlay concrete underwent shrinkage in both directions, the crack front was concave towards the clamped end as shown in the figures. Figs. 5.13 and 5.14 show the crack front movement and the relative displacement readings in SFMC-dry $@ 23^{\circ} \mathrm{C}$ $\left(73^{\circ} \mathrm{F}\right) \# 1$ and $\# 2$. It is found that the crack front moved consistently with the development of the relative displacements at the interface. The larger the relative displacements were, the further the crack front moved, thus causing a larger delamination area.

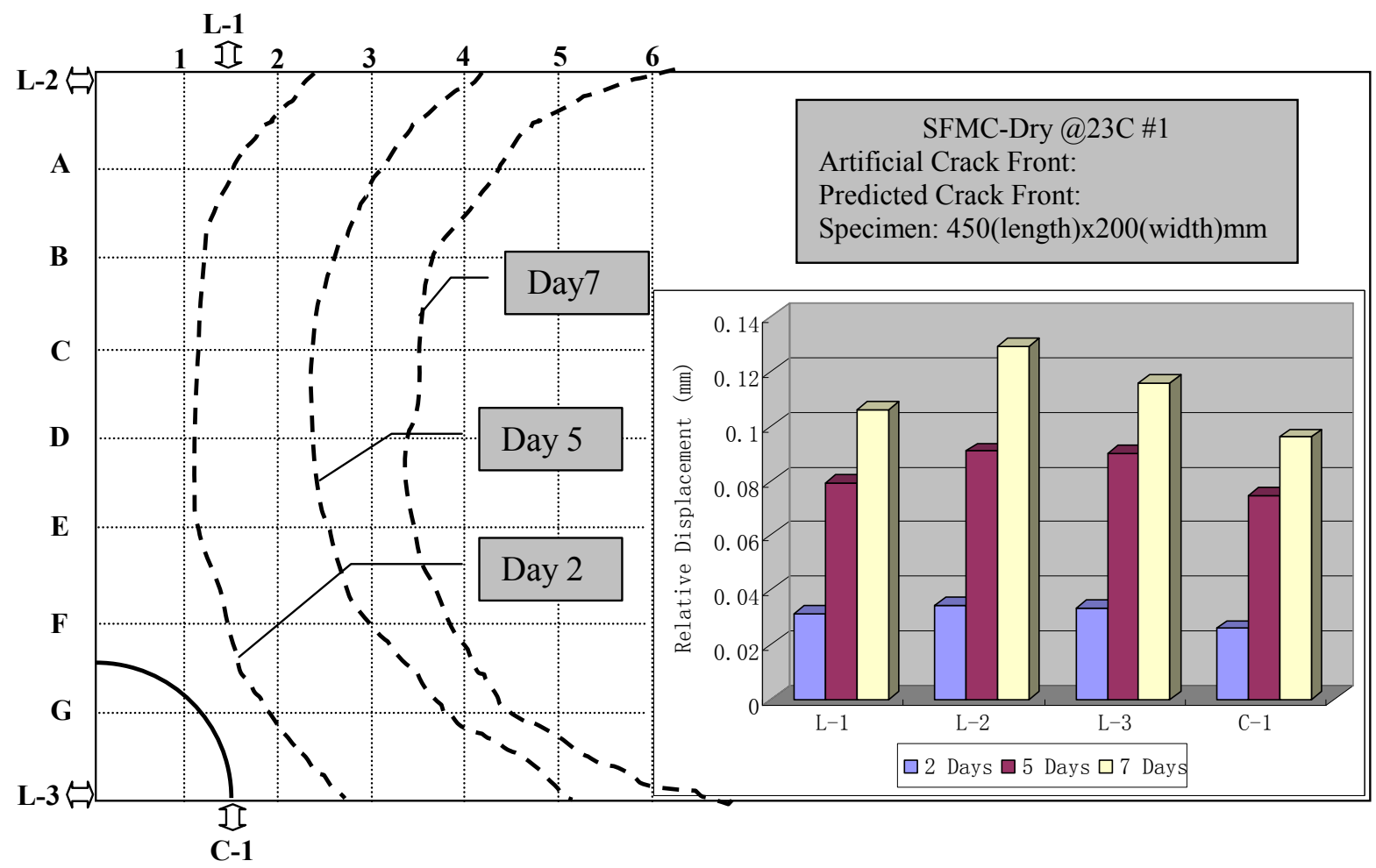

Fig. 5.13 Predicted crack front movement for SFMC-Dry @ $23^{\circ} \mathrm{C} \# 1$ 

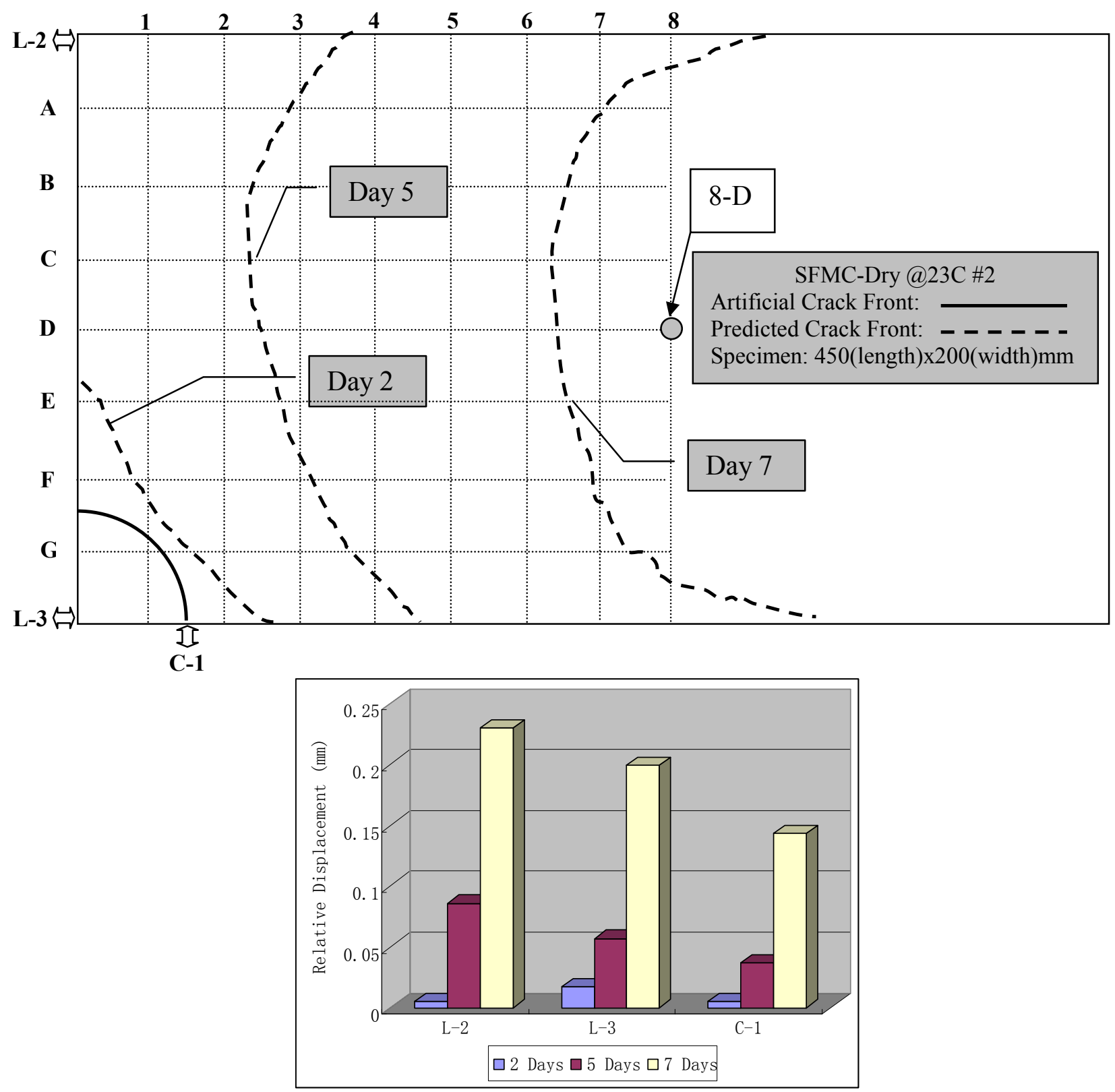

Fig. 5.14 Predicted crack front movement for SFMC-Dry @ $23^{\circ} \mathrm{C} \# 2$

By comparing the crack front profiles in specimens tested at $23^{\circ} \mathrm{C}\left(73^{\circ} \mathrm{F}\right)(\mathrm{Fig}$. 5.13 for SFMC-dry, Fig. 5.15 for SFMC-saturated, and Fig. 5.16 for SFMC-saturated-w/ slurry), it is noticed that SFMC-saturated-w/ slurry specimens had the smallest delamination area, followed by SFMC-saturated and SFMC-dry in sequence. This result 
was consistent with the result from comparison of the relative displacement readings for these specimens. Once again, it is confirmed that saturated substrate surface with applied bonding slurry was the best surface condition method.

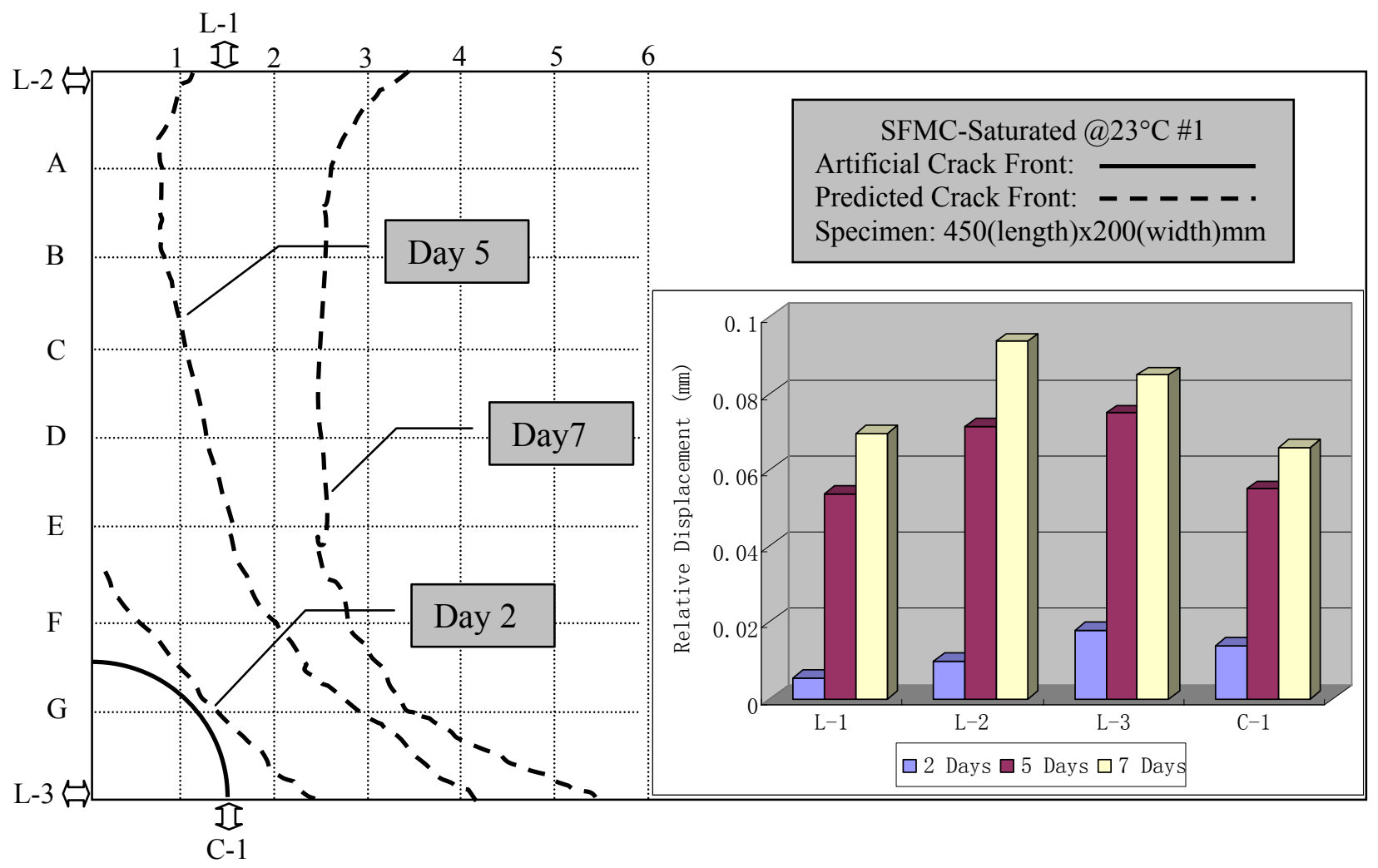

Fig. 5.15 Predicted Crack front movement for SFMC-Saturated @ $23^{\circ} \mathrm{C} \# 1$ 


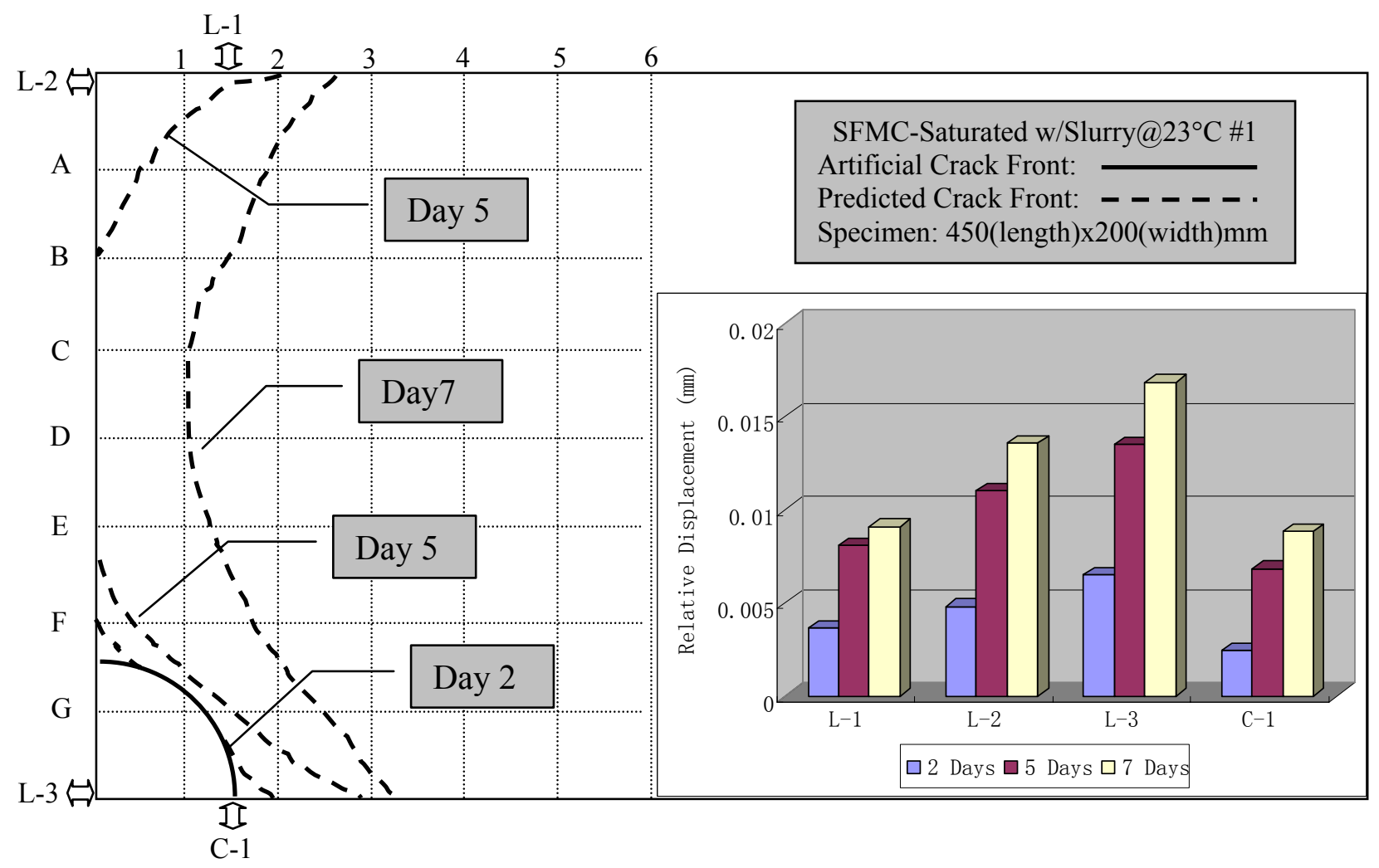

Fig. 5.16 Predicted crack front movement for SFMC-Saturated-w/Slurry @ $23^{\circ} \mathrm{C} \mathrm{\# 1}$

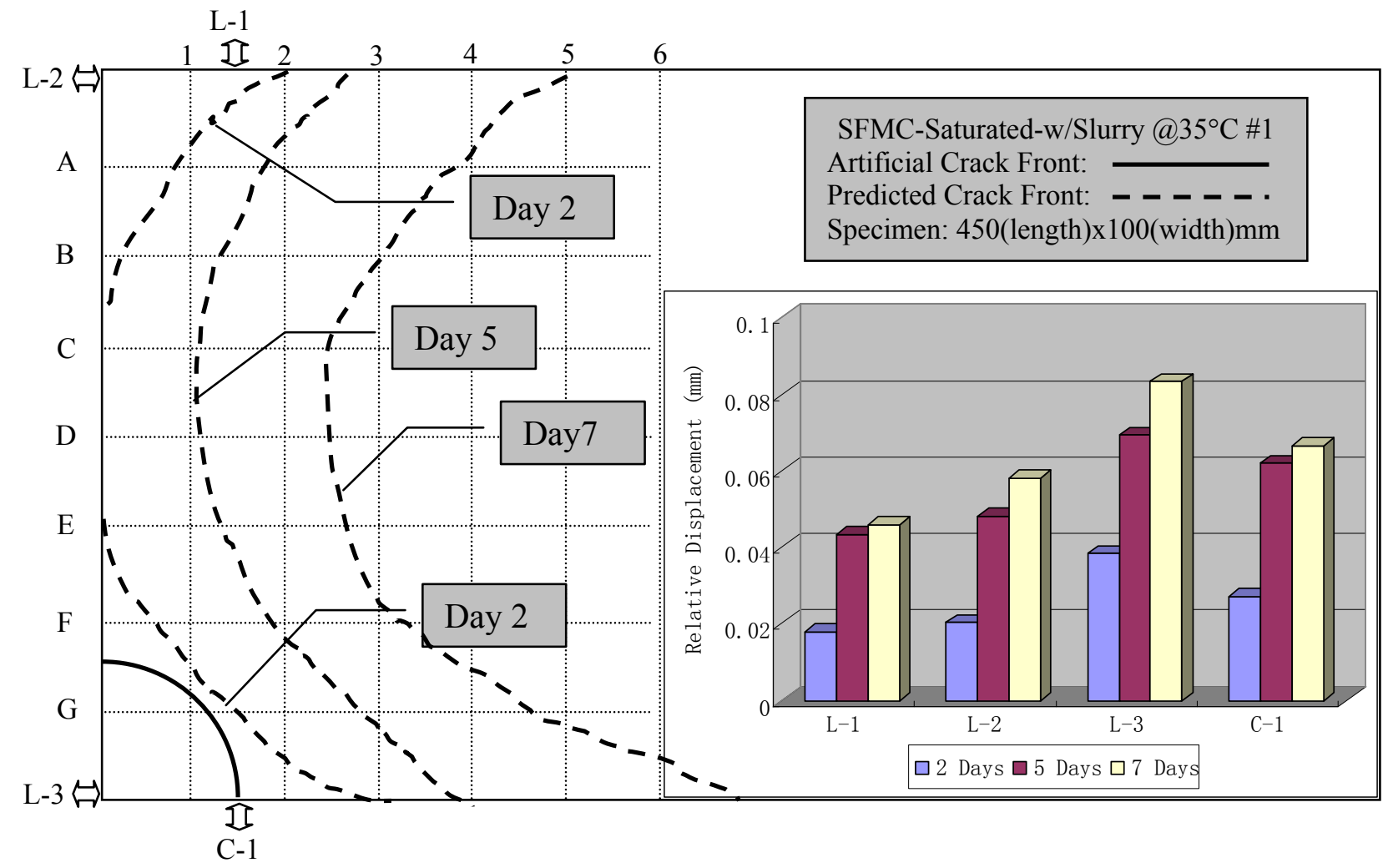

Fig. 5.17 Predicted crack front movement for SFMC-Saturated-w/Slurry @35 $35^{\circ} \mathrm{C}$ \#1 
By comparing the crack front profiles in SFMC-saturated-w/ slurry @ $23^{\circ} \mathrm{C}\left(73^{\circ} \mathrm{F}\right)$ (Fig. 5.16) and SFMC-saturated-w/ slurry $@ 35^{\circ} \mathrm{C}\left(95^{\circ} \mathrm{F}\right)$ (Fig. 5.17), the adverse effect of high temperature is obviously noticed. High temperature aggravated the delamination area at the interface.

From the comparison of the crack front profiles in SFMC-saturated-w/ slurry $@ 35^{\circ} \mathrm{C}\left(95^{\circ} \mathrm{F}\right)$ (Fig. 5.17), LMC-saturated-w/ slurry @ $35^{\circ} \mathrm{C}\left(95^{\circ} \mathrm{F}\right)$ (Fig. 5.18), SFMC+SRA-saturated-w/ slurry @ $35^{\circ} \mathrm{C}\left(95^{\circ} \mathrm{F}\right)$ (Fig. 5.19), and FRC-saturated-w/ slurry @ $35^{\circ} \mathrm{C}\left(95^{\circ} \mathrm{F}\right)$ (Fig. 5.20$)$, it is found that $\mathrm{SFMC}+\mathrm{SRA}$ had the smallest delamination area, followed by LMC, FRC, and SFMC in sequence. Thus, shrinkage reducing admixture (SRA) is highly recommended for all silica fume modified concrete in overlay construction. When delamination at the interface is concerned, LMC is also a very good choice for overlay concrete. As discussed in 5.1.4, the small delamination area of FRC overlay might be due to the relatively less curing time of the substrate (5 weeks vs. 16 weeks for the other substrates), which was still undergoing shrinkage together with the FRC overlay causing a lower differential shrinkage. However the presence of fiber might also have some effect on reducing interface cracking. A further study is required with 16 weeks aged substrate overlaid by FRC. When the overlay and substrate concrete undergo simultaneous shrinkage, the relative movement between them is reduced, which probably leads to smaller stresses at the interface and smaller delamination area. The large delamination area of SFMC overlays without SRA may be attributed to the large differential shrinkage of SFMC compared to the rest of overlays. Although silica fume can be a good admixture to optimize the performance of normal concrete, the tendency of 
large shrinkage could have an adverse effect on the performance of overlay, but this can be reduced significantly by adding SRA. 


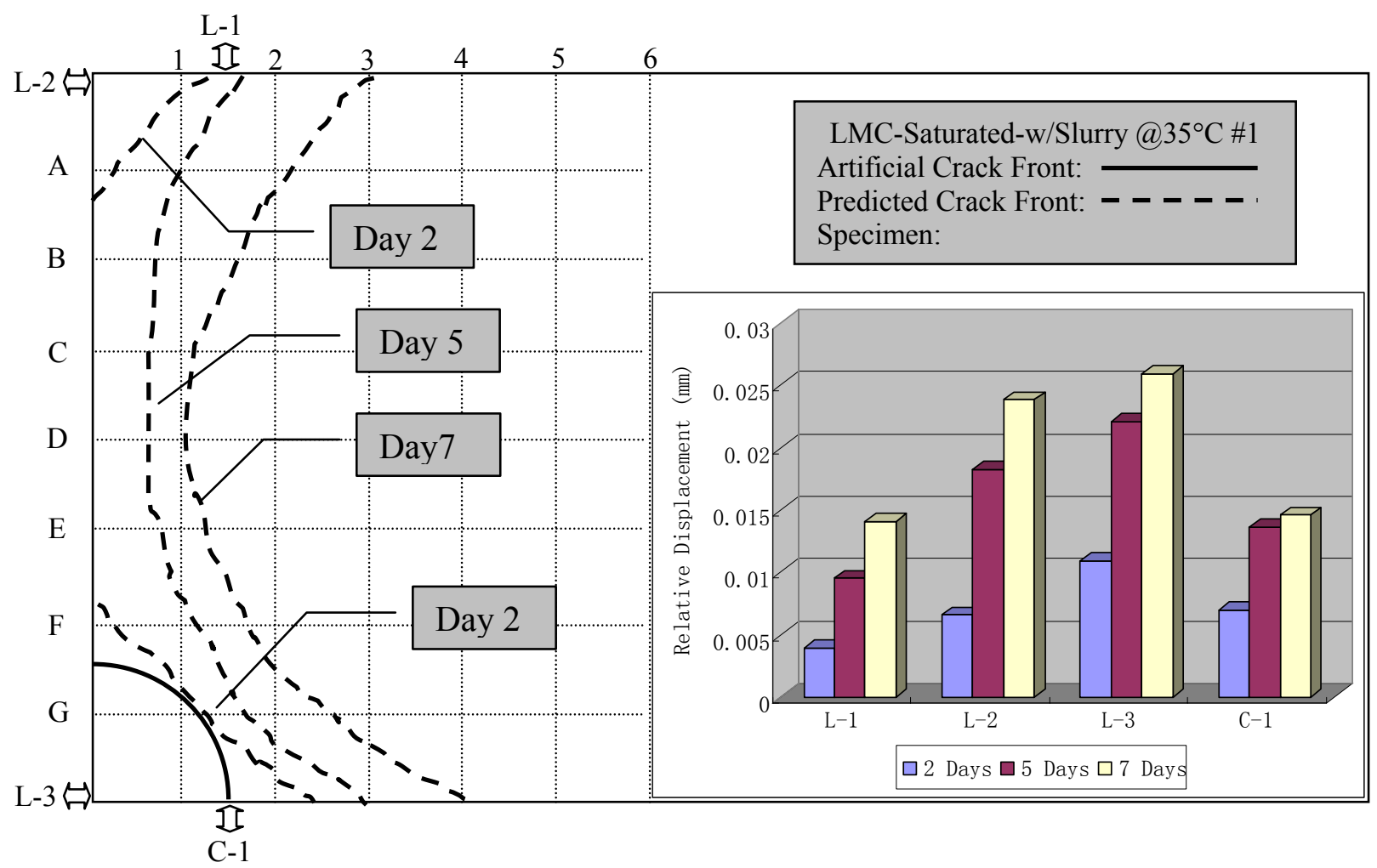

Fig. 5.18 Predicted crack front movement for LMC-Saturated-w/Slurry @ $35^{\circ} \mathrm{C} \# 1$

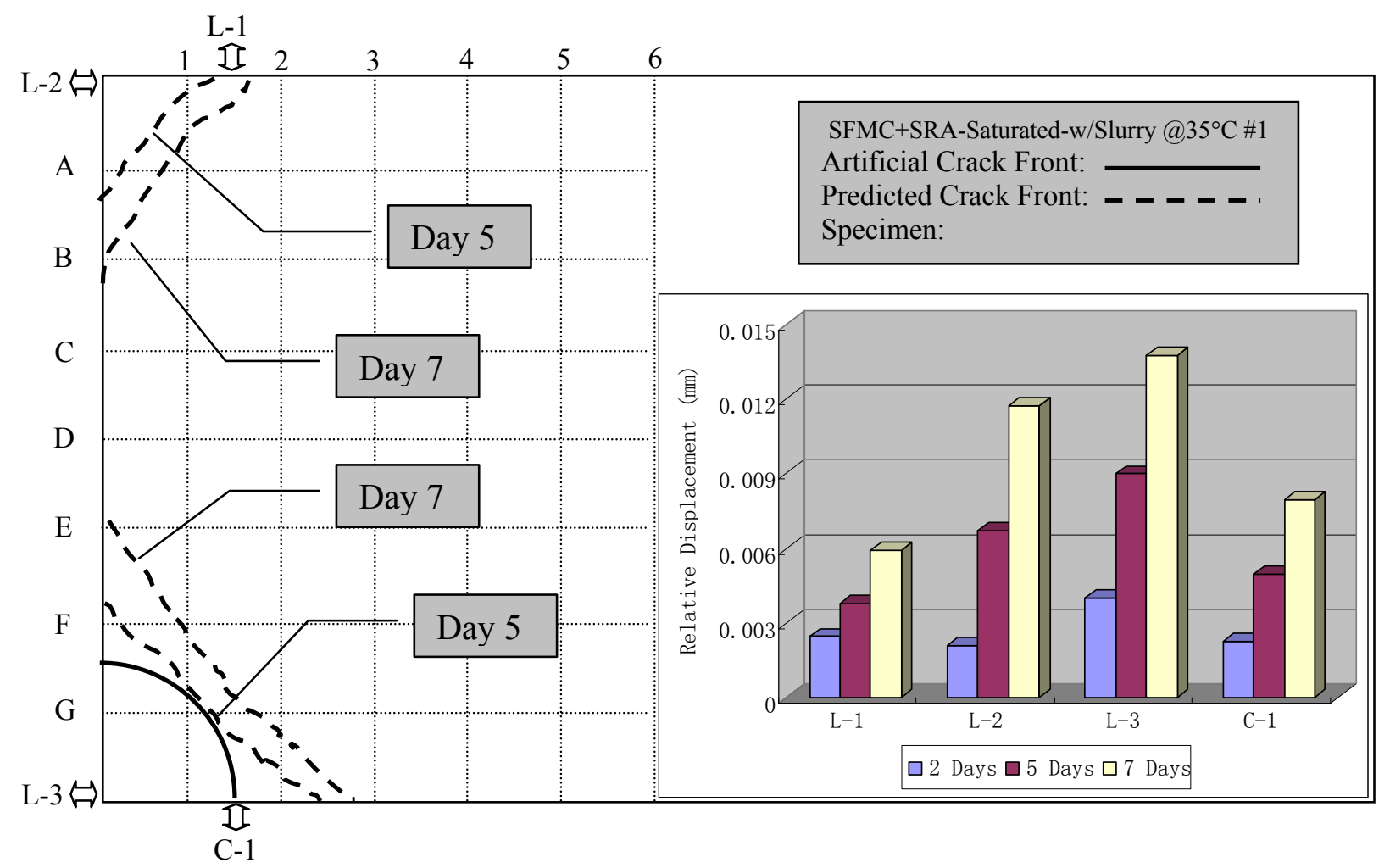

Fig. 5.19 Predicted crack font movement for SFMC+SRA-Saturated-w/Slurry @ $35^{\circ} \mathrm{C} \# 1$ 


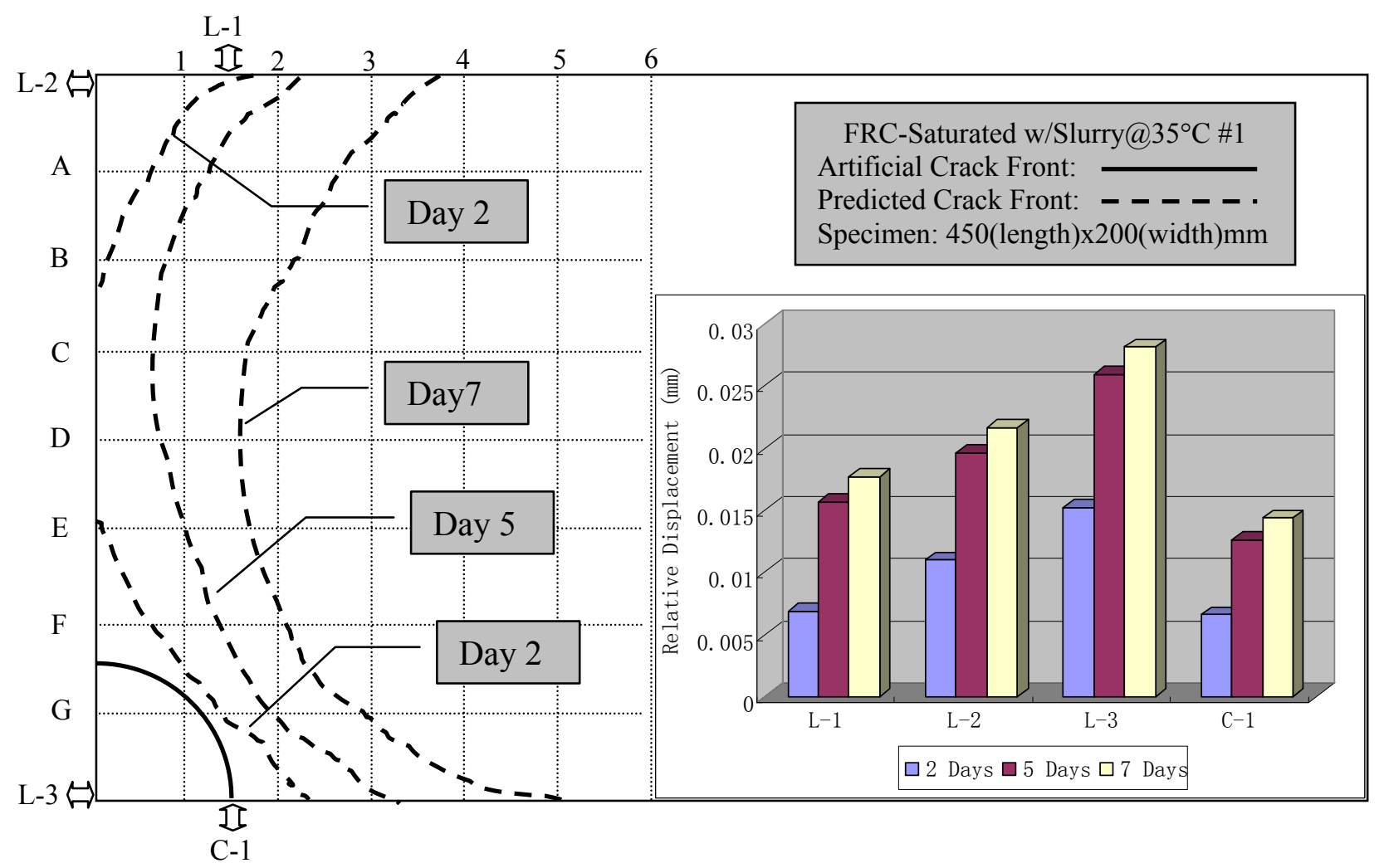

Fig. 5.20 Predicted crack front movement for FRC-Saturated-w/Slurry @ $35^{\circ} \mathrm{C} \# 1$

\subsubsection{Signal processing}

\subsubsection{Spectral Analysis (Matlab Help Documentation)}

The goal of spectral estimation is to describe the distribution (over frequency) of the power contained in a signal, based on a finite set of data. Estimation of power spectra is useful in a variety of applications, including the detection of signals buried in wideband noise.

The power spectral density (PSD) of a stationary random process $x_{n}$ is mathematically related to the correlation sequence by the discrete-time Fourier transform. In terms of normalized frequency, this is given by 


$$
P_{x x}(\omega)=\frac{1}{2 \pi} \sum_{m=-\infty}^{\infty} R_{x x}(m) e^{-j \omega m}
$$

This can be written as a function of physical frequency $\mathbf{f}$ (e.g., in Hertz) by using the relation $\Theta=2 \pi \mathbf{f} / \mathbf{f}_{s}$, where $\mathbf{f}_{\mathbf{s}}$ is the sampling frequency.

$$
\boldsymbol{P}_{x x}(f)=\frac{1}{f_{s}} \sum_{m=-\infty}^{\infty} R_{x x}(m) e^{-2 \pi j f m / f_{s}}
$$

The correlation sequence can be derived from the PSD by use of the inverse discrete-time Fourier transform:

$$
\boldsymbol{R}_{x x}(m)=\int_{-\pi}^{\pi}\left(P_{x x}(\omega) e^{j \omega m}\right) d \omega=\int_{-f_{z} / 2}^{f_{s} / 2}\left(P_{x x}(f) e^{2 \pi j f m / f_{s}}\right) d_{\boldsymbol{f}}
$$

The average power of the sequence $x_{n}$ over the entire Nyquist interval is represented by

$$
\boldsymbol{R}_{x x}(0)=\int_{-\pi}^{\pi} P_{x x}(\omega) d \omega=\int_{-f_{s} / 2}^{f_{s} / 2} P_{x x}(f) d f
$$

The average power of a signal over a particular frequency band, $\left[\omega_{1}, \omega_{2}\right]$, can be found by integrating the PSD over that band:

$$
\bar{P}_{\left[\omega_{1}, \omega_{2}\right]}=\int_{\omega_{1}}^{\omega_{2}} P_{x x}(\omega) d \omega+\int_{-\omega_{2}}^{-\omega_{1}} P_{x x}(\omega) d \omega
$$


It can be seen from the above expression that $\mathbf{P}_{\mathbf{x x}}(\omega)$ represents the power content of a signal in an infinitesimal frequency band, which is why it is called the power spectral density.

The units of the PSD are power (e.g., Watts) per unit of frequency. In the case of $\mathbf{P}_{\mathbf{x x}}(\boldsymbol{\omega})$, this is Watts/radian/sample or simply Watts/radian. In the case of $\mathbf{P}_{\mathbf{x x}}(\mathbf{f})$, the units are Watts/Hertz. Integration of the PSD with respect to frequency yields units of watts, as expected for the average power $\bar{P}_{\left[\omega_{1}, \omega_{2}\right]}$.

\subsubsection{Results and Discussion}

The virgin signal that was transmitted directly from the transmitting transducer to the receiving transducer was recorded and transformed into power distribution spectrum by Fast Fourier Transform (FFT). Fig. 5.21 shows the virgin signal in both time domain (waveform) and frequency domain (power spectral). As expected, the waveform had a very regular attenuation and fairly simple power distribution concentrating around 150 $\mathrm{kHz}$, which was the frequency of the transmitting transducer, since the signal had a relatively pure transmitting path (only a layer of gel between the two transducers). 


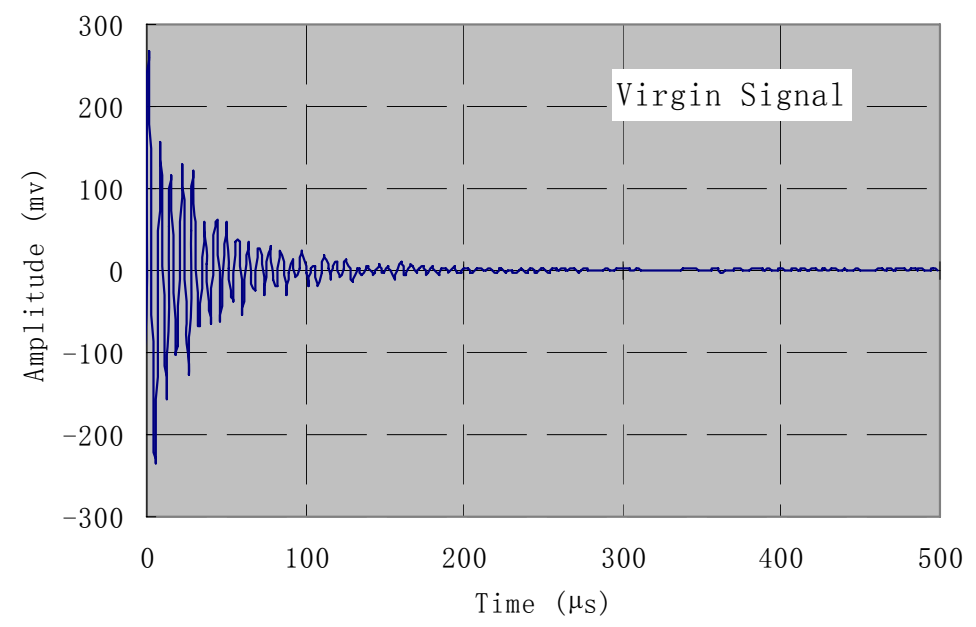

(a) Virgin waveform in time domain

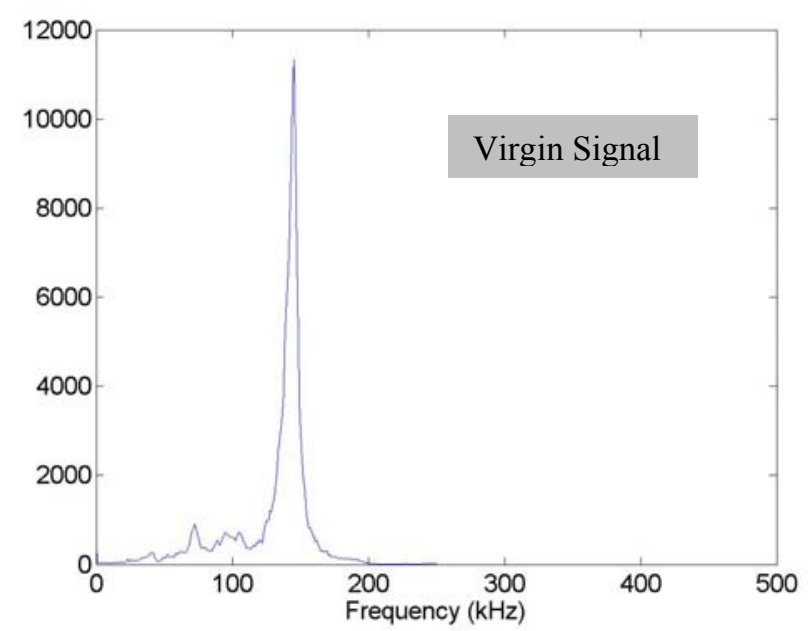

(b) Power distribution spectrum of virgin signal

Fig. 5.21 Virgin signal in time domain and frequency domain

The signals at the grid points $1-\mathrm{A}, 3-\mathrm{G}$ and 8-D (Fig. 5.22) across the specimens were recorded in time domain Table 5.4 lists the pulse transmitting time at points 1-A, 3G and 8-D in specimen SFMC-dry @23 \#1. As discussed in 5.2.1, points 1-A and 3-G were considered as delaminated points at day 2 and day 7;8-D was considered as intact point at both ages, which was taken as a reference. Fig. 5.23 shows the waveforms 
recorded for SFMC-dry @ $23^{\circ} \mathrm{C} \# 1$ at the ages of 2 days and 7 days. Fig. 5.24 shows the power distribution spectral of signals for SFMC-dry @ $23^{\circ} \mathbf{C} \# 1$ after being converted in frequency domain by FFT at the ages of 2 days and 7 days.

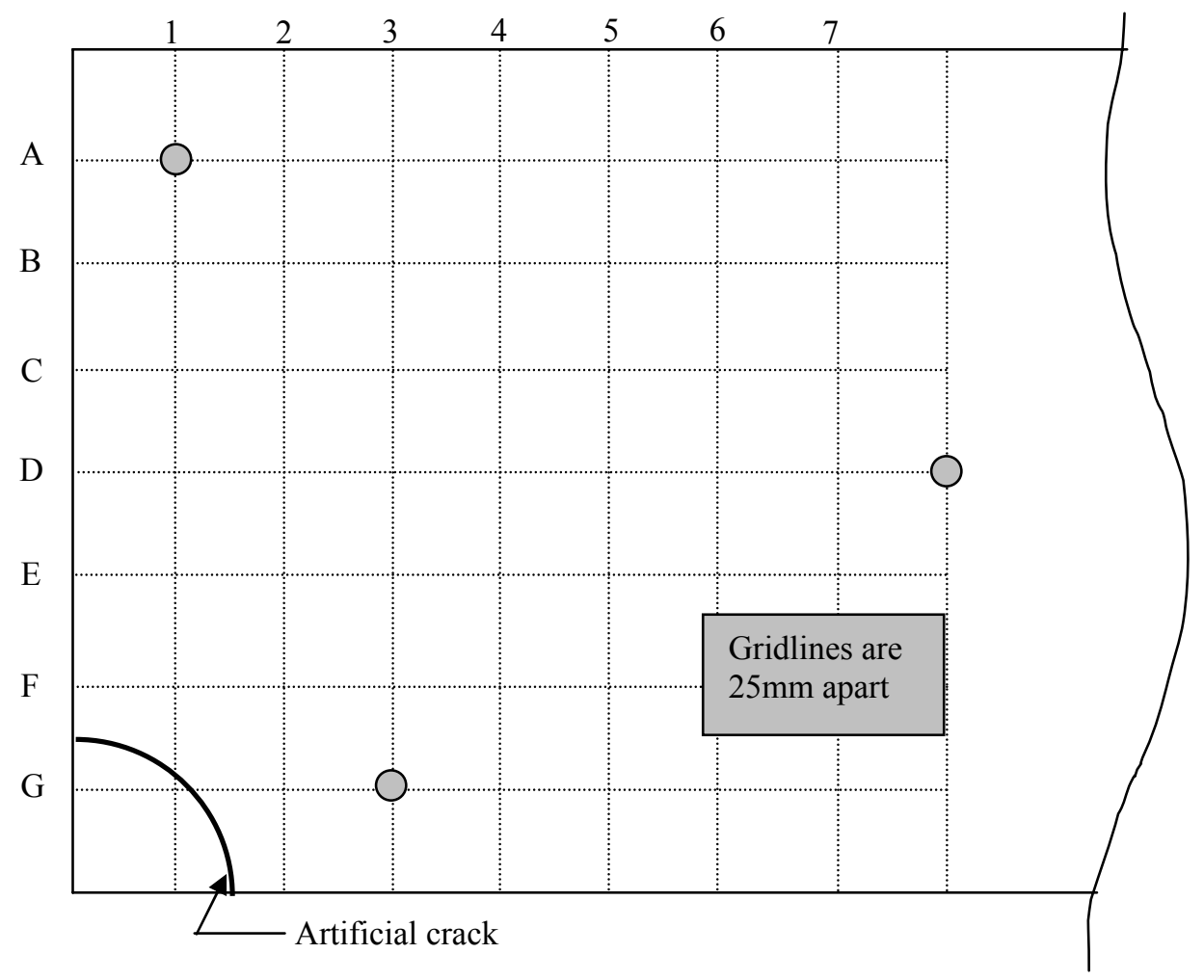

Fig. 5.22 Locations for signal recording and processing

Table 5.4 Pulse transmitting time at points 1-A and 8-D for SFMC-dry @ $23^{\circ} \mathrm{C} \# 1$

\begin{tabular}{|c|c|c|c|c|}
\hline \multirow{2}{*}{ Grid } & \multicolumn{2}{|c|}{ Day 2} & \multicolumn{2}{c|}{ Day 7 } \\
\cline { 5 - 5 } point & Reference $(\mu \mathrm{s})$ & Reading $(\mu \mathrm{s})$ & Reference $(\mu \mathrm{s})$ & Reading $(\mu \mathrm{s})$ \\
\hline 1-A & & 38.3 & & 39.9 \\
\hline 3-G & \multirow{3}{*}{$37.3 \pm 0.5$} & 37.9 & \multirow{2}{*}{$35.6 \pm 0.5$} & 36.9 \\
\cline { 5 - 5 } & & & & 35.6 \\
\hline 8-D & & 37.4 & & \\
\cline { 5 - 5 } & & & & \\
\hline
\end{tabular}




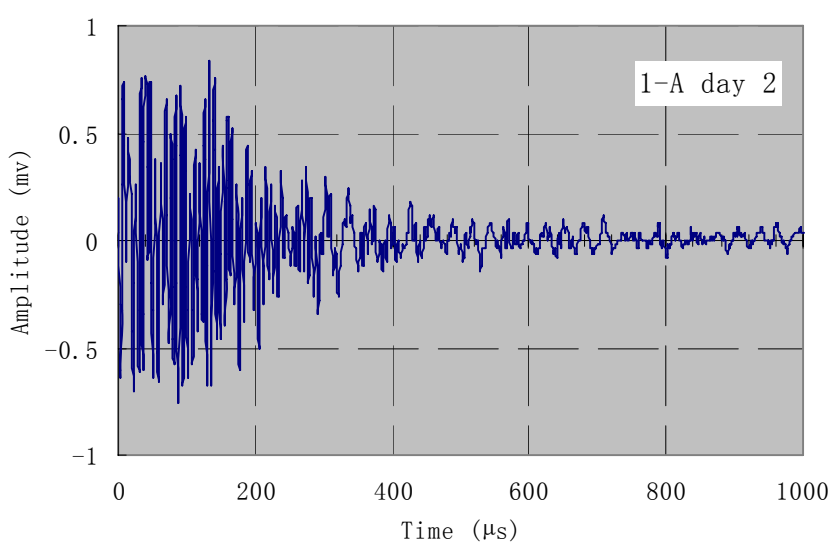

(a)

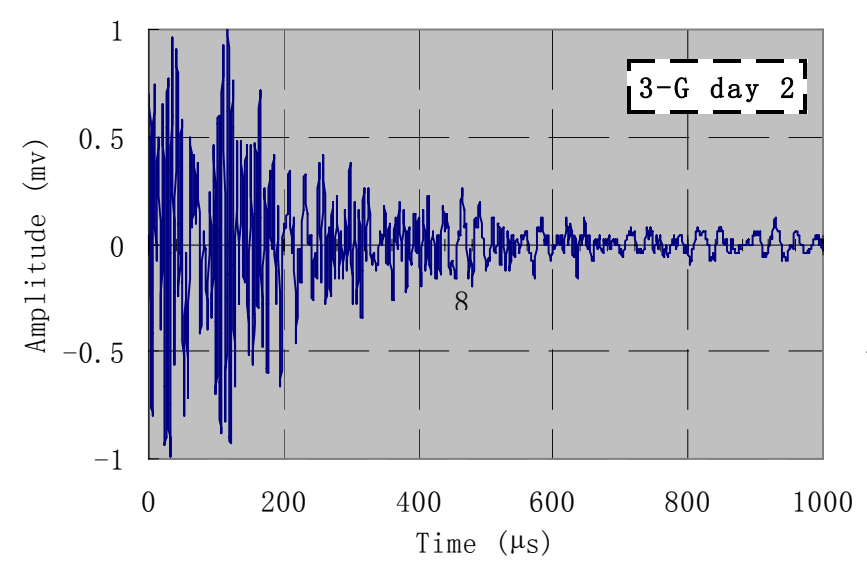

(c)

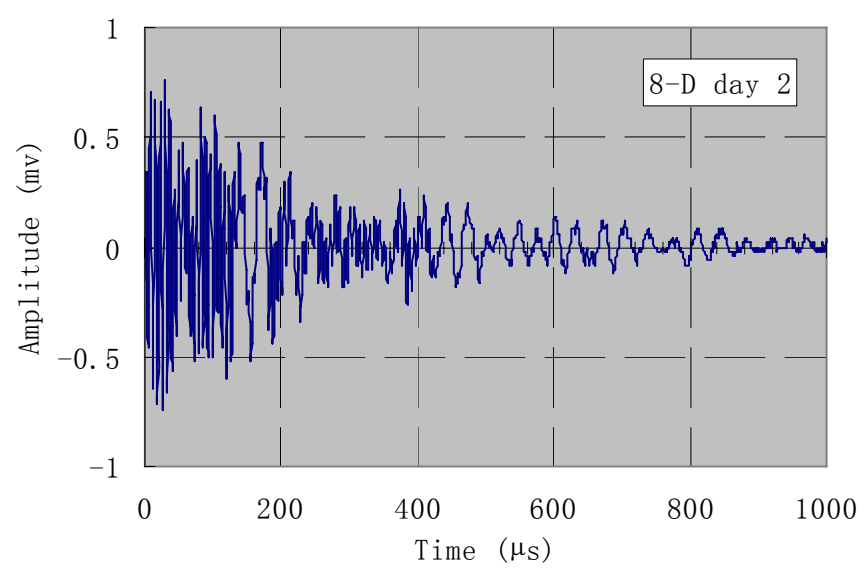

(e)

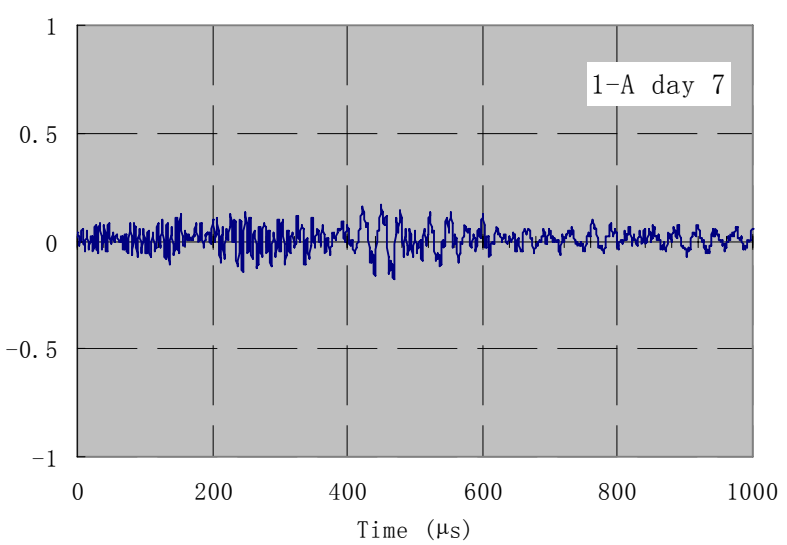

(b)

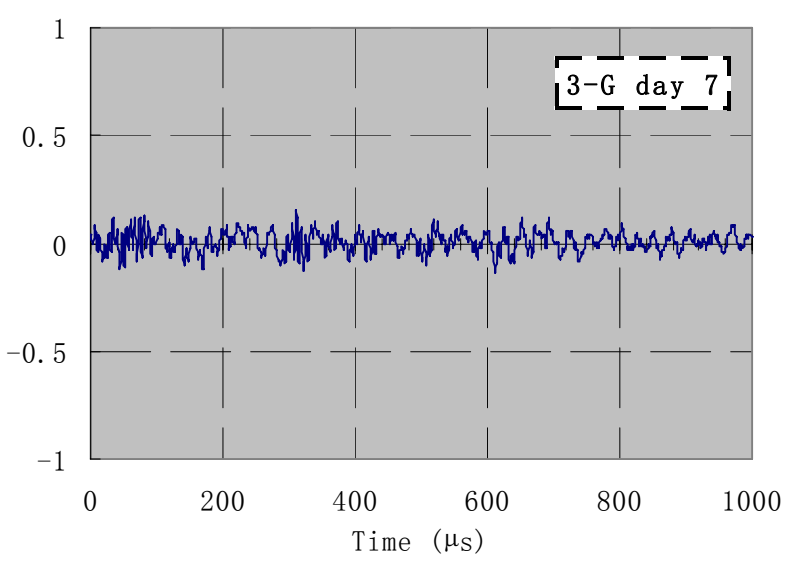

(d)

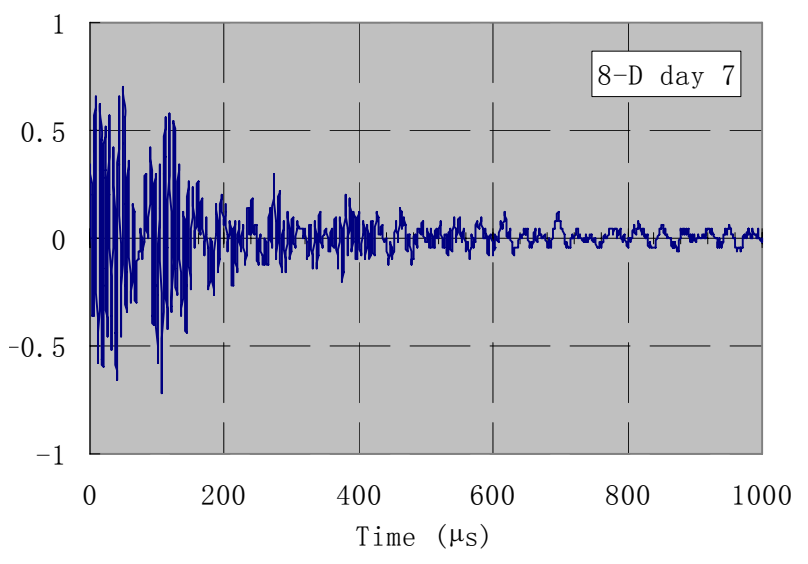

(f)

Fig. 5.23 Comparison of waveforms of SFMC-dry @ $23^{\circ} \mathbf{C} \# 1$ 


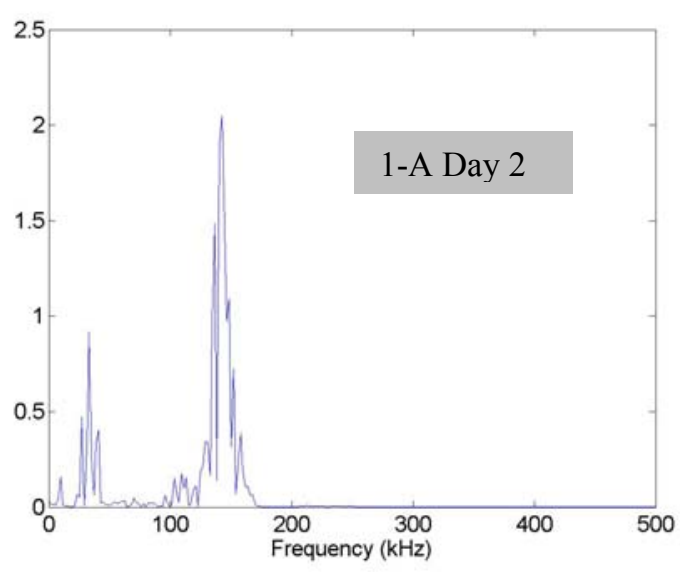

(a)

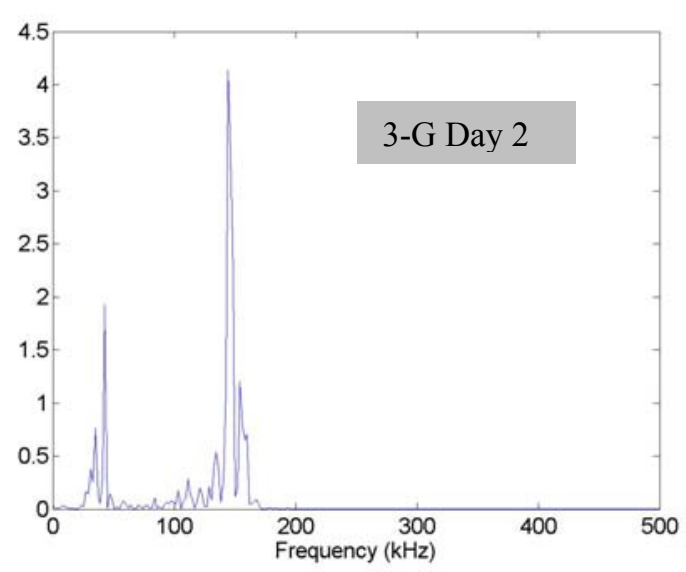

(c)

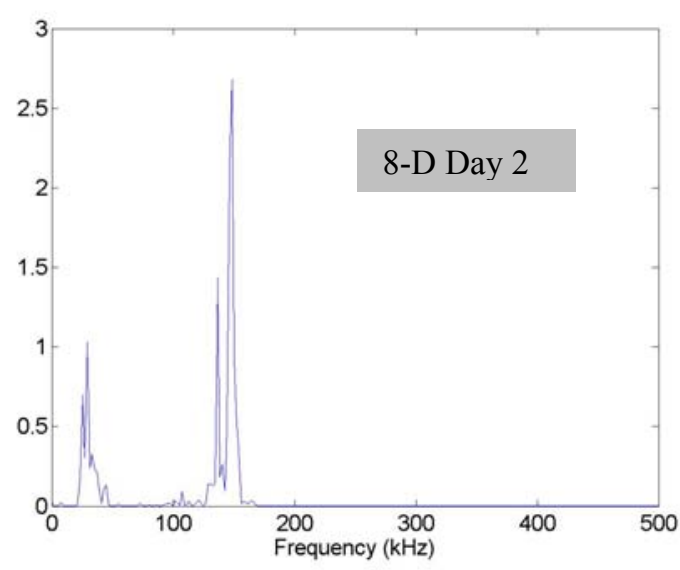

(e)

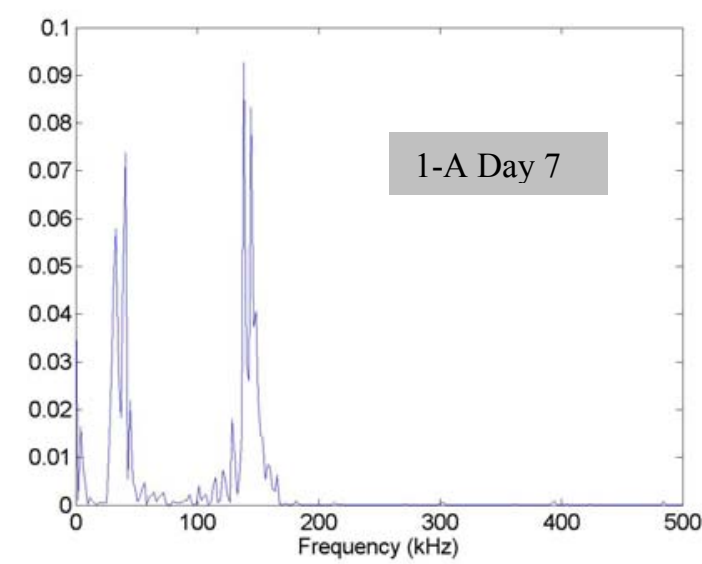

(b)

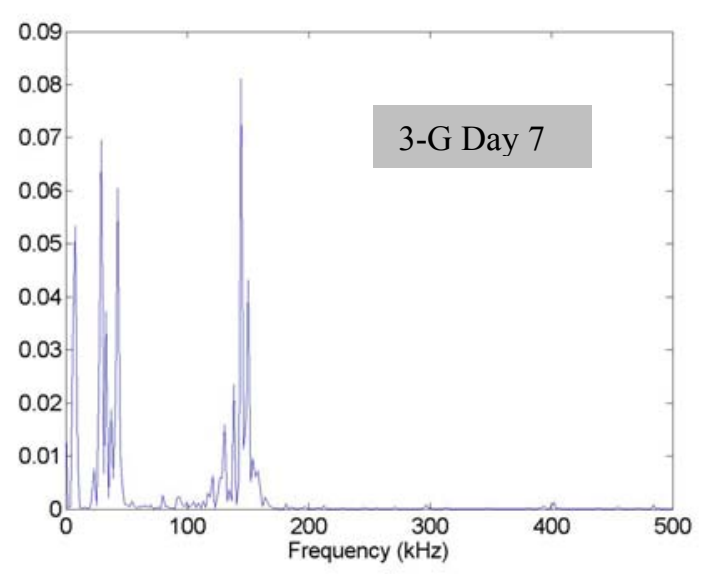

(d)

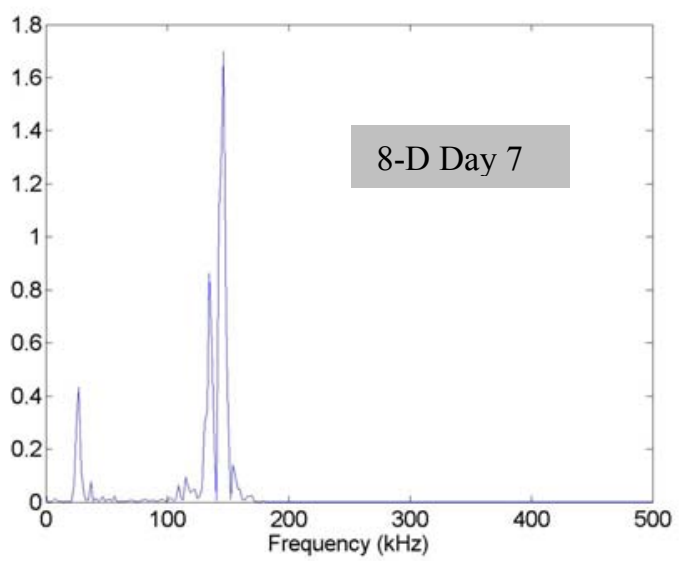

(f)

Fig. 5.24 Comparison of power distribution spectral of SFMC-dry $@ 23^{\circ} \mathrm{C} \# 1$ 
It is noticed that the amplitude of waveform at point 1-A has greatly decreased from $0.8 \mathrm{mv}$ (day 2, Fig 5.23 (a)) to $0.2 \mathrm{mv}$ (day 7, Fig 5.23 (b)) with the development of delamination at the interface. This is in agreement with the increase in relative displacement of LVDT L-2 (25 mm from point 1-A) from $0.034 \mathrm{~mm}$ to $0.129 \mathrm{~mm}$. For point 3-G, the waveform amplitude had undergone similar changes (Fig. 5.23 (c) and (d)). The decrease in waveform amplitude should be attributed to the deflection and diffraction of the ultrasonic pulse at the delaminated interface. The greater the delamination was, the larger the deflection and diffraction of ultrasonic pulse were at the interface. Thus the signal received by the receiving transducer became weaker.

By comparing the pulse transmitting times at different ages at point 1-A and point 3-G (Table 5.4), it is found that the pulse transmitting time was a very good index for evaluating the delamination. The larger the discrepancy between the reading and the reference, the more severe was the delamination. This was consistent with the changes in both waveform and the relative displacement at the interface. When no delamination occurred, the waveform simply remained unchanged as in the case of point 8-D (Fig. 5.23 (e) and (f)).

By comparing Fig. 5.21 with Fig 5.23 and Fig. 5.24, it is evident that the signal strength in the bi-layer overlay substrate specimen has greatly decreased, from about 250 $\mathrm{mV}$ to about $1 \mathrm{mV}$. Also transmitting through the specimen induced more frequency components within $150 \mathrm{kHz}$ in the power distribution spectral (PDS). This was found to be consistent for every specimen. The heterogeneity of the concrete could be the cause of development of more frequency components in the PDS. 
From Fig. 5.24 it is noticed that at the age of 2 days, the power spectral at each point had very similar form with varying amplitude. The differences in amplitude are well in agreement with the waveform amplitude in time domain However, at the age of 7 days, the spectral at point 1-A and 3-G had additional frequency components less than $150 \mathrm{kHz}$ compared to the age of 2 days. Also it is noticed that more power (energy of ultrasonic pulse) was redistributed to the lower frequency range. As for the intact point 8D, no additional frequency components were observed and the PDS curves almost had no change except for the amplitude. All of these indicated that delamination at the interface had greatly complicated the signals. After delamination, the received signal had more frequency components under $150 \mathrm{kHz}$, which was the frequency of the ultrasonic pulse transmitting transducer used in this study. It is believed that the deflection and diffraction of signal at the delaminated interface were the cause. After delamination occurred at the interface, a complex irregular contact surface was induced between the overlay and substrate. When ultrasonic pulse traveled through the specimen, part of the signal was reflected at this irregular contact surface and part of the signal was diffracted by the complicated irregular contact surface after transmitting through it.

The waveforms of point 1-A for SFMC with different surface conditions are presented in Fig. 5.25. The results showed a close consistency with the discussion above. The usual attenuation of amplitude due to delamination is missing for (e) and (f). This could be because saturated substrate surface and bonding slurry minimized the separation or debonding between overlay and substrate, which helped the transmission of ultrasonic pulse. 
Figs. 5.26 and 5.27 show the waveforms of point 1-A for the other testing cases. The decreases in the waveform amplitudes are in good agreement with the predicted delamination profile at the interface. The delamination at the interface reduced the amplitude of the received signal. 


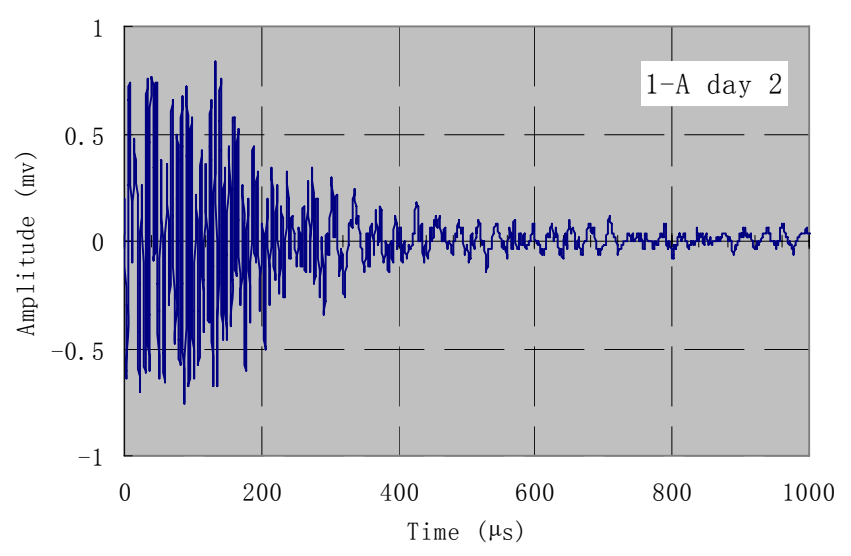

(a)

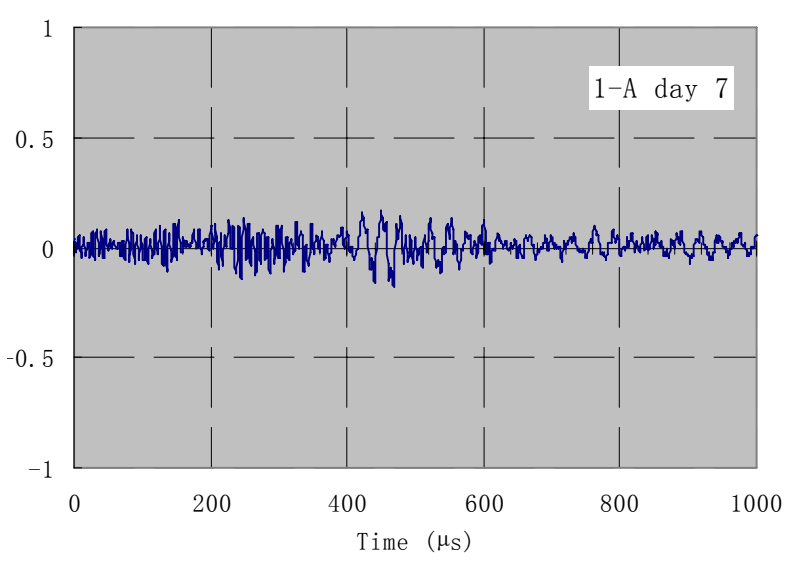

(b)

SFMC-dry @ $23^{\circ} \mathbf{C} \# 1$

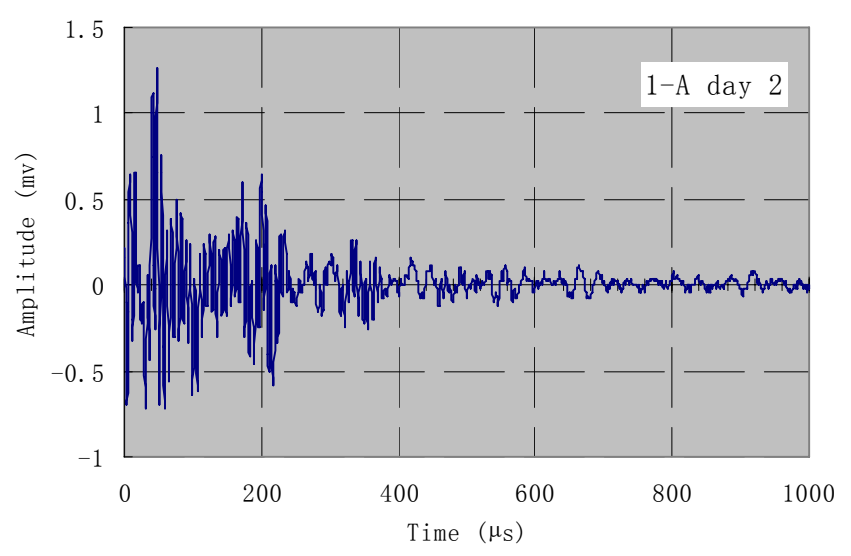

(c)

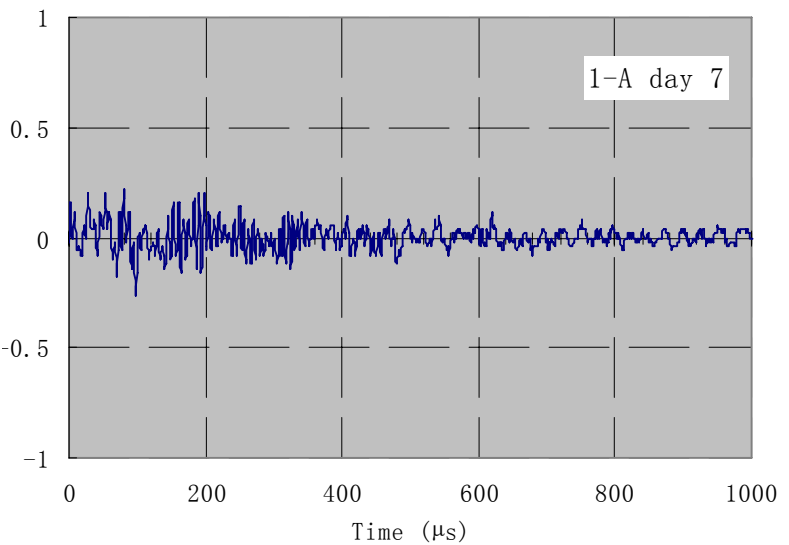

(d)

SFMC-saturated @ $23^{\circ} \mathbf{C} \# 1$

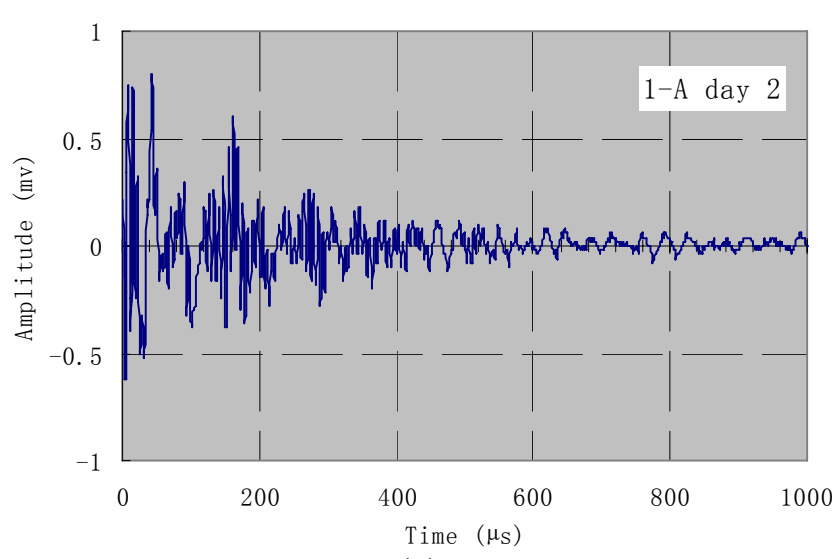

(e)

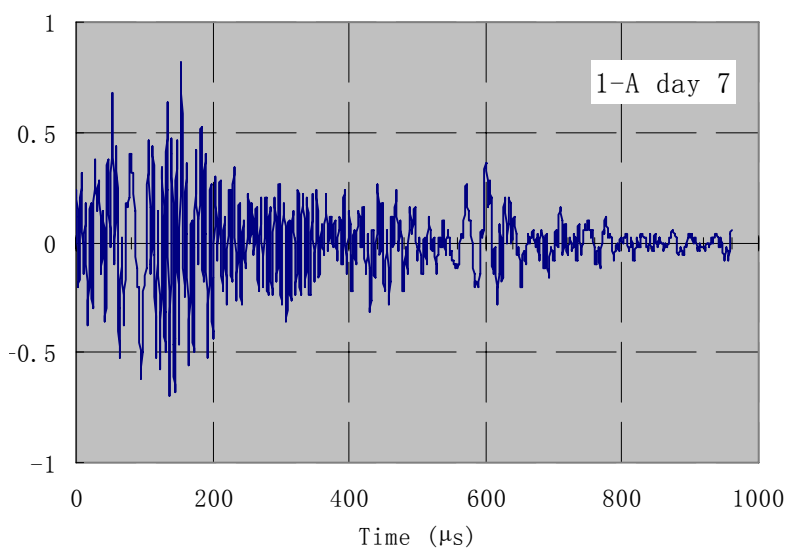

(f)

SFMC-saturated-w/ slurry $23^{\circ} \mathbf{C} \# 1$

Fig. 5.25 Waveforms of point 1-A in each overlay 


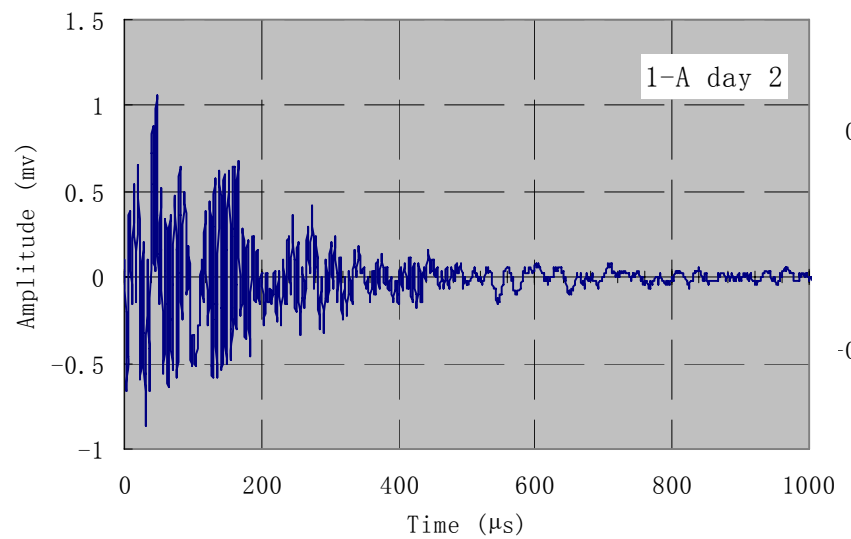

(a)

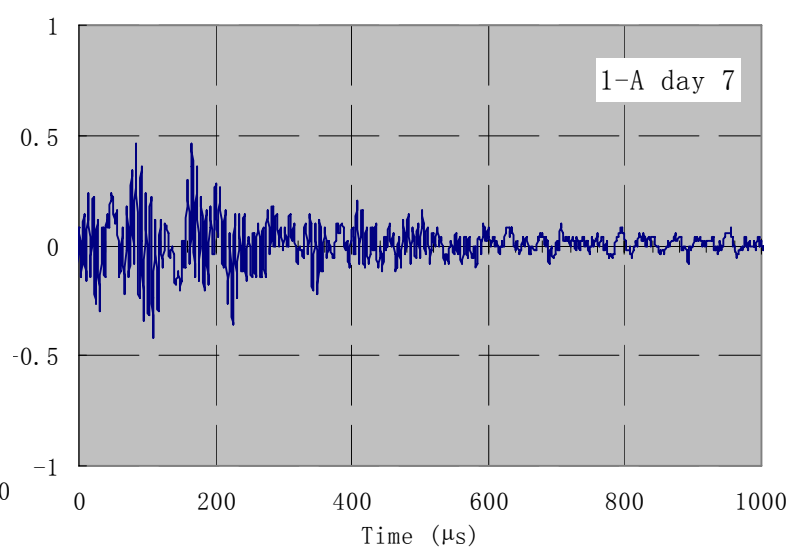

(b)

SFMC-saturated-w/ slurry $35^{\circ} \mathbf{C} \# 1$

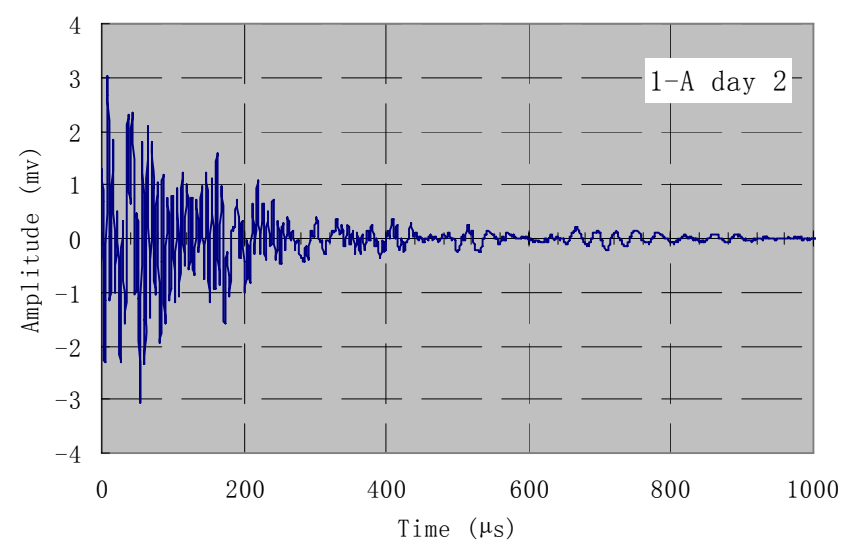

(c)

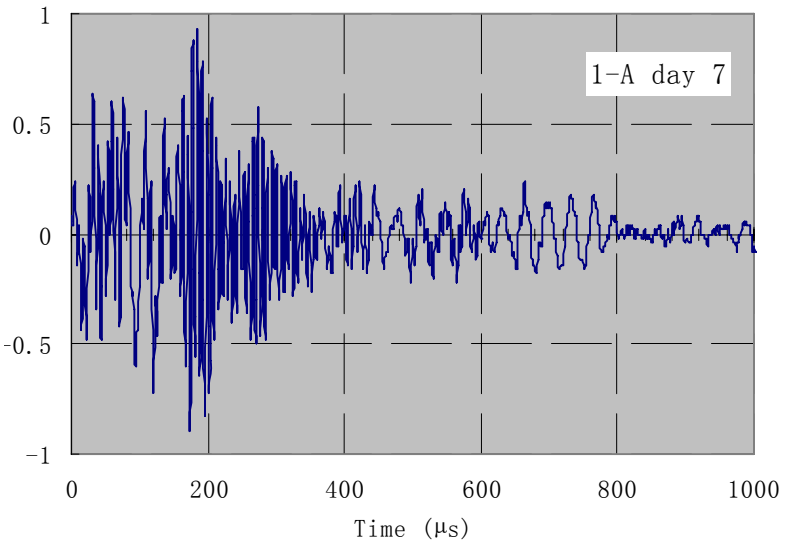

(d)

LMC-saturated-w/ slurry $35^{\circ} \mathrm{C} \# 1$

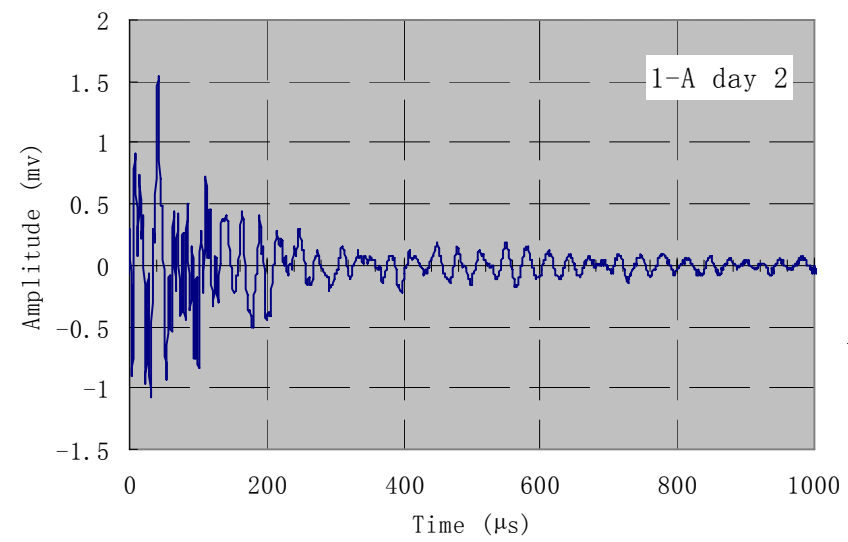

(e)

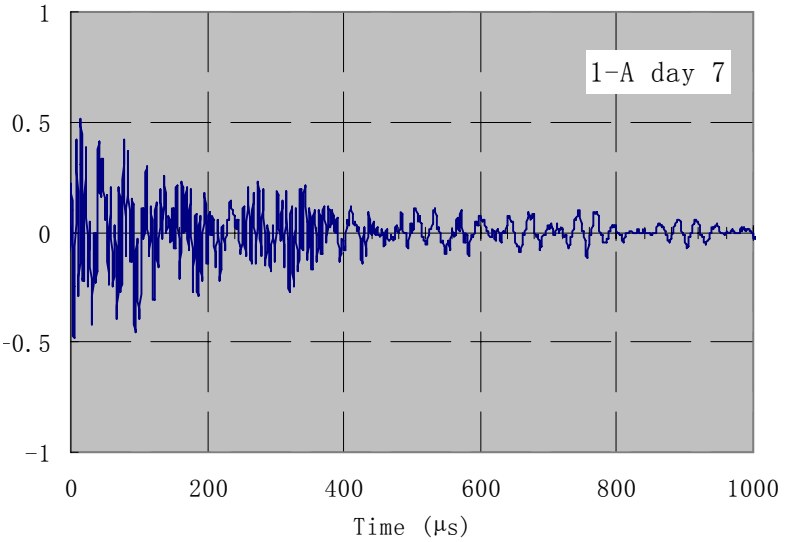

(f)

SFMC+SRA-saturated-w/ slurry @ 35² \#1

Fig. 5.26 Waveforms of point 1-A in each overlay 

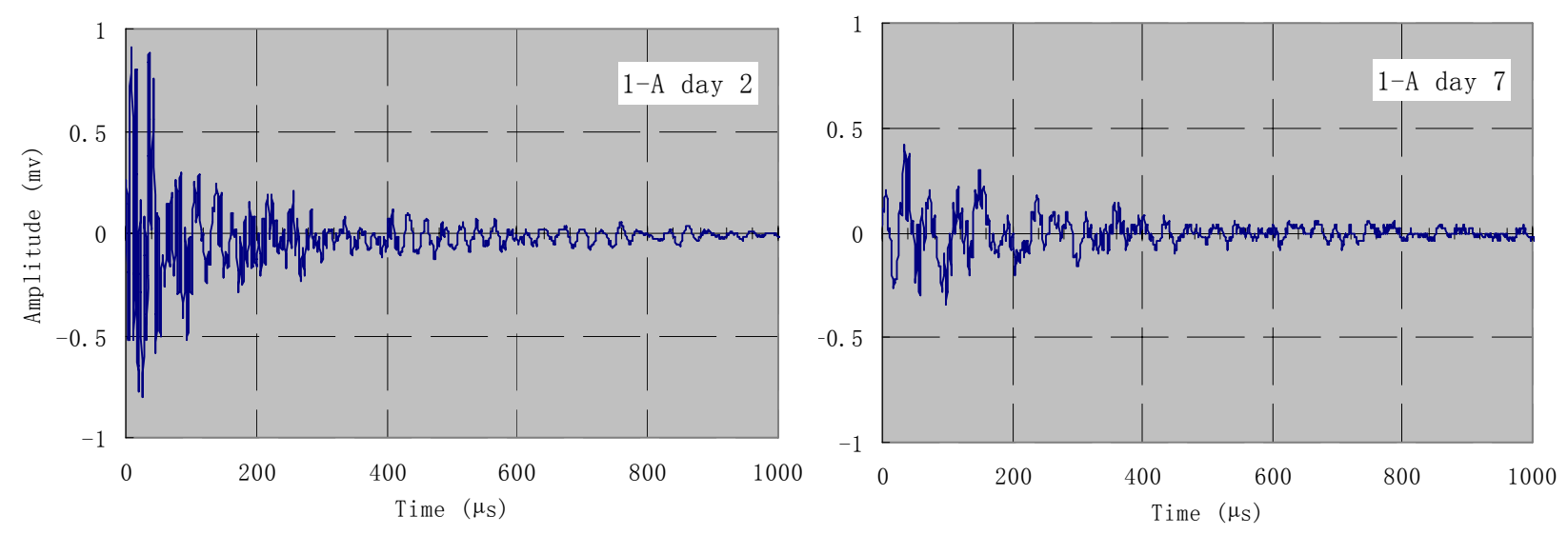

FRC-saturated-w/ slurry @ $35^{\circ} \mathbf{C ~ \# 1}$

Fig. 5.27 Waveforms of point 1-A in each overlay

\subsection{Overlay Temperature Measurement}

A typical temperature evolution in overlay concrete is shown in Fig. 5.28. In this case the overlay concrete was FRC. The ambient temperature was around $33.4^{\circ} \mathrm{C}\left(92^{\circ} \mathrm{F}\right)$, which was recorded(b)y the temperature data logger although the rofom temperature was set to $35^{\circ} \mathrm{C}\left(95^{\circ} \mathrm{F}\right)$. That discrepancy was due to the location of the ambient sensor whining the chamber is at the top, while the storage of the specimen was on the floor, where the temperature was relatively lower. The overlay concrete was cast at room temperature of $19^{\circ} \mathrm{C}\left(66^{\circ} \mathrm{F}\right)$. The specimen was then moved into the environmental chamber where the ambient temperature was set to $35^{\circ} \mathrm{C}\left(95^{\circ} \mathrm{F}\right)$. This contributed to the initial temperature difference between the overlay and ambient condition. In the next eight hours, due to the emitted heat by the cement hydration, the temperature in the overlay kept on rising and reached a peak temperature. Once the cement hydration process slowed down the temperature in the overlay kept falling down and descended to the ambient temperature within 24 hours. At about 22 hours, the cover plastic sheet was 
removed, which is reflected in the graph by the sudden drop of temperature recorded at 6 $\mathrm{mm}(0.25 \mathrm{in})$ depth. The sudden surface moisture loss by evaporation caused a rapid temperature drop within overlay. In Fig. 5.28, only the temperatures at depths of $6 \mathrm{~mm}$ (0.25 in), $25 \mathrm{~mm}(1 \mathrm{in})$ and $44 \mathrm{~mm}(1.75 \mathrm{in})$ are listed. Similar to the temperature evolution at the depth of $25 \mathrm{~mm}(1 \mathrm{in})$, the rest of the temperatures showed same behavior in between $25 \mathrm{~mm}(1 \mathrm{in})$ and $44 \mathrm{~mm}$ (1.75 in), but for clarity they are not drawn in the Fig. 5.28.

Fig. 5.29 shows the temperature gradient in the FRC overlay at different ages. The shifting of temperature gradient curve on the temperature axis reflects the progress of heat emission in the overlay concrete due to cement hydration and heat exchange between the specimen and ambient air. This is consistent with the expected temperature evolution within the overlay. After 18 to 24 hours the temperature gradient curve becomes nearly straight, around $34^{\circ} \mathrm{C}\left(92^{\circ} \mathrm{F}\right)$, which means that the temperature across the depth of the overlay became nearly uniform and had approached the ambient temperature.

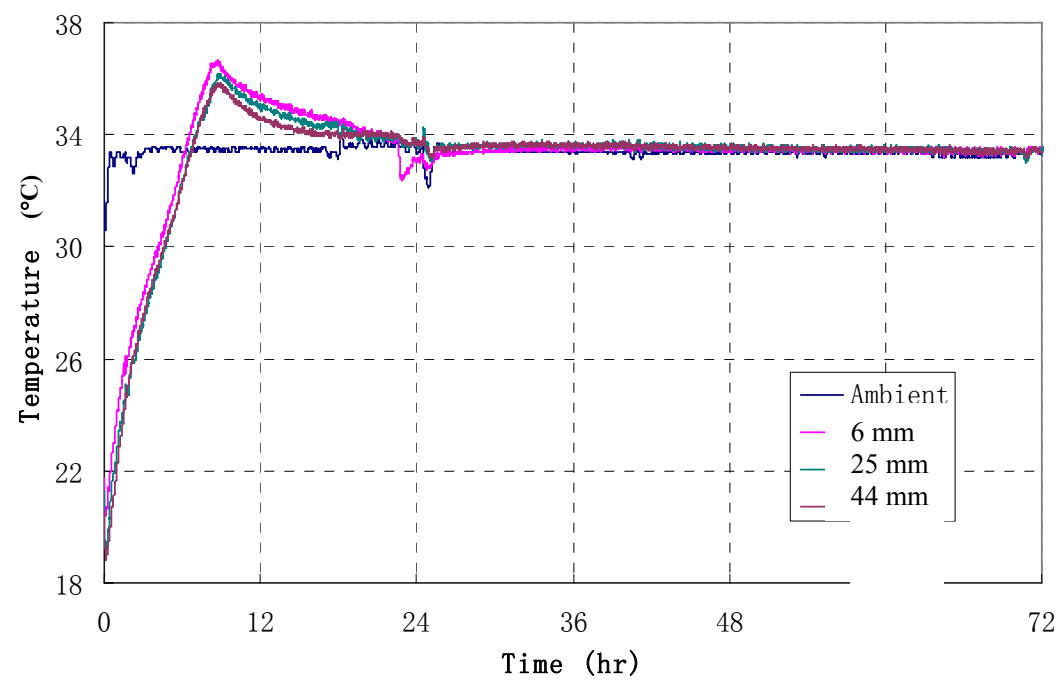

Fig. 5.28 Temperature Evolution in FRC Overlay 


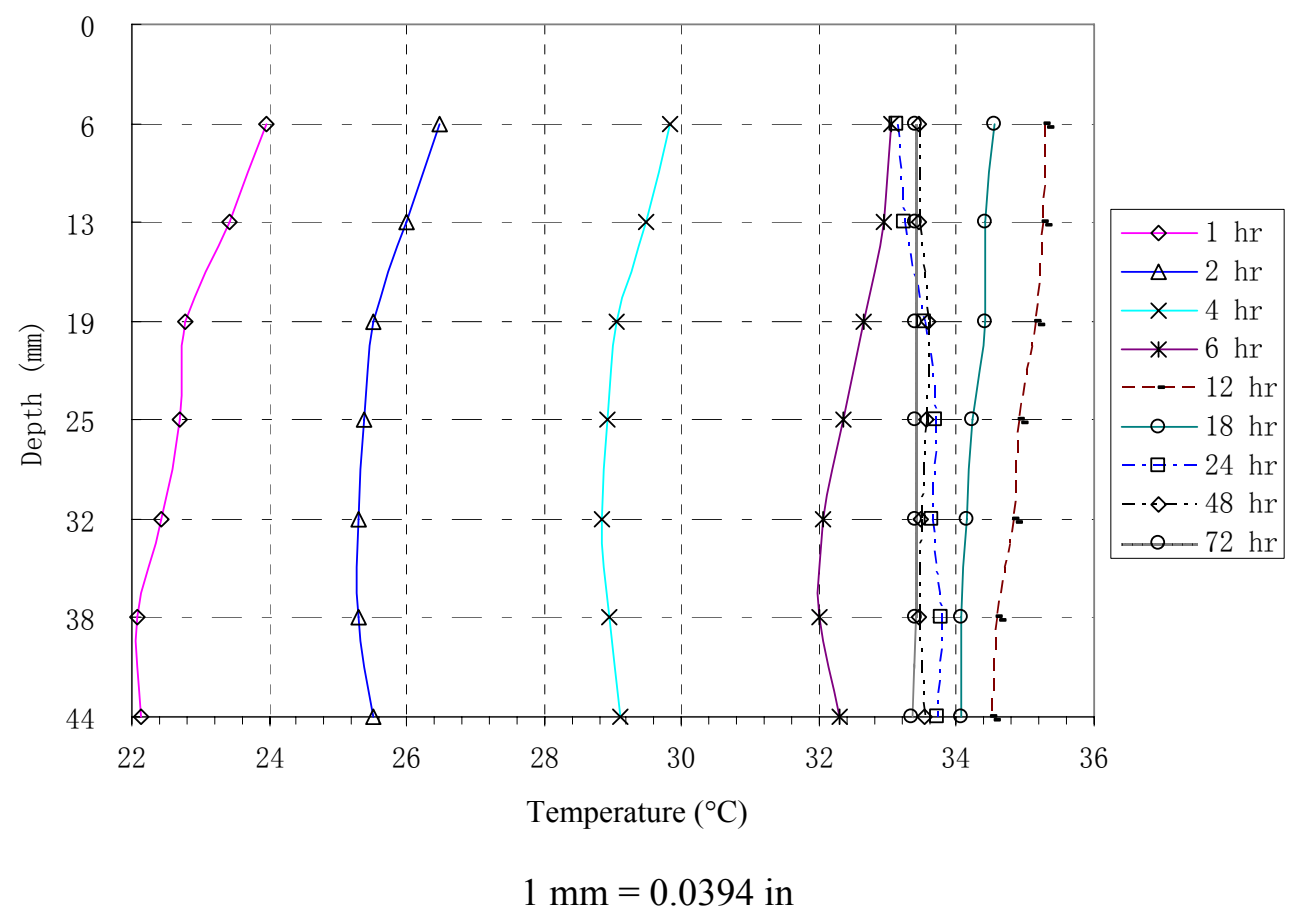

Fig. 5.29 Temperature Gradient in FRC Overlay

Figs. 5.30-5.35 show the temperature evolution and temperature gradient of SFMC, LMC and MMC+SRA overlays. They all follow the similar trend as discussed for FRC. There were some disturbances during the testing of LMC and SFMC+SRA overlays. The door of the environmental chamber was left open for a few hours, which caused "V" shape drops in the curves at the points shown clearly in the graphs. 


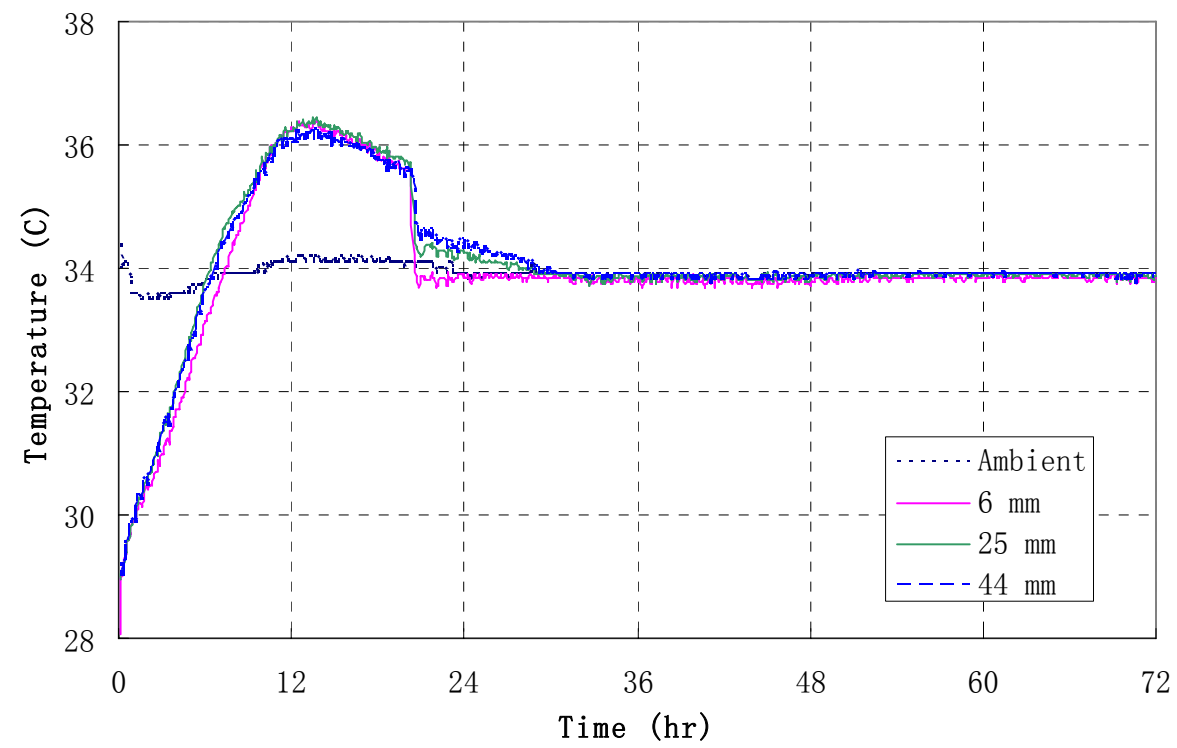

$1 \mathrm{~mm}=0.0394 \mathrm{in}$

Fig. 5.30 Temperature evolution in SFMC overlay over time

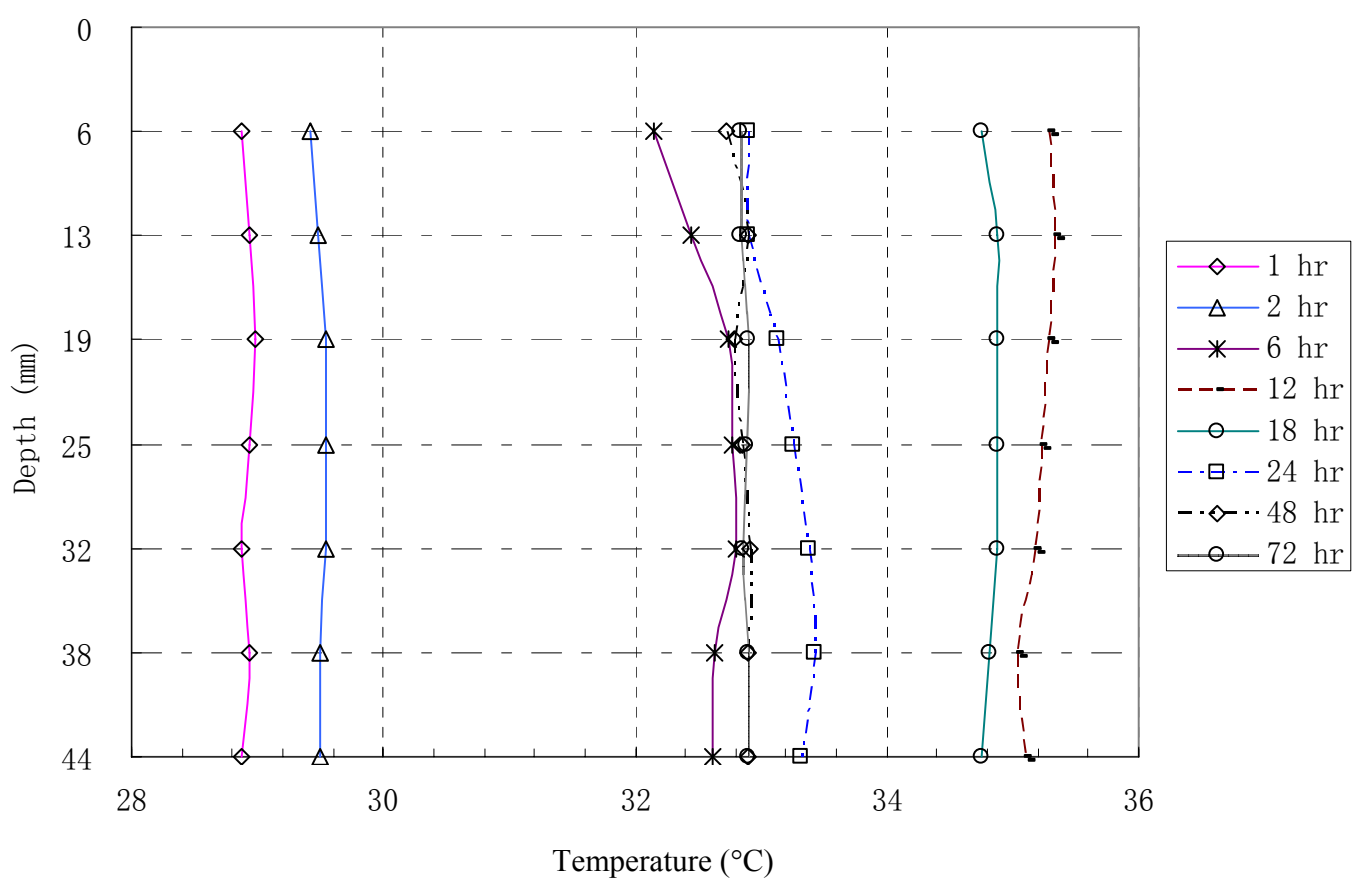

$1 \mathrm{~mm}=0.0394$ in

Fig. 5.31 Temperature gradient in SFMC overlay 


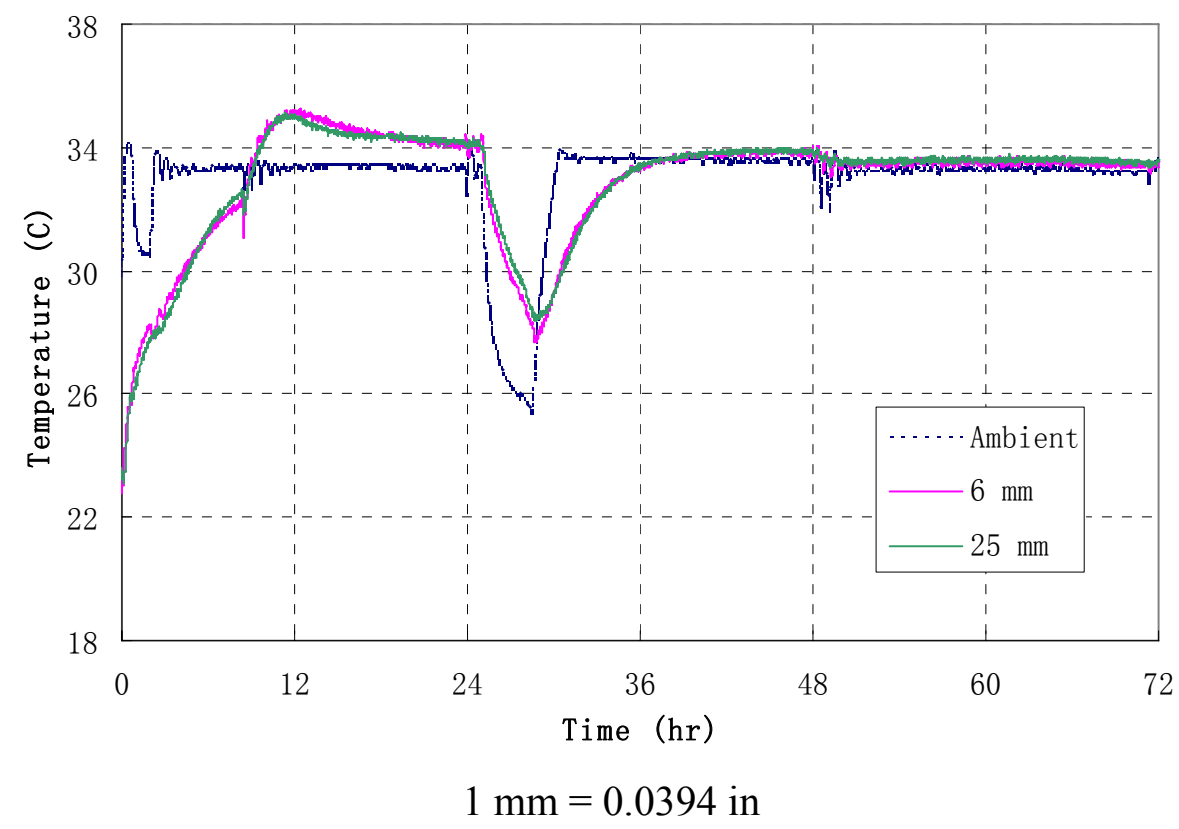

Fig. 5.32 Temperature evolution in LMC overlay over time

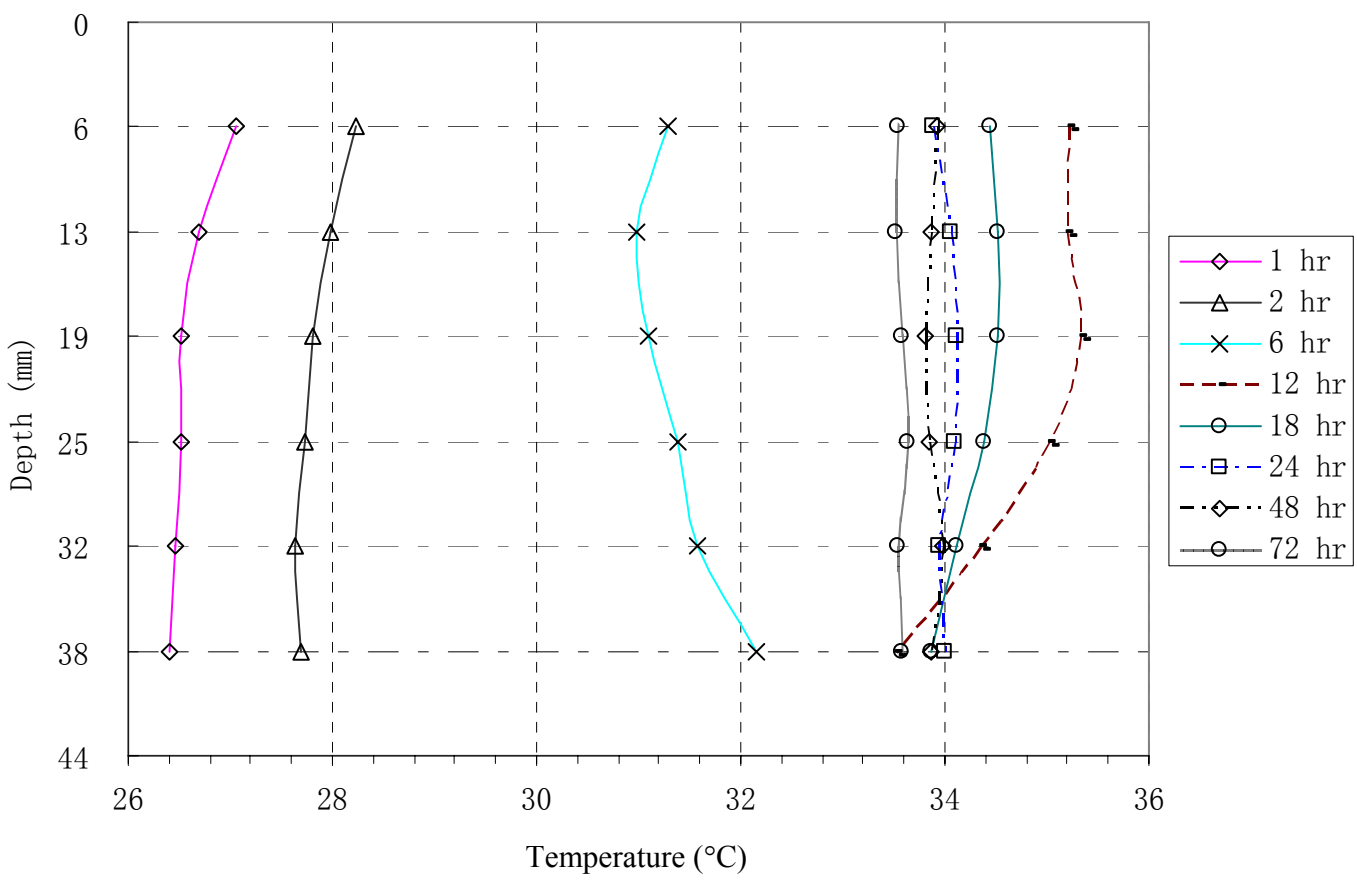

$1 \mathrm{~mm}=0.0394$ in

Fig. 5.33 Temperature gradient in LMC overlay*

* Thermalcouple at $44 \mathrm{~mm}$ (1.75 in) was out of order 


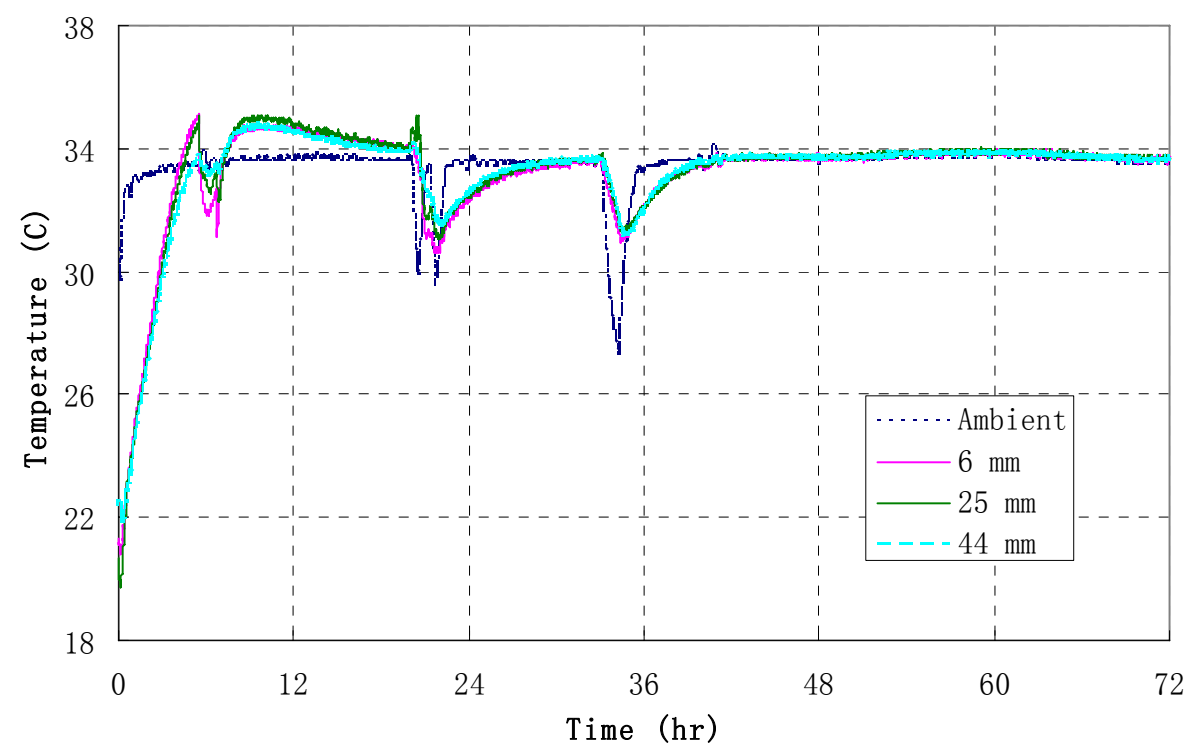

$$
1 \mathrm{~mm}=0.0394 \mathrm{in}
$$

Fig. 5.34 Temperature evolution in SFMC+SRA overlay over time

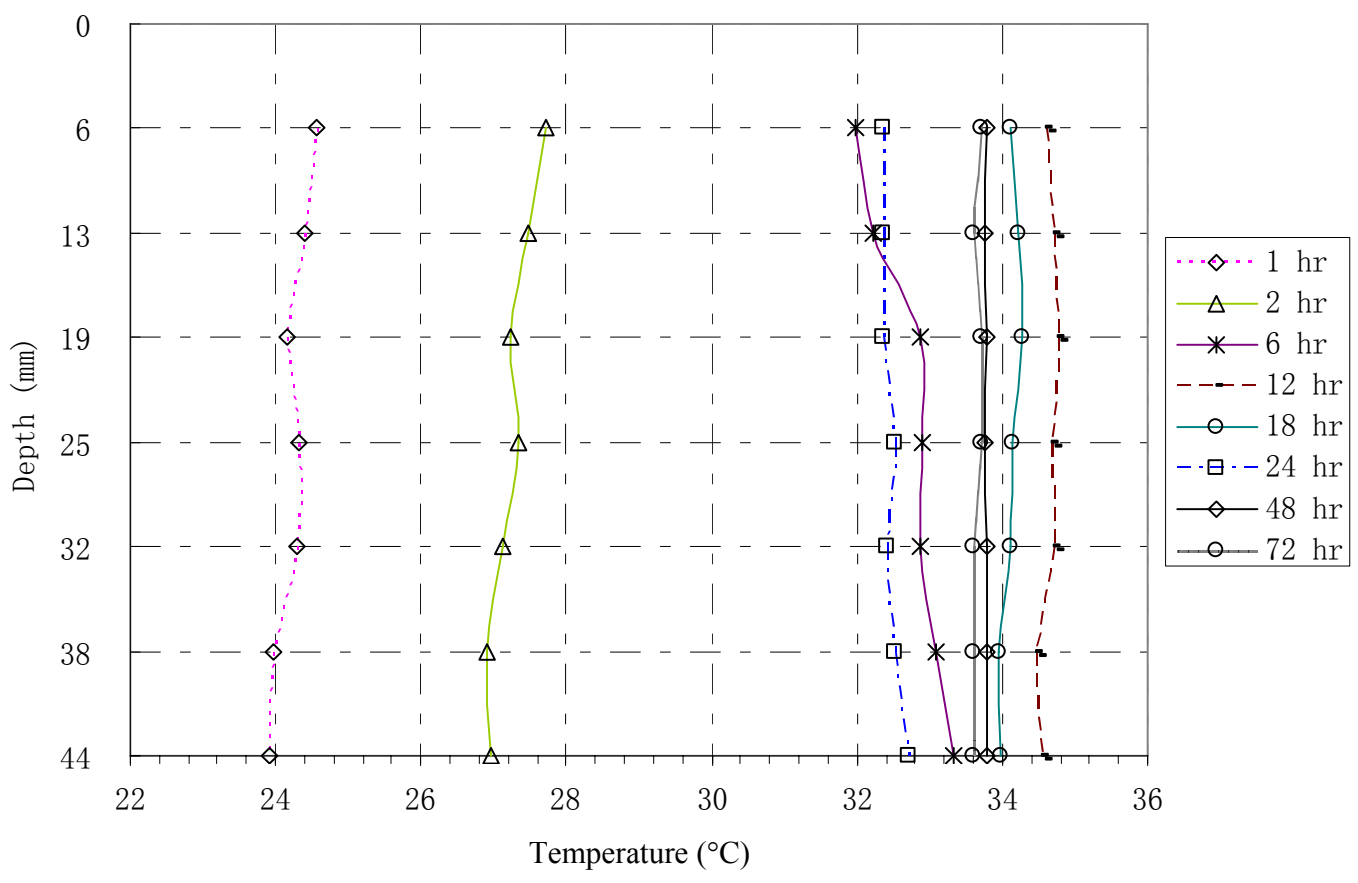

$$
1 \mathrm{~mm}=0.0394 \text { in }
$$

Fig. 5.35 Temperature gradient in SFMC+SRA overlay 
Table 5.5 summarizes the peak temperature, approximate time to reach the peak temperature, maximum temperature difference, and approximate time to approach the maximum temperature difference in each overlay mix. It is noticed that peak temperature and maximum temperature difference did not occur at the same time. All the temperature differences reached the maximum value before 24 hours and they were all less than $2.1^{\circ} \mathrm{C}$ $\left(3.8^{\circ} \mathrm{F}\right)$. It is noticed that $\mathrm{FRC}$ reached maximum temperature difference at 0.4 hours after casting overlay, which was much quicker that the rest of the overlays. This was due to the high conductivity of steel fiber. With the help of favorable heat conductivity of steel fibers and the heat transferred from ambient air, the outer layer of concrete in FRC overlay was subject to a rapid increase in temperature than the inner layers, which led to the maximum temperature difference. After 24 hours, all the temperature gradient curves became fairly straight, which meant the temperature gradient in the overlay concrete across the depth became almost uniform. Normally the curling and debonding of overlay started one day (24 hours) after concrete mixing. So the temperature gradient did not had no or little effect on the curling and debonding behavior of overlay in this study, since most curling and debonding occurred 24 hours after casting the overlay concrete. However, during the summer time the temperature gradient in a bridge deck would be much higher because the top surface would be exposed to direct heat from sunlight and the bottom surface would be much cooler. In that case the temperature gradient would be an important role in the curling behavior of concrete overlay. 
Table 5.5 Summary of Temperatures $\left({ }^{\circ} \mathrm{C}\right)$ in the Overlay Concrete

\begin{tabular}{|c|c|c|c|c|}
\hline & SFMC & LMC & SFMC+SRA & FRC \\
\hline Peak Temperature & $\begin{array}{c}36.5 \\
\left(97.7^{\circ} \mathrm{F}\right)\end{array}$ & $\begin{array}{c}35.3 \\
\left(95.5^{\circ} \mathrm{F}\right)\end{array}$ & $\begin{array}{c}35.1 \\
\left(95.2^{\circ} \mathrm{F}\right)\end{array}$ & $\begin{array}{c}36.6^{\circ} \mathrm{C} \\
\left(97.9^{\circ} \mathrm{F}\right)\end{array}$ \\
\hline $\begin{array}{c}\text { Time to Reach Peak } \\
\text { Temperature (hr) }\end{array}$ & 13.4 & 12.0 & $5.5 / 9.5$ & 9.0 \\
\hline $\begin{array}{c}\text { Maximum Temperature } \\
\text { Difference }\end{array}$ & 1.1 & 2.0 & 1.6 & 2.1 \\
$\left(2.0^{\circ} \mathrm{F}\right)$ & $\left(3.6^{\circ} \mathrm{F}\right)$ & $\left(2.9^{\circ} \mathrm{F}\right)$ & $\left(3.8^{\circ} \mathrm{F}\right)$ \\
\hline $\begin{array}{c}\text { Time to Reach Maximum } \\
\text { Temperature Difference(hr) }\end{array}$ & 20.5 & 13.1 & 21.1 & 0.4 \\
\hline
\end{tabular}

\subsection{Direct Tensile Test}

Direct tensile tests on butterfly-type specimens were carried out to obtain the tensile bond strength between the overlay and the substrate. Fig. 5.36 shows the typical failure surfaces. It can be clearly seen that the failure occurred right at the interfacial zone. Figs. 5.37 and 5.38 show the tensile bond strength of each overlay mix at different ages. It is noticed that SFMC+SRA had the highest tensile bond strength at the ages of one day and three days, and SFMC had the highest tensile bond strength at the age of seven days. All the mixes had similar tensile bond strength developing trends and the readings were fairly close up to three days. From three days to seven days, SFMC had the largest gain of strength by $47 \%$, followed by LMC by $32 \%$, SFMC+SRA by $26 \%$, and FRC by $7 \%$.

During the study of overlay curling and delamination it was found that SFMC had the largest relative displacements at corners at all ages, and the relative displacements for the rest of the overlays were less and the values were within a fairly close range. Ultrasonic pulse test also confirmed that SFMC overlay had larger delamination and 
debonding area. In general, it may be stated that although the tensile bond strength is a measure of interfacial strength between overlay and substrate, it is not the appropriate or sole means to evaluate the interface behavior, which is more critically affected by differential early-age shrinkage and volume change, and subsequent curling and debonding. However for qualification of overlay materials (without environmental effects) a direct tensile test is a useful and effective mechanical test, as these values can be compared with the pull-off test conducted in the field.

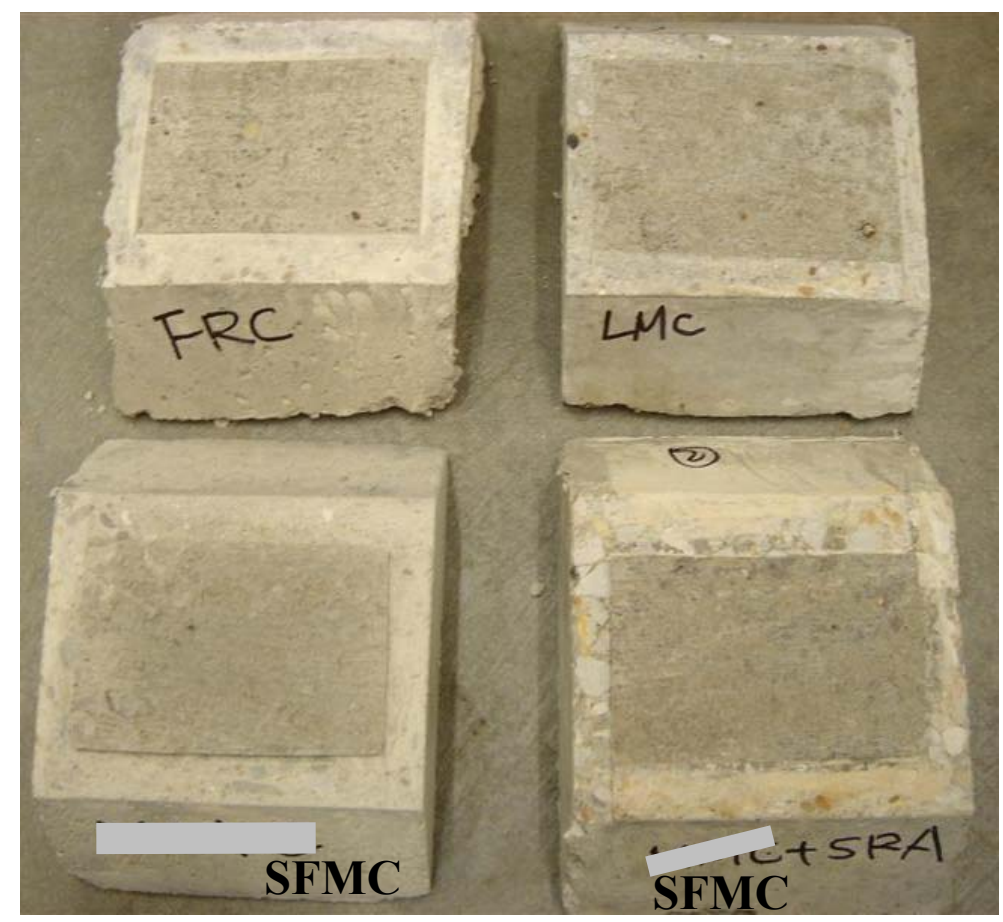

Fig. 5.36 Typical failure surfaces in direct tensile tests 


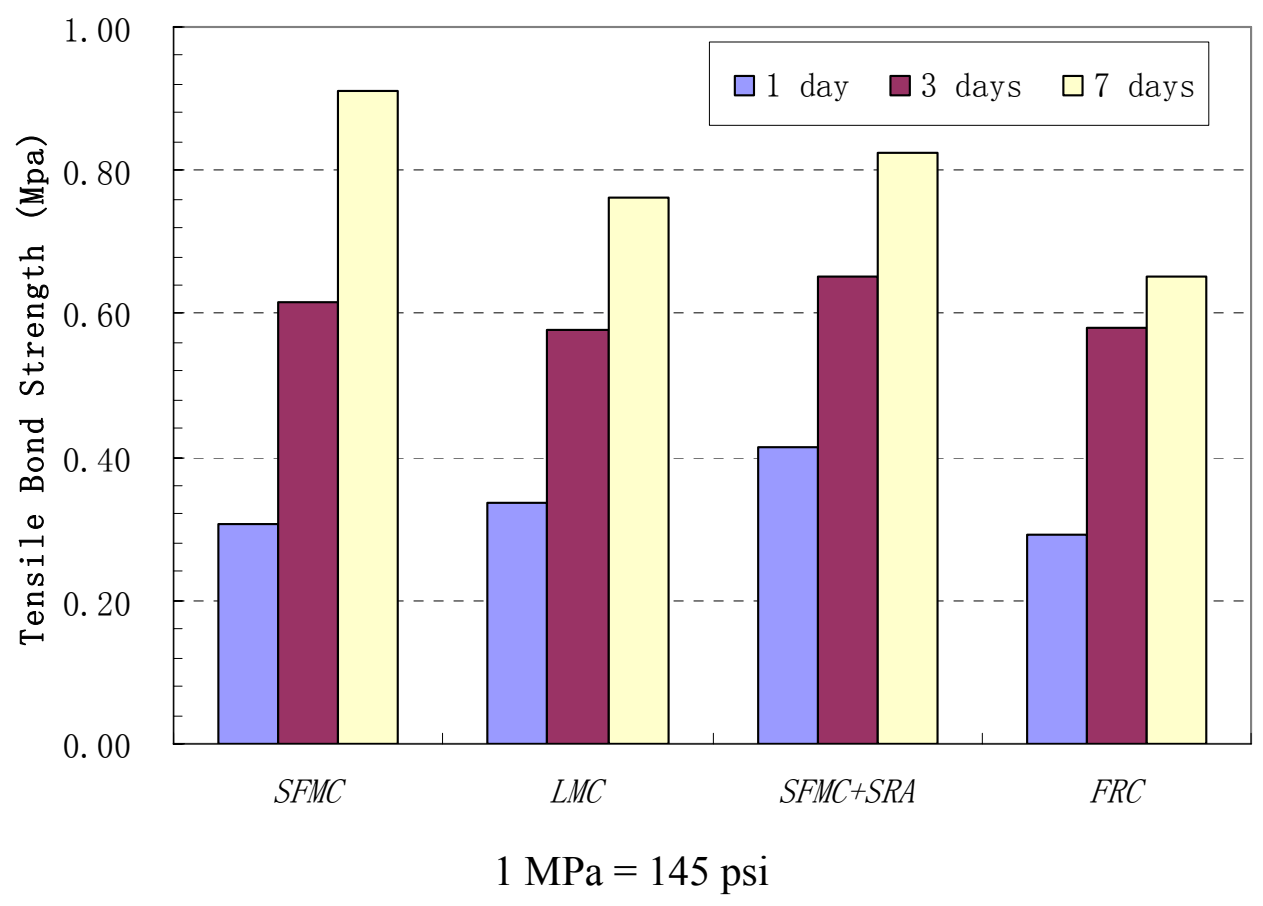

Fig. 5.37 Tensile Bond Strength of Overlays at Different Ages

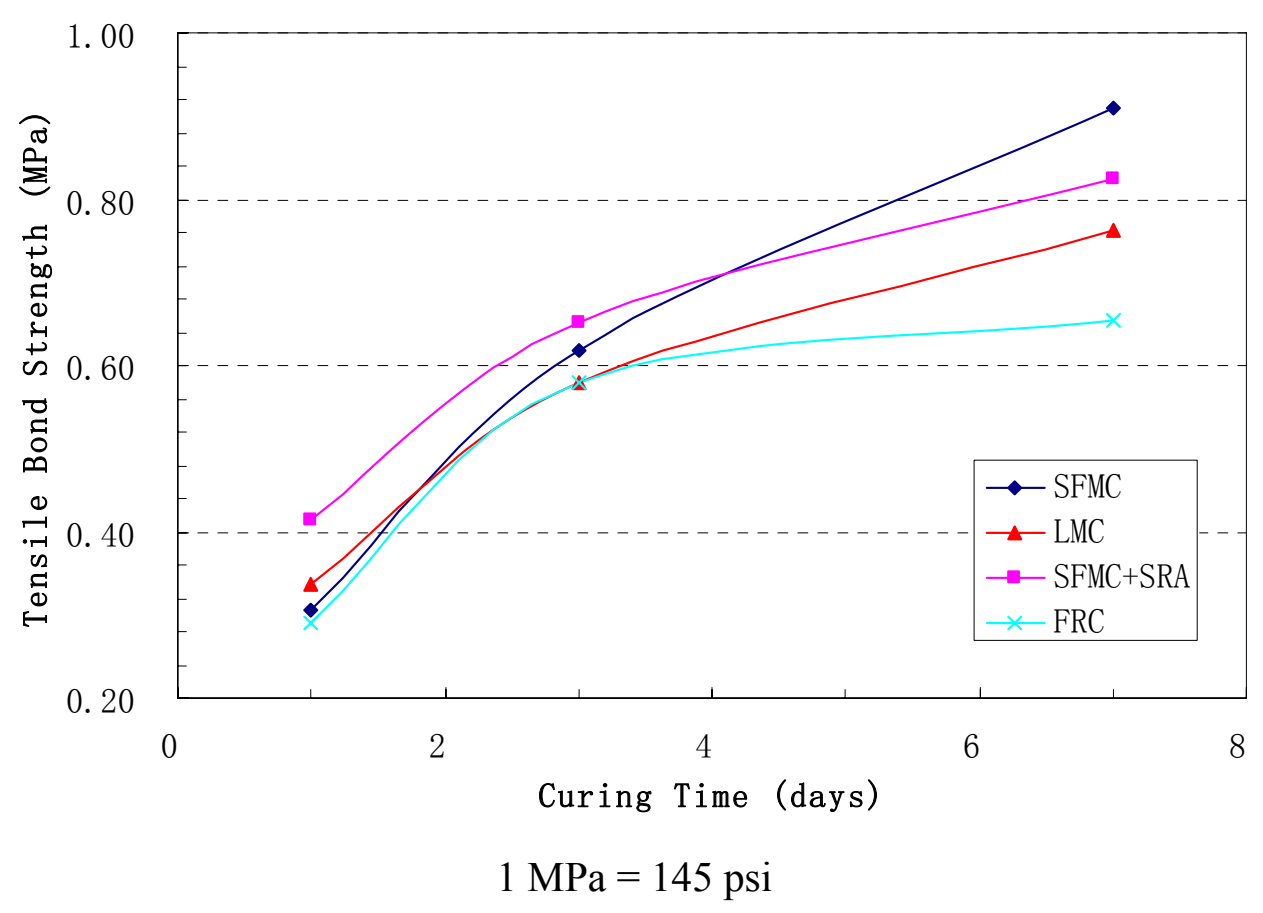

Fig. 5.38 Development of Tensile Bond Strength of Overlays 


\section{CHAPTER 6}

\section{CONCLUSIONS AND RECOMMENDATIONS}

As part of the research project "Concrete Overlays for Bridge Deck Repair and New Construction in West Virginia," this study is focused on early-age edge-curling effect and delamination of bonded concrete overlays due to temperature and shrinkage induced volume deformation. In total, three substrate surface conditions, two temperatures, and four types of overlay were investigated. In order to assess the delamination at the interface between overlay and substrate, the nondestructive ultrasonic pulse velocity testing method was adopted. Temperature evolution and temperature gradient within the overlay concrete were also evaluated in this study. Direct tensile test was conducted to evaluate the tensile bond strength between overlay and substrate, to perhaps attempt a correlation with interface bond delamination behavior.

\subsection{Conclusions}

\subsubsection{Early age curling effect}

Overlay concrete undergoes curling as a result of early-age shrinkage in relation to a stable concrete substrate. The interface crack was initiated at the corner and propagated through the edges and inside of the specimen. The interface between the overlay and substrate debonded, as the fracture energy that was accumulated in the process of curling in the overlay exceeded the critical fracture toughness, which was indicated by the jumps in crack propagation at discrete times in the graphs for relative 
displacement versus time. As the delamination developed, a continuous crack front was formed at the interface.

At first, tests were conducted to compare three substrate surface conditions with one type of overlay-SFMC. The profile of substrate surfaces was prepared by following the ICRI CSP \#2 sample model. Among the surface conditions considered, saturated surface with bonding slurry had the best performance, followed by saturated surface. Totally dry surface should be avoided by all means since it exhibited the largest relative displacement at the interface due to curling effect of overlay.

High temperature proved to be a very adverse factor for bonded concrete overlay at early age. High temperature increased the moisture loss and accelerated the paste shrinkage and eventually shrinkage in the overlay concrete. As a result, specimens at high temperature had larger relative displacements at the interface, which resulted in larger delaminaiton areas.

Among the four types of overlays consisting of: SFMC, SFMC+SRA, LMC, and FRC, the last three overlays had fairly close relative displacements due to curling effect, which were much smaller than SFMC overlay. By referring to the free shrinkage developments in these overlay concretes, it was believed that the curling effect of overlay very much depended on the shrinkage in overlay concrete. By adding SRA, the shrinkage in SFMC was reduced to a great extend; thus resulted in a low tendency of debonding at the interface. LMC also had a satisfactory performance in early age curling effect tests. The small relative displacements in the FRC overlay were believed to be due to the continuous shrinkage of substrate, as the substrate concrete reached only 35 days before 
the overlay was cast on top. So it is the relative displacement that is primarily responsible for the early age curling and delamination.

\subsubsection{Ultrasonic Pulse Test}

The ultrasonic pulse transmitting time at different points were recorded and a map of pulse transmitting time was drawn for each tested specimen. Based on the map of pulse transmitting time, the crack front and the delamination area were predicted. It is

found that the crack front moved consistently with the development of the relative displacements at the interface. The larger the relative displacements were, the further was the crack front, which caused larger delamination area.

Through the tests, it was confirmed that saturated surface with applied bonding slurry was the best substrate surface condition. Also, high temperature aggravated the delamination at the interface.

By comparing the delamination profiles at the interface, it was found that $\mathrm{SFMC}+\mathrm{SRA}$ had the smallest delamination area, followed by LMC, FRC, and SFMC in sequence, which was consistent with the results from edge curling effect tests. Shrinkage reducing admixture (SRA) is highly recommended for all silica fume modified concrete overlays.

After analyzing the signals recorded by the oscilloscope, it was found that the delamination at the interface reduced the amplitude of waveforms. Also amplitude in the frequency spectral was reduced once delamination occurred. The complex irregular contact surface between the overlay and substrate that was formed after delamination induced more frequency components of less magnitude than the natural frequency of the pulse transmitting transducer. 


\subsubsection{Overlay Temperature Measurement}

Within 24 hours, the temperature in the overlay approached to the ambient temperature and the temperature gradient over the overlay thickness became nearly straight, which meant that the temperature in the overlay concrete was rather uniform. Normally the curling and debonding of overlay started one day (24 hours) after concrete mixing. So the temperature gradient did not affect the curling and debonding behavior of overlay in this study, which focused on early-age behavior and assumed a constant temperature within the specimens.

\subsubsection{Direct Tensile Test}

In the direct tensile tests it was found that all the failure occurred right at the interface between the overlay and substrate, which indicated a relatively weak bond between the overlay and substrate under tension. While all the four overlays had similar tensile bond strengths at early age, the SFMC overlay showed the largest relative displacements at corners at all times during the delamination tests, while the rest of the overlays had fairly close readings. It can be concluded that the tensile bond strength may be used to qualify the overlay in terms of debonding at the interface between overlay and substrate, but not as a direct measure of delamination potential. The differential shrinkage developed in the overlay concrete should be considered as the most critical factor, and the debonding or delamination issue primarily depends on early age volume change.

\subsection{Recommendations}

Although this study has presented relatively conclusive results regarding the edge curling effect and delamination of bonded concrete overlays, further investigations are needed to understand the problem more clearly, as recommended below. 
1. Instead of using free shrinkage data, the restrained shrinkage data is more useful to analyze the results in the case of bonded concrete overlay, since overlay concrete always undergoes differential shrinkage due to the restraint from substrate.

2. In order to better understand the behavior of overlays at early age, relative humidity profile over the thickness is required. Then it would be possible to model the shrinkage profile in the overlay based on the relative humidity profile.

3. The effects of creep in overlay concrete need to be investigated since creep may offset some shrinkage.

4. A different CSP profile (\#5 or \#8) may be included in the study with different surface conditions (dry, saturated and saturated with slurry). However, the environmental condition needs to be more critical (high temperature and low humidity) in order to induce delamination and be able to obtain meaningful data.

5. In order to use the ultrasonic pulse velocity method to predict the delamination area at the interface with more certainty, a validation test should be conducted. Pull-off test and Dye technique would be good choices.

6. A detailed characterization of overlay concretes and substrate concrete using ultrasonic pulse is needed in order to better assess the delamination at the interface. The properties of waveforms and frequency spectral of different concretes need to be studied in detail in order to precisely characterize the interface between the overlay-substrate system in terms of waveform and frequency spectrum. 


\section{REFERENCES}

1. ACI Committee 209R-92, "Prediction of Creep, Shrinkage, and Temperature Effects in Concrete Structures," American Concrete Institute.

2. ASTM C 260, "Specification for Air-Entraining Admixtures for Concrete."

3. ASTM C 494, "Specification for Chemical Admixtures for Concrete."

4. ASTM C 597-02, "Standard Test Method for Pulse Velocity through Concrete."

5. Babaei, K. and Hawkins, N. M.; "Performance of Bridge Deck Concrete Overlays, Extending the Life of Bridges,” ASTM STP 1100, 1990, pp. 95-108.

6. Babaei, K. and Hawkins, M.; "Performance of Rehabilitated / Protected Concrete Bridge Decks,” ASTM Special Technical Publication, No. 1137, 1992, pp. 140-154.

7. Banthia, N.; Yan C. and Mindess S.; "Restrained Shrinkage Cracking in Fiber Reinforced Concrete: a Novel Test Technique," Cement and Concrete Research, V. 26, No. 1, 1996, pp. 9-14.

8. Baun, M. D.; "Steel fiber-reinforced Concrete Bridge Deck Overlays: Experimental Use by Ohio Department of Transportation," Transportation Research Record, No. 1392, 1993, pp. 73-78.

9. Cole J.; "Performance of Overlays Placed over Sealed Decks under Static and Fatigue Loading," Journal of bridge Engineering, V. 7, No. 4, 2002, pp. 206-213.

10. Delatte, N. J., "Investigating Performance of Bonded Concrete Overlays," Journal of Performance of Constructed Facilities, V. 12, No. 2, 1998, pp 62-70.

11. Delatte, N. J.; "Interface Stresses and Bond Strength in Bonded Concrete Overlays," in session 334 "Bond Interaction Between Two-Layer Concrete Systems," Transportation Research Board $78^{\text {th }}$ Annual Meeting, 13 January 1999

12. Delatte, N. J.; Chen, Shen-en; Davidson, James; Sehdev, Anshuman; "Design and Quality Control of Concrete Overlays," Report No. 01220, University Transportation Center for Alabama, December 2001.

13. FHWA; "Tensile Bond Strength of a High Performance Concrete Bridge Deck Overlay," Field Test Report, FHWA MCL Project \# 9904, February 2000.

14. Gillum, A. J.; "Bond Characteristics of Portland Cement Overlays on Sealed Existing Bridge Decks," Thesis, University of Cincinnati, 1995. 
15. Granju, Jean-Louis; Sabathier, Vincent; Turatsinze, Anaclet; Toumi, Ahmed ; "Interface Between an Old Concrete and a Bonded Overlay: Debonding Mechanism," Interface Science, V. 12, No. 4, 2004, pp. 381-388.

16. Granju, J. L.; "Debonding of Thin Cement-Based Overlays," Journal of Materials in Civil Engineering, V. 13, No. 2, 2001, pp. 114-120.

17. http://www.ndted.org/EducationResources/CommunityCollege/Ultrasonics/Measure mentTech/signalprocessing.htm

18. International Concrete Repair Institute, "No. 03732 Guideline for Selecting and Specifying Concrete Surface Preparation for Sealers, Coatings, and Polymer Overlays," 1997.

19. Jones, R. and Facaoaru, I.; "Recommendations for Testing Concrete by the Ultrasonic Pulse Method," Materiaux et Constructions, V. 2, No. 10, 1969, pp. 275-284.

20. Kosmatka, S. H., Kerkhoff, B., and Panarese, W. C.; "Design and Control of Concrete Mixtures," $14^{\text {th }}$ edition, 2002.

21. Kim, S. M. and Nelson, P. K.; "Early-age Behavior of Concrete Overlays on Continuously Reinforced Concrete Pavements," 82nd Annual Meeting of the Transportation Research Board, Washington, D.C., January, 2003.

22. Kumar, S. V.; "Fatigue Response of Concrete Decks Reinforced with FRP Rebars," Journal of Structural Engineering, V. 124, No. 1, 1998, pp. 11-16.

23. Lau, C. M. and Fwa, T. F.; "Interface Shear Stress in Overlaid Concrete Pavements," Journal of Transportation Engineering, V. 120, No. 2, 1994, pp 163-177.

24. Leung, C.; "Delamination Failure in Concrete Beams Retrofitted with a Bonded Plate," Journal of Materials in Civil Engineering, V.13, No. 2, 2001, pp.106-113.

25. Lin, J. M.; Sansalone, M.; and Poston, R.; "Impact-Echo Studies of Interfacial Bond Quality in Concrete: Part II - Effects of Bonded Tensile Strength," ACI Material Journal, V. 93, No. 4, 1996.

26. Mailvaganam, N. P; Springfield, J., Repette, W.; and Taylor, D.; "Curling of Concrete Slabs on Grade," Construction Technology Update No. 44, Dec. 2000. http://irc.nrc-cnrc.gc.ca/pubs/ctus/44_e.html\#ref2 
27. Mailvaganam, N. P.; Pye, G. B.; and Arnott, M. R.; "Surface Preparation of the Concrete Substrate," Construction Technology Update No. 24, Dec. 1998. http://irc.nrc-cnrc.gc.ca/pubs/ctus/24_e.html

28. The Mathwork Inc.; "Matlab Help Documentation."

29. Minoru, K.; Toshiro, K.; Yuichi, U., and Keitetsu, R.; "Evaluation of Bond Properties in Concrete Repair Materials," Journal of Materials in Civil Engineering, V. 13, No. 2, 2001, pp. 98-105.

30. Neville, A. M.; Properties of Concrete, $4^{\text {th }}$ Edition; 1996.

31. Perdickaris, P. C. and Beim, S.; "RC Bridge Decks under Pulsating and Moving Load,” Journal of Structure Engineering, V. 114, No.3, 1998, pp.591-607.

32. Ruiz, J. M.; "Validation of Bond Prediction Models as A System: JPCP," Final Report; Submitted to FHWA; December 2001.

33. Sherwin-Williams Company, "Guideline Instructions for Concrete Surface Preparation," 2005. www.generalpolymers.com/tech_lib/conc_surf_prep.pdf

34. Shin, H. C.; "Early Age Behavior of Bonded Concrete Overlays Due to Shrinkage and Thermal Changes," Ph.D. Dissertation, University of Illinois at UrbanaChampaign, 2000

35. Silfwerbrand, J.; "Stresses and strains in composite concrete beams subjected to differential shrinkage,” ACI Structural Journal, V. 94, No. 4, 1997, pp. 347-353

36. Sprinkel, M. M. and Ozyildirim, C.; "Evaluation of High Performance Concrete Overlays Placed on Route 60 Over Lynnhaven Inlet in Virginia," Report VTRC 01R1, August 2000.

37. Stauffer, J. D.; Woodward, C. B.; and Whie, K. R.; "Nonlinear Ultrasonic Testing with Resonant and Pulse Velocity Parameters for Early Damage in Concrete," ACI Material Journal, V. 102, No. 2, 2005, pp. 118-121.

38. Sun, Z. H., "Evaluation of Concrete Bridge Deck Overlays," Thesis of WVU, 2004

39. Suprenant, B. A. and Malisch, R.W.; "Repairing curled slabs," Concrete Construction, V. 9, 1999, pp. $58-65$.

40. Wall, J. S. and Shrive, N. G.; "Factors Affecting Bond between New and Old Concrete,” ACI Materials Journal, V. 85, No. 2, 1988, pp. 117-125. 
41. Whiting, D. A.; Detwiler, R. J.; and Lagergren, E.S.; "Cracking Tendency and Drying Shrinkage of Silica Fume Concrete for Bridge Deck Applications," ACI Materials Journal, V. 97, No. 1, 2000, pp.71-77.

42. Yaman, I. O.; Inci, G.; Yesiller, N.; and Aktan, H. M.; "Ultrasonic Pulse Velocity in Concrete Using Direct and Indirect Transmission," ACI Materials Journal, V. 98, No. 6, 2001, pp. 450-457.

43. Zhang, J. and Li, V. C.; "Monotonic and fatigue performance in bending of fiberreinforced engineered cementitious composite in overlay system," Cement and Concrete Research, V. 32, No. 3, 2002, pp. 415-423. 


\section{Appendix A}




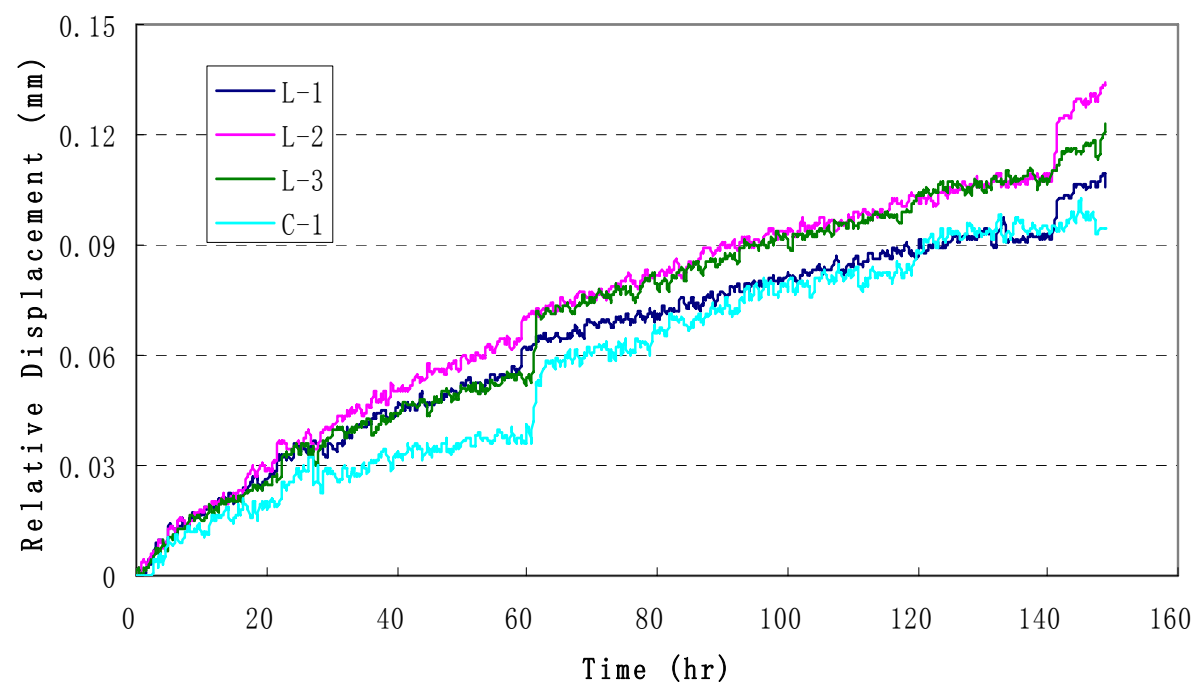

Fig. A-1 Relative Displacement in SFMC-Dry-without Slurry @ $23^{\circ} \mathrm{C} \# 1$

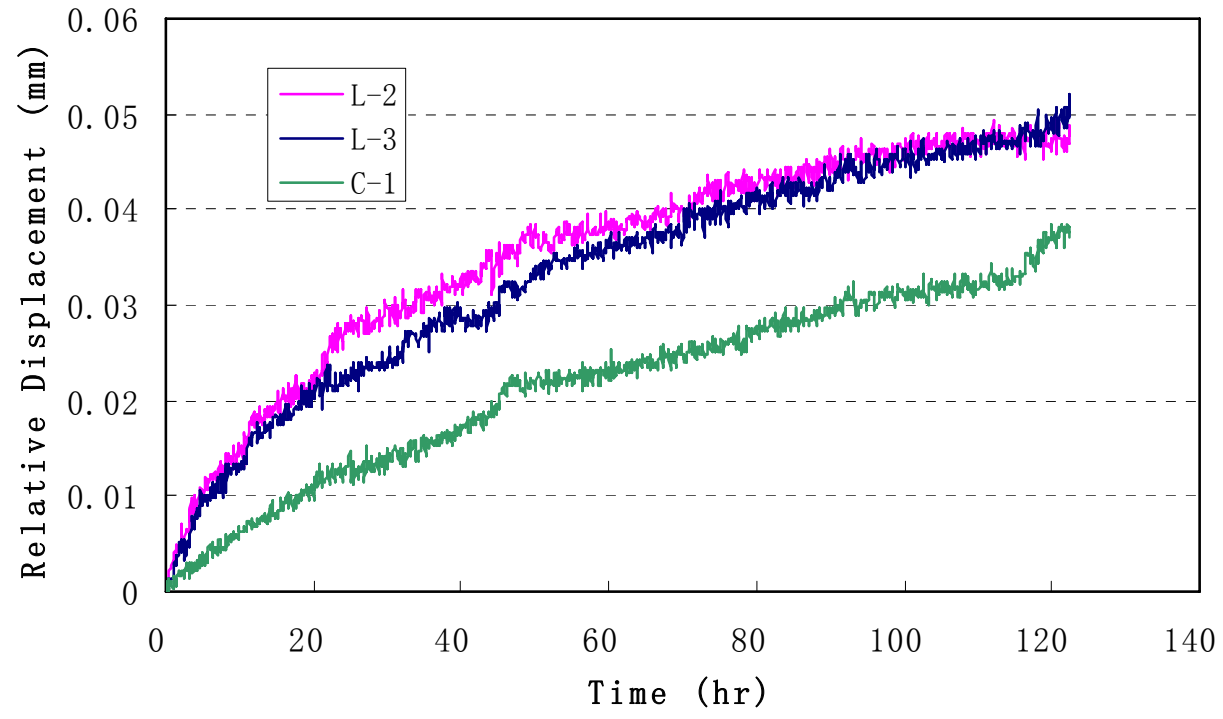

Fig. A-2 Relative Displacement in SFMC-Saturated-without Slurry @ $23^{\circ} \mathrm{C} \# 2$ 


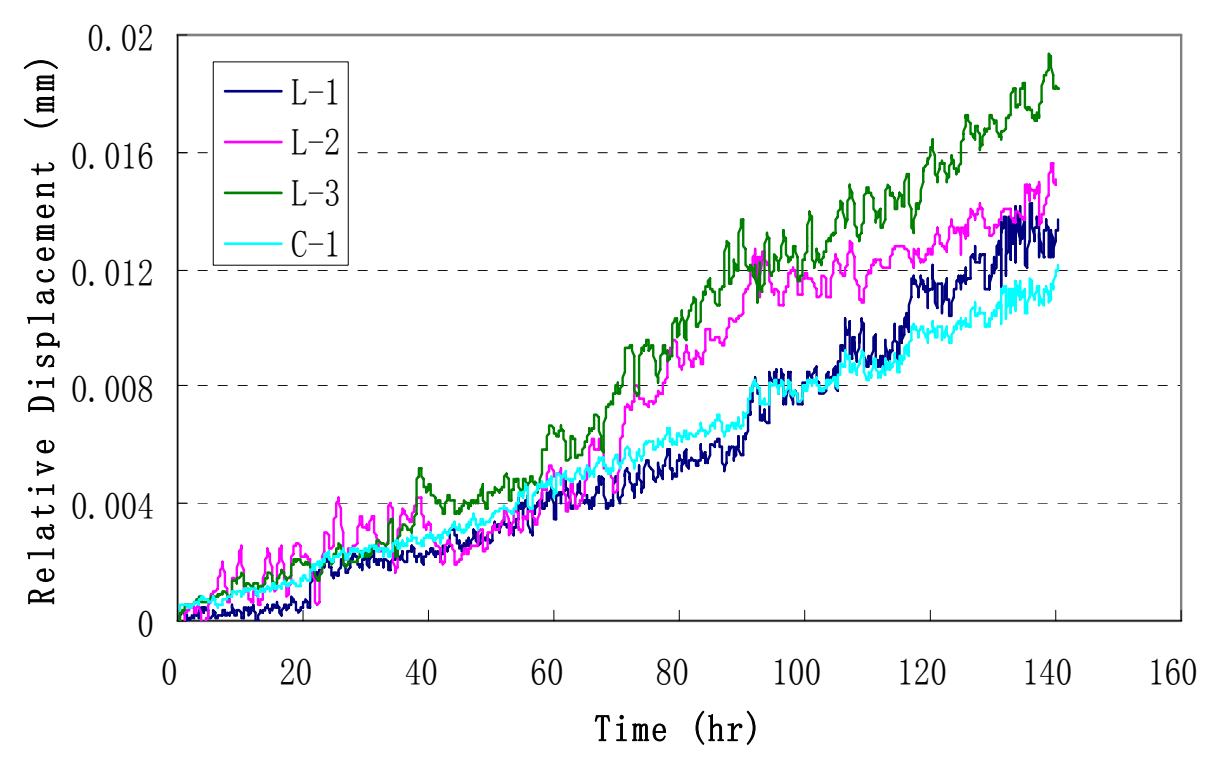

Fig. A-3 Relative Displacement in SFMC-Saturated-with Slurry @ $23^{\circ} \mathrm{C} \# 1$

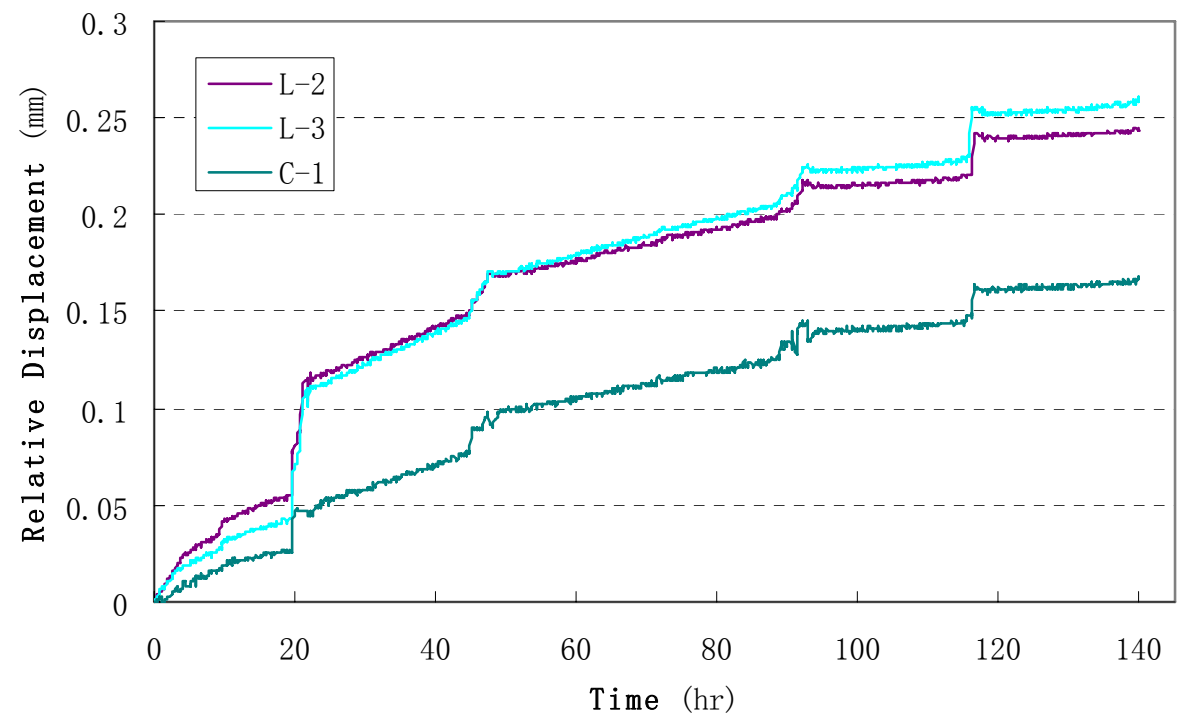

Fig. A-4 Relative Displacement in SFMC-Saturated-with Slurry @ $35^{\circ} \mathrm{C} \# 2^{*}$

*: large discrepancy compared to other specimens; relative displacement data for ultrasonic pulse test only; results not taken for any comparison with other specimens. 


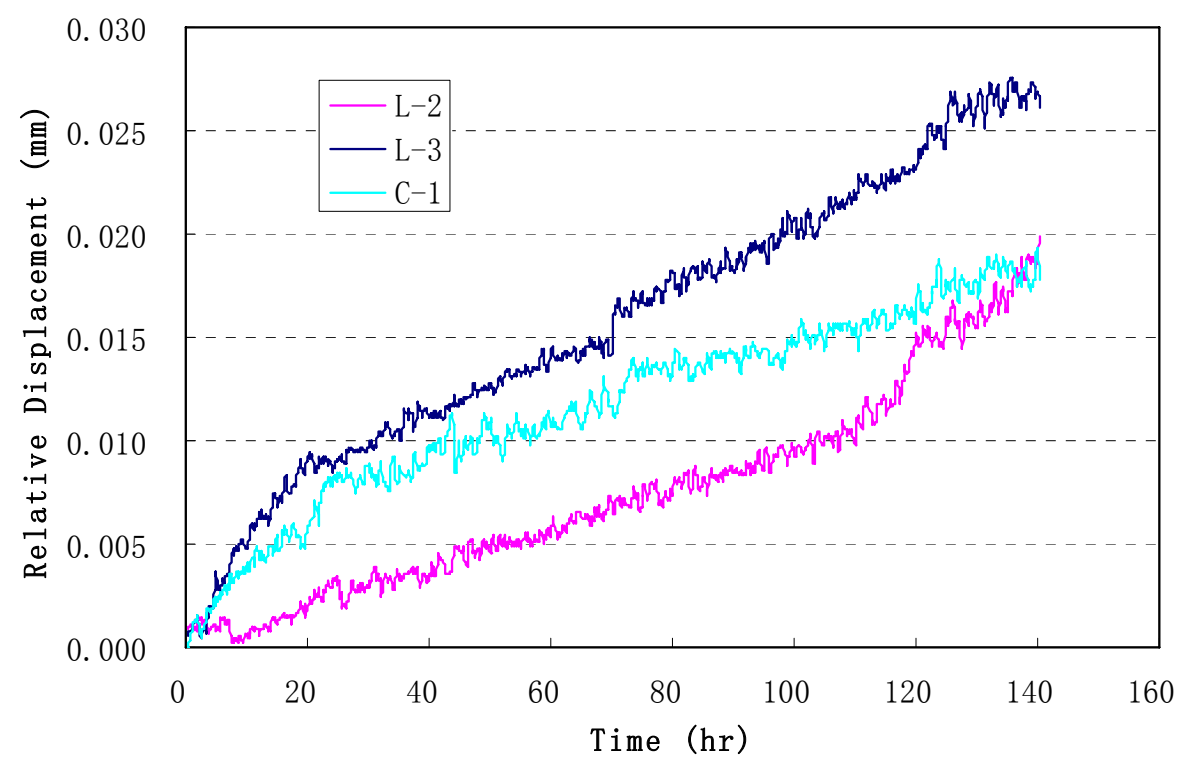

Fig. A-5 Relative Displacement in LMC-Saturated-with Slurry @35 $35^{\circ} \mathrm{C}$ \#2

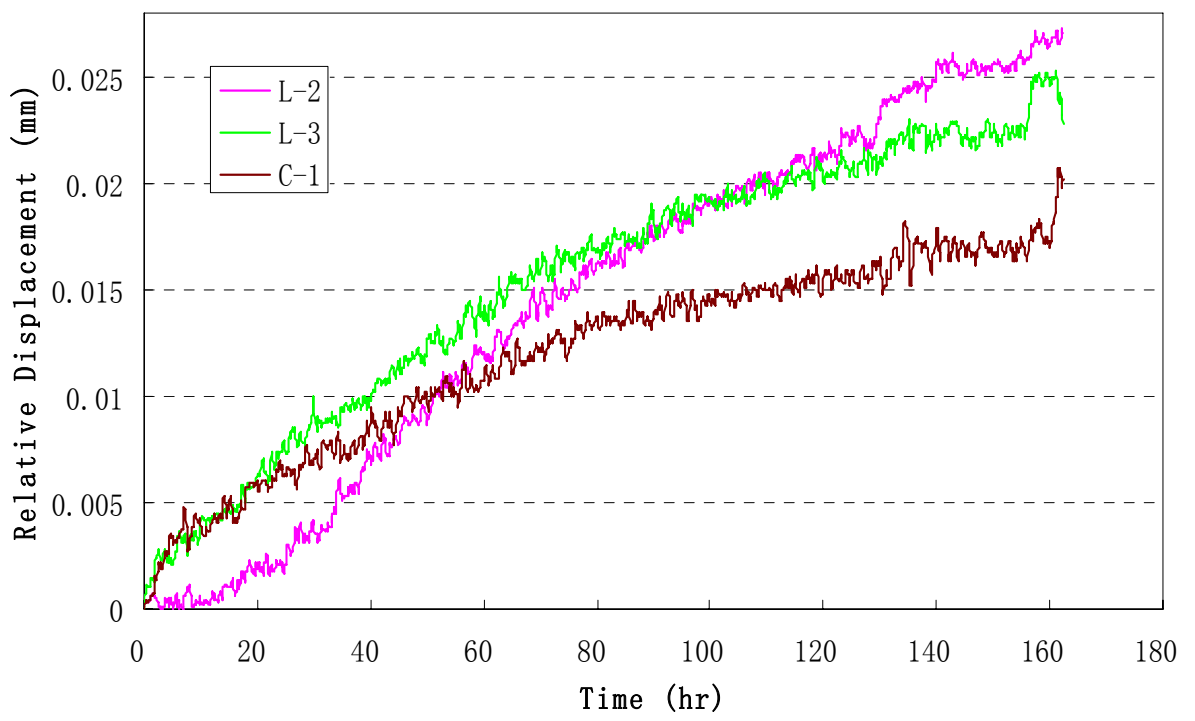

Fig. A-6 Relative Displacement in SFMC+SRA-Saturated-with Slurry @ $35^{\circ} \mathrm{C} \# 2$ 


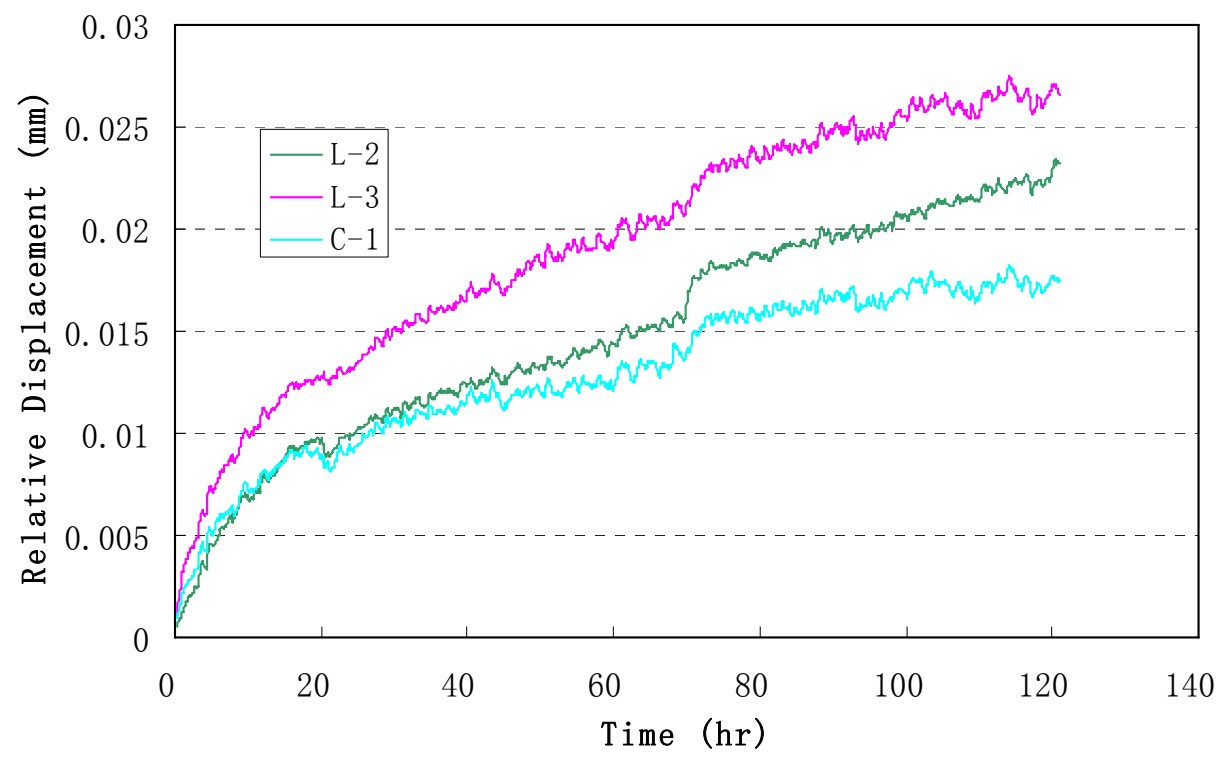

Fig. A-7 Relative Displacement in FRC-Saturated-with Slurry @35 $35^{\circ}$ \#2 
Appendix B 


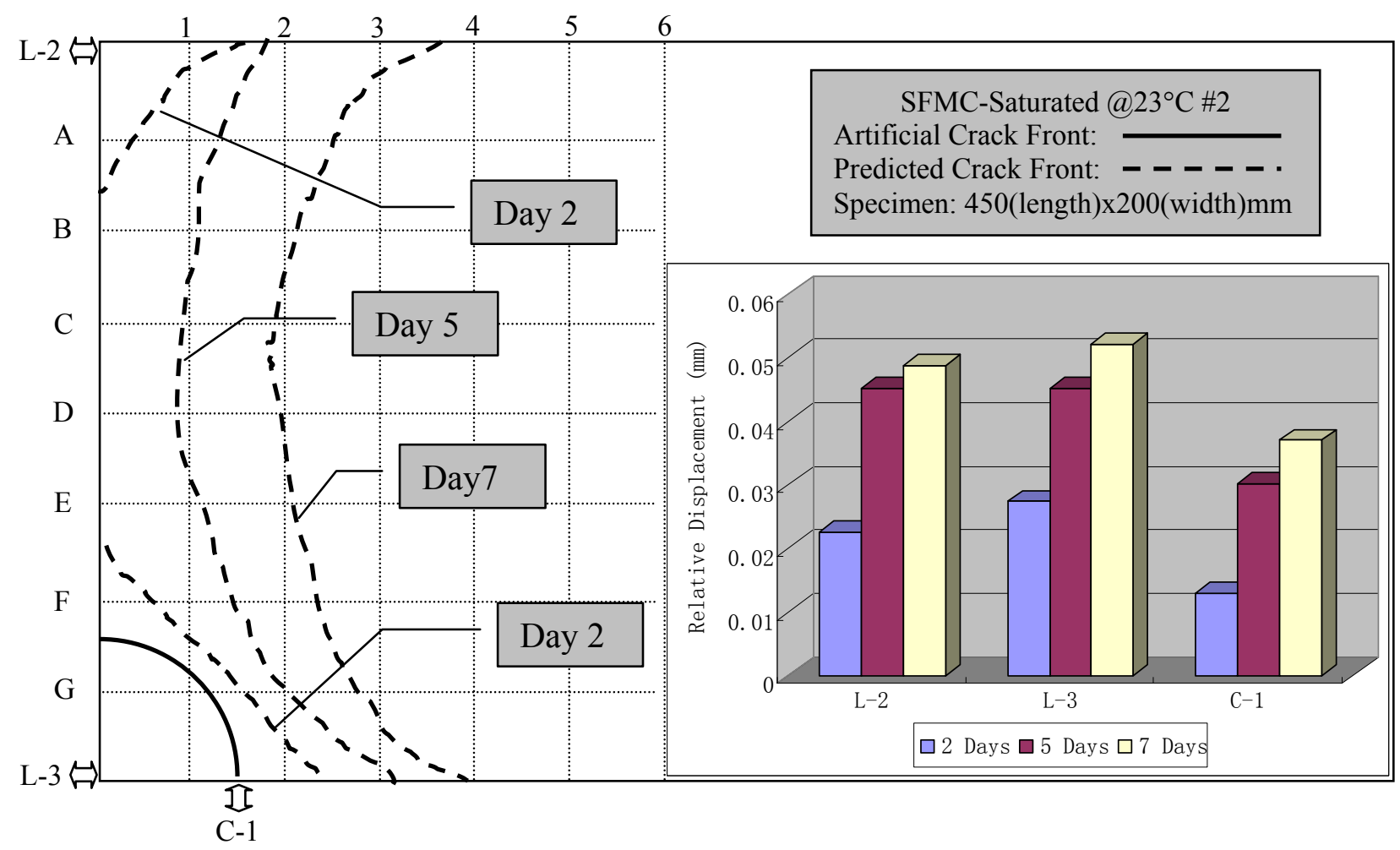

Fig. B-1 Predicted Crack front movement for SFMC-Saturated @ $23{ }^{\circ} \mathrm{C} \# 2$

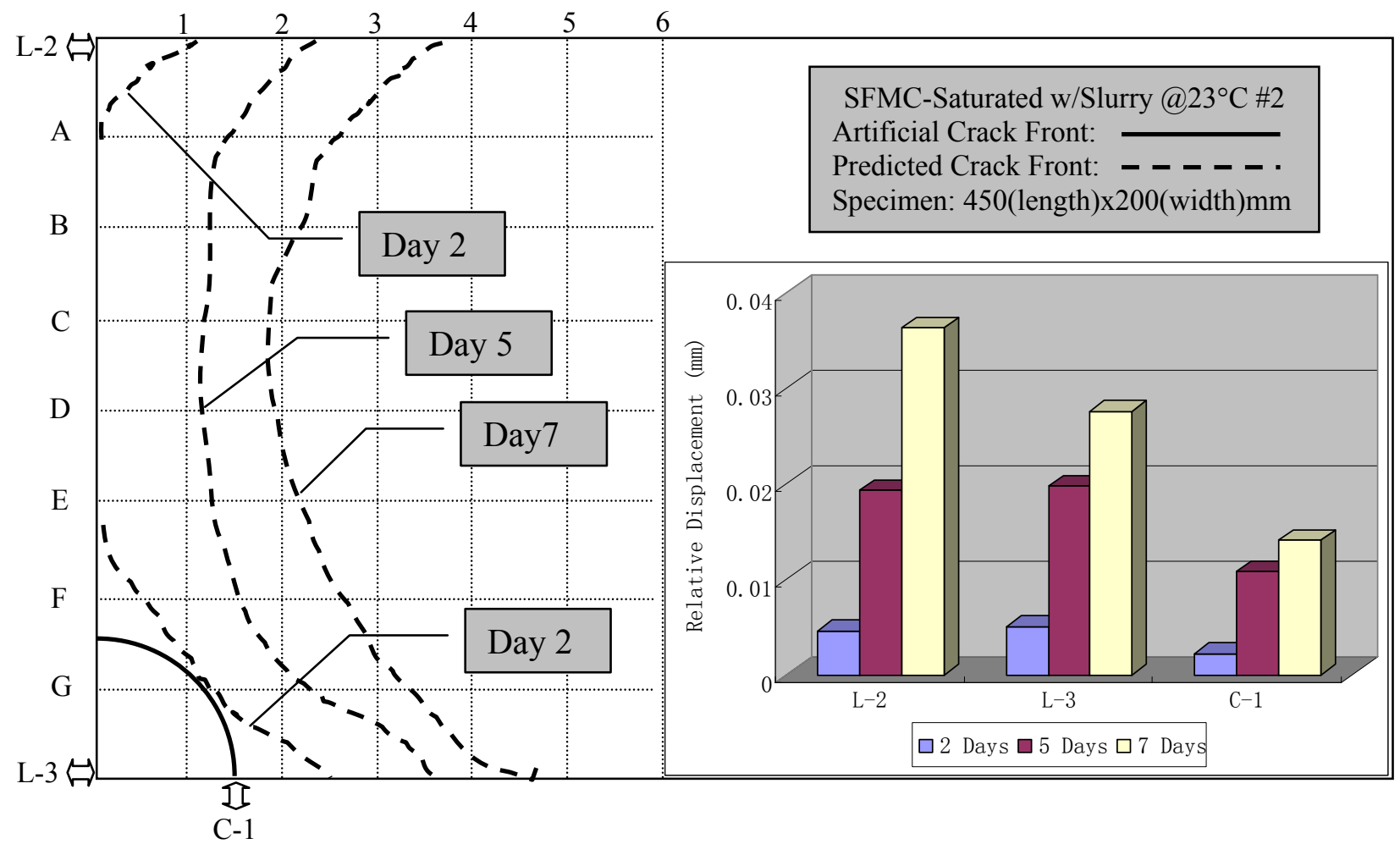

Fig. B-2 Predicted Crack front movement for SFMC-Saturated-w/Slurry @2 $23^{\circ} \mathrm{C} \mathrm{\# 2}$ 


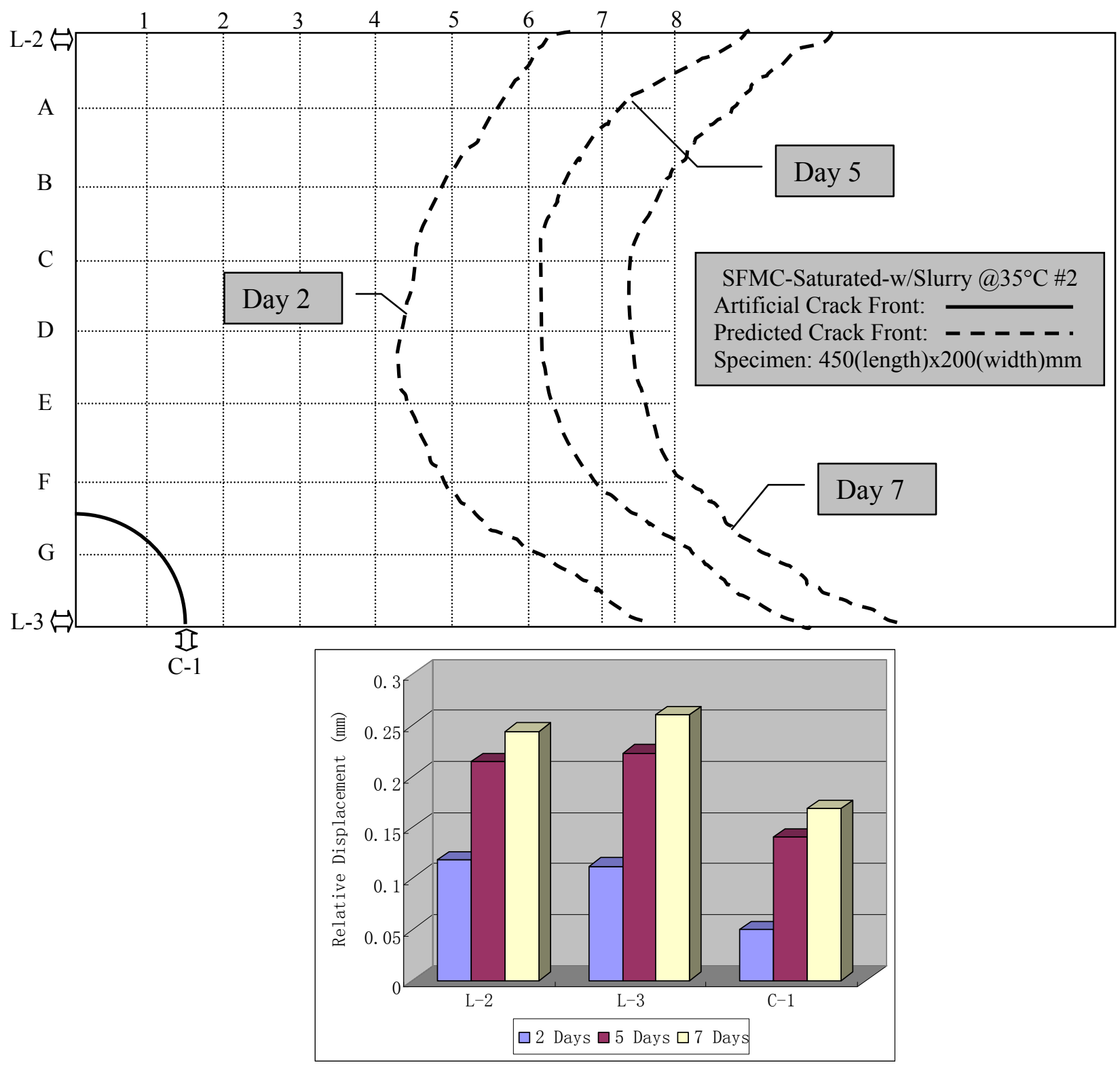

Fig. B-3 Predicted Crack front movement for SFMC-Saturated-w/Slurry @ $35^{\circ} \mathrm{C} \# 2^{*}$

*: large discrepancy compared to other specimens; relative displacement data for UPV

test only; results not taken for any comparison with other specimens. 


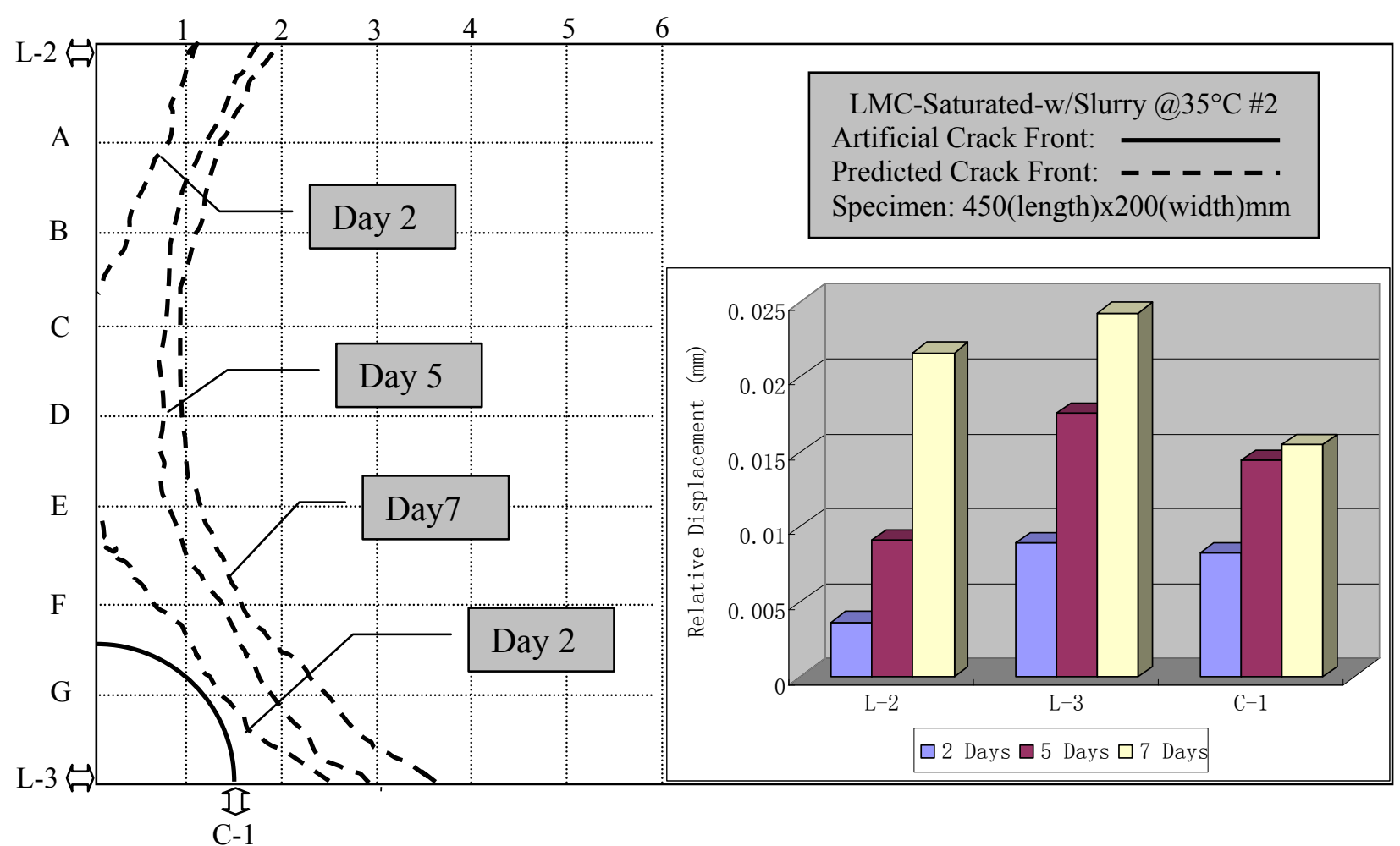

Fig. B-4 Predicted Crack front movement for LMC-Saturated-w/Slurry @35ㄷ \#2

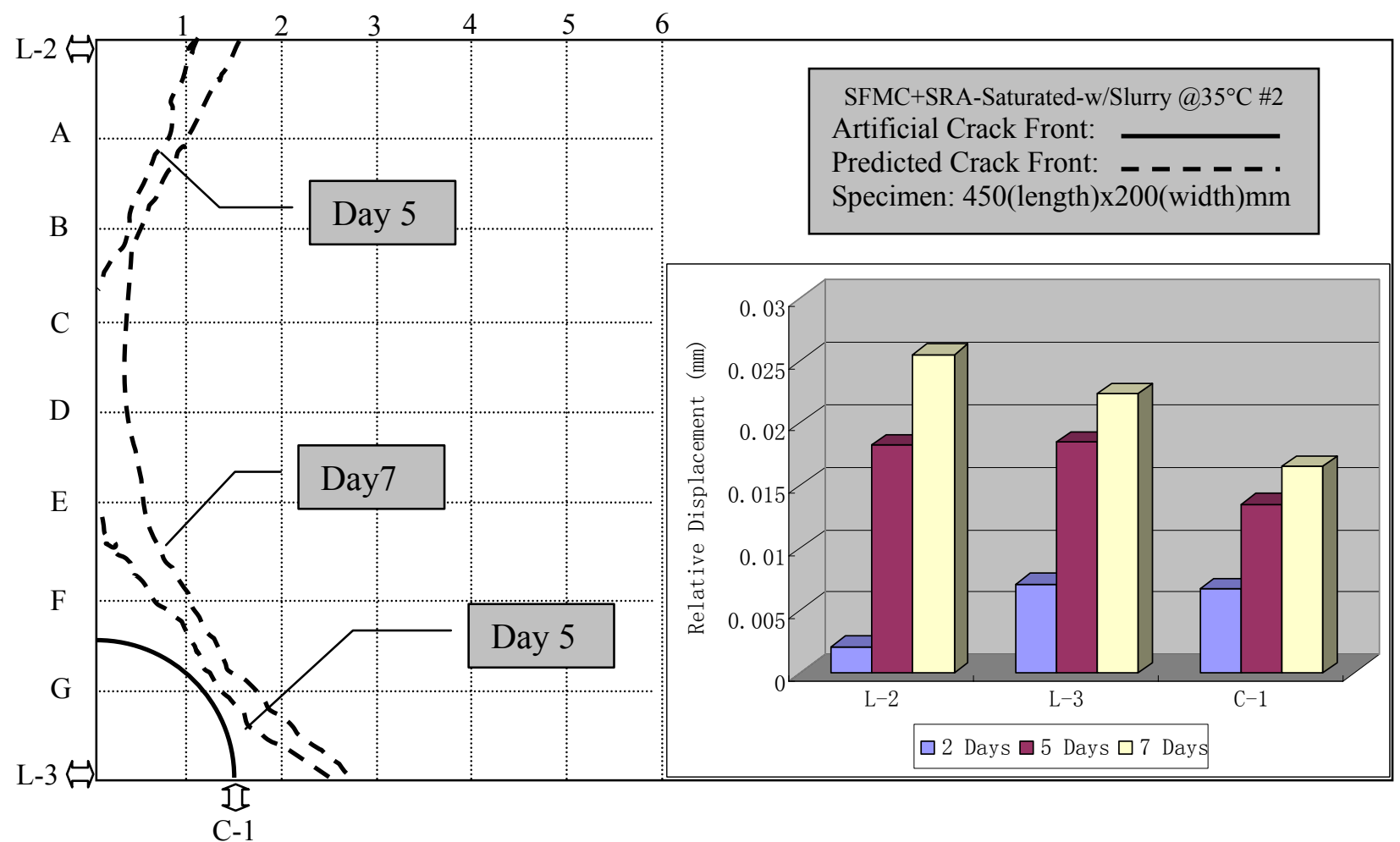

Fig. B-5 Predicted Crack front movement for SFMC+SRA-Saturated-w/Slurry @ $35^{\circ} \mathrm{C} \# 2$ 


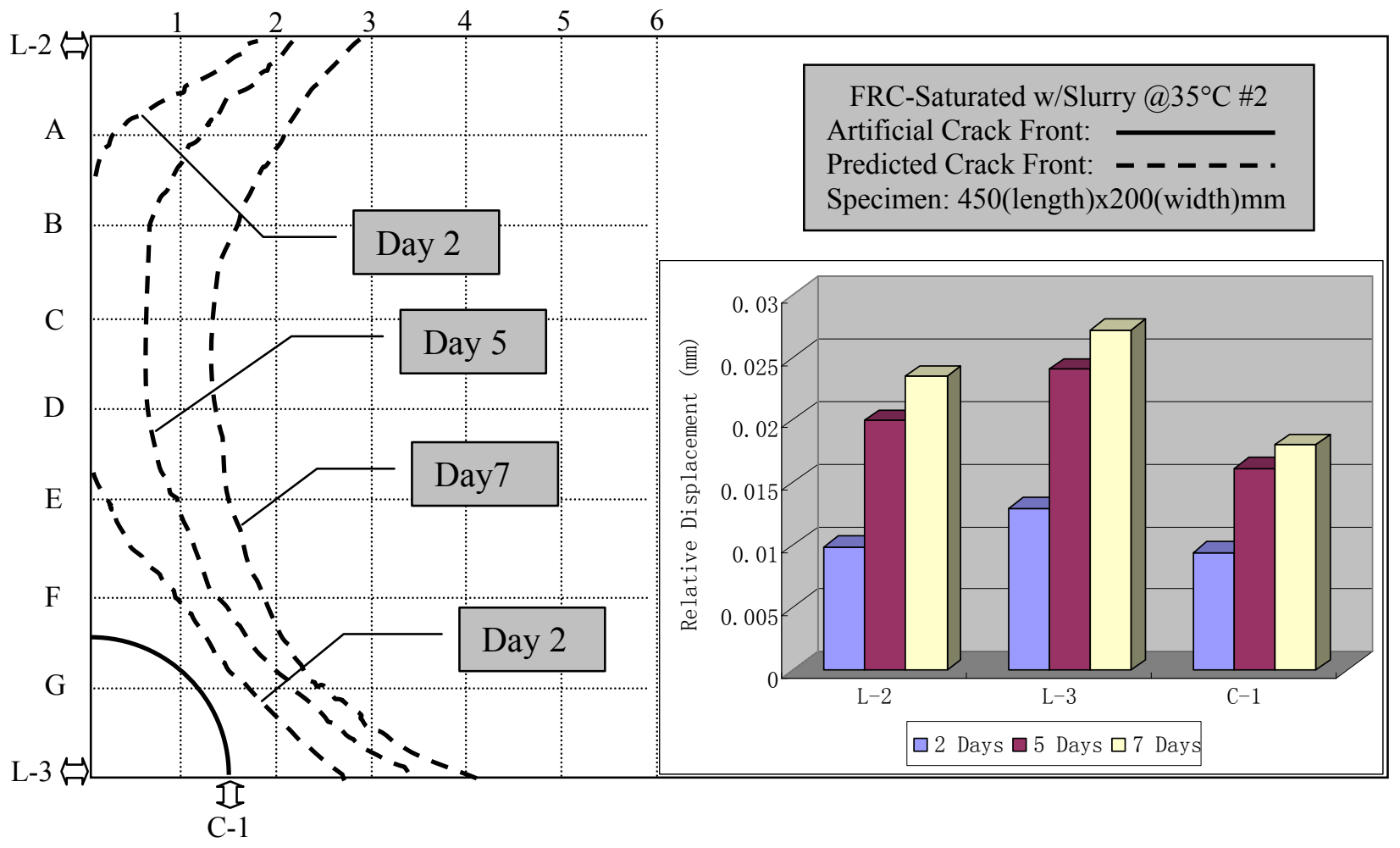

Fig. B-6 Predicted Crack front movement for FRC-Saturated-w/Slurry @ $35^{\circ} \mathrm{C} \# 2$ 
Appendix C 


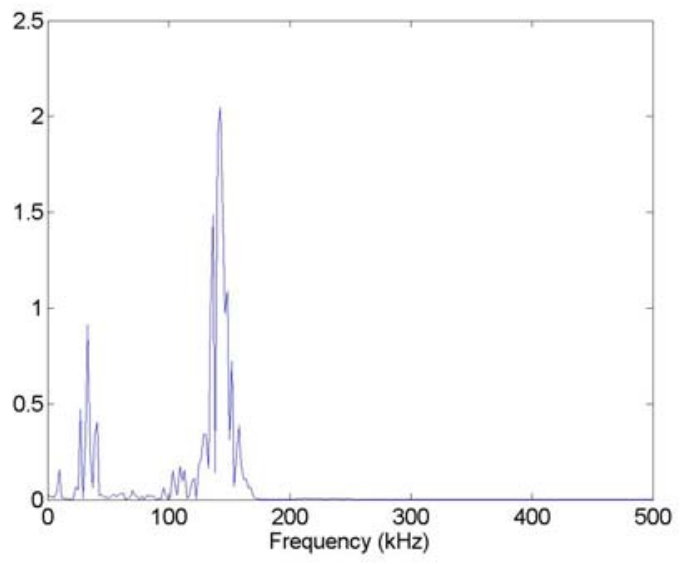

(a)

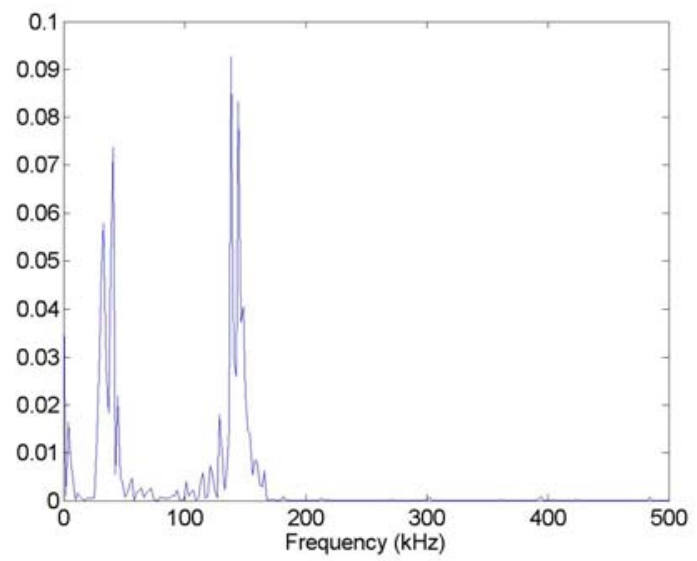

(b)

SFMC-dry @ 23ㅜㄹ \#1

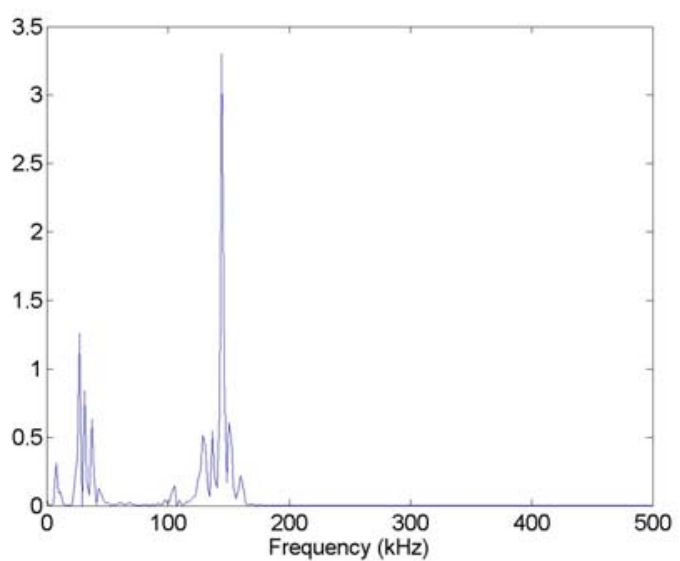

(c)

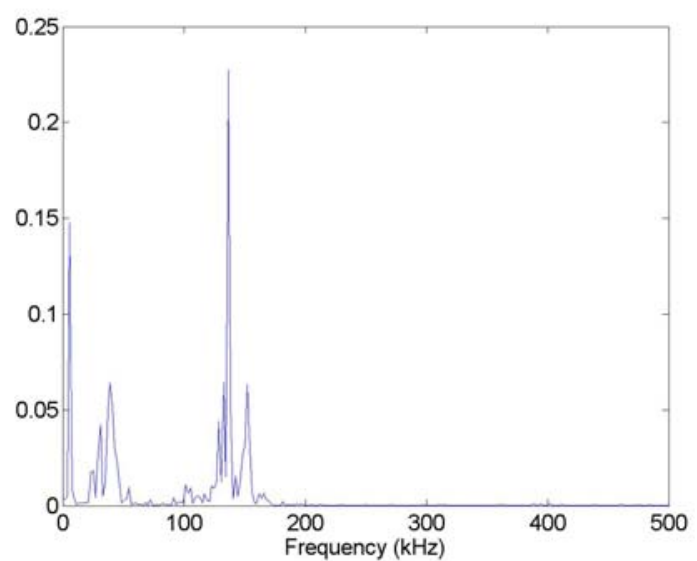

(d)

SFMC-saturated @ $23^{\circ} \mathrm{C} \# 1$

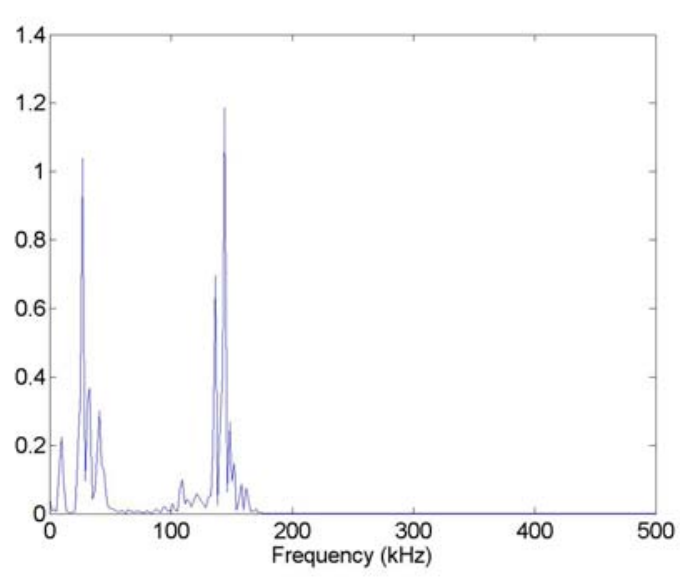

(e)

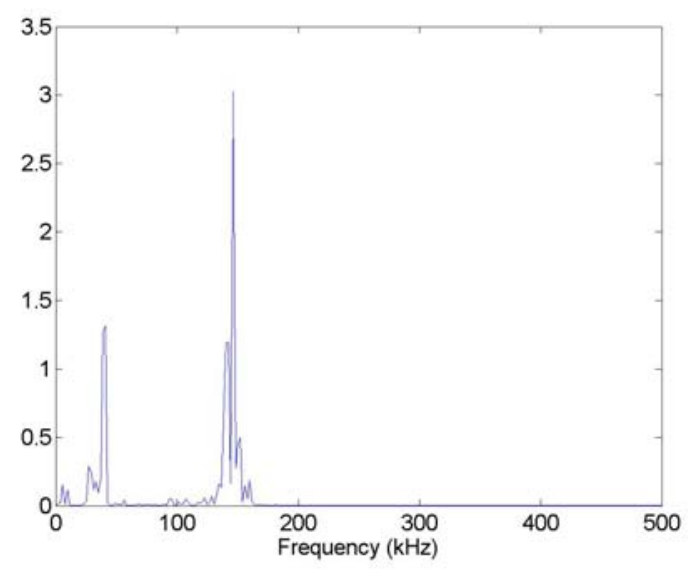

(f)

SFMC-saturated-w/ slurry $23^{\circ} \mathrm{C} \# 1$

Fig. C-1 Power distribution spectral of point 1-A (a) 


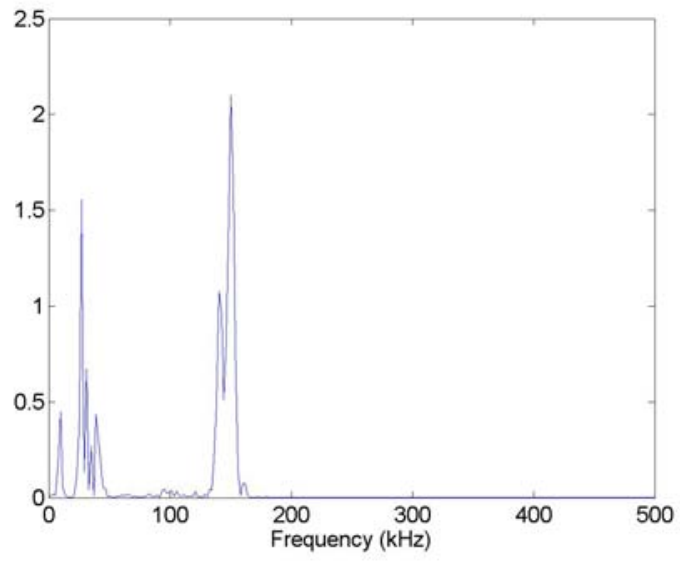

(a)

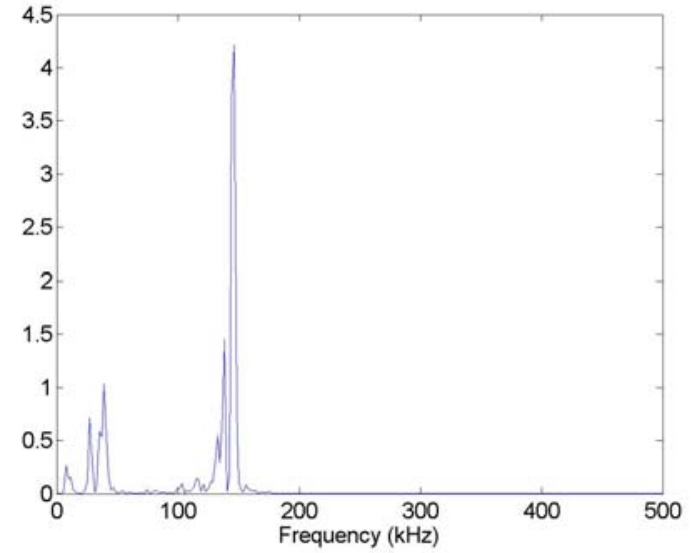

(b)

SFMC-saturated-w/ slurry @33 $35^{\circ} \mathbf{C} \# 1$

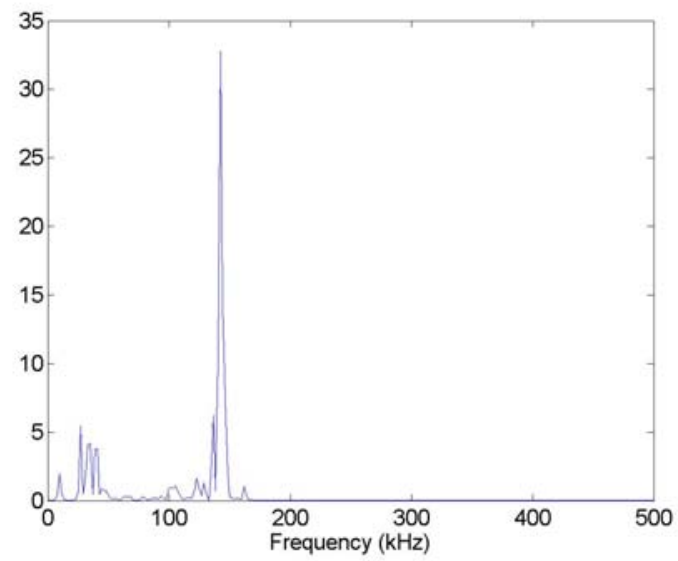

(c) LMC-saturated-w/ slurry @ $35^{\circ} \mathrm{C} \# 1$

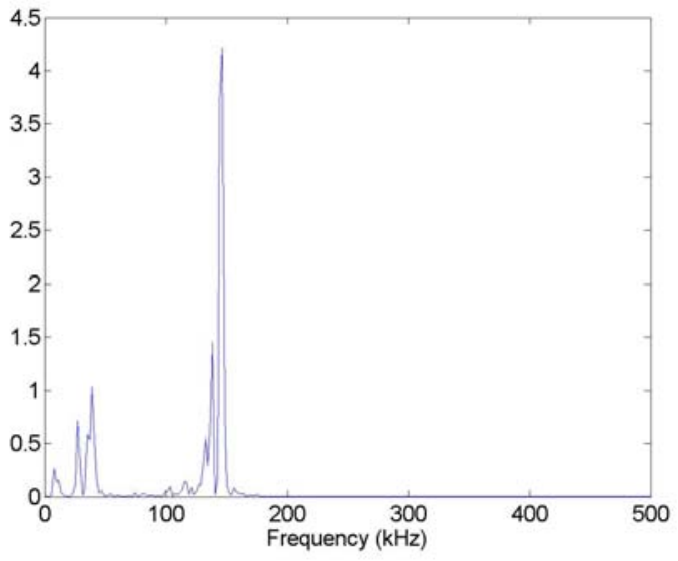

(d)

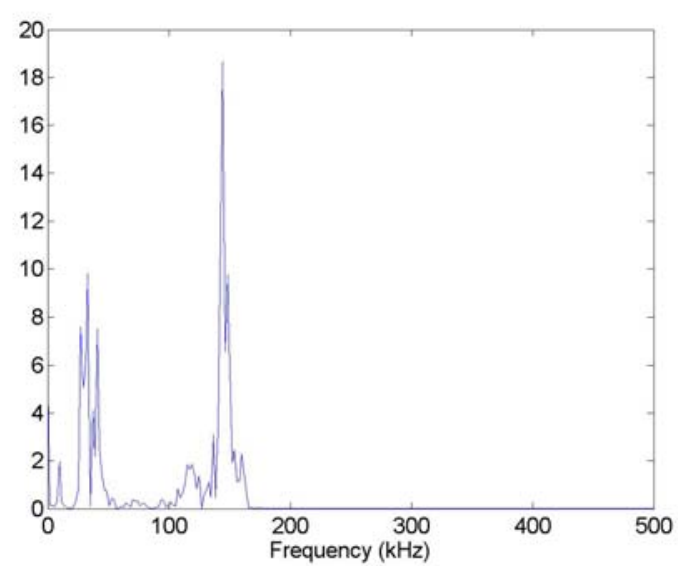

(e)

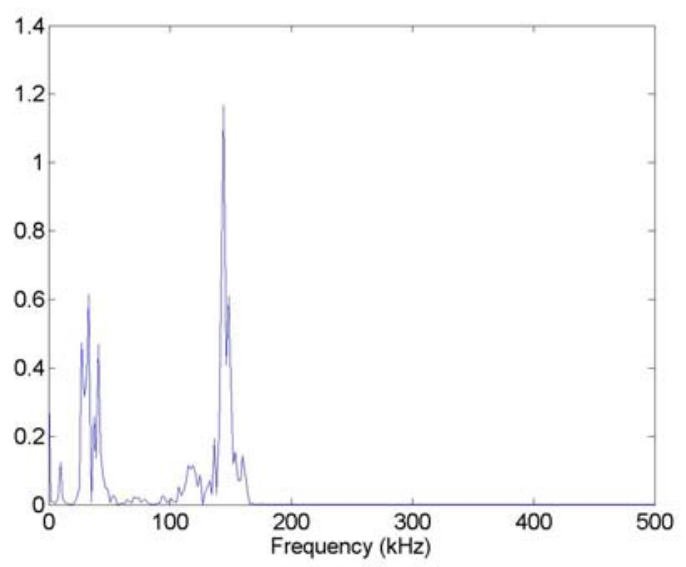

(f)

SFMC+SRA-saturated-w/ slurry @3 $35^{\circ} \mathbf{C ~ \# 1 ~}$

Fig. C-2 Power distribution spectral of point 1-A (b) 


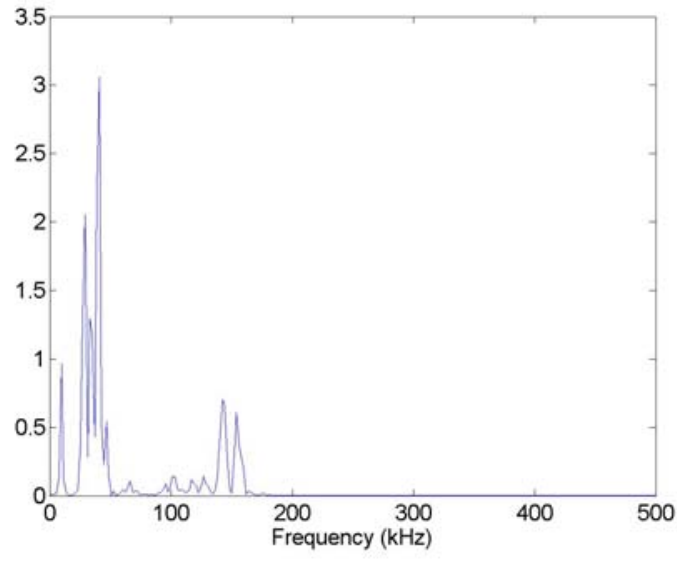

(a)

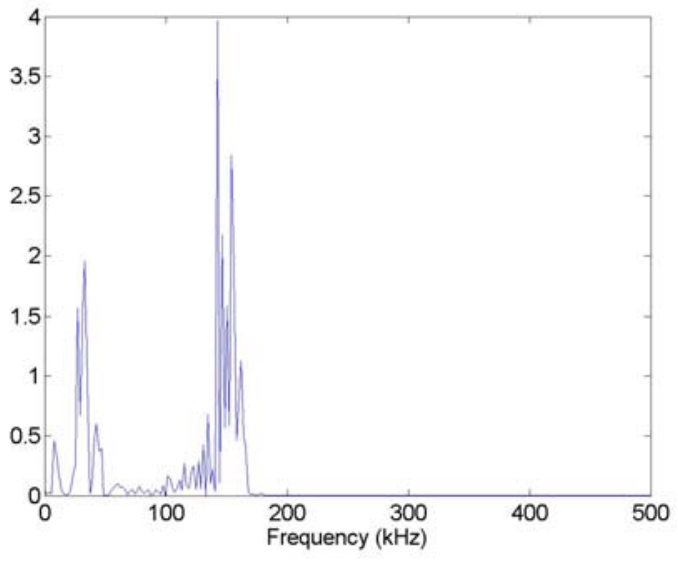

(b)

FRC-saturated-w/ slurry @ $35^{\circ} \mathrm{C} \# 1$

Fig. C-3 Power distribution spectral of point 1-A (c) 